\title{
EFFECTS OF COOLANT
} VOLATILITY ON SIMULATED HCDA BUBBLE EXPANSIONS

FINAL

Technical Report No. 10

September 1980

By: Robert J. Tobin, Project Leader

Project Supervisor: Alexander L. Florence

Prepared for:

U.S. DEPARTMENT OF ENERGY

Reactor Research and Technology

Headquarters

Germantown, MD 20767

\section{Attention: $\quad H$. Alter, Chief Safety Section Safety and Physics Branch}

Contract EXG.03 [ATO3-76 SF 70097] 189 No. SX 063

SRI International Project PYU 3929

NOTICE

This report was prepared as an account of work sponsored by the United States Government. Neither the United States nor the United States Department of Energy, nor any of their employees, nor any of their contractors, subcontractors, or their employees, makes any warranty, expressed or implied, or assumes any legal liability or responsibility for the accuracy, completeness or usefulness of any information, apparatus, product or process disclosed, or represents that its use would not infringe privately owned rights.

SRI International

333 Ravenswood Avenue

Menlo Park, California 94025

(415) 326-6200

Cable: SRI INTL MPK

TWX: 910-373-1246 


\section{DISCLAIMER}

This report was prepared as an account of work sponsored by an agency of the United States Government. Neither the United States Government nor any agency Thereof, nor any of their employees, makes any warranty, express or implied, or assumes any legal liability or responsibility for the accuracy, completeness, or usefulness of any information, apparatus, product, or process disclosed, or represents that its use would not infringe privately owned rights. Reference herein to any specific commercial product, process, or service by trade name, trademark, manufacturer, or otherwise does not necessarily constitute or imply its endorsement, recommendation, or favoring by the United States Government or any agency thereof. The views and opinions of authors expressed herein do not necessarily state or reflect those of the United States Government or any agency thereof. 


\section{DISCLAIMER}

Portions of this document may be illegible in electronic image products. Images are produced from the best available original document. 


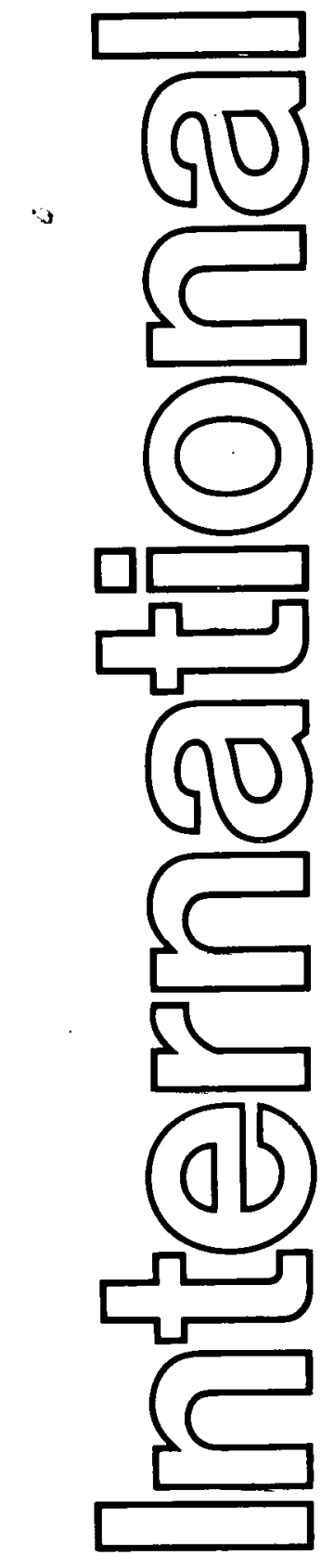

EFFECTS OF COOLANT VOLATILITY ON SIMULATED HCDA BUBBLE EXPANSIONS

FINAL

Technical Report No. 10

September 1980

By: Robert J. Tobin, Project Leader

DE82 007107 $\rightarrow 1$ $\therefore$ in

Project Supervisor: Alexander L. Florence

Prepared for:

U.S. DEPARTMENT OF ENERGY

Reactor Research and Technology

Headquarters

Germantown, MD 20767

Attention: $\quad H$. Alter, Chief

Safety Section

Safety and Physics Branch

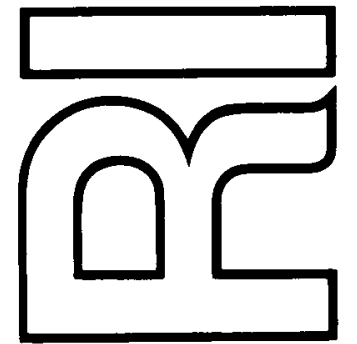

ATO3-765F 70097

Contract EF-76-G 03-045T297

189 No. SX 063

SRI International Project PYU 3929

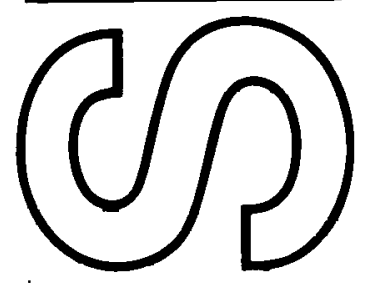

Approved by:

G. R. Abrahamson, Director

Poulter Laboratory 
THIS PAGE

\section{WAS INTENTIONALLY \\ LEFT BLANK}


The effects of coolant volatility on the expansion dynamics and cover loading of hypothetical core disruptive accidents (HCDA) were studied by performing experiments with a transparent $1 / 30$-scale model of a typical demonstration size loop-type liquid metal fast breeder reactor (LMFBR). In past experiments, we used water to simulate the sodium coolant in the prototype. In these experiments, we used Freon 113 and Freon 11 as coolant simulants of increasing volatility. Highpressure nitrogen gas (1450 psia) or flashing water (1160 psia) were used to simulate the qualitative features of sodium vapor or molten fuel expansions.

Freon is $50 \%$ denser than water; therefore, to directly evaluate the effect of coolant volatility in flashing water bubble source experiments, it was necessary to adjust the heights of the upper core and coolant pool above the upper core so as to maintain the same coolant mass in experiments with different coolants. In addition to these "constant mass" experiments, a set of "constant geometry" experiments were conducted. These included experiments with water and Freon 113 coolants in the reference 1/30-scale apparatus. Included in this set were experiments with and without upper core and upper internal structures to evaluate their effect on the expansion dyndmics and cover loading with more volatile coolants.

To validate the use of constant mass and constant geometry experiments as a means of evaluating the effects of coolant volatility, a set of baseline expcriments was performed in these configurations with the room temperature nitrogen bubble source. Volatility effects are not present in nitrogen bubble source experiments since all the fluids are at the same temperature. Hence, these nitrogen source experiments allow. direct evaluation of the effects of experiment geometry and coolant mass. In all the experiments, the expanding HCDA bubbles, the motion of the 
coolant simulant, and the vessel loads were monitored by pressure transducers, a thermocouple in the bubble, and high-speed photography.

As expected, the results of the constant mass experiments with the flashing water source show that higher volatility results in higher pressure driving the coolant slug and therefore higher impact loads. The Freon experiments had about $50 \%$ higher pressure in the upper core and bubble, a 30\% larger slug impact impulse, and $25 \%$ greater expansion work done on the coolant slug. The higher pressure in the Freon experiments is belleved due to vaporization of some of the Freon that mixes with the hot flashing water in the upper core very early in the expansion. Entrainment of coolant within the bubble and the bubble shape were comparable in the Freon and water experiments. Entrainment at slug impact varied between $20 \%$ and $40 \%$ of the bubble volume. The presence of internal vessel structures attenuated the slug impact impulse by about $50 \%$ whether the coolant was Freon 113 or water. 
CONTENTS

ABSTRACT . . . . . . . . . . . . . . . . . .

LIST OF ILLUSTRATIONS . . . . . . . . . . . . . . . . v vii

LIST OF TABLES . . . . . . . . . . . . . . . . . . . xi

PREFACE ........................... xii

I INTRODUCTION AND SUMMARY . . . . . . . . . . . . . 1

A. Background .. . . . . . . . . . . . . . . 1

B. Approach .. . . . . . . . . . . . . . . . . 2

C. Experimental Method and Program . . . . . . . . . 5

D. Summary and Recommendations . . . . . . . . . 8

II EXPERIMENTAL METHOD . . . . . . . . . . . . . . . . 23

A. Coolant Simulants . . . . . . . . . . . . 23

B. Constant Geometry and Constant Mass Configurations . . 24

C. Experimental Apparatus .............. 25

1. Test Section ................. 27

2. Lower Core . . . . . . . . . . . . . . . . . . . 29

3. Sliding Door Pressure Release Mechanism . . . . 31

D. Instrumentation ................ 31

E. Experiment Matrix .............. 36

III RESULTS OF THE NITROGEN SOURCE EXPERIMENTS . . . . . . . . . 39

A. Coolant Surface Displacement . . . . . . . . . . . 39

B. Bubble Profiles and Volume .............. 41

C. Entrainment ................ 41

IV RESULTS OF THE FLASHING WATER CONSTANT MASS EXPERIMENTS . . 45

A. Pressure and Temperature Measurements . . . . . . 45

1. Lower Core Pressure . . . . . . . . . . . 45

2. Upper Corre Pressure............... 47

3. Pool and Bubble Pressure ............ 48

4. Pool and Bubble Temperature . . . . . . . . 50

5. Cover Pressure and Impulse . . . . . . . . 53

B. Coolant Surface and Bubble Motion . . . . . . . . . 54

1. Coolant Surface Displacement . . . . . . . 54 
2. Bubble Profiles and Volume ........... 55

3. Entrainment ................. 58

C. Flashing Source Expansion .. . . . . . . . . 60

1. Pressure-Volume Increase .'. . . . . . . . 60

2. Expansion Work .............. 62

V RESULTS OF THE FLASHING WATER CONSTANT GEOMETRY EXPERIMENTS WITHOUT INTERNAL STRUCTURES . . . . . . . . . . . . 69

A. Pressure Measurements . . . . . . . . . . . . 69

1. Lower Core Pressure . . . . . . . . . . . . 69

2. Upper Core Pressure . . . . . . . . . . . . . 69

3. Pool and Bubble Pressure . . . . . . . . . . TL

4. Cover Pressure and Impulse . . ....... . 71

B. Coolant Surface and Bubblc Motion . . . . . . . . 73

1. Coolant Surface Displacement . . . . . . . 73

2. Bubble Profiles and Volume . . . . . . . . . 73

3. Entrainment .............. . 76

VI EFFECTS OF INTERNAL VESSEL STRUCTURES IN FLASHING WATER CONSTANT GEOMETRY EXPERIMENTS . . . . . . . . . . . . . . . 79

A. Lower Core Pressure . . . . . . . . . . . . . . 79

B. Coolant Surface Displacement . . . . . . . . . . 79

C. Bubble Profiles .. . . . . . . . . . . . . . 80

D. Cover Pressure and Impulse ............. . 84

VII INTERPRETATION OF RESULTS, . . . . . . . . . . . . . . 87

VIII CONCLUSIONS AND RECOMMENDATIONS . . . . . . . . . . . . . 97

REFERENCES ......................... . . . . . 103

APPENDICES

A. Apparatus and Instrumentation . . . . . . . . . . A-1

B. Initial Cond1tions................. . B-1

C. Experiment Instrumentation. . . . . . . . . . . C $\mathrm{C}-1$

D. Experimental Data .. . . . . . . . . . . D D-1

E. Experiment Reproducibility ............... E-1

F. Simple Model of Pool Motion . . . . . . . . . . . . F-1 
1/30-Scale Vessel . . . . . . . . . . . .

Typical Demonstration Size Loop-Type LMFBR . . . . .

1/30-Scale Vessel Assembly . . . . . . . . . .

4 Experimental Configurations . . . . . . . . . .

5 HCDA Bubble Photographs at Slug Impact in the Constant Mass Flashing Water Bubble Source Experiment . . .

Pressure-Volume Change in the Constant Mass Flashing Water Source Experiments. . . . . . . . . . . . .

HCDA Bubble Photographs at Slug Impact in the Nitrogen Source Experiments . . . . . . . . . . . . . . .

8 Comparison of Geometry Effects and Volatility Effects on Coolant Surface Displacement . . . . . . . . .

HCDA Bubble Photographs at Slug Impact Showing the Effect of Internal Vessel Structures . . . . . .

Effect of Internal Vessel Structures and Coolant Volatility on Coolant Surface Displacement . . . .

14 Water Heating Diagram . . . . . . . . . . 
19 HCDA Bubble Photographs at Slug Impact in the Nitrogen Source Experiments . . . . . . . . . . . . . .

20 Entrainment in the Expanding Bubble in the Nitrogen Source Experiments . . . . . . . . . . . . 43

21 Constant Mass Experiments . . . . . . . . . . 46

22 Lower Core Pressure $\left(P_{1}\right)$ in the Constant Mass Experiments . . . . . . . . . . . . . . . . .

23 Effect of Coolant Volatility on the Upper Core Pressure $\left(\mathrm{P}_{4}\right)$ in Constant Mass Experiments . . . .

24 Effect of Coolant Volatility on the fonl and Bubble Pressure $\left(\mathrm{P}_{8}\right)$ in Constant Mass Experiments . . . .

25 Bublle Temperature Measurements in the Constant Mass Experiments . . . . . . . . . . . . . . . . . . .

26 Relation Between. Measured Bubble Temperature and Thermocouple $\mathrm{T}_{2}$ Position Within the Bubble . . . . .

Primary Slug Impact Pressure $\left(\mathrm{P}_{5}\right)$ Pulse in the Constant Mass Experiments ...............

Effect of Coolant Volatility on Coolant Surface Displacement in Constant Mass Experiments . . . . .

Bubble Growth Profiles in Constant Mass Experiments .

Comparison of the Bubble Profile in G-011 (Water) and G-007 (Freon 113) at a Coolant Surface Displacement of 0.75 Inch . . . . . . . . . . . . . .

HCDA Bubble Photographs at Slug Impact in the Constant Mass Flashing Water Bubble Source Experiments . . .

Effect of Coolant Volatility on Bubble Volume in Constant Mass Experiments... . . . . . . . .

33 Effect of Coolant Volatility on Entrainment in the Expanding Buhh1e or Constant Mase Expcriments . . .

34 Expansion Work Done in Moving the Coolant Slug, Experiment G-011 (Water). . . . . . . . . . .

35 Expansion Work Done in Moving the Coolant Slug, Experiment G-007 (Freon 113). . . . . . . . .

Composite Pressure Acting on the Coolant Slug in Constant Mass Experiments G-002, G-007, and G-009 . . 
37 Expansion Work as a Function of Coolant Slug Motion in the Constant Mass Experiments ... . . . . .

38 Lower and Upper Core Pressures in the Constant Geometry Experiments Without Internal Structures . . . . . .

39 Pool, Bubble, and Slug Impact Pressure in the Constant Geometry Experiments Without Internal Structures . .

40 Coolant Surface Displacement in Constant Geometry Experiments Without Internal Structures . . . . .

41 Bubble Growth Profiles in the Constant Geometry Experiments . . . . . . . . . . . . . .

42 Bubble Volume in Constant Geometry Experiments Without Internal Structures . . . . . . . . . .

Lower Core Pressure $\left(P_{1}\right)$ in Experiments G-004 (No Internal Structures), G-005 (UCS + UIS), and G-006

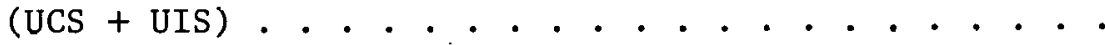

Effect of Internal Vessel Structures and Coolant Volatility in 1/30-Scale HCDA Simulations . . . . .

Effect of Lower Core Pressure in Experiments With Both a UCS and UIS .................

HCDA Bubble Photographs at Slug Impact Showing the Effect of Internal Vessel Structures . . . . . .

HCDA Bubble Photographs at Slug Impact Showing the Effecl of Initial Pressure . . . . . . . . . . .

Simple Expansion Model . . . . . . . . . .

50 Coolant Surface Displacement Predictions From Simple Model with Phase A Driving Pressure of 650 psia...

51 Compar1sun of Geomctry Efferts and Volatility Effects on Coolant Surface Displacement . . . . . . . .

A.1 Lower Core Detail . . . . . . . . . . . . A-2

A. 2 Heating and Pressure Control System . . . . . . . A-3

A.3 Water Heating Diagram . . . . . . . . . . A

A.4 Door-Piston-Cylinder Assembly . . . . . . . . $\mathrm{A}=7$ 
A.5 Sliding Door Opening Sequence . . . . . . . . $\mathrm{A}-9$

A.6 Nomina1 Door Opening Sequence . . . . . . . . . A-11

A. 7 Representative Sliding Door Displacement History . . A-12

B.1 Water Heating Diagram ............. B-2

B.2 Characterization of Experiment Initiation . . . . B-3

B.3 Heating and Pressure Control System . . . . . . B-5

B.4 Typical Early Lower Core Pressure History ( $\mathrm{P}_{1}$,

C.1 Experiment Geometry and Working Tnstrumentation . . . C-2

L.2 Initial Condition Recording System . . . . . . . C-6

C.3 Experiment Triggering System . . . . . . . . . C $\mathrm{C}$-7

C. 4 Dynamic Instrumentation Recording System . . . . . C-8

D.1 Experiment G-002, Flashing Water Bubble Source . . D-4

D.2 Experiment G-003, Flashing Water Bubble Source . . D D-8

D. 3 Experiment G-004, Flashing Water Bubble Source . . . D-12

D.4 Experiment G-005, Flashing Water Bubble Source . . . D-16

D.5 Experiment G-006, Flashing Water Bubble Source . . . D-19

D. 6 Experiment G-007, Flashing Water Bubble Source . . . D-22

D.7 Experiment G-008, Nitrogen Bubble Source . . . . . D-26

D.8 Experiment G-009, Flashing Water Bubble Source : . n-30

D.9 Experiment G-010, Nitrogen Bubble Source . . . . . D-34

D,10 Fixperiment G-011, Flaghing WaLtr Bubblc source . . . I-38

E.1 Experiment Reproducibility, Water Coolant . . . . . E-2

E.2 Experiment Reproducibility, Freon 113 Coolant . . . E-5

F.1 Simple Expansion Model . . . . . . . . . . . F-2 
1 Experimental Program . . . . . . . . . . . .

2 Summary of Effects of Coolant Volatility in Constant Coolant Mass Experiments . . . . . . . . . . . . .

3 Summary of Effects of Internal Vessel Structures With Different Coolant Simulants . . . . . . . . . . .

Material Critical Constants . . . . . . . . .

6 Experiment Matrix . . . . . . . . . . . . .

7 Impulse on the Vessel Cover from the First Slug Impact Pulse, Constant Mass Experiments . . . . . . . . . .

8 Expansion Work Constant Mass Experiments . . . . . . .

9 Impulse on the Vesse1 Cover from the First Slug Impact Pulse, Constant Geometry Experiments Without Internal Structures . . . . . . . . . . . . . . . . .

10 Effect of Internal Vessel Structures on the Impulse from the Fist SIug Impact Pulse . . . . . . . . . .

11 Acoustic Impedance of Coolant Simulants . . . . . .

12 Comparison of Slug Impact Pressure and Velocity, Constant Mass Experiments . . . . . . . . . . . .

13 Slug Impact Impulse in Constant Mass and Constant Geometry Experiments . . . . . . . . . . . . . . 96

14 Summary of Experimental Results . . . . . . . . . . . 98

A.1 Representative Sliding Door Displacement . . . . . . . . A-13

A.2 Instrument Sting Volume . . . . . . . . . . . . A-15

B.1 Measured Lower Core Initial Conditions, Flashing Water
Source Experiments . . . . . . . . . . . B-6

B.2 Effect of Coolant Heating on Initial Cover Gas Gap . . . B-8 
B.3 Initial Cover Gas Pressure Flashing Source

Experiments . . . . . . . . . . . . . . B-9

C. 1 Experiment Instrumentation . . . . . . . . . . . C $\mathrm{C}-5$

D.1 Sliding Door Opening Time and Volume Created . . . . . D D-2

D.2 Slug Impact Time . . . . . . . . . . . . . D D-3

F.1 Expansion Model Calculations . . . . . . . . . . F-4 
PREFACE

This task was pexformed during the period December 1979 to June 1980 under the support of the U.S. Department of Energy, Contract EY-76-C-03-0115. Mechanical and explosive, electronic, and data reduction support were provided by A. Baggett, W. Heckman, and B. Bain, respectively.

This report is the final technical report for this contract. The technical reports previously published under this contract are listed below.

"Experimental Study of Heat Transfer from a Simulated Hypothetical Core Disruptive Accident Bubble," Technical. Report 1. (November 1975).

"Development and Characterization of a Liquid-Vapor Bubble Source for Modeling HCDA Bubbles," Technical Report 2 (March 1977).

"Static Response of a 1/20-Scale Model of the Clinch River Breeder Reactor Head," Technical Report 3 (Ju1y 1977).

"Structural Response of 1/20-Scale Models of the Clinch River Breeder Reactor to a Simulated Hypothetical Core Disruptive Accident," Technical Report 4 (October 1978).

"Effects of Vessel Internal Structures on Simulated HCDA Bubble Expansions," Technical Report 5 (November 1978).

"The Potential Hazard to Secondary Containment from HCDA-Generated Missiles and Sodium Fires," Technical Report 6 (February 1979).

"Structural Response of 1/20-Scale Models of Above Core Structures to Increasingly Energetic Hypothetical Core Disruptive Accidents," Technical Report 7 (July 1979).

"Nonequilibrium Phenomena in Flashing Water Used as an HCDA Source Simulant," Technical Report 8 (November 1979).

"Experimental Investigation of the Effect of Nucleation Surface Area on Nonequilibrium Phenomena in Flashing Water," Technical Report 9 (September 1980). 


\section{INTRODUCTION AND SUMMARY}

\section{A. Background}

The philosophy behind the design of liquid metal fast breeder reactors (LMFBR) is to keep the risk to the public from accidental releases of radioactivity extremely small by providing engineered safety features and LMFBR behavior characteristics that combine to

- Prevent plant system or component faults and malfunctions.

- Protect against the possibility of faults and malfunctions leading to severe accidents.

- Mitigate the consequences of severe accidents.

LMFBR accidents now considered to have the greatest potential for releasing significant amounts of radioactivity to the environment involve core meltdown. Such accidents, which are called core disruptive accidents (CDAs), are extremely low in probability of occurrence but are studied to assure that the risk from such accidents is acceptably small. Safety technology research sponsored by DOE focuses on the support of four lines of assurance (LOA), each of which is intended to provide an independent barrier to prevent a CDA from occurring or progressing to the point of releasing unacceptable amounts of radioactivity to the environment:

LOA 1: Prevent CDAs

LOA 2: Limit core damage

LOA 3: Maintain Containment Integrity

LOA 4: Attenuate radiological consequences of CDAs.

LOA 1 would assure that the probability of a CDA occurring is so low that these accidents can be considered hypothetical. Even so, their consequences must be understood to ensure that adequate margin exists in the plant to protect the public if such an accident actually occurs. LOA 2, 3 , and 4 would provide this assurance.

If a core meltdown could occur, then theoretically, core material motions and interactions might lead to rapid pressure-generation events that could cause significant structural damage to the reactor. LOA 3 
would ensure that the probability of such rapid pressure generation is small.

Even in the unlikely event that a CDA results in pressure generation that challenges the structural integrity of the reactor, no significant amounts of radioactivity could be released until radioactive materials were transported from the core to the leakage paths created in the reactor by the pressure excursion. LOA 4 would ensure that this transport would be accompanied by attenuation mechanisms that would reduce potential releases of radioactivity to very low levels.

In support of LOA 3, we have previously conducted scale model experiments simulating a hypothetical CDA (HCDA) using nitrogen gas or flashing water as the fuel simulant and water as the coolant simulant. ${ }^{1}$ These experiments were conducted to increase our understanding of the dynamics and thermodynamics of expanding bubbles similar to the CDA bubble in LMFBRs and to aid in developing analytical models for predicting CDA energetics and core material transport. The experiments described in this report were conducted to further increase this understanding by using coolants that more closely simulate the volatility of sodium in the LMFBR.

The remainder of this section briefly describes our approach to this problem and our experimental method, and gives a comprehensive summary of our major findings. Section II describes our experimental method in detail. The experimental results are discussed in Sections III through VI, an interpretation of the results is given in Section VII, and our conclusions and recommendations are presented in section VIII.

\section{B. Approach}

Our approach was to choose a practical coolant simulant that in relation to water as a fuel simulant is similar to the relationship between sodium coolant and uranium dioxide fuel. Freon 113 refrigerant is practical and has a critical pressure in relation to that of water similar to the relationship between the critical pressure of sodium and that of uranium dioxide. Freon 11 is also practical and slightly more 
volatile; that is, it has a higher vapor pressure at a given temperature. Both Freons, have significantly higher volatility than water, the previously used coolant simulant.

Experiments were planned using each Freon as a coolant simulant in a simple 1/30-scale model (Figure 1) of the interior of a typical demonstration size loop-type LMFBR (Figure 2). The effects of coolant volatility on HCDA expansion dynamics and cover loading were evaluated in experiments using a flashing water bubble source at 1160 psia and $563^{\circ} \mathrm{F}$ to simulate the expansion of molten fuel in the LMFBR. Baseline experiments in which volatility effects were not present were conducted with a nitrogen gas bubble source at 1450 psia and room temperature. The effects of internal vessel structures with volatile coolants were evaluated by including upper core (UCS) and upper internal (UIS) structures in some experiments. To compensate for the difference in density between the Freon and water coolants, we adjusted the coolant pool height in some experiment to maintain the same coolant mass in experiments with different coolants.

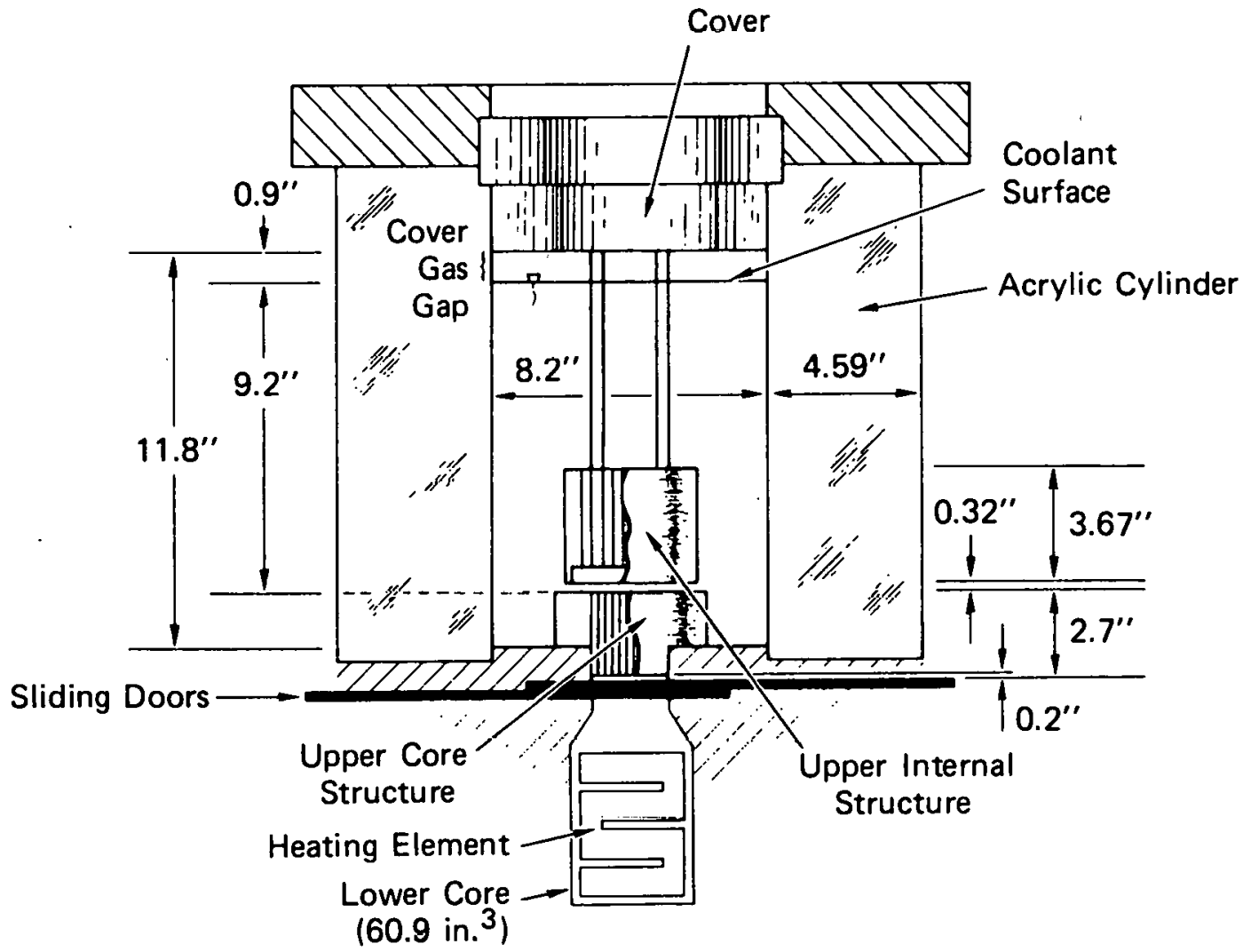

MA-3929-296C

FIGURE 1 1/30-SCALE VESSEL 


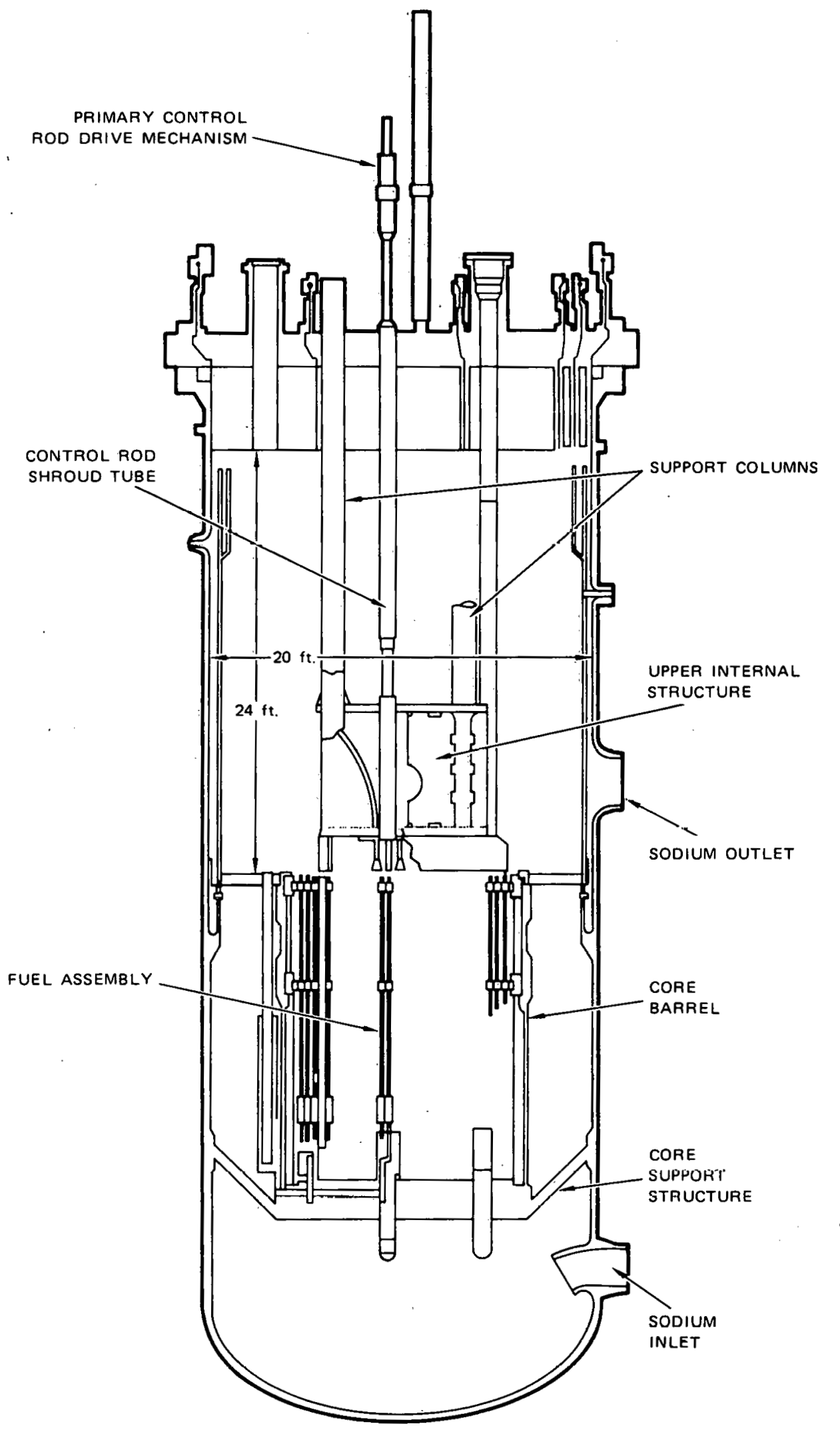

$M A-3929-393 A$

FIGURE 2 TYPICAL DEMONSTRATION SIZE LOOP-TYPE LMFBR 
The components in the $1 / 30-$ scale model were rigid. Structural response was not scaled in these experiments, but it was previously addressed in experiments by Romander and Cagliostro. ${ }^{2}$

\section{Experimental Method and Program}

Since Freon is $50 \%$ denser than water, direct evaluation of the effect of coolant volatility in flashing water bubble source experiments without internal structures was accomplished by adjusting the heights of the upper core and coolant pool above the upper core so as to maintain the same coolant mass in experiments with different coolants. The cover gas gap was kept the same in all experiments. In addition to these "constant mass" experiments, a set of "constant geometry" experiments was conducted using the flashing water bubble source. These included experiments with water and Freon 1.1.3 coolants in the reference 1/30-scale apparatus. Included in this set were experiments with and without upper core and upper internal structures to evaluate their effect on the expansion dynamics and cover loading with more volatile coolants.

To validate the use of constant mass and constant geometry experiments as a means of evaluating the effects of coolant volatility, a set of baseline experiments was performed in the constant mass and constant geometry configurations with the room temperature nitrogen bubble source. Volatility effects are not present in nitrogen bubble source experiments since all the fluids are at the same temperature. Hence, these nitrogen source experiments allow direct evaluation of the effects of experiment configuration and coolant mass. The program of experiments described above is summaried tin Table 1. The discussions in this report are based on the ten experiments conducted in this experiment series. as well as the three experiments from the previous experiment series, ${ }^{1}$ which are also listed in Table 1.

The flashing water or nitrogen gas bubble source was contained in the lower core shown in Figure 3. After the appropriate initial conditions were established within the lower core and acrylic cylinder (Figure 3), the experiments were initiated by detonating the explosive that drives: the piston and sliding door assembles. The flow path between the lower and upper cores was opened when the s.liding doors, carried b.y the pistons, 
cleared the flow path. The expansion of the gas or flashing liquid contained in the lower core then proceeded to drive the liquid coolant out of the upper core and form an expanding bubble within the coolant pool that drove the coolant pool to impact on the vessel cover.

Table 1

\section{EXPERIMENTAL PROGRAM}

$\underline{\text { Configuration }}$

Reference

(1/30-scale LMFBR)

Constant Mass
Bubble

Source

Flashing

Water

Nitrogen*

Flashing

Water

Flashing

Water

Constant

Geometry

Nitrogen

Nitrogen
Flashing
Water
Flashing
Water

Freon 113

Freon 113

Freon 113

Freon 113

Freon 11

None

Internal

Structures

None

2

None

1

None

1

1

None

1

None ${ }^{\dagger}$

2

Freon 113
Upper Core and Upper Internal Structures ${ }^{\dagger}$

* The reference experiment for the nitrogen source with water as the coolant and no internal structures is experiment D-006 of the previous experiment series ${ }^{1}$.

t The comparable experiments with water as the coolant are experiments E-001 (no internal structures) and E-003 (upper core and upper internal structures) of the previous experiment series'. 


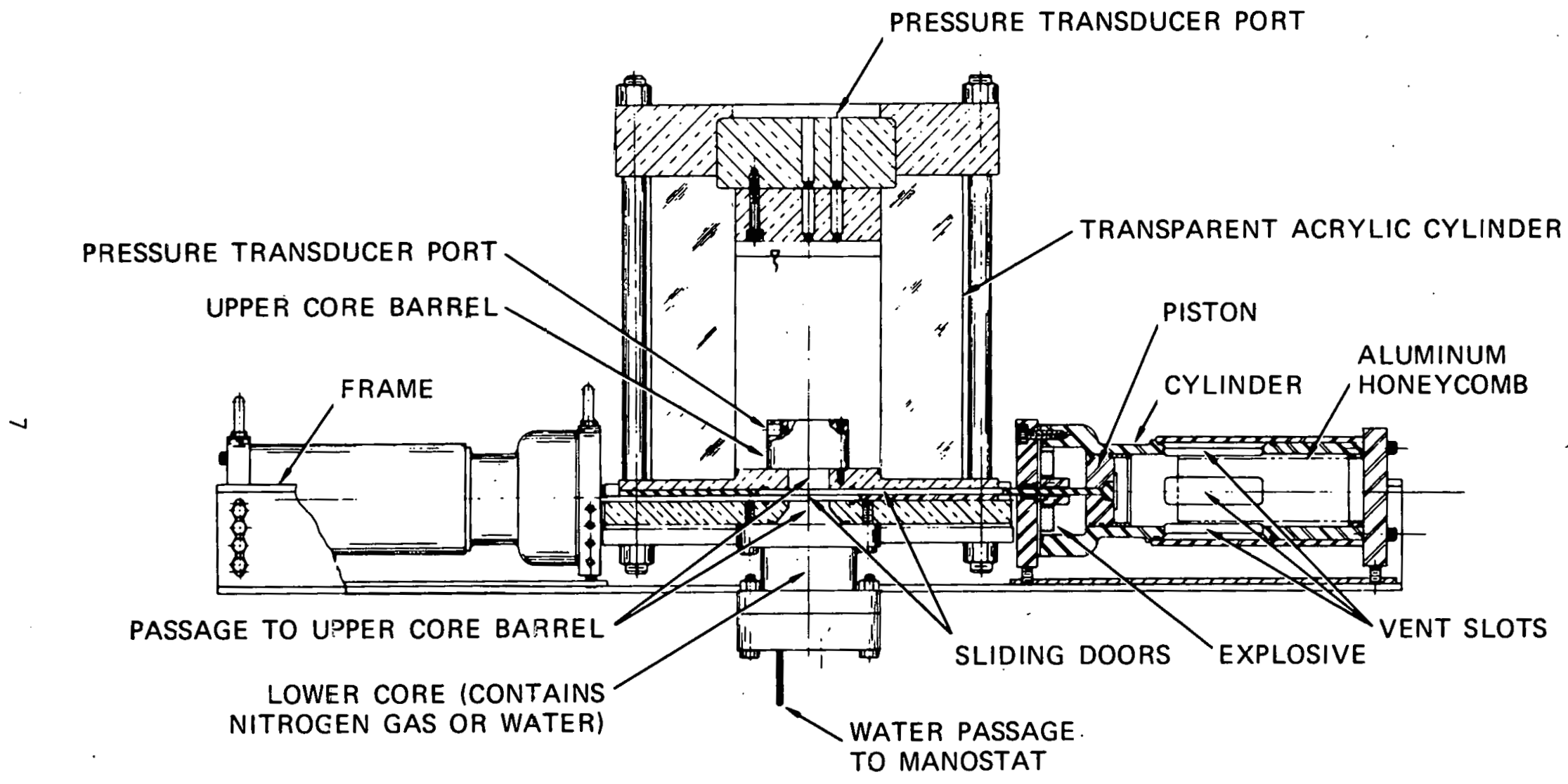

FIGURE 3 1/30-SCALE VESSEL ASSEMBLY 
Pressures were recorded in the lower and upper core, within the coolant pool and HCDA bubble, and on the vessel cover. Temperature was measured within the expanding bubble. High-speed photography was used to determine the bubble growth and coolant surface motion. These measurements were used to calculate such quantities as the expansion work done by the source, the liquid entrainment in the bubble, and the impulse on the vessel cover.

\section{Summary and Recommendations}

The experimental configurations used to evaluate the effcrtis of coolant volatility on HCDA expansion dynamics and cover loading are shown in Figure 4. The experimental program condulit with these configurations is summarized in Table 1 . The conclusions reported here are based on the ten experiments conducted in this experiment series and the three experiments from the previous experiment series ${ }^{1}$ as listed in Table 1. To demonstrate and quantify the effects of coolant volatility was more difficult a task than, say, to demonstrate and quantify the effects of internal structures as we did in our earlier work. ${ }^{1}$ Internal structures provided flow resistance and flow diversion that had noticable impact on the HCDA expansion hydrodynamics. The effects of coolant volatility are thermodynamic effects that depend on heat transfer and phase change between the fuel and coolant simulants and on the ther uodynamic properties of these materials. We were not certain whether the coolant would evaporate enough to make a detectable difference on the vessel pressures or bubble structure. However, the experimental program was successful in identifying measurable effects of coolant volatility. As we summarize the results, we will refer to Figure 4 to clarify the experimental configurations used to support a particular conclusion.

It was our hope that a comparison of measurements from experiments using different coolants, but with the same coolant mass in the upper core and in the coolant pool above the upper core, would dcmonstrate whether volatility effects were detectable or not. If volatility was not significant, then experiments with the same moving mass should proceed in the same manner to coolant impact on the vessel cover. If volatility was 


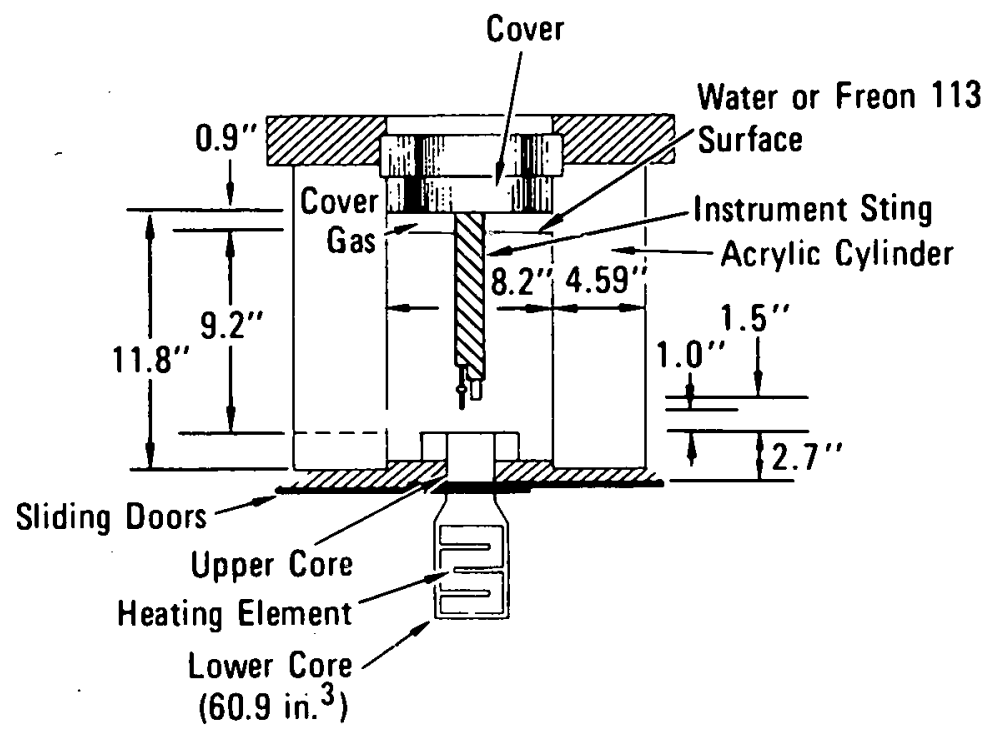

(a) REFERENCE 1/30-SCALE (CONSTANT GEOMETRY) CONFIGURATION

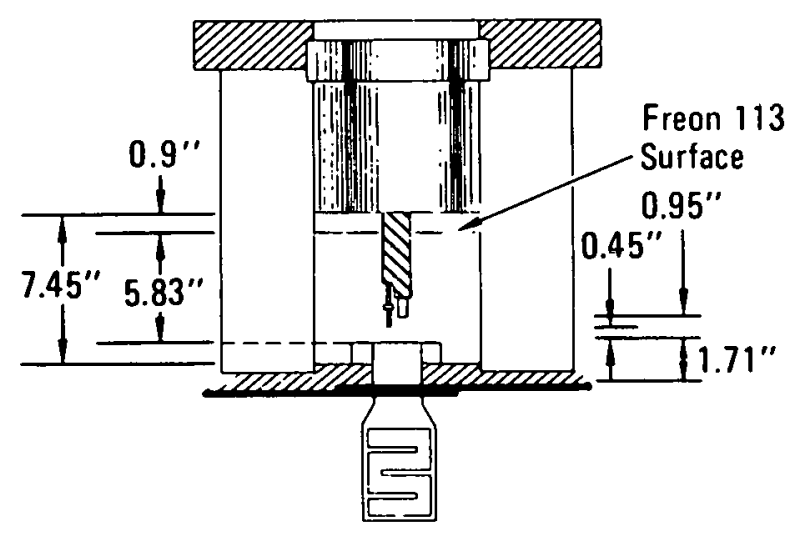

(b) CONSTANT MASS CONFIGURATION FOR FREON 113

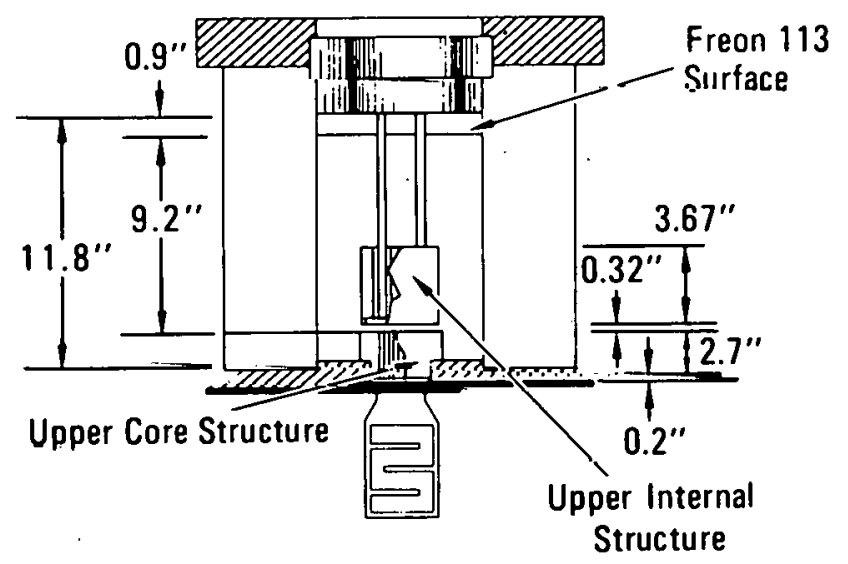

(c) CONSTANT GEOMETRY CONFIGURATION WITH INTERNAL VESSEL STRUCTURES

MA-3929-589

FIGURE 4 EXPERIMENTAL CONFIGURATIONS 
significant, then higher pressures should be measured in the upper core and HCDA bubble and the coolant pool should impact the vessel cover sooner and at higher velocity.

Constant mass experiments were conducted with water as the coolant [Figure 4(a)], with Freon 113 as the coolant [Figure 4(b)], and with Freon 11 as the coolant [not shown in Figure 4 but with only slightly different dimensions than Figure 4(b)]. A comparison of the appearance of the HCDA bubble at coolant slug impact in these experiments is shown in Figure 5. 'lhe bubbles are slightly different in profile and surface texture in the experiments with the denser Freon coolants than in the water experiment.

'l'he pressure inside the upper core and bubble is higher in the Freon experiments. This is most clearly demonstrated in Figure 6 . The pressurevolume change curves in Figure 6 show the pressure acting on the lower side of the coolant slug, driving it toward the vessel cover; the volume displaced by the motion of the coolant slug; and the expansion work done in moving the slug (the area under the curve). The pressure shown is a composite of the pressures in the lower core, upper core, and HCnA hibble, and represents our best estimate of the pressure acting on the moving lower boundary of the coolant slug. By comparing Figures $6(a)$ and (b), we see that for most of the event in Freon 113 experiment G-007, the pressures driving the coolant slug are higher by about 200 psi or $50 \%$ than in the water experiment shown, G-011; therefore, the expansion work done on the slug for a given displaced volume is also significantly higher. The higher pressure in the Freon experiments is believed due to vaporization of some of the Freon that mixes with the hot flashing water in the upper core very early in the expansion. The higher pressure in the upper core and bubble shnuld result in higher 1 oating wn the UIS when it is presenc. However, this loading was not measured in this experiment series.

Quantitative results of the constant mass experiments are summarized in Table 2. Shown are percentage differences of expansion work and slug impact impulse from an average of the values in the two water coolant experiments, G-002 and G-011. The slug impact pressure pulses used in 


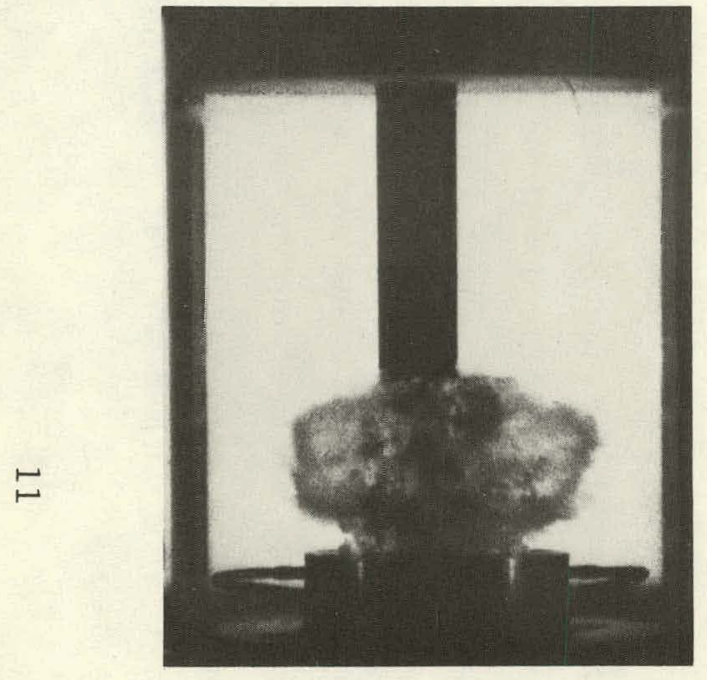

(a) WATER COOLANT (EXPERIMENT G-011)

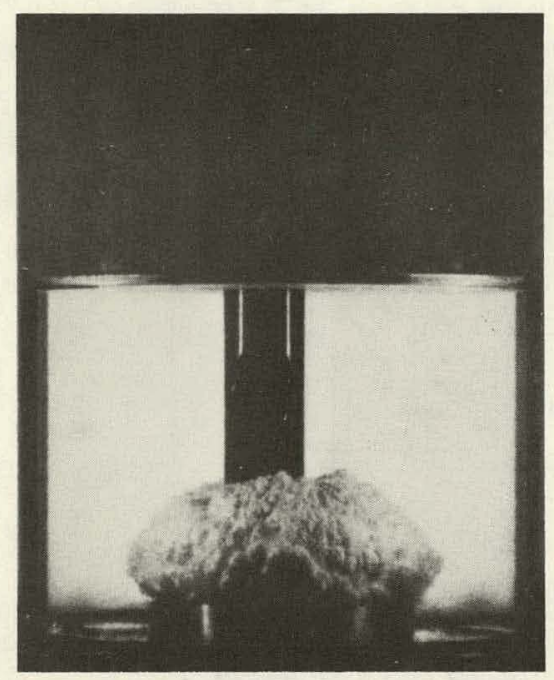

(b) FREON 113 COOLANT (EXPERIMENT G-007)

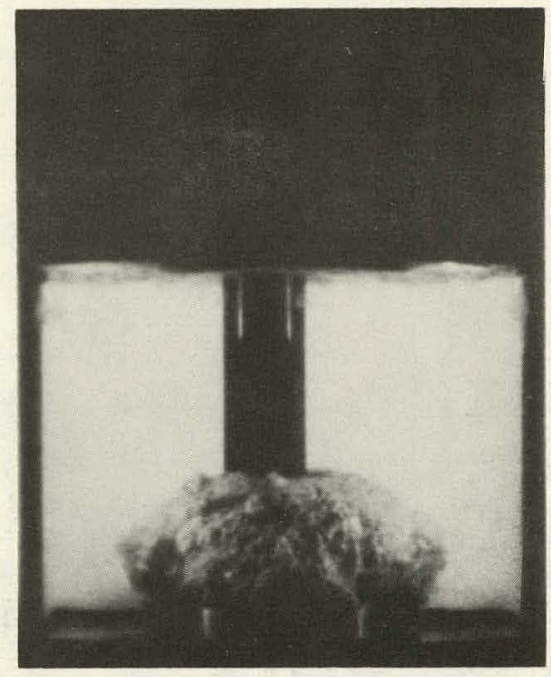

(c) FREON 11 COOLANT (EXPERIMENT G-009)

MA-3929-58

FIGURE 5

HDCA BUBBLE PHOTOGRAPHS AT SLUG IMPACT IN THE CONSTANT MASS FLASHING WATER BUBBLE SOURCE EXPERIMENTS 
(a) WATER COOLANT (EXPERIMENT G-011)

(b) FREON 113 COOLANT (EXPERIMENT G-007)
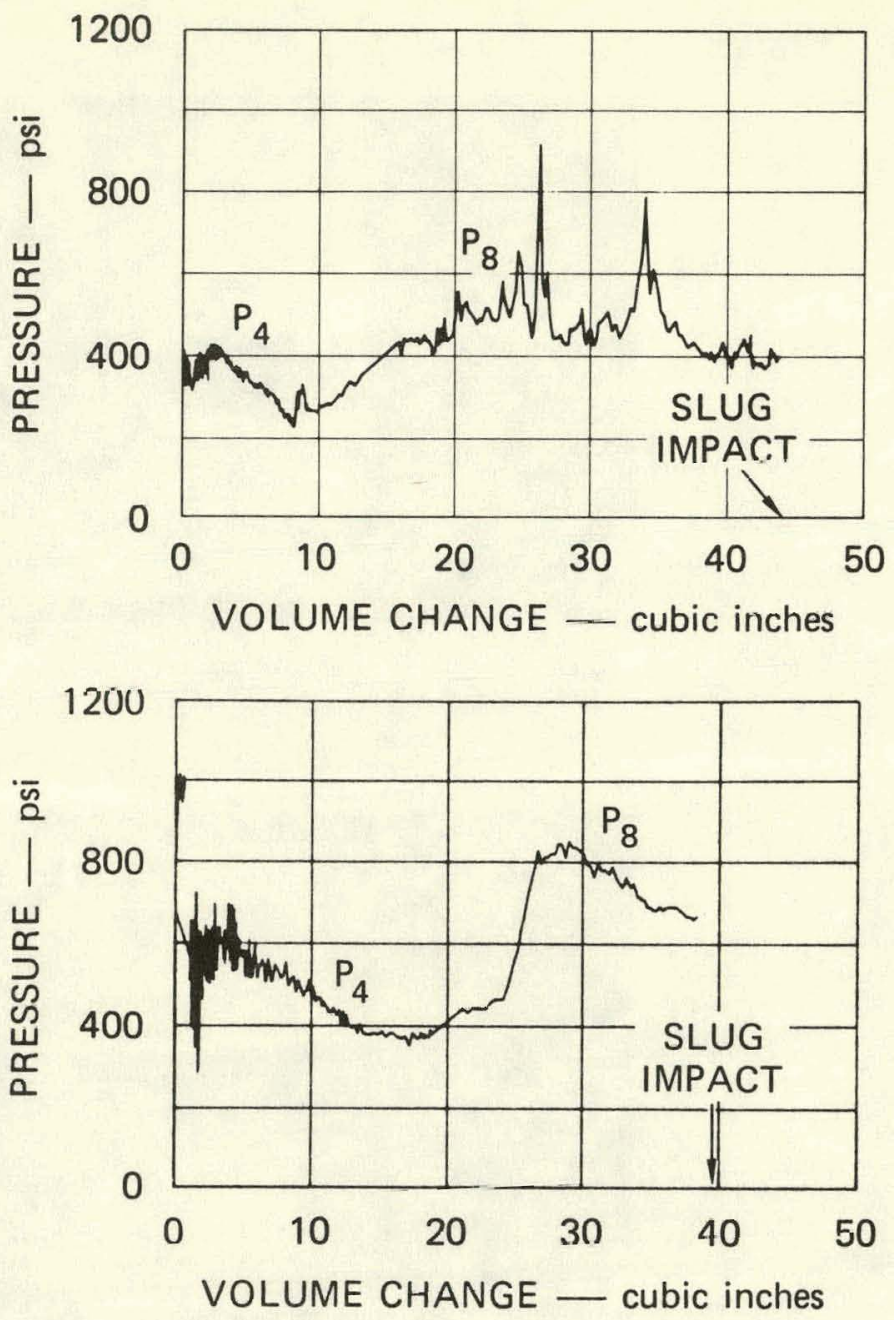

MA-3929-590

FIGURE 6 PRESSURE-VOLUME CHANGE IN THE CONSTANT MASS FLASHING WATER SOURCE BUBBLE EXPERIMENTS

calculating the impulse are shown in Figure 27. Expansion work is compared at a constant coolant surface displaced volume of 35 cubir inches. Comparisun of the expansion work at slug impact is not revealing because of the different expansion volumes corresponding to the different initial cover gas gaps in the experiments. Different gaps were measured even though the gap in all experiments was set during vessel filling to within about 0.01 inch. The gaps at time zero varied because density changes occurred in the coolant as it was warmed by heat conducted through the 
sliding doors from the $563^{\circ} \mathrm{F}$ water in the lower core. The expansion work comparison indicates a $\pm 8.2 \%$ variation in the two water experiments and a $23.4 \%$ to $25.1 \%$ higher expansion work in the Freon experiments than in the average of the two water experiments. The slug impact impulse is also significantly higher in the two Freon experiments than in the average of the two water experiments. In these constant mass experiments, the impulse is a measure of the slug impact velocity (see Section VII). Thus, the values for pressure, expansion work, and slug impact impulse shown in Figure 6 and Table 2 support the conclusion that coolant volatility does influence the HCDA expansion dynamics and cover loading.

Table 2

\section{SUMMARY OF EFFECTS OF COOLANT VOLATILITY IN CONSTANT COOLANT MASS EXPERIMENTS}

\begin{tabular}{|c|c|c|c|c|}
\hline Experiment & Coolant & $\begin{array}{c}\text { Initial Cover } \\
\text { Gas Volume } \\
\text { (inch }^{3} \text { ) }\end{array}$ & $\begin{array}{l}\text { Expansion Work } \\
\text { at } \Delta \mathrm{V}=35 \text { inch }^{3} \\
\text { Relative to the } \\
\text { Average of } \mathrm{G}-002 \\
\text { and } \mathrm{G}-011(\%)\end{array}$ & $\begin{array}{l}\text { Slug Impact } \\
\text { Impulse Relative } \\
\text { to the Average } \\
\text { of G-002 } \\
\text { and G-011 (\%) }\end{array}$ \\
\hline G-002 & $\mathrm{H}_{2} \mathrm{O}$ & 45.7 & +8.2 & +2.3 \\
\hline G-011 & $\mathrm{H}_{2} \mathrm{O}$ & 44.1 & $-\quad 8.2$ & -2.3 \\
\hline G-007 & F113 & 39.5 & +25.1 & +28.4 \\
\hline G-009 & F11 & 43.1 & +23.4 & +30.4 \\
\hline
\end{tabular}

There is also subjective support for the evaporation of some of the Freon coolant in the flashing source experiments, as evidenced by the appearance of the HCDA bubble in nitrogen and flashing water source experiments. The striking similarity in the shape and surface texture of the HCDA bubbles in the nitrogen source experiments is shown in Figure 7. The bubbles appear very similar to the bubbles in the flashing source experiments with Freon coolants, Figures $5(\mathrm{~b})$ and (c), but not with the 


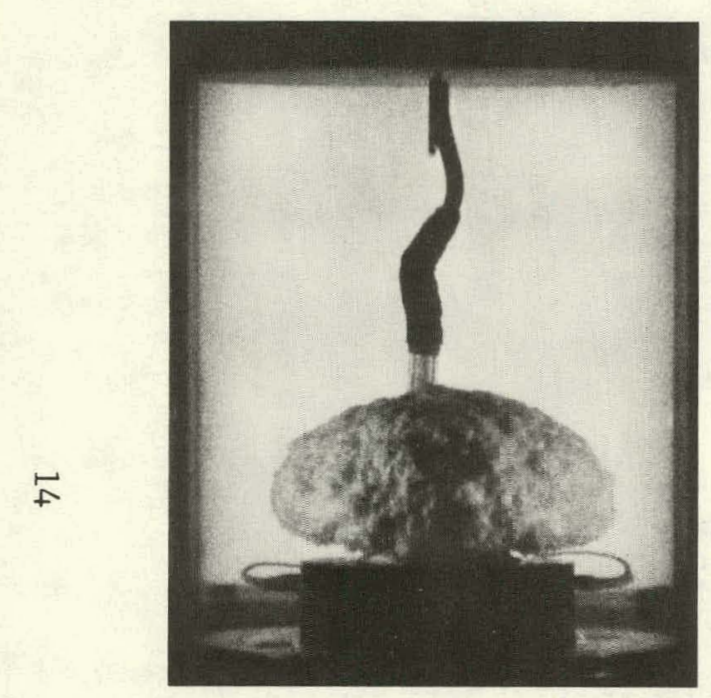

(a) WATER COOLANT (D-006) REFERENCE CASE

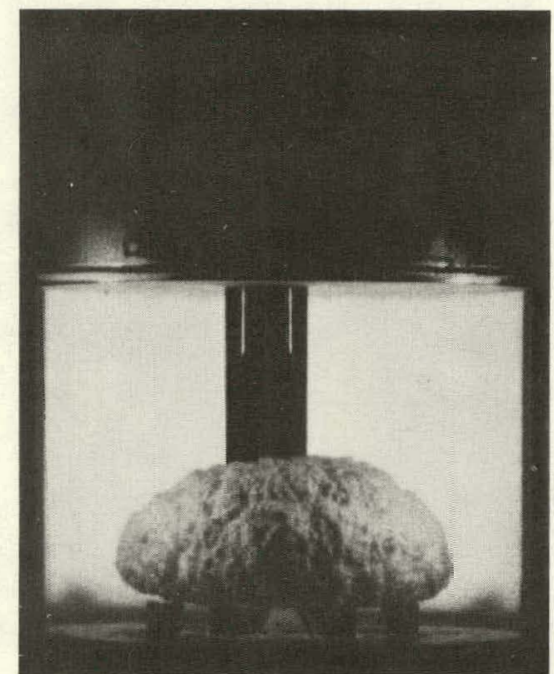

(b) FREON 113 COOLANT (G-008) CONSTANT MASS CONFIGURATION

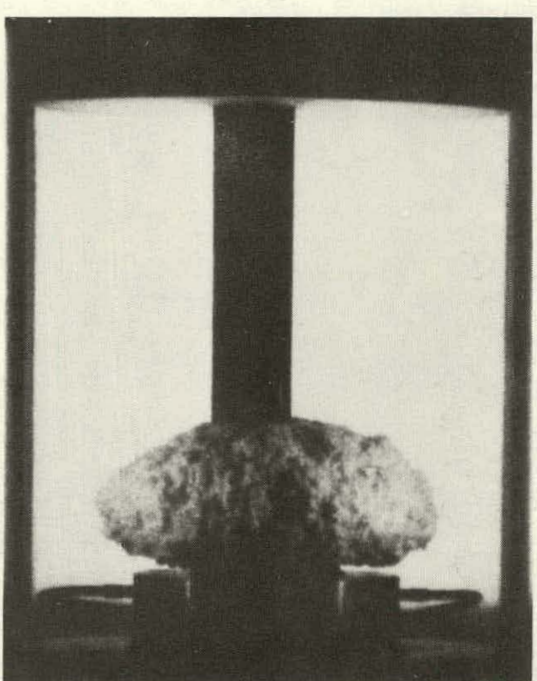

(c) FREON 113 COOLANT (G-010) CONSTANT GEOMETRY CONFIGURATION

MP-3929-584

FIGURE 7 HDCA BUBBLE PHOTOGRAPHS AT SLUG IMPACT IN THE NITRDGEN SOUPCE EXPERIMENTS 
water coolant, Figure 5(a). The bubbles in the flashing water Freon experiments contain some Freon vapor that may act gas-like (i.e., noncondensible) and result in a similar appearance to the nitrogen gas bubble. The boundary of the flashing water bubble in the water coolant is the most condensible boundary of the series and has the fuzziest appearance.

Although it does not change our conclusions based on the slug impact impulse in Table 2, we must note that the higher impulse in the Freon experiments is partly the result of the shortened geometry of the experiment. This is explained through the use of an analytical model in Section VII, but it can be shown here by comparing nitrogen source experiments with flashing water source experiments in both constant mass and constant geometry configurations [Figure $4(a)$ and (b)]. The coolant surface displacement in the nitrogen source experiments is shown in Figure $8(a)$. Since volatility effects are not present in the nitrogen experiments, this figures demonstrates the effect of experiment geometry on the expansion dynamics. The coolant surface moves faster in the shortened geometry of the constant mass Freon 113 experiment G-008 than in the reference case D-006 because higher accelerations in the upper core emptying phase of the expansion results in higher velocities throughout the expansion. Thus, the slug impact impulse in constant mass Freon experiments would be slightly higher because geometry effects result in a somewhat higher coolant surface velocity. The constant geometry experiment G-010 proceeds more slowly because of the $50 \%$ heavier coolant mass being moved.

Figure $8(\mathrm{~b})$ demonstrates the combined effects of volatility and experiment geometry on the coolant surface displacement. Relative to the reference experiment G-011 with water, the constant mass and constant geometry curves G-007 and G-004 are shifted earlier in time than in the nitrogen source experiments. This demonstrates the effect of volatility and explains why the slug impact impulse comparison in Table 2 resulted from the effects of both experiment geometry and coolant volatility. 


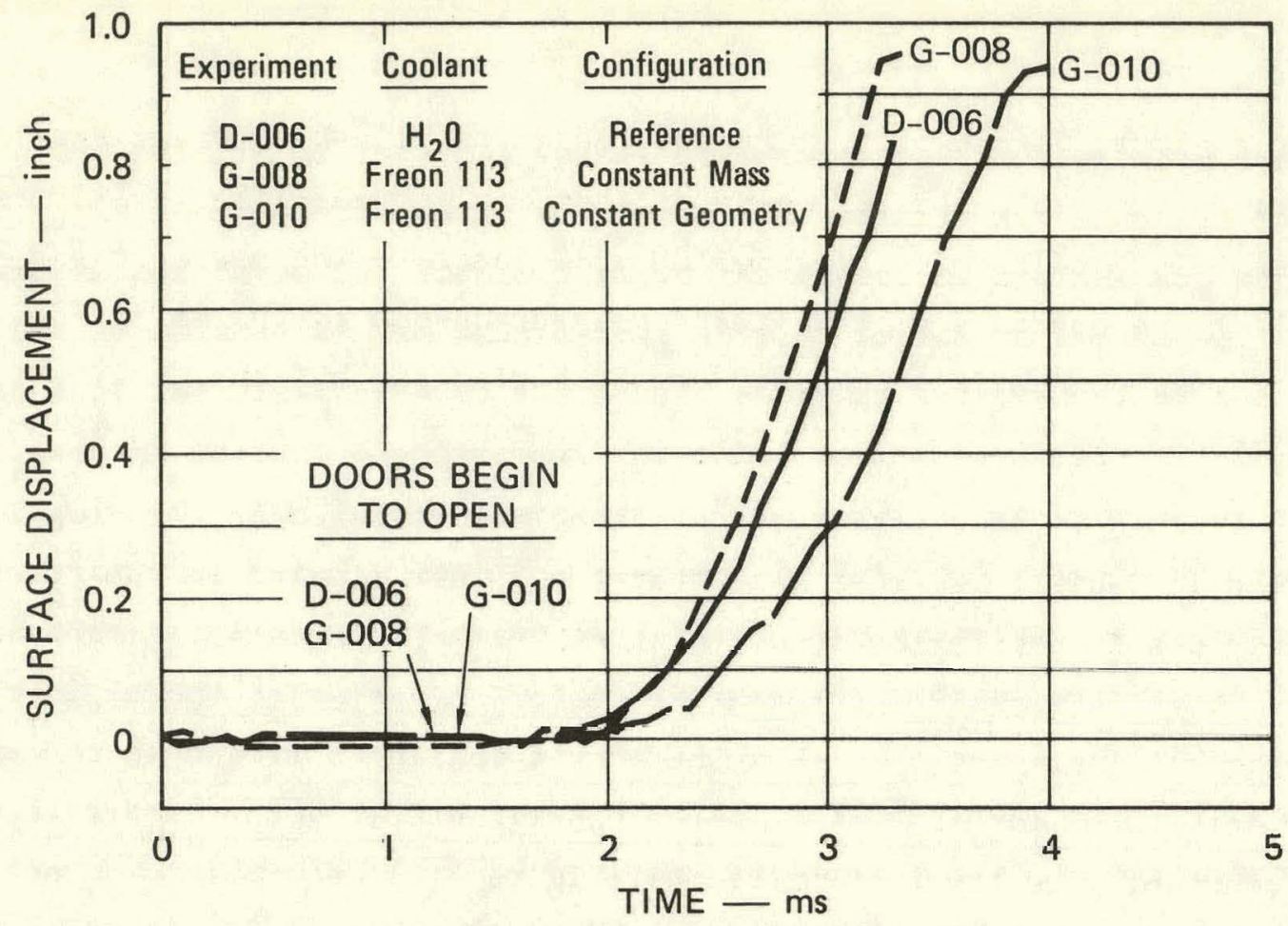

(a) GEOMETRY EFFECTS (Nitrogen Source)

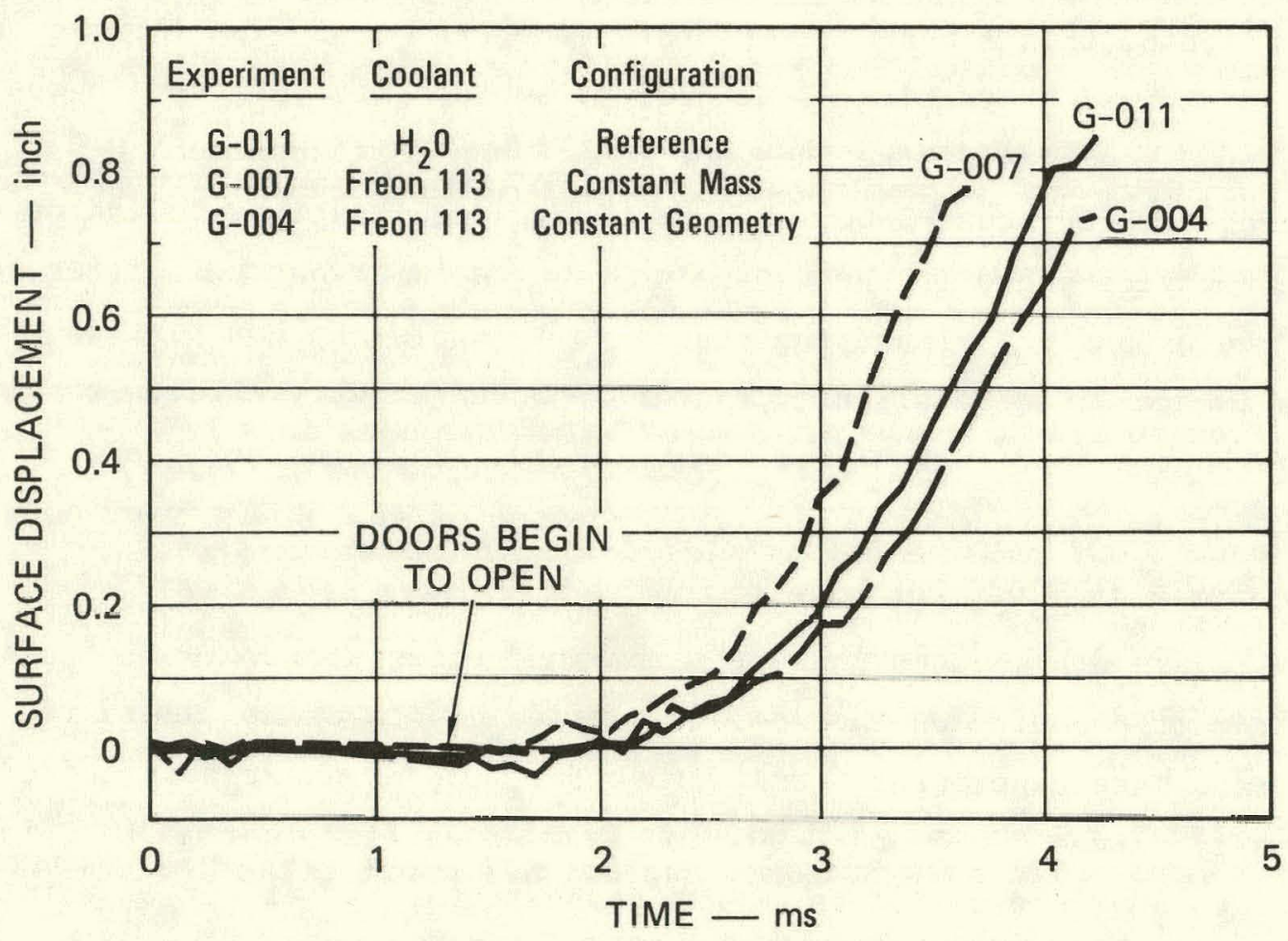

(b) VOLATILITY EFFECTS (Flashing Water Source)

MA-3929-526

FIGURE 8 COMPARISON OF GEOMETRY EFFECTS AND VOLATILITY EFFECTS ON COOLANT SURFACE DISPLACEMENT 
The bubble volume and coolant entrainment within the bubble were within the range typical of our previous HCDA simulations. 1 Entrainment is at least $60 \%$ of the bubble volume as the bubble emerges from the upper core into the pool. Entrainment in the upper core is certainly even higher. Entrainment at slug impact ranges from $20 \%$ to $40 \%$ of the bubble volume. The percentage of entrainment decreases during the expansion because the bubble grows faster than liquid is entrained into it. Although the percentage of entrainment decreases during the expansion, the entrained volume of liquid increases from about 5 cubic inches as the bubble enters the pool to about 20 to 30 cubic inches at slug impact. Entrainment in the upper core is due to the significant mixing that occurs as the sliding doors open. Entrainment in the pool occurs in the dissipating vortex at the lateral periphery of the bubble and at the bubble-coolant interface. The location of vortices within the coolant pool depends on the geometry of the internal structures. With an open upper core, a vortex ring forms just above the upper core due to convection from the upper core into the pool of a viscous liquid layer that forms at the wall of the upper core. This vortex is engulfed by the bubble and entrains liquid into the bubble by the circulation it creates at the lateral periphery of the bubble. With a UCS or a UIS, other vortices are formed, which entrain coolant into the bubble.

Temperature measurements in the HCDA bubble of flashing water source experiments were taken for the first time in this experiment series. The thermocouple was located approximately $1 / 2$ to 1 inch above the core depending on the experiment and approximately 0.7 inch off-axis. The measured temperature increases with time as the bubble passes over the thermocouple, indicating a temperature gradient through the bubble and providing evidence for a fairly thick mixing layer inside the bubble boundary. Temperatures in the bubble varied between $100^{\circ} \mathrm{F}$ when the bubble reached the thermocouple and $350^{\circ} \mathrm{F}$ at slug impact. This compares with a steam temperature no higher than $500^{\circ} \mathrm{F}$ for saturated steam emerging from the lower core at 700 psi. Further measurements are needed to map the bubble temperature field and structure. 
The effects of internal vessel structures on the expansion dynamics and cover loading with water and Freon 113 coolants are shown in Figures 9 and 10 and Table 3 . Figure 9 shows the effect of coolant and structures on the appearance of the HCDA bubble at slug impact on the cover. The effect of the structures on the bubble shape is independent of the coolant. The coolant surface displacement for these four experiments is compared in Figure 10. The figure demonstrates the significant slowing of the expansion that results from the presence of internal vessel structures with either coolant. As shown in Table 3, the quantitative reductions in slug impact impulse due to the presence of internal structures is slightly less when Freon 113 is the coolant. The small contribution of the load on the UIS to the cover loading at slug impact was not measured in these experiments. The slug impact pressure pulses in experiments G-004 (no internal structures) and G-006 (UCS and UIS) are shown in Figure 45.

The major results of these experiments can be summarized as follows:

- In the constant mass flashing water bubble source experiments:

- The upper core and bubble pressures were on the order of $50 \%$ higher than in the water experiment.

- The expansion work at a coolant surface displaced volume of 35 cubic inches was $25 \%$ higher than in the water experiment.

- The slug impact impulse was on the order of $29 \%$ higher than in the water experiment.

- The temperature in the bubble varied between $100^{\circ} \mathrm{F}$ when the bubble reached the thermocouple and $350^{\circ} \mathrm{F}$ at slug impact.

- In all experiments without internal structures, the entrainment at slug impact was $20 \%$ to $40 \%$ of the bubble volume.

- Tnternal vessel structures reduced the slug impact impulse by $45 \%$ using Freon 113 coolant compared with $56 \%$ using water as the coolant. 


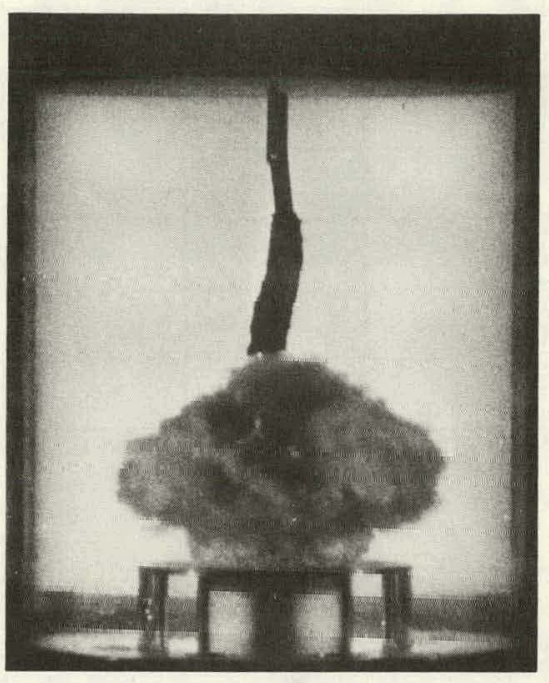

(a) WATER COOLANT (E-001) NO STRUCTURES

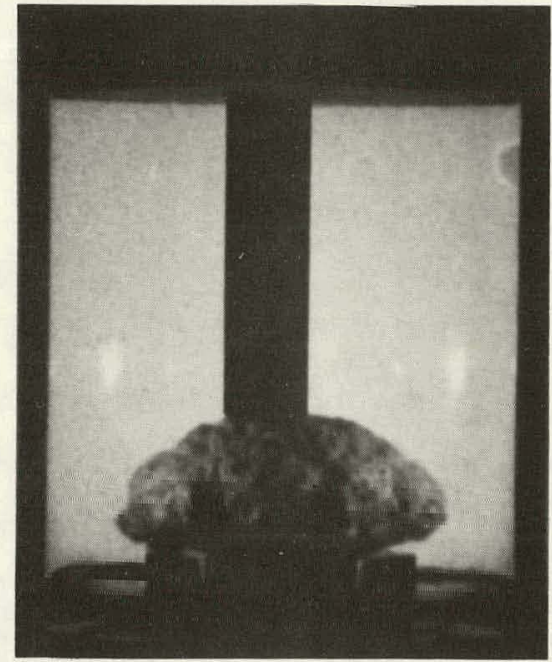

(c) FREON 113 COOLANT (G-004) NO STRUCTURES

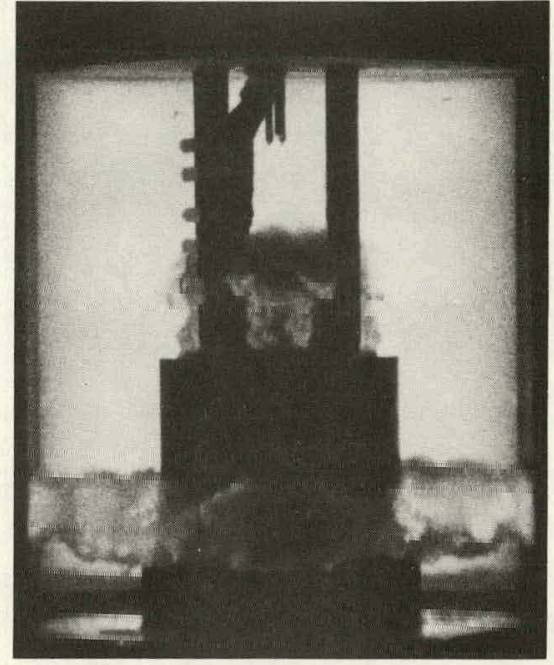

(b) WATER COOLANT (E-003) UPPER CORE AND UPPER INTERNAL STRUCTURES

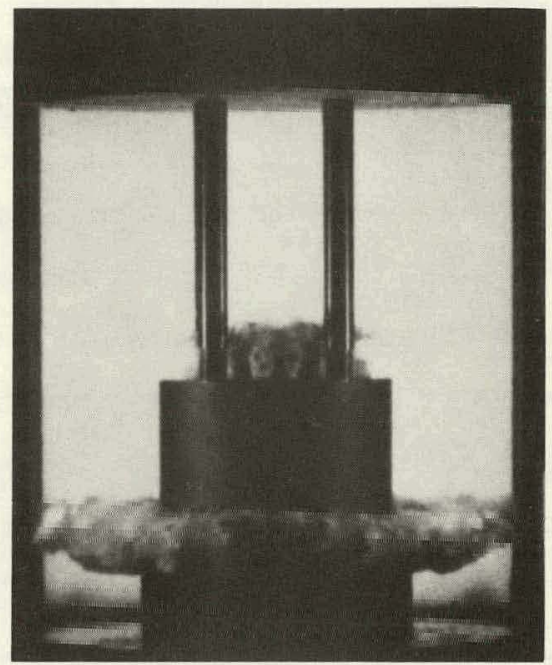

(d) FREON 113 COOLANT (G-006) UPPER CORE AND UPPER INTERNAL STRUCTURES

MA-3929-582

FIGURE 9 HCDA BUBBLE PHOTOGRAPHS AT SLUG IMPACT SHOWING THE EFFECT OF INTERNAL VESSEL STRUCTURES 


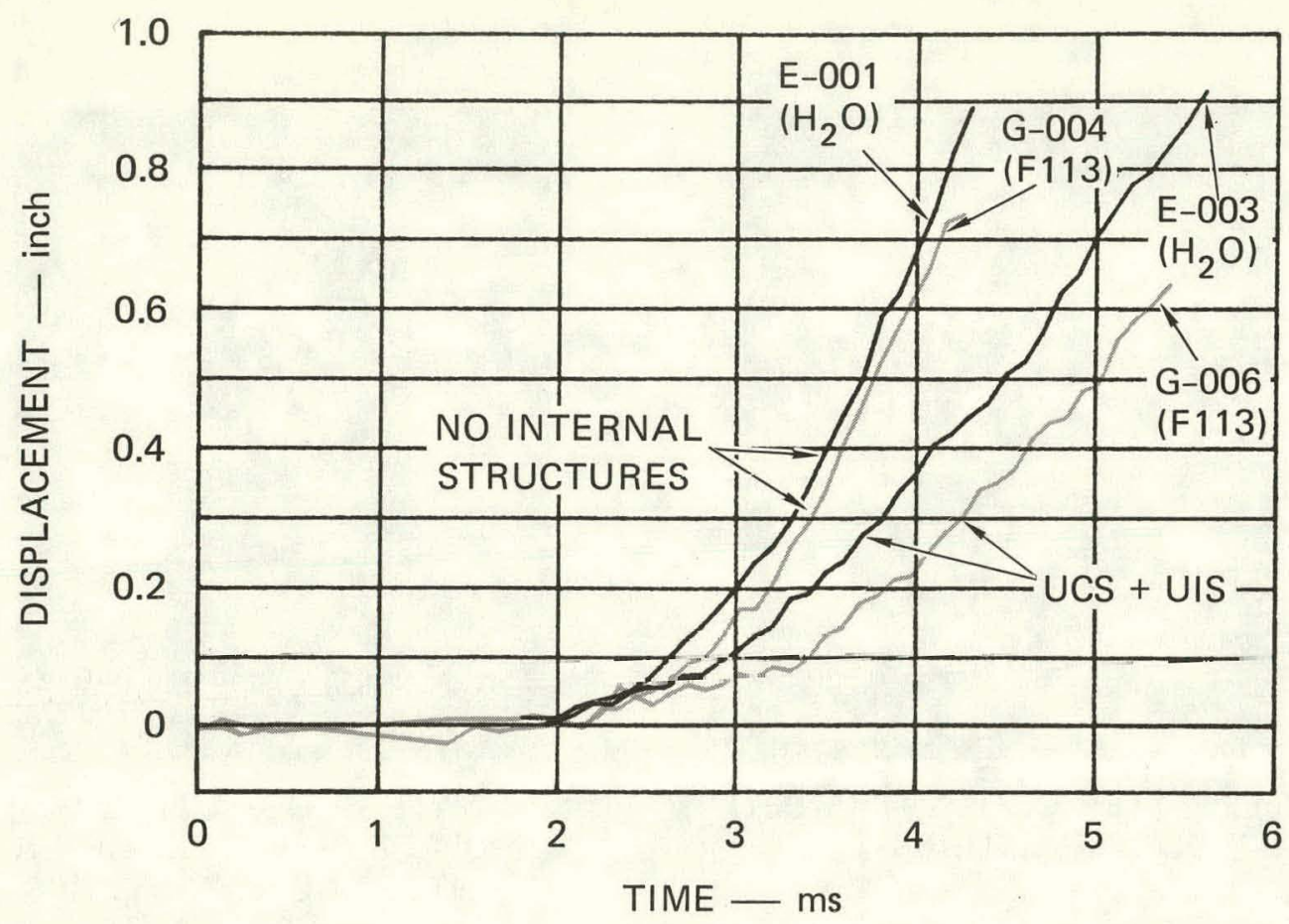

MA-3929-503A

FIGURE 10 EFFECT OF INTERNAL VESSEL STRUCTURES AND COOLANT VOLATILITY ON COOLANT SURFACE DISPLACEMENT

Future work in this area should entail 1/30-scale experiments that address aspects of the expansion dynamics abnut which the most yuestions remain. These areas include the forces on the UCS and UIS and on the wall of the acrylic vesse1, the mechanisms of mixing and entrainment in the upper core and bubble, the composition of the hubble, the attenualion effects of heat transfer with a more protntypic upper cnre structurc, and the temperature distribution in the bubble. Questions also still remain about the scaling of thermodynamic phenomena observed in these experiments, and application of our results to the demonstration size TMFBR and the newly proposed 1000-MW plant. 
Table 3

\section{SUMMARY OF EFFECTS OF INTERNAL VESSEL STRUCTURES WITH DIFFERENT COOLANT SIMULANTS ${ }^{*}$}

\begin{tabular}{cccc} 
Experiments & Coolant & $\begin{array}{c}\text { Internal } \\
\text { Structures }\end{array}$ & $\begin{array}{c}\text { Reduction in Slug } \\
\text { Impact Impulse } \\
\text { to No Internal } \\
\text { Structures (\%) }\end{array}$ \\
\hline E-001 & $\mathrm{H}_{2} \mathrm{O}$ & None & 0.0 \\
E-003 & $\mathrm{H}_{2} \mathrm{O}$ & UCS + UIS & -56.1 \\
G-003 & $\mathrm{F} 113$ & None & -5.4 \\
G-004 & F113 & None & +5.4 \\
G-006 & F113 & UCS + UIS & -44.9
\end{tabular}

"Average of G-003 and G-OU4 used fur F913 oomparison.

TNeglects load transmitted to the cover through the UIS columns. 


\section{THIS PAGE \\ WAS INTENTIONALLY \\ LEFT BLANK}

22 


\section{EXPERIMENTAL METHOD}

\section{A. Coolant Simulants}

Our previous HCDA simulations using a flashing source ${ }^{1,3}$ were conducted using water as the fuel and coolant simulant. Table 4 gives the thermodynamic relation between prototype and simulant fuel and coolants; as showr in the table, the water temperature in the lower core at 1160 psi is $88 \%$ of the coolant (water) critical temperature. In the prototype, the fuel temperature is almost twice the coolant critical temperature. The likelihood of vaporization of the coolant entrained in the HCDA bubble is much greater, therefore, in the prototype than in our past simulations. Vaporization of the coolant in the HCDA bubble could increase the bubble pressure and therefore the impact pressure of the coolant slug on the vesse1 cover.

Table 4

\section{FUEL/COOLANT RELATIONSHIP*.}

\begin{tabular}{|c|c|c|c|c|c|}
\hline & Fuel & Coolant & $\begin{array}{c}\text { Fuel Temperature } \\
\text { at } 1160 \text { psia } \\
{ }^{\circ} \mathrm{R}\left({ }^{\circ} \mathrm{F}\right)\end{array}$ & $\begin{array}{c}\text { Fuel Temperature/ } \\
\text { Coolant Critical } \\
\text { Temperature }\end{array}$ & $\begin{array}{c}\text { Fuel Critical Pressure/ } \\
\text { Coolant Critical } \\
\text { Pressure }\end{array}$ \\
\hline \multirow[t]{2}{*}{$\begin{array}{l}\text { Prototype } \\
\text { Materials }\end{array}$} & $\mathrm{UO}_{2}$ & $\mathrm{Na}$ & 8799 (8339) & 1.95 & $5.20-7.80$ \\
\hline & $\mathrm{H}_{2} \mathrm{O}$ & $\mathrm{H}_{2} \mathrm{O}$ & $1023(56.3)$ & 0.88 & 1.00 \\
\hline \multirow{2}{*}{$\begin{array}{l}\text { Simulant } \\
\text { Materials }\end{array}$} & $\mathrm{H}_{2} \mathrm{O}$ & F113 & $1023(563)$ & 1.17 & 6.48 \\
\hline & $\mathrm{H}_{2} \mathrm{O}$ & F11 & $1023(563)$ & 1.21 & 5.02 \\
\hline
\end{tabular}

* From references 3 through 7 
Another measure of the relationship between prototype and simulant fuel and coolant is the ratio of the critical pressure of the fuel to that of the coolant. In the prototype, this ratio is about 6 , whereas in our past experiments with water as the fuel and coolant it was 1 . To more adequately reproduce the prototypic relationship between the fuel and coolant, we sought another coolant liquid for our HCDA simulation experiments.

Our objective was to find a coolant material that approaches as closely as possible the prototypic ratios shown in Table 4. Equal1y important was the need to meet practical requirements of transparency, low toxicity, low combustibility, and noncorrosiveness. These practical requirements lead us to limit our attention to the Frenn refrigeranto. Two of these of increasing volatility (i.e., a higher vapor pressure at a given temperature) are Freon 113 and Freon 11, also shown in Table 4. The critical constants of the prototype and simulant materials discussed are shown in Table 5. Freon 113 and 11 meet both our thermodynamic and practical requirements. They are the most volatile Freons that would not boil at atmosphere pressure. Their boiling temperatures at 1 atmosphere are $117.6^{\circ} \mathrm{F}$ (Freon 113) and $74.9^{\circ} \mathrm{F}$ (Freon 11). It was expected that Freon 113 would be less difficult to use, so it was chosen for most of our experiments. Freon 11, which is of slightly higher volatility, was used in one experiment.

We should note that although using Freon as a coolant more adequately simulated the fuel/coolant relationship, the temperature regime of the simulations $\left(563^{\circ} \mathrm{F}\right)$ was much lower than the temperatures in the prototype $\left(8339^{\circ} \mathrm{F}\right)$. The nature of heat transfer in the simulations and the prototype is therefore different.

\section{B. Cunstant Ecometry and Constant Mass Configurations}

One problem with replacing water by Freon in the coolant pool of 1/30-scale experiments is that Freon is about $50 \%$ denser than water. The heavier pool in Freon tests makes direct quantitative comparisons between water and Freon experiments difficult since both coolant volatility and coolant mass will be changing and it may be difficult to sort 
Table 5

MATERIAL CRITICAL CONSTANTS

\begin{tabular}{|c|c|c|c|c|}
\hline & Material & $\begin{array}{c}\text { Critical Pressure, } P_{c} \\
\text { (psia) }\end{array}$ & $\begin{array}{c}\text { Critical Temperature, } T_{c} \\
\left({ }^{\circ} \mathrm{R}\right)\end{array}$ & Reference \\
\hline \multirow{2}{*}{$\begin{array}{l}\text { Prototype } \\
\text { Materials }\end{array}$} & {$\left[\mathrm{UO}_{2}\right.$} & $19319-29008$ & $12101-14742$ & 5 \\
\hline & $\mathrm{Na}$ & 3718.8 & 4517.0 & 6 \\
\hline \multirow{3}{*}{$\begin{array}{l}\text { Simulant } \\
\text { Materials }\end{array}$} & $\mathrm{H}_{2} \mathrm{O}$ & 3208.2 & 1165.1 & 7 \\
\hline & F113 & 495 & 877.1 & 8 \\
\hline & F11 & 639.5 & 848.07 & 8 \\
\hline
\end{tabular}

out these two effects. It would be desirable to conduct experiments in which only the coolant volatility is varying. A simple approach that comes close to achieving this aim is to vary the height of the upper core and coolant pool so as to maintain constant the mass of coolant that moves during an experiment. This was done in the "constant mass" Freon 113 and 11 experiments by reducing by about one-third the heights of the upper core and the coolant pool above the upper core from their reference values of 2.7 and 9.2 inches, respectively, to compensate for the $50 \%$ higher coolant density. The densities of water, Freon 113, and Freon 11 at $70^{\circ} \mathrm{F}$ are $62.3,98.3$, and $92.7 \mathrm{lbm} / \mathrm{ft}^{3}$, respectively. $7,9,10$

Experiments with the Freon coolants were also conducted in the reference configuration and are designated "constant geometry" experiments in contrast to the constant mass experiments described above.

\section{Experimenta1 Apparatus}

The apparatus, shown in Figure 11, consists of three primary components: (1) the test section consisting of the acrylic cylinder, upper 


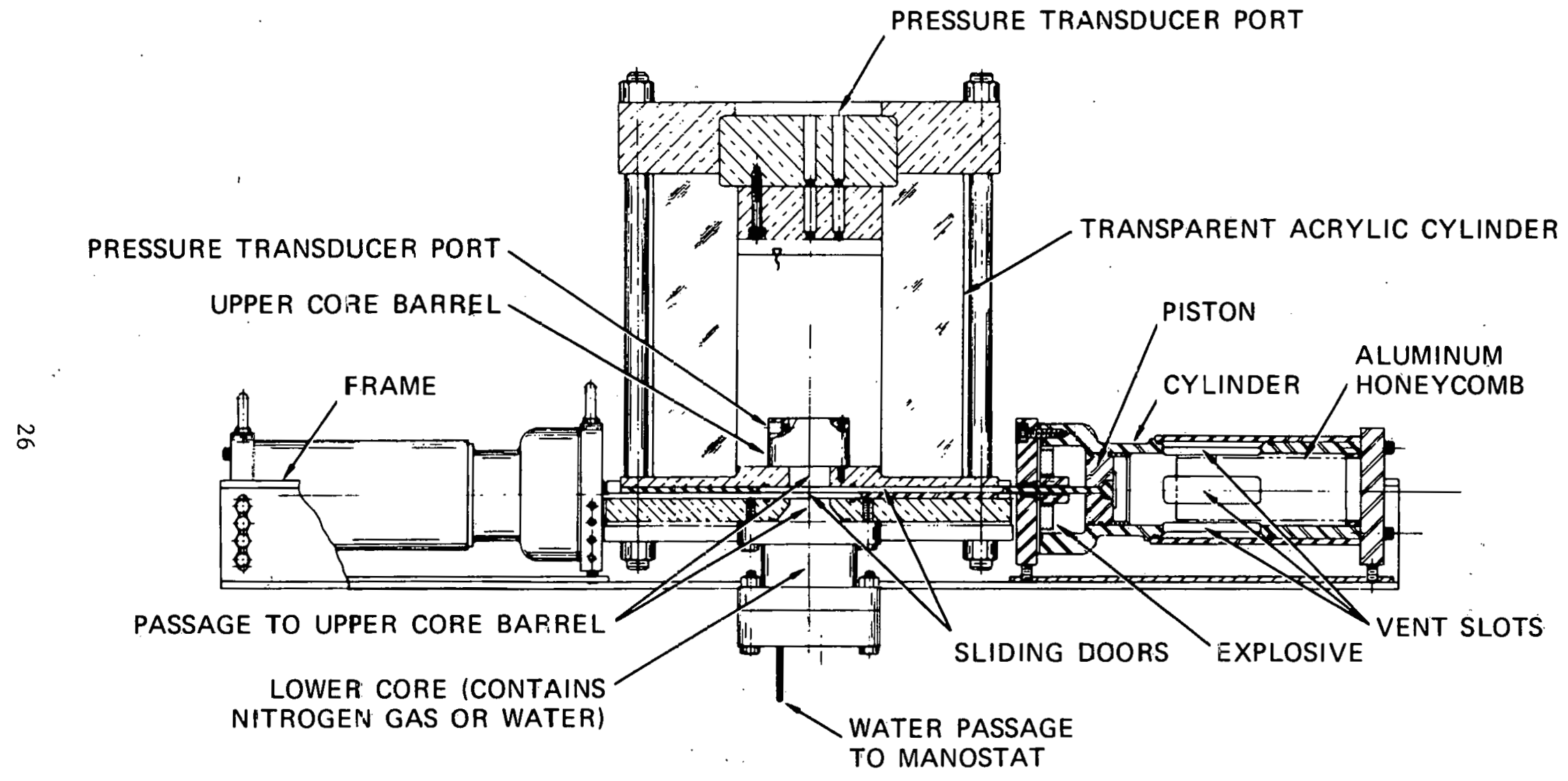

FIGURE $11 \quad 1 / 30$-SCALE VESSEL ASSEMBLY 
core barrel, upper core structure, upper internal structure, sodium coolant simulant, cover gas simulant, and top cover; (2) the lower core, which contains the high energy bubble source material; and (3) the release mechanism consisting of the sliding doors, pistons, and their containing structure. Each of these components is described below.

\section{Test Section.}

The test section, shown in Figure 12, is a simple, rigid 1/30scale model of the interior of a typical demonstration size loop-type LMFBR (Figure 2). Room temperature water, Freon 113, or Freon 11 near atmospheric pressure were used to simulate the sodium coolant. Air was used to simulate the cover gas; however, in the Freon experiments, the cover gas was mostly Freon vapor. The transparent acrylic cylinder allowed high-speed photography of the simulated HCDA bubble expansion. Details of the internal structures are shown in Figure 13.

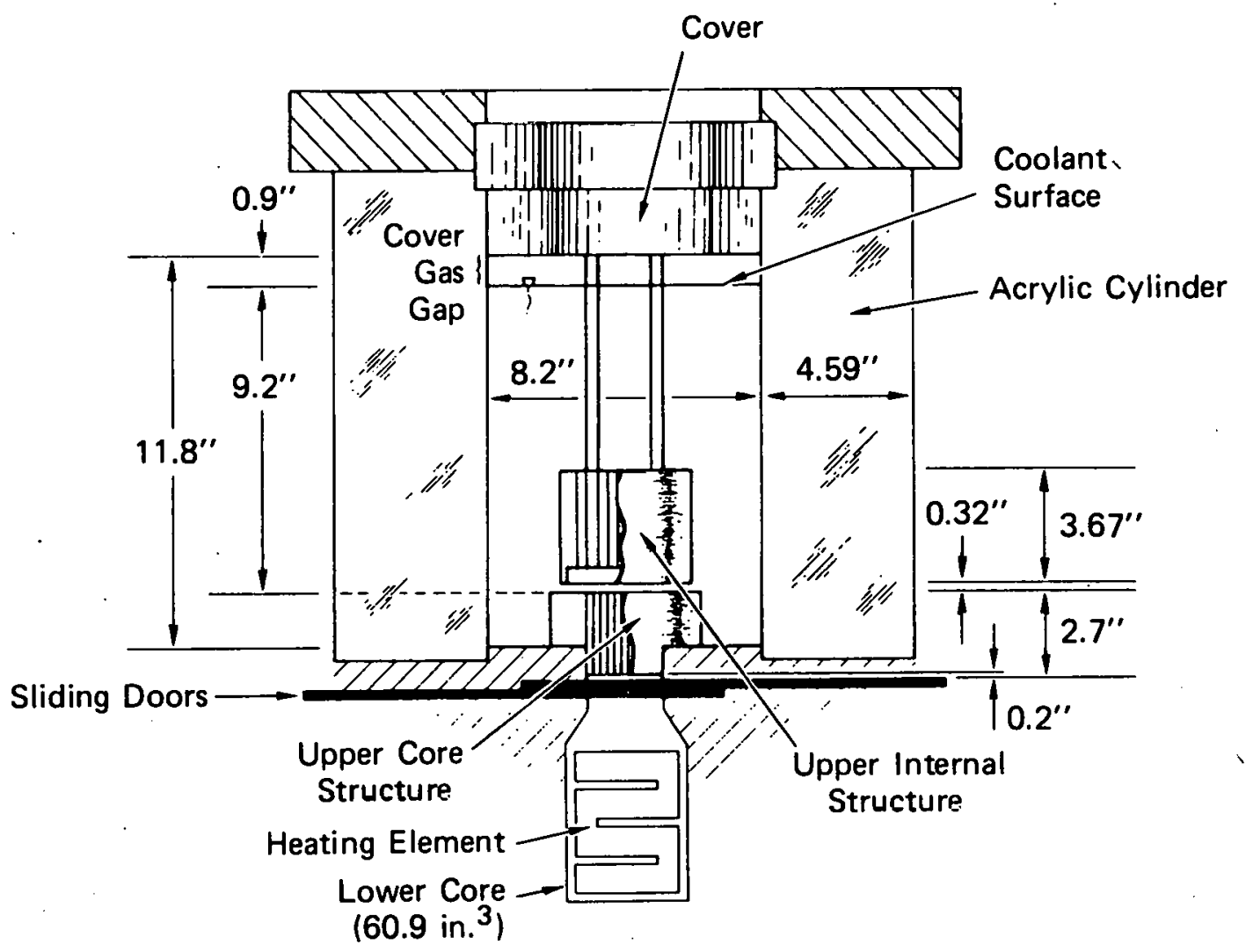

MA-3929-296C

FIGURE 12 1/30-SCALE VESSEL 

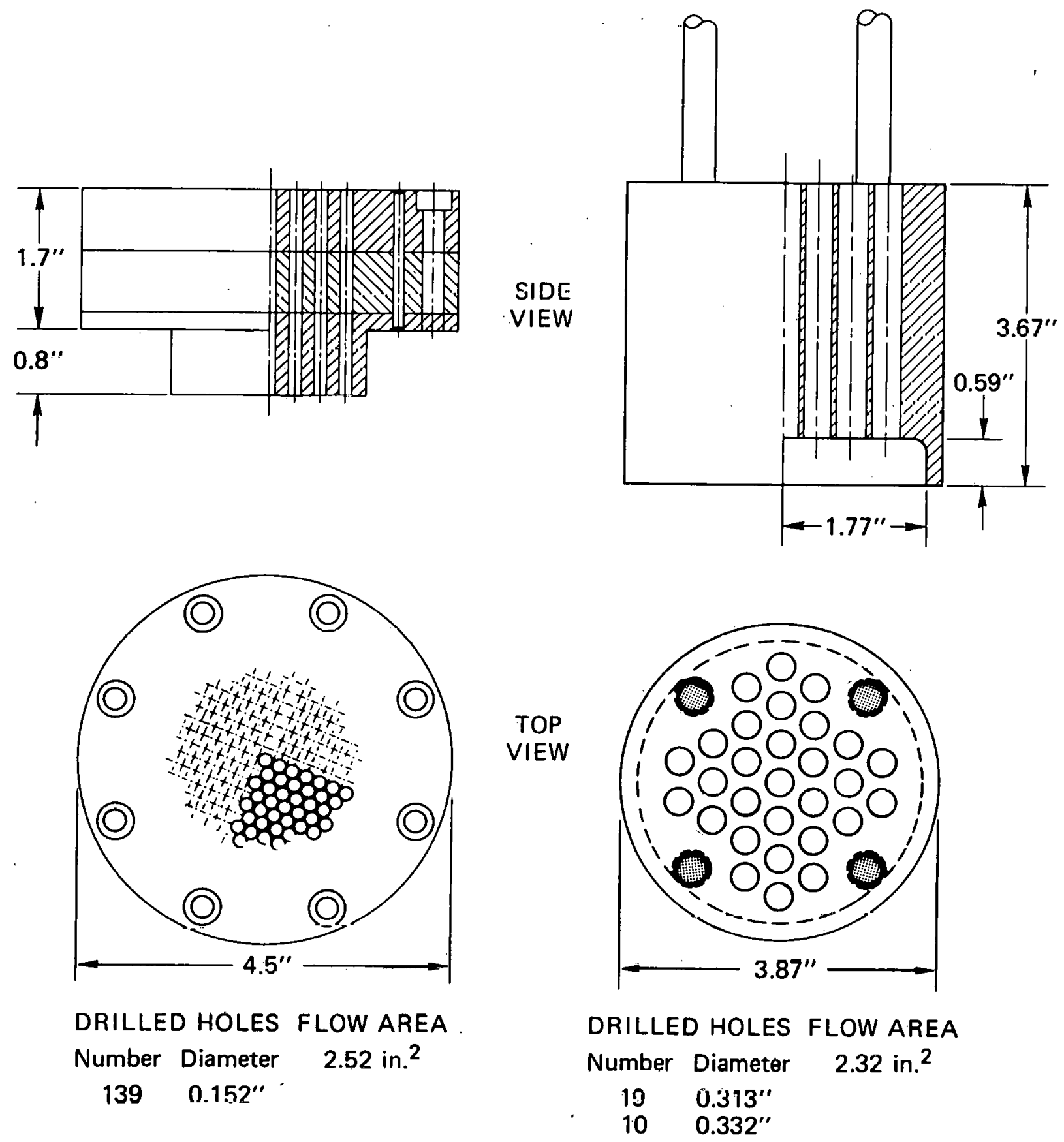

(a) UPPER CORE STRUCTURE (UCS)

(b) UPPER INTERNAL STRUCTURE (UIS)

MA-3929-297A

FIGURE 13 INTERNAL VESSEL STRUCTURES 
The upper internal structure. (UIS) geometry is linearly scaled to the UIS geometry of a typical demonstration size loop-type LMFBR. The diameter of cach flow channel in the upper core structure (UCS) was chosen to scale the cross-sectional area of an empty subassembly duct. Thus, 139 holes were drilled within the available cross-sectional area of the vessel upper core (2.3-inch diameter). The gap between the top of the upper core and the bottom edge of the UIS was set such that the ratio of area available to lateral flow through the gap divided by the UIS flow area was equal to that found in the Clinch River Breeder Reactor structural response experiments ${ }^{2}$ following UIS displacement under a simulated $661 \mathrm{MW}-\mathrm{s}$ HCDA. The four columns supporting the UIS in the transparent vessel experiments were intentionally made strong enough to prevént any permanent deformation.

\section{Lower Core}

The lower core (Figure 11) contains the bubble source material used to simulate the qualitative features of the expansion of sodium vapor and molten fuel in an HCDA. Two bubble sources were used in these experiments: room temperature, high-pressure nitrogen gas and saturated, zero quality, high-pressure water. When nitrogen gas was used as the bubble source, the lower core was filled to the desired pressure (100 bars) using a 6000-psi (413.8-bar) gas bottle. When the bubble source was to be. flashing water, the lower core was first evacuated and then filled with ronm temperature, degassed, deionized water. The desired saturated initial condition ( 80 bars, $563^{\circ} \mathrm{F}$ ) was then reached by the path ABCD shown in Figure 14. The water was first pressurized to 117 bars (point B), then heated to $563^{\circ} \mathrm{F}$ (point $\mathrm{C}$ ), and finally depressurized to 80 bars (point D). A detailed description of the lower core and its heating and pressure control system is presented in Appendix $A$.

\footnotetext{
* The UCS does not simulate the percent open cross section in the prototype.
} 


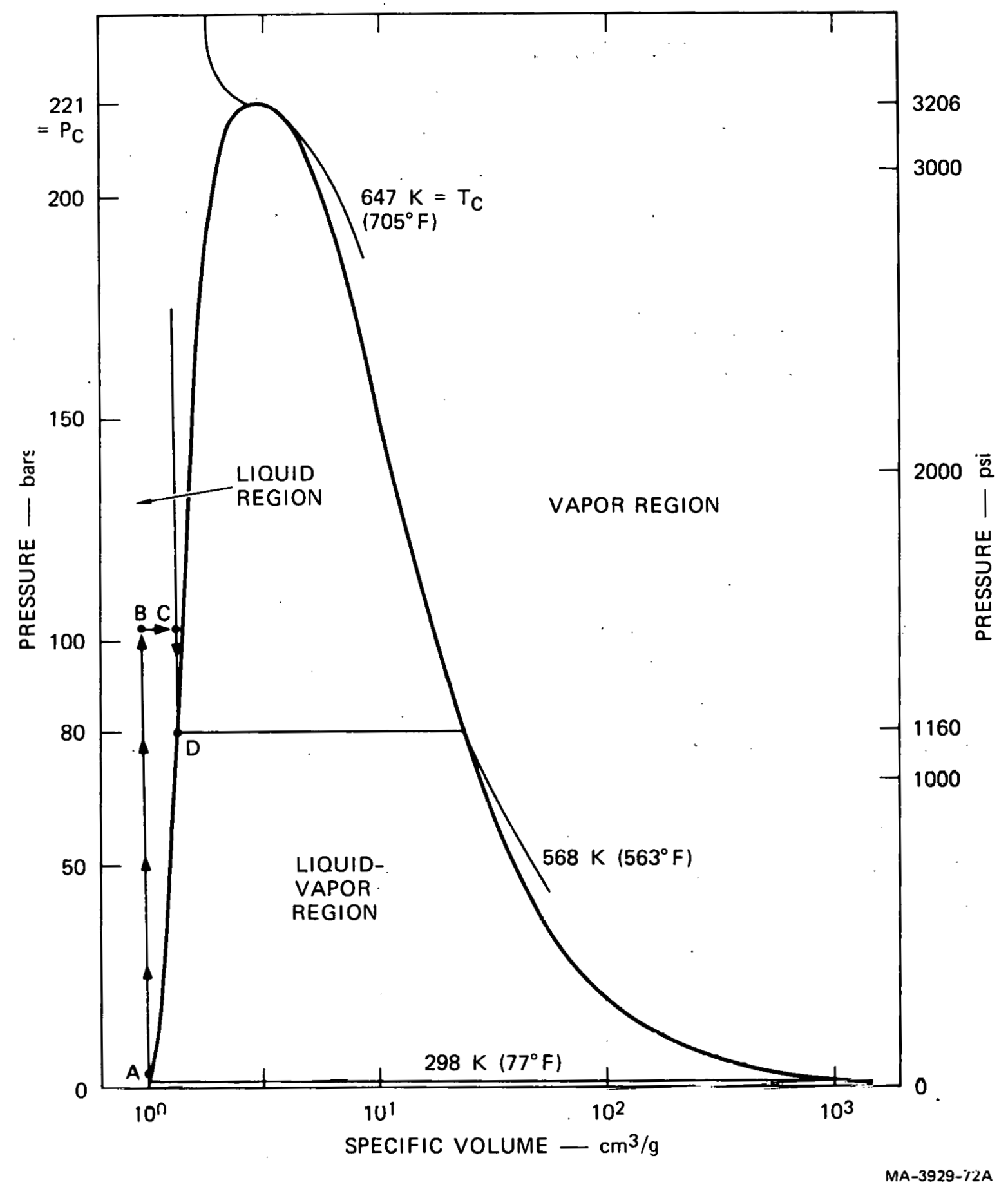

FIGURE 14 WATER HEATING DIAGRAM 


\section{Sliding Door Pressure Release Mechanism}

The sliding door mechanism was chosen as the best method for releasing in a very rapid yet clean manner the bubble source material contained in the lower core. The sliding doors are shown in their initial position in Figure 15(a). Detonation of the explosive charge accelerates the pistons and sliding doors to a high velocity. At this point, Figure 15(b), the tips of the doors pass each other and the passage between the lower and upper core begins to open. When the passage is clear, Figure $15(\mathrm{c})$, the pistons are decelerated without rebound by the crushing of aluminum honeycomb, and the explosive charge products are vented to the atmosphere. An opening time about one-tenth of the expansion time of the bubble in the vessel was considered adequate. An opening time of approximately $230 \mu$ s from the time the door tips pass each other and begin to open until the door tips just clear the passage boundary was used. A detailed description of the sliding door pressure release mechanism is presented in Appendix A.

D. Instrumentation

The following measurements were made in these experiments.

- Initial conditions:

- Lower core pressure

- Lower core temperature

- Cover gas gap

- Transient measurements :

- Stiding door motion

- Lower core pressure

- Upper core pressure

- Pressure in the poil and bubble

- Temperature in the pool and bubble

- Vessel cover pressure

- High-speed photography of the bubble expansion.

In the nitrogen source experiments, the initial conditions in the lower cure were cetablished using a Heise pressure gage. During the 
(a)

CLOSED POSITION
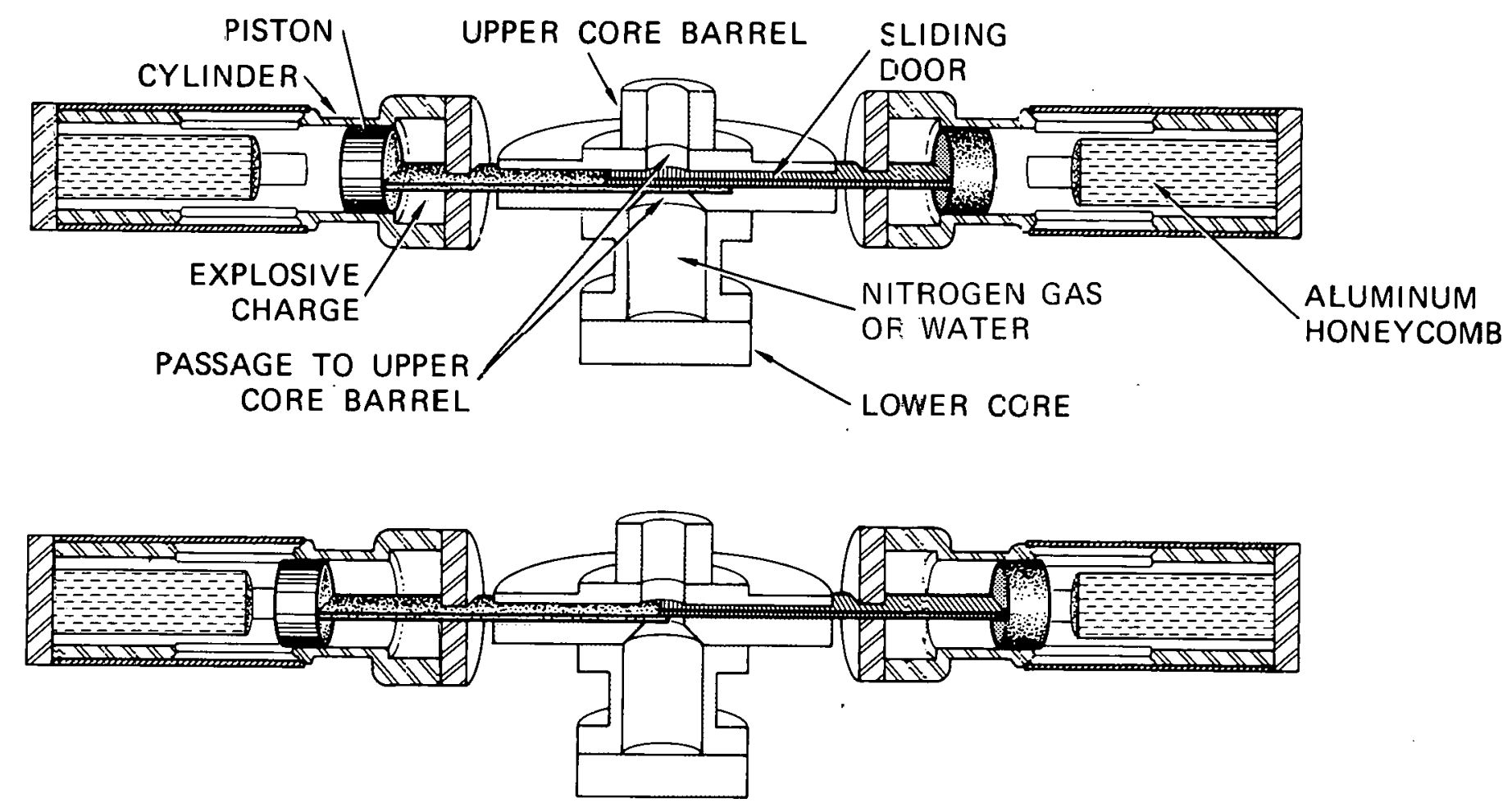

(b) DOORS BEGIN TO OPEN

(c)

OPEN POSITION

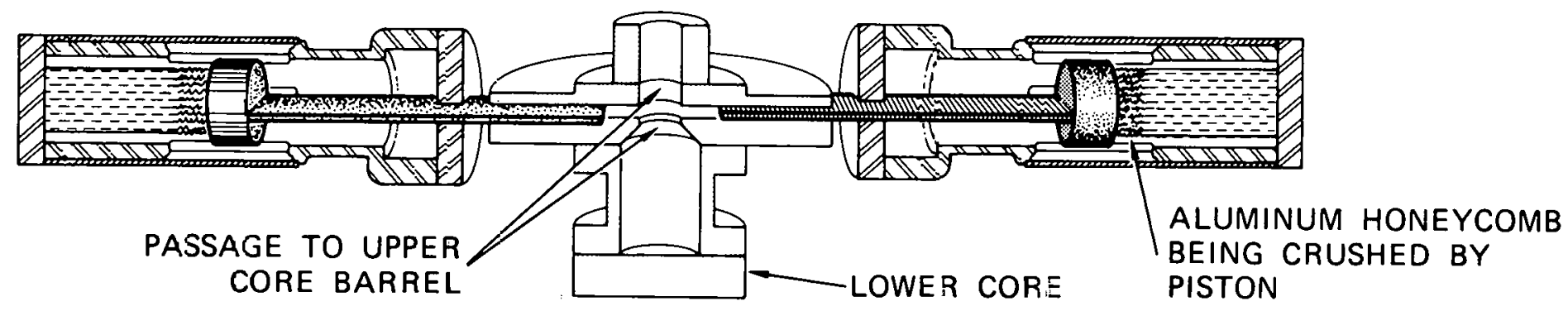


flashing source experiments, the pressure and temperature in the lower core, measured using a Kulite Model HEM 375 pressure transducer and a Chromel-constantan thermocouple, were recorded on a slow-speed tape recorder.. The initial cover gas gap was established to within about 0.01 inch through the use of a syringe and sharply pointed rod extending from the cover. Establishment and determination of the initial experimental conditions are described in Appendix $B$.

The reactor model instrumentation is shown schematically in Figure 16. The specific instrumentation used in each experiment is described in Appendix C. The door opening motion was measured by a photodiode device that can detect differences in the reflectivity of a surface. The photodiode output signal fluctuates between two voltages as light and dark bands on an extension of the sliding doors pass by the detector. The output was recorded on a high-speed tape recorder. The photodiode system is described in detail in Appendix A.

The lower core pressure was measured at the bottom of the lower core ( 6.25 inches below the sliding doors) and 2.50 inches from the bottom. Two pressure transducers were mounted opposite each other at the inside wall of the upper core 0.44 inch below the top of the upper core. Pressure at the bottom face of the top cover (radius 4.1 inches) was measured 0.69 inches from the center, 1.88 inches from the center, and 3.53 inches from the center. PCB pressure transducer Models 113M07, 102M50, and 102M56 were used in the lower core, upper core, coolant pool, and cover. Those in the lower core were water-cooled and electrically isolated, whereas those in the upper core and cover were mounted in electrically isolated adaptors. The pressure and temperature in the pool and bubble were measured using a PCB pressure transducer and a Nanmac Model E12-1 Pencil Probe mounted in the instrument sting shown in Figure 17. The sting was suspended in to the coolant pool from the vessel cover (Figure 16). Three sting lengths were used as indicated in the figure. The distances between the transducers and the top of the upper core in each experiment are shown in Figure C.l. The data from the photodiodes, pressure transducers, and thermocouple were recorded on oscilloscopes for immediate examination of the results and on a magnetic tape machine for later use in data reduction. 


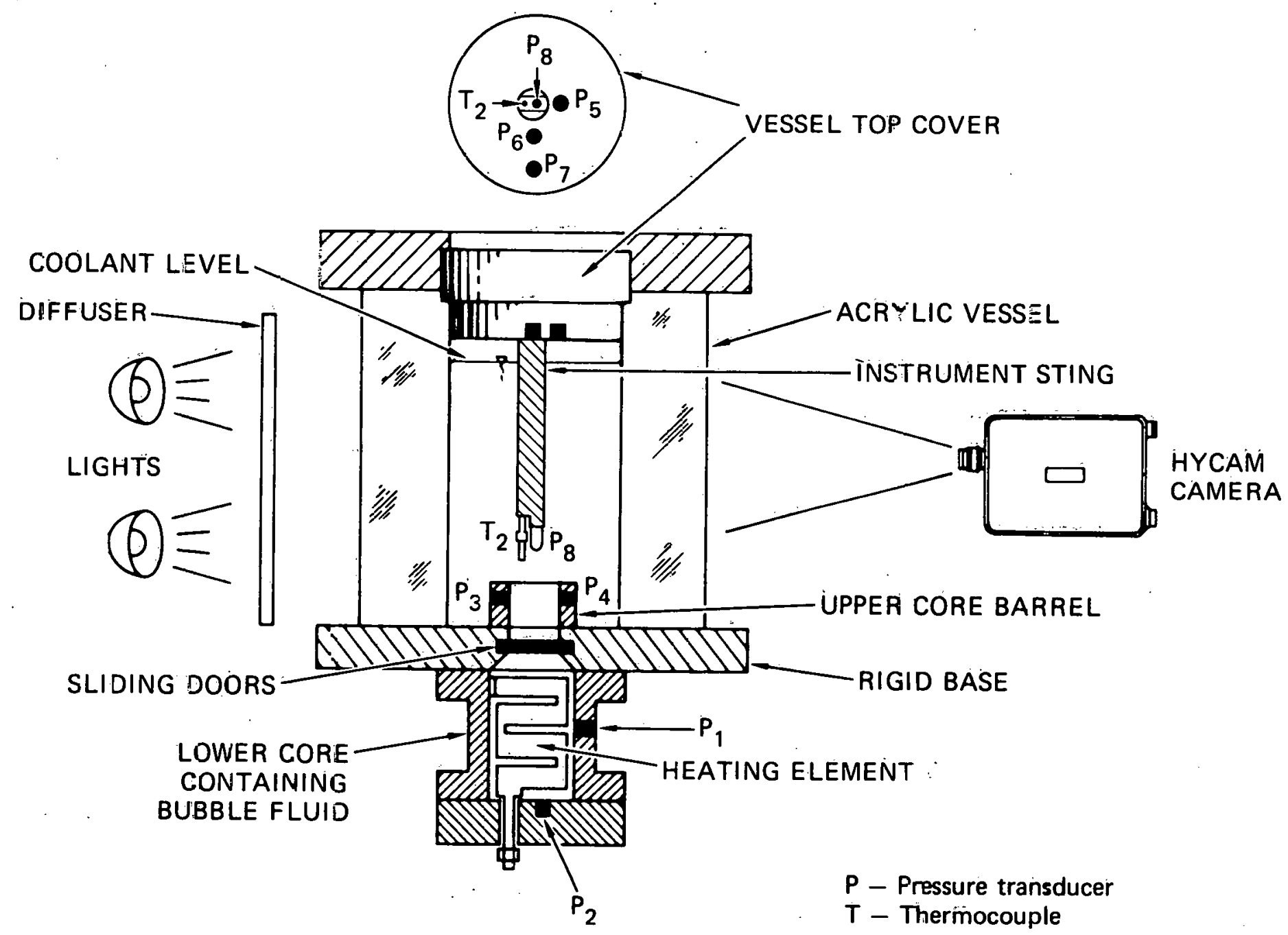




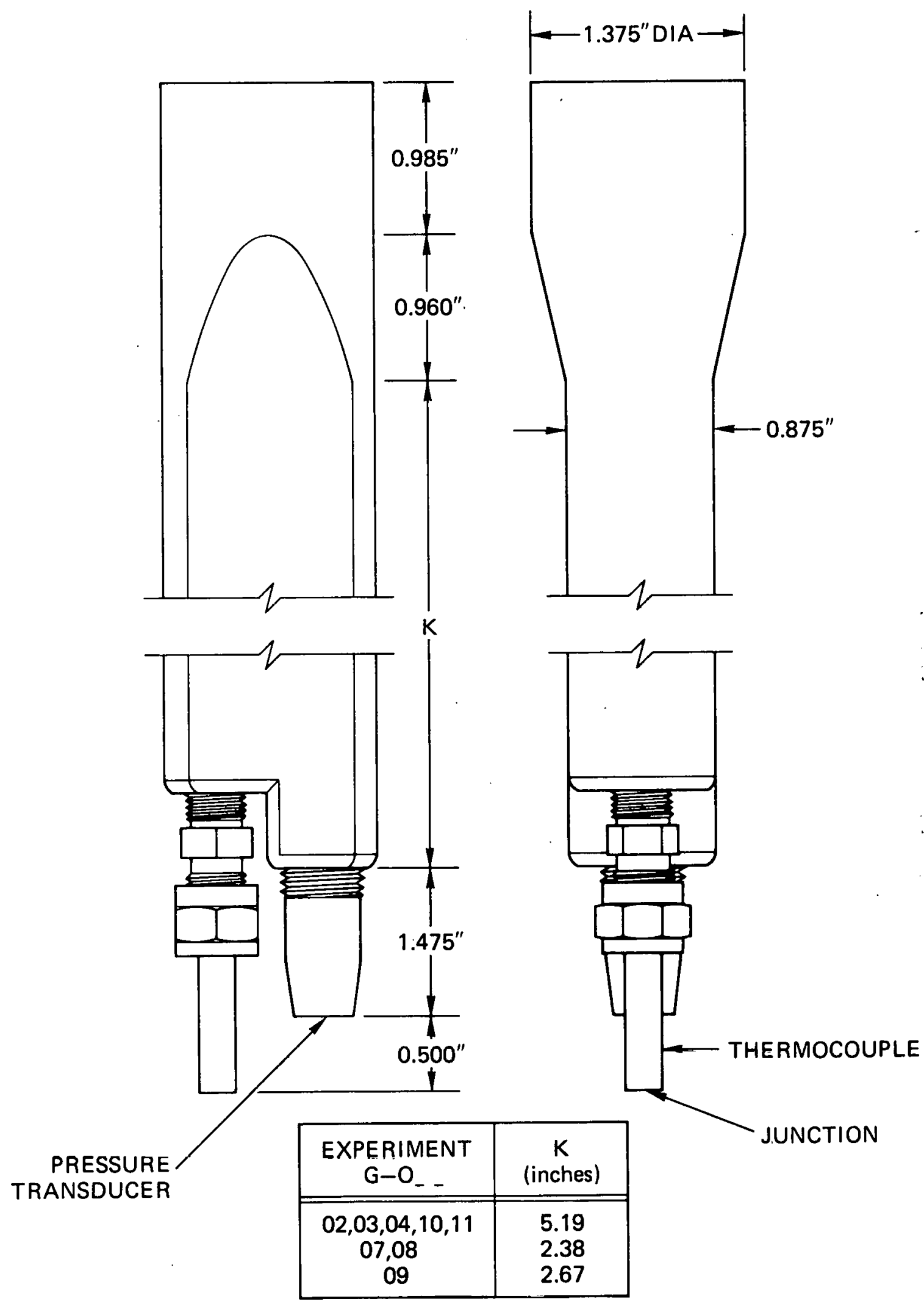

MA-3929-494

FIGURE 17 INSTRUMENT STING (Full Scale) 
The bubble expansion was recorded by a Hycam Model 41-004 camera at a nominal speed of 10,000 frames per second. A timing device in the camera determines the exact film speed. The vessel was back-1it to silhouette the bubble, and front-lit to highlight the bubble surface detail. The camera focal plane was 56 inches from the vessel and centerline. Analysis of the movies provided data on the coolant surface displacement and bubble volume.

\section{E. Experiment Matrix}

Table 6 presents the matrix of experiments planned for this experimcnt series. As described in Section IIB, both constant geometry (1/30-scale) experiments and constant (coolant) mass experiments were planned. Constant mass experiments $2,11,7$, and 9 were intended to reveal the effects of coolant volatility. Constant geometry experiments 3, 4, 5, and 6 were intended to demonstrate the effects of internal structures with more volatile coolants. Experiments 8 and 10 with a nitrogen source were planned to verify the constant mass and constant geometry approaches when compared with a previously conducted experiment (D-006). I Coolant volatility effects are absent in room temperature nitrogen experiments, but coolant density effects are still present. Experiments 4, 6, and 11 are repeatability checks.

The initial fuel state in the nitrogen experiments is rooll temperature and 1450 psia. In the flashing water fuel source, the initial state is $563^{\circ} \mathrm{F}$ and 1160 psia. 
Table 6

\section{EXPERIMENT MATRIX}

$\begin{array}{ccccc}\text { Experiment } & \text { Fuel } & \text { Coolant } & \text { Configuration } & \begin{array}{c}\text { Internal } \\ \text { Structures }\end{array} \\ \text { G-002 } & \mathrm{H}_{2} \mathrm{O} & \mathrm{H}_{2} \mathrm{O} & \text { Reference } & - \\ \text { G-003 } & \mathrm{H}_{2} \mathrm{O} & \mathrm{F} 113 & \text { Constant Geometry } & - \\ \text { G-004 } & \mathrm{H}_{2} \mathrm{O} & \mathrm{F} 113 & \text { Constant Geometry } & - \\ \text { G-005 } & \mathrm{H}_{2} \mathrm{O} & \mathrm{F} 113 & \text { Constant Geometry } & \text { UCS+UIS } \\ \text { G-006 } & \mathrm{H}_{2} \mathrm{O} & \mathrm{F} 113 & \text { Constant Geometry } & \text { UCS+UIS } \\ \text { G-007 } & \mathrm{H}_{2} \mathrm{O} & \mathrm{F} 113 & \text { Constant Mass } & - \\ \text { G-008 } & \mathrm{N}_{2} & \mathrm{~F} 113 & \text { Constant Mass } & - \\ \text { G-009 } & \mathrm{H}_{2} \mathrm{O} & \mathrm{F} 11 & \text { Constant Mass } & - \\ \text { G-010 } & \mathrm{N}_{?} & \mathrm{~F} 113 & \text { Constant Geometry } & - \\ \text { G-011 } & \mathrm{H}_{2} \mathrm{O} & \mathrm{H}_{2} \mathrm{O} & \text { Reference } & -\end{array}$

*UCS - upper core structure, UIS - upper internal structure 
THIS PAGE

\section{WAS INTENTIONALLY LEFT BLANK}

$$
38
$$


Two experiments were conducted with the nitrogen bubble source, using Freon 113 as the coolant simulant. Experiment G-008 was in the constant mass configuration and experiment G-010 was in the constant geometry configuration [Figures $4(a)$ and (b)]. The experimental data from these two experiments are presented in Appendix D. The reference experiment with water as the coolant was experiment D-006 conducted in the previous HCDA experiment series. ${ }^{l}$ These three experiments constitute as set of baseline experiments in which volatility effects are not present.

\begin{tabular}{lll} 
Experiment & \multicolumn{1}{c}{ Configuration } & Coolant \\
D-006 & Reference & $\mathrm{H}_{2} \mathrm{O}$ \\
G-008 & Constant Mass & $\mathrm{F} 113$ \\
G-010 & Constant Geometry & $\mathrm{F} 11$
\end{tabular}

The flashing water source experiments in which volatility is important will be described in later sections and compared with these baseline experiments in Section VII. In these three nitrogen experiments, the effects of experiment geometry and coolant mass are demonstrated.

\section{A. Coolant Surface Displacement}

The coolant surface displacements in the three nitrogen source experiments are compared in Figure 18(a). The constant mass and reference experiments have very similar histories, but the constant mass coolant rises somewhat faster. This slight difference is a geometry effect that results in slightly different accelerations in the two experiments with the same coolant mass. This effect is discussed further in Section VII. The constant geometry experiment with the $50 \%$ heavier coolant mass demonstrates the effect of coulant masc when crimpared with the reference experiment. We note, as indicated on the figure, that $0.1 \mathrm{~ms}$ of the difference between experiments $\mathrm{G}-010$ and $D-006$ is the later opening of the sliding doors in $\mathrm{C}-010$. 


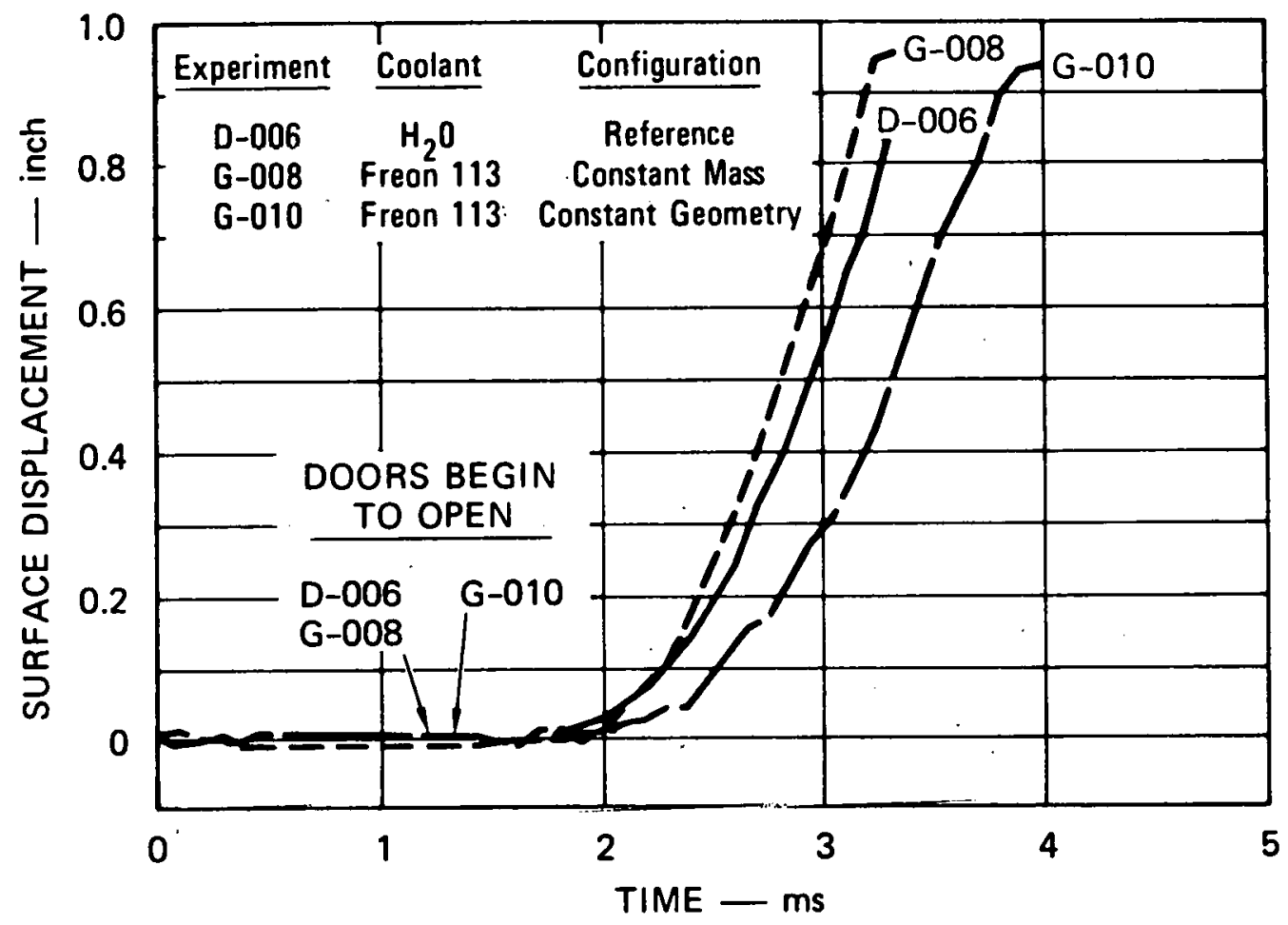

(a) COOLANT SURFACE DISPLACEMENT

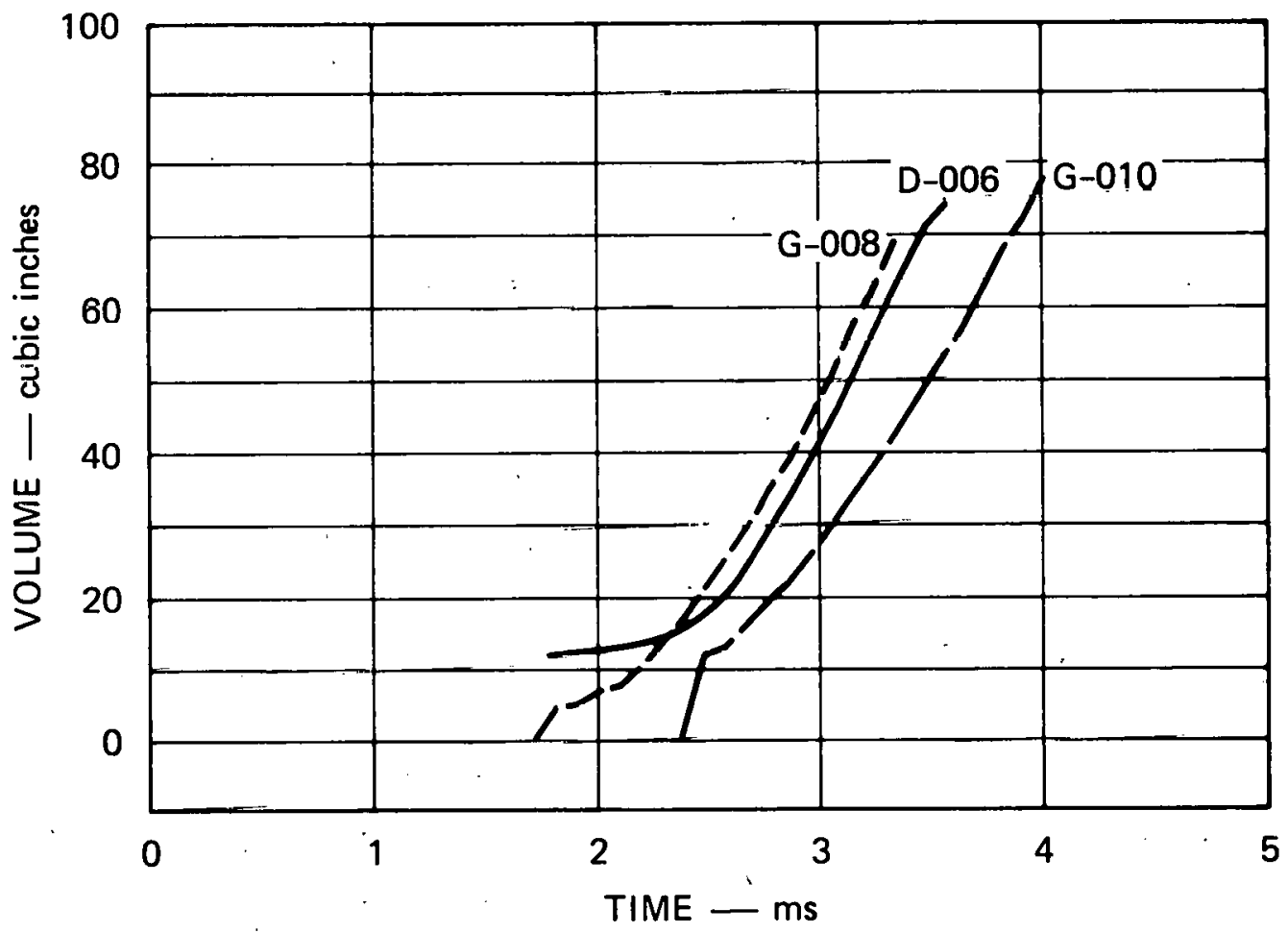

(b) BUBBLE VOLUME

MA-3929-587

FIGURE 18 COOLANT SURFACE DISPLACEMENT AND BUBBLE VOLUME IN THE NITROGEN GOURCE EXPERIMENTS 


\section{B. Bubble Profile and Volume}

The growth of the bubble volume in these three experiments is shown in Figure 18(b). The comparison is the same as above in that the constant mass and reference experiments have very similar histories (with the constant mass slightly earlier), and the constant geometry experiment has the later growth. The striking similarity in the shape and surface texture of the bubbles at coolant slug impact on the vessel cover is seen in Figure 19.

\section{Entrainment}

The volume of liquid entrainment in the bubble is the difference between the bubble volume and the volume displaced by the coolant slug motion. The entrained volume and entrainment as a percent of bubble volume are presented in Figure 20. The entrained volume increases with time, but not enough to keep up with the bubble growth; hence, the percent entrainment falls. The percent entrainment is very high as the bubble emerges from the upper core and decreases to $30 \%$ of the bubble volume at slug impact in all three experiments. 


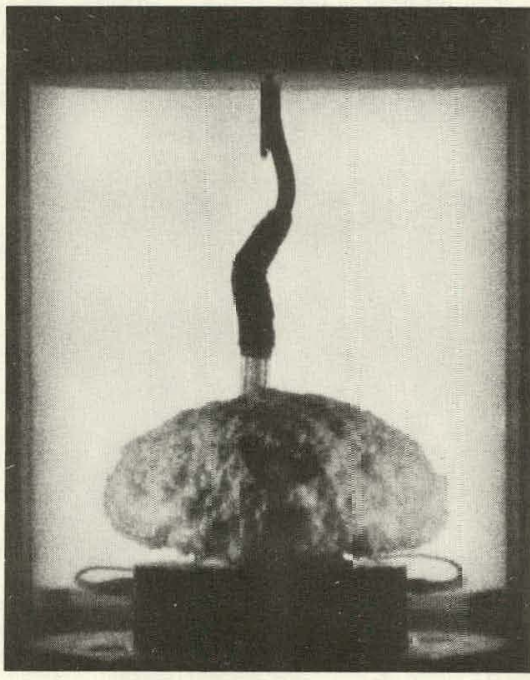

(a) WATER COOLANT (D-006) REFERENCE CASE

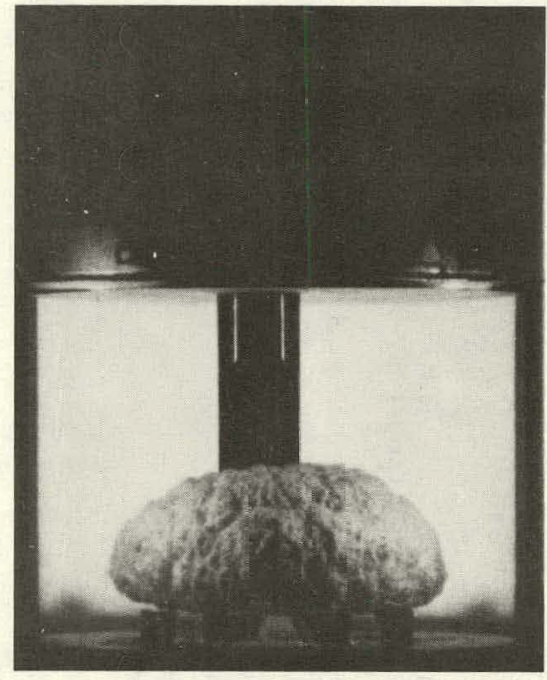

(b) FREON 113 COOLANT (G-008) CONSTANT MASS CONFIGURATION

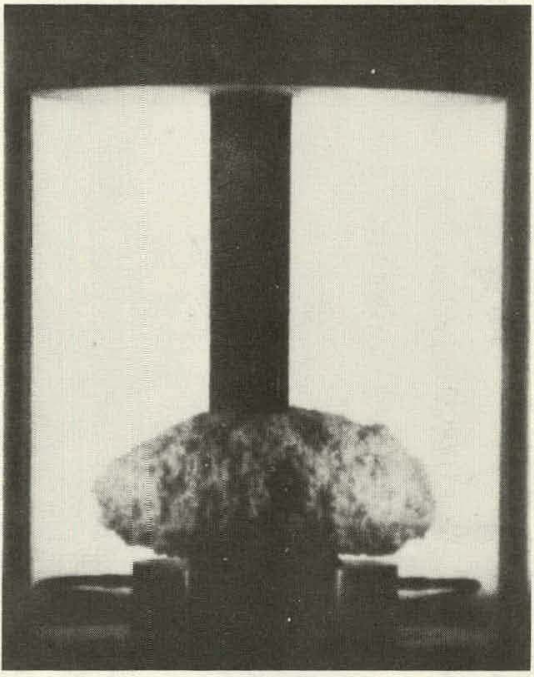

(c) FREON 113 COOLANT (G-010) CONSTANT GEOMETRY CONFIGURATION

MP-3929-584

FIGURE 19 IDCA 3UBBLE PHOTOGRAPHS AT SLUG IMPACT IN THE NITROGEN SOURCE EXPERIMENTS 


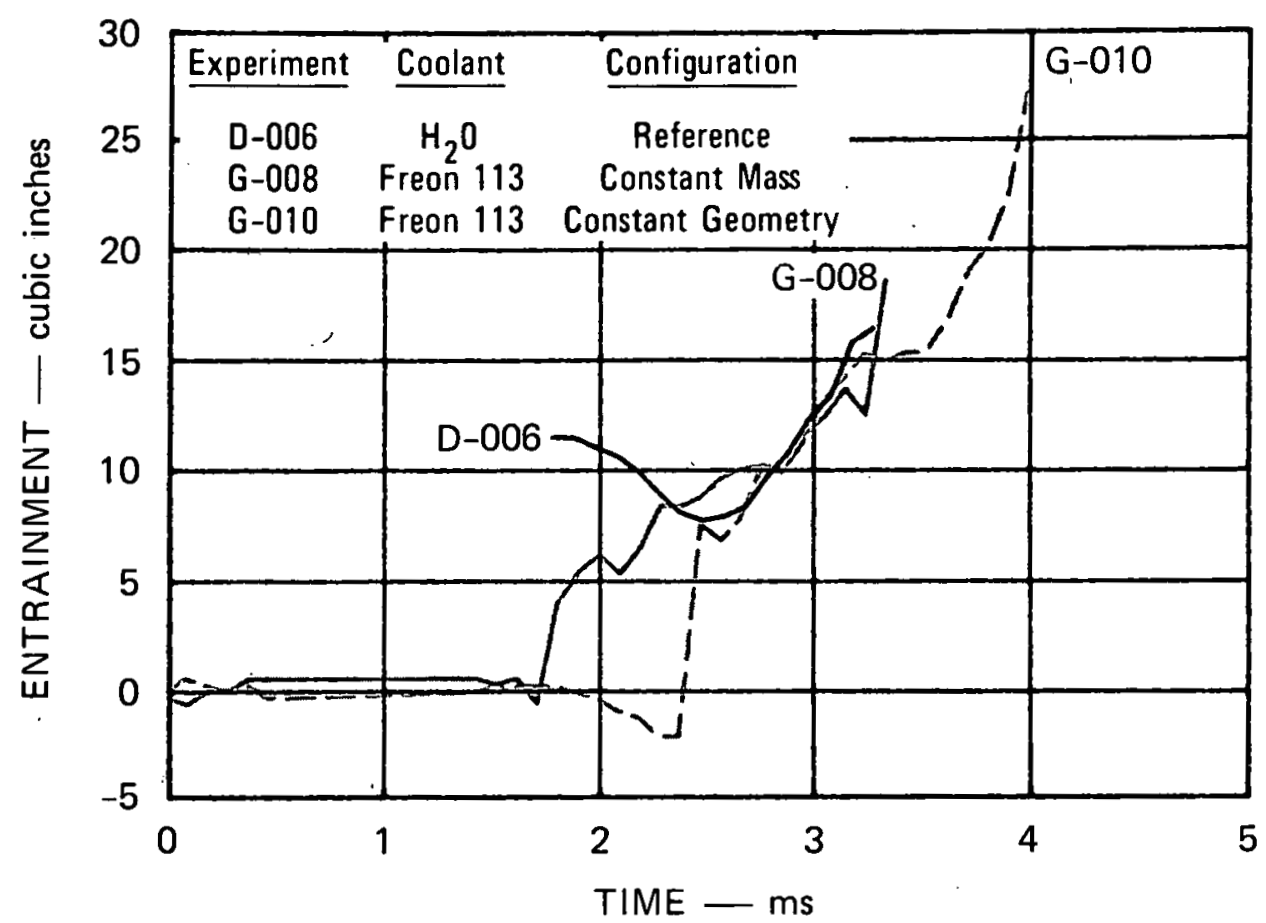

(a) ENTRAINED VOLUME

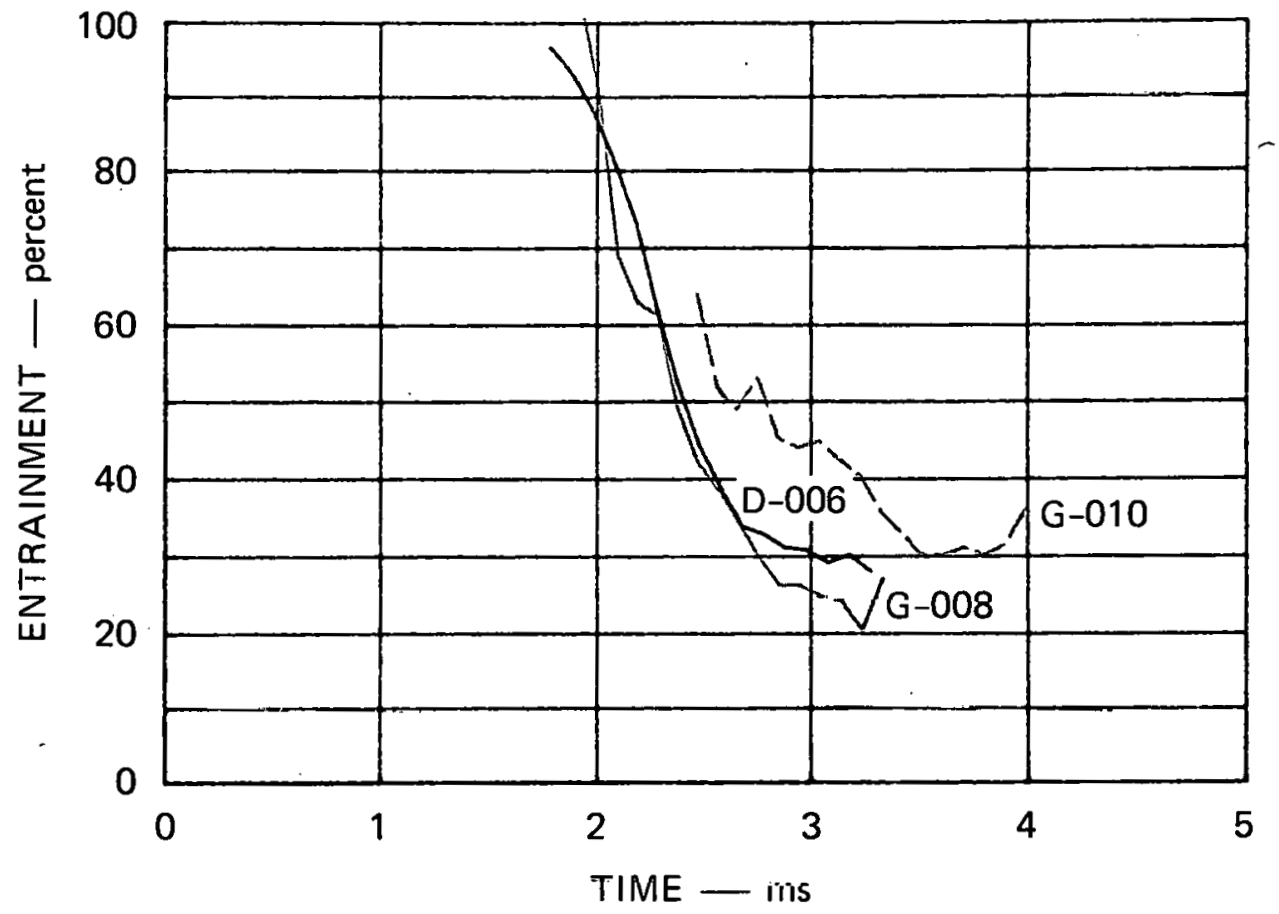

(b) ENTRAINMENT AS A PERCENTAGE OF BUBBLE VOLUME

FIGURE 20 ENTRAINMENT IN THE EXPANDING BUBBLE IN THE NITROGEN SOURCE EXPERIMENTS 
THIS PAGE

\section{WAS INTENTIONALLY \\ LEFT BLANK}

$$
.44
$$




\section{RESULTS OF THE FLASHING WATER \\ CONSTANT MASS EXPERIMENTS}

Four experiments have the same coolant mass in and above the upper core.

Experiment
G-002
G-011
G-007
G-009

$\begin{array}{ll}\text { Configuration } & \text { Coolant } \\ \text { Reference } & \mathrm{H}_{2} \mathrm{O} \\ \text { Reference } & \mathrm{H}_{2} \mathrm{O} \\ \text { Constant Mass } & \mathrm{F} 113 \\ \text { Constant Geometry } & \mathrm{F} 11\end{array}$

These experiments are represented in Figure 21. The reproducibility of experiments G-002 and G-011. is discussed in Appendix E. Most of the comparisons in this section are based on experiment G-011, because the sliding doors opened at virtually the same time in it as in G-007 and G-009. The initial conditions for these experiments are discussed in Appendix $B$, and all the experimental data obtained from them are presented in Appendix $D$. We note here that in the flashing source experiments discussed in this and the next two sections, variations occurred in the initial cover gas gap. These variations, discussed in Appendix $B$, were due to expansion of the coolant pool (to a greater degree with Freon) when heat from the lower core conducted through the sliding doors and heated the pool before the experiment was initiated. The effect of these variations on comparison of the slug impact time and cover loading is discussed from time to time in the remainder of this report.

\section{A. Pressure and Temperature Measurements \\ 1. Lower Corc Prcscure}

The lower core pressure in the flashing water constant mass experiments is shown in Figure 22. The pressure response in the lower core is characteristic of our lower core configuration. When the sliding doors begin to open, vapor bubbles form in the lower core by nucleation 
EXPERIMENT G-002

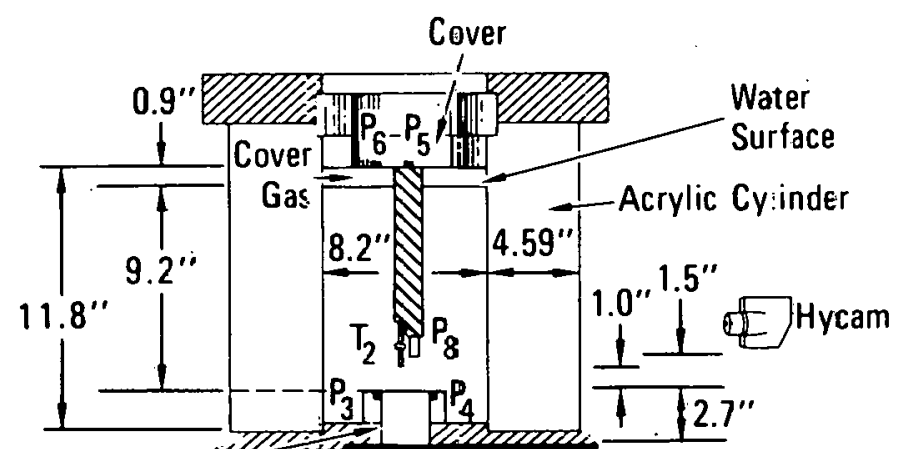

Upper Core

Sliding Daors $P_{1} \quad$ P-Pressure Transducer

Heating Element

Lower Csre

$\left(60.9\right.$ in $\left.^{3}\right)$

EXPERIMENT G-007

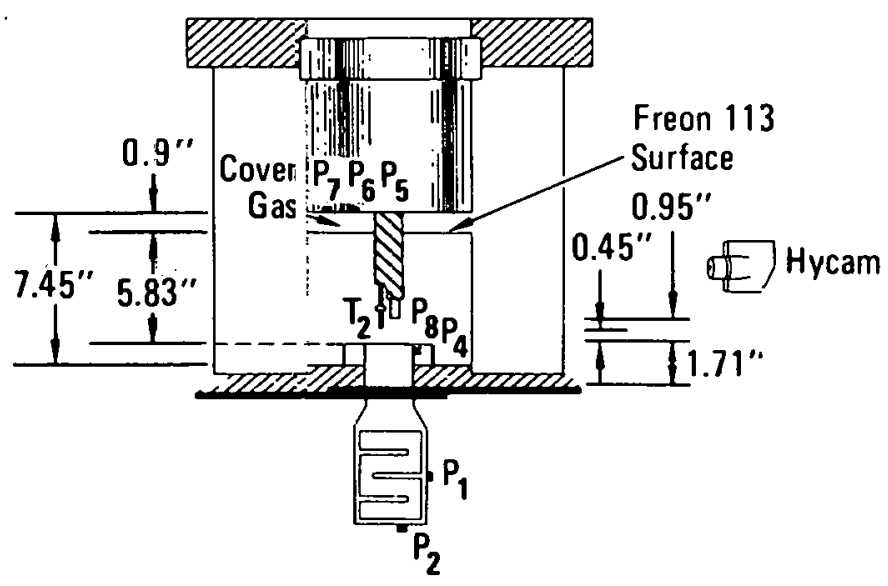

EXPERIMENT G-011

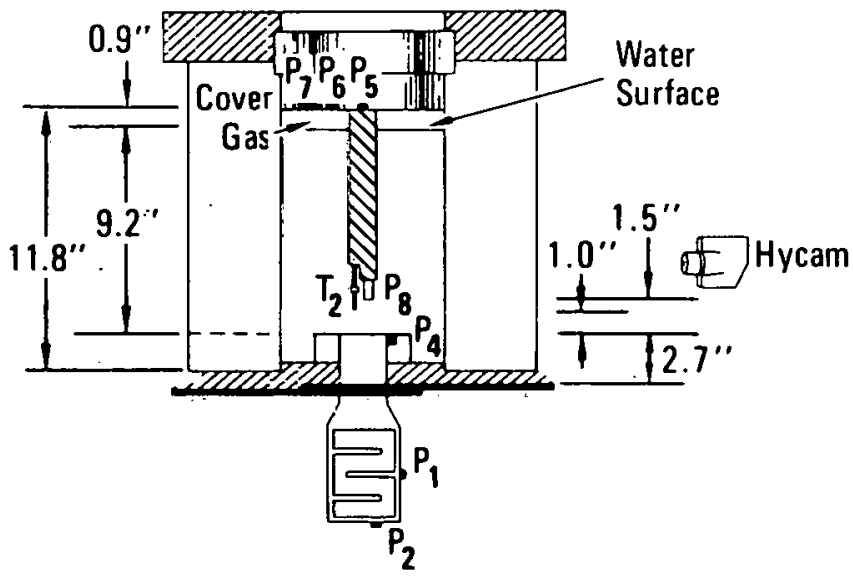

EXPERIMENT G-009

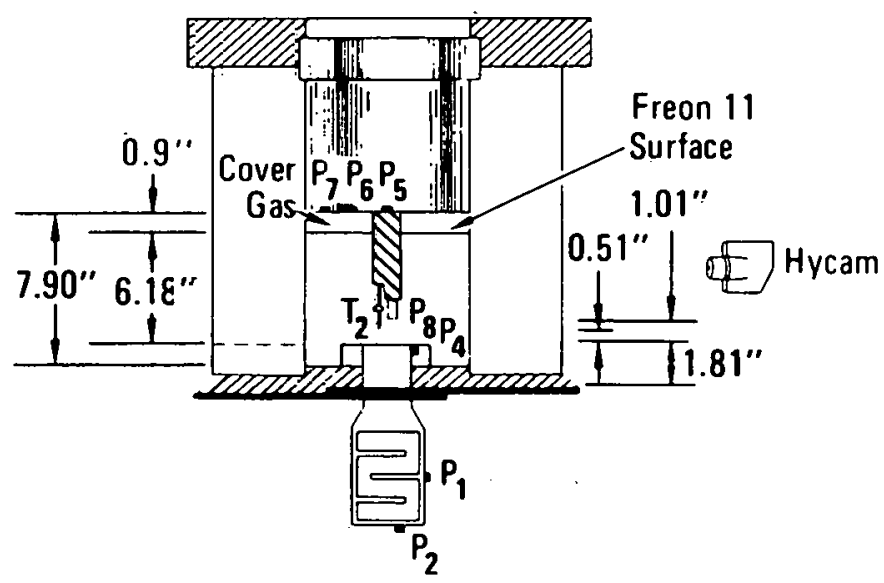

MA-3929-513

FIGURE 21 CONSTANT MASS EXPERIMENTS 


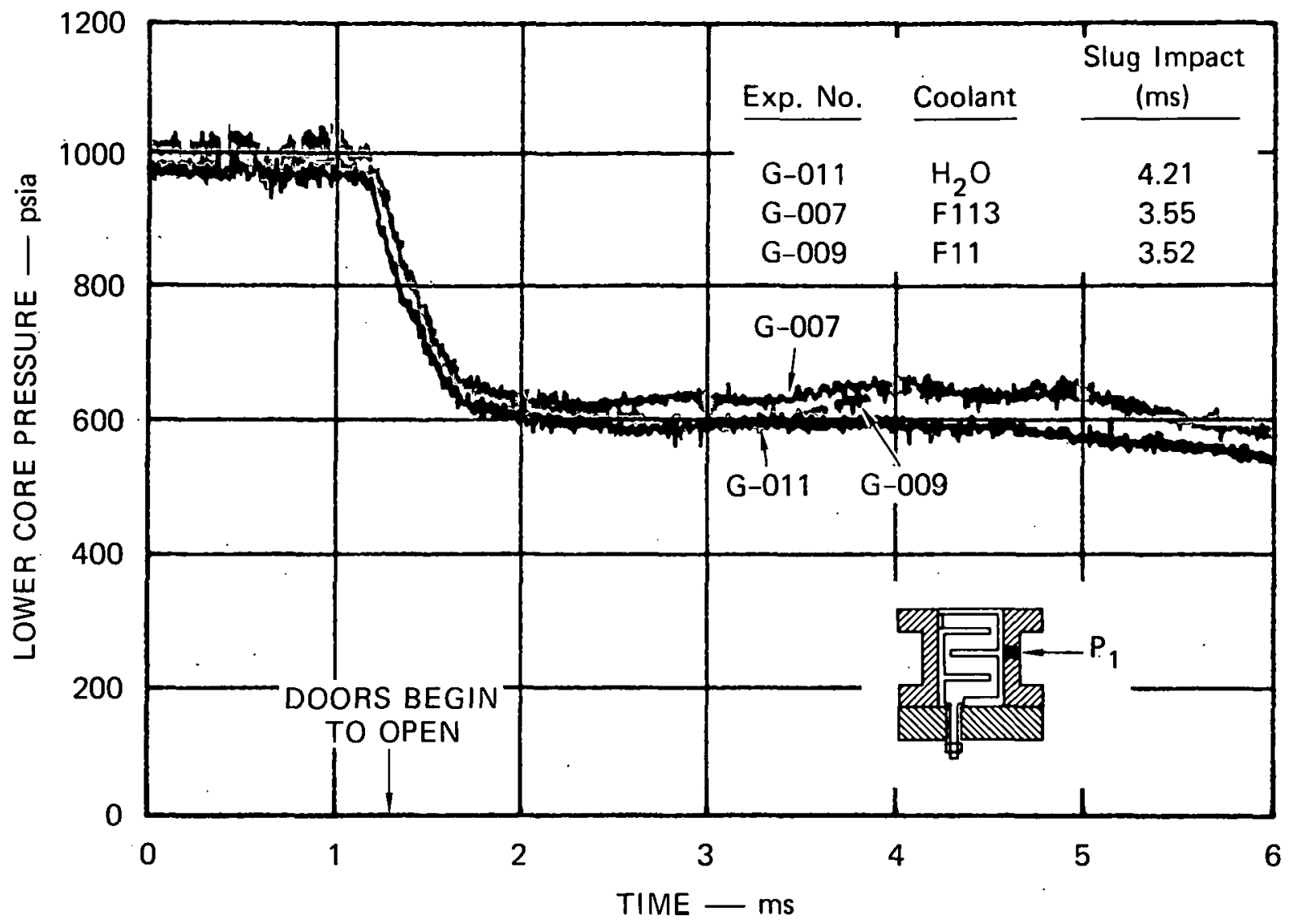

MA-3929-498

FIGURE 22 LOWER CORE PRESSURE $\left(\mathrm{P}_{1}\right)$ IN THE CONSTANT MASS EXPERIMENTS

on the available solid surfaces. As they form, the surrounding liquid cools to provide the necessary heat of vaporization, and thus, the vapor pressure falls below the initial pressure. The pressure plateau of about 675 psia drives the expansion.

\section{Upper Core Pressure}

The upper core pressure records in Figure 23 were filtered through a low pass filter at $10 \mathrm{kHz}$ to facilitate a comparison. The unfiltered data are given in Appendix D. When the sliding doors open, the pressure in the upper core immediately rises sharply. The expanding bubble fills the upper core and reaches the upper core pressure transducer at about 2-1/2 ms. Although the pressure falls as the bubble expands into the coolant pool, it remains higher in the Freon tests than in the water test through slug impact. For the entire expansion, the pressure is 100 


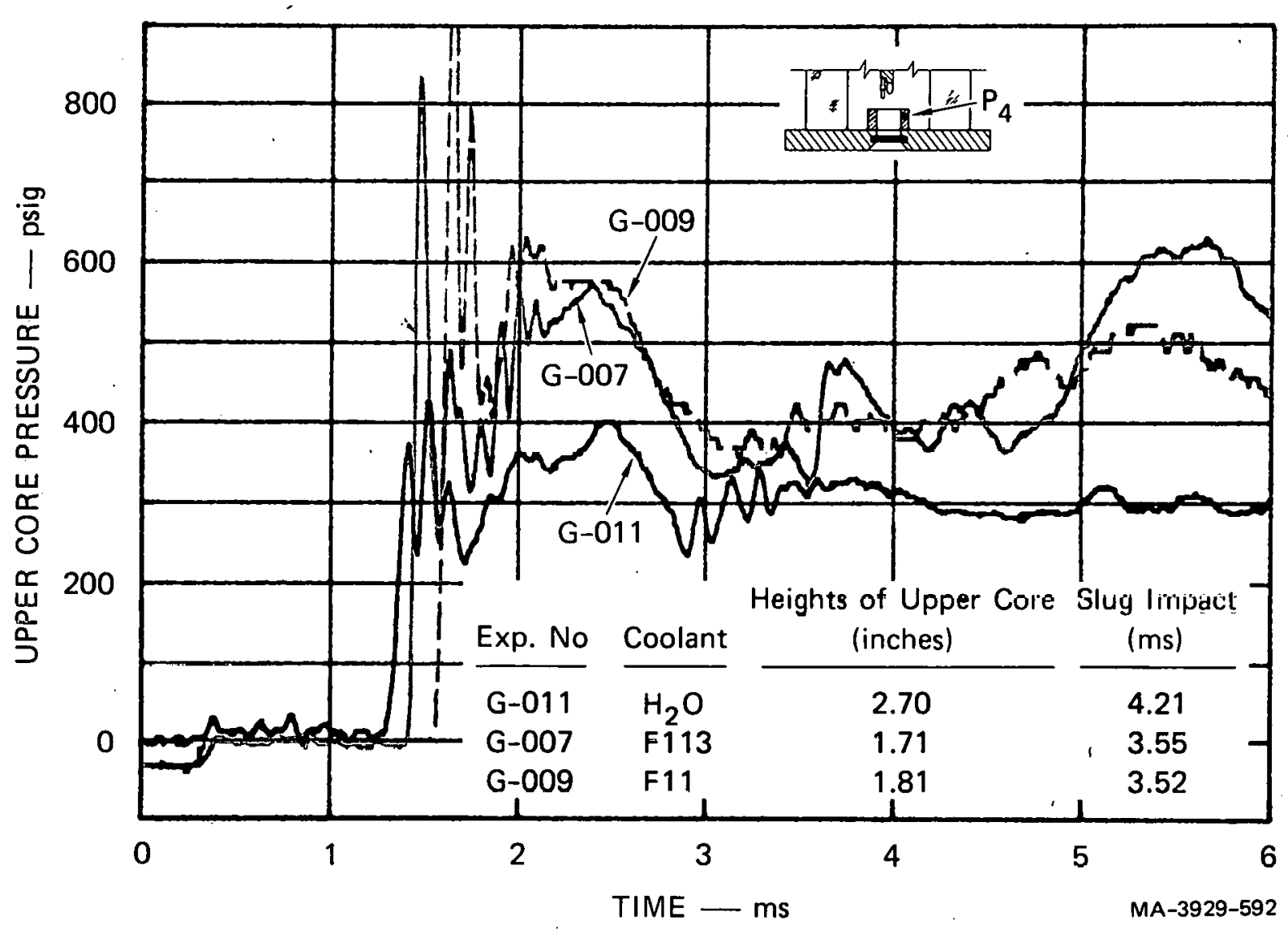

FIGURE 23 EFFECT OF COOLANT VOLATILITY ON THE UPPER CORE PRESSURE $\left(\mathrm{P}_{4}\right)$ IN CONSTANT MASS EXPERIMENTS (Data Low Pass Filtered at $10 \mathrm{kHz}$ )

to 200 psi higher in the Freon tests. This increase in pressure is believed to be due to vaporization of some of the Freon that mixes with Lhe high temperature water as the sliding doors open and the expansion commences.

\section{Pool and Bubble Pressure}

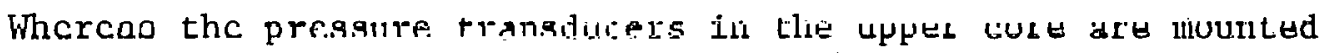
in a vertical wall and therefore measure the static pressure, the transducer used to measure the pressure in the pool and bubble is mounted normal to the flow at the end of the instrument sting (Figures 16 and 17).

- Therefore, it measures the sum of the static and dynamic pressures--that is the stagnation pressure. In Figure 24, the pool and bubble pressure is 


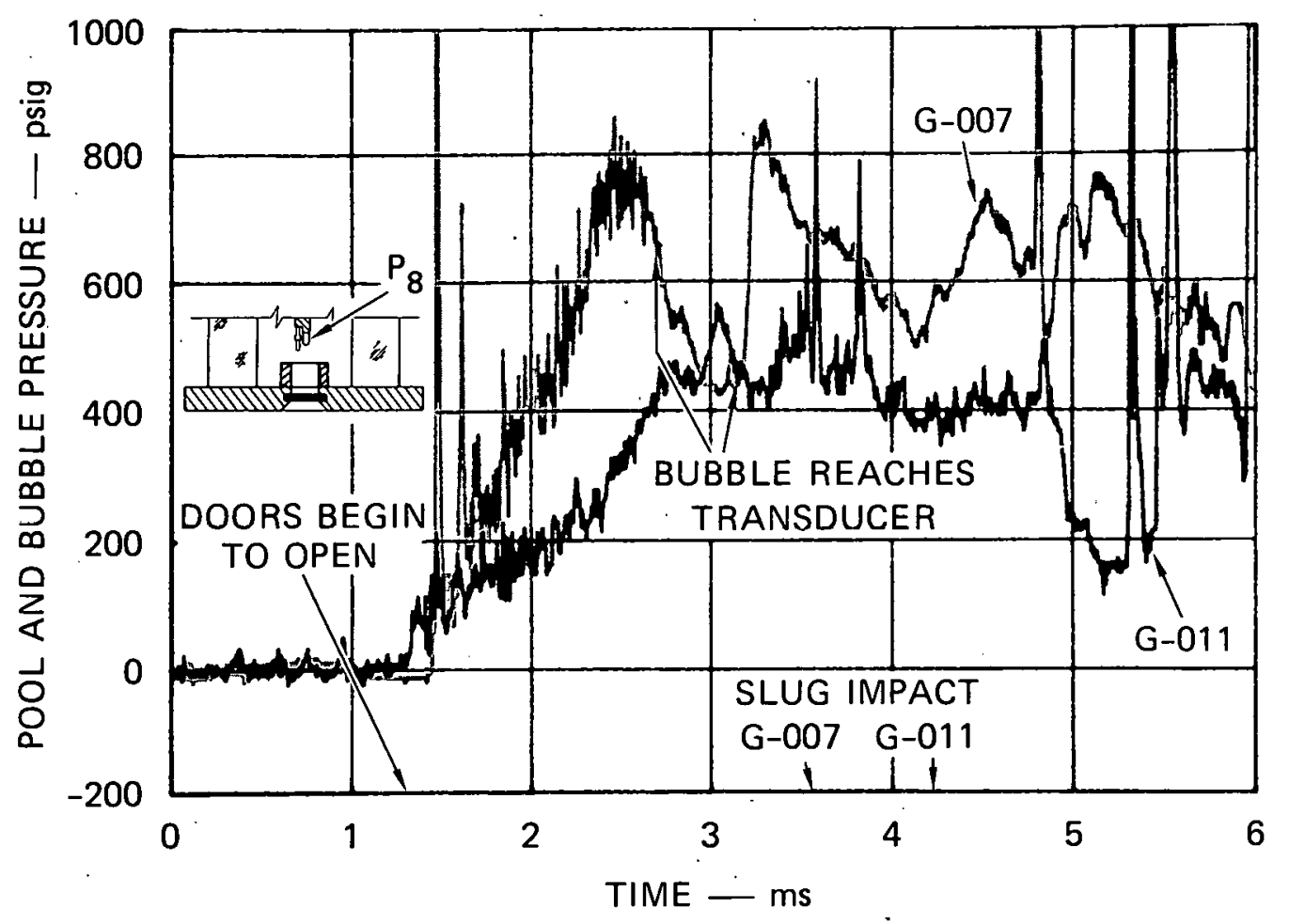

\begin{tabular}{|c|c|c|}
\hline Exp. No. & Coolant & $\begin{array}{l}\text { Height of Transducer } \\
\text { Above Upper Core } \\
\text { (inches) }\end{array}$ \\
\hline G-011 & $\mathrm{H}_{2} \mathrm{O}$ & 1.50 \\
\hline G-007 & $F 113$ & 0.95 \\
\hline
\end{tabular}

MA-3929-499

FIGURE 24 EFFECT OF COOLANT VOLATILITY ON THE POOL AND BUBBLE PRESSURE $\left(P_{8}\right)$ IN CONSTANT MASS EXPERIMENTS

compared for water experiment G-011 and Freon 113 experiment G-007. The time at which the bubble reaches the transducer is indicated, as is the time of slug impact. The height of the transducer above the upper core is varied in these tests to maintain the same initial mass of liquid above and below the transducer. The heights used are shown in Figure 21 .

Before the bubble reaches the transducer, the pressure in the Freon test is higher than in the water test. When the bubble reaches the transducer, the difference is about 200 psi. These differences are due to a combination of the $150 \mathrm{psi}$ higher static pressure seen in the 
upper core records in Figure 23 and to a 36 psi larger dynamic pressure. When the bubble reaches the transducer, the liquid dynamic head is about 208 psi (bubble boundary velocity $=1.68 \mathrm{inch} / \mathrm{ms}$ ) in the Freon experiment (G-007) and $172 \mathrm{psi}$ (bubble boundary velocity $=1.92 \mathrm{inch} / \mathrm{ms}$ ) in the water experiment (G-011).

Centered around the time the bubble reaches the transducer, the pressure measured drops about $300 \mathrm{psi}$ in the Freon experiment and 150 psi in the water experiment. This drop is due both to a drop in liquid velocity as the bubble emerges from the upper core and spreads radially and to the change in dynamic head as the transducer sees first liquid, then vapor as the bubble passes by:

Before slug impact in the Freon experiment, the bubble pressure rises to more than 700 psi, whereas in the water experiment, except for some spikes, the pressure remains around 450 psi until slug impact. As we saw in the upper core, the bubble pressure is higher in the Freon experiment than in the water experiment.

\section{Pool and Bubble 'lemperature}

An attempt was made in this experiment series to measure the temperature in the HCDA bubble, using a Namnac thermocouple. It has an extremely thin thermal junction that in shock tube experiments has a response time of $6 \mu \mathrm{s}$. The response time of the thermocouple in these experiments depends on the fluid dynamic environment. The thermocouple is positioned 0.50 inch below pressure transducer $\mathrm{P}_{8}$ and 0.7 inch offaxis. It is surrounded by coolant until the bubbles reaches it. After the bubble reaches it, the thermocouple may be covered by a liquid film for a short time. The measured temperatures are presented in Figures 25 and 26.

Figure 25 shows the bubble temperatures measured in the water and Freon experiments. Note the similarity of the measurement in each test both in trend and magnitude. The bubble reaches the thermocouple slightly sooner in the Freon tests, as evidenced by its earlier rise. By about $7 \mathrm{~ms}$ (see Appendix D, Figures D.6, D.8, and D.10), the temperature in all three experiments reaches a plateau of about $410^{\circ} \mathrm{F}$, corresponding 


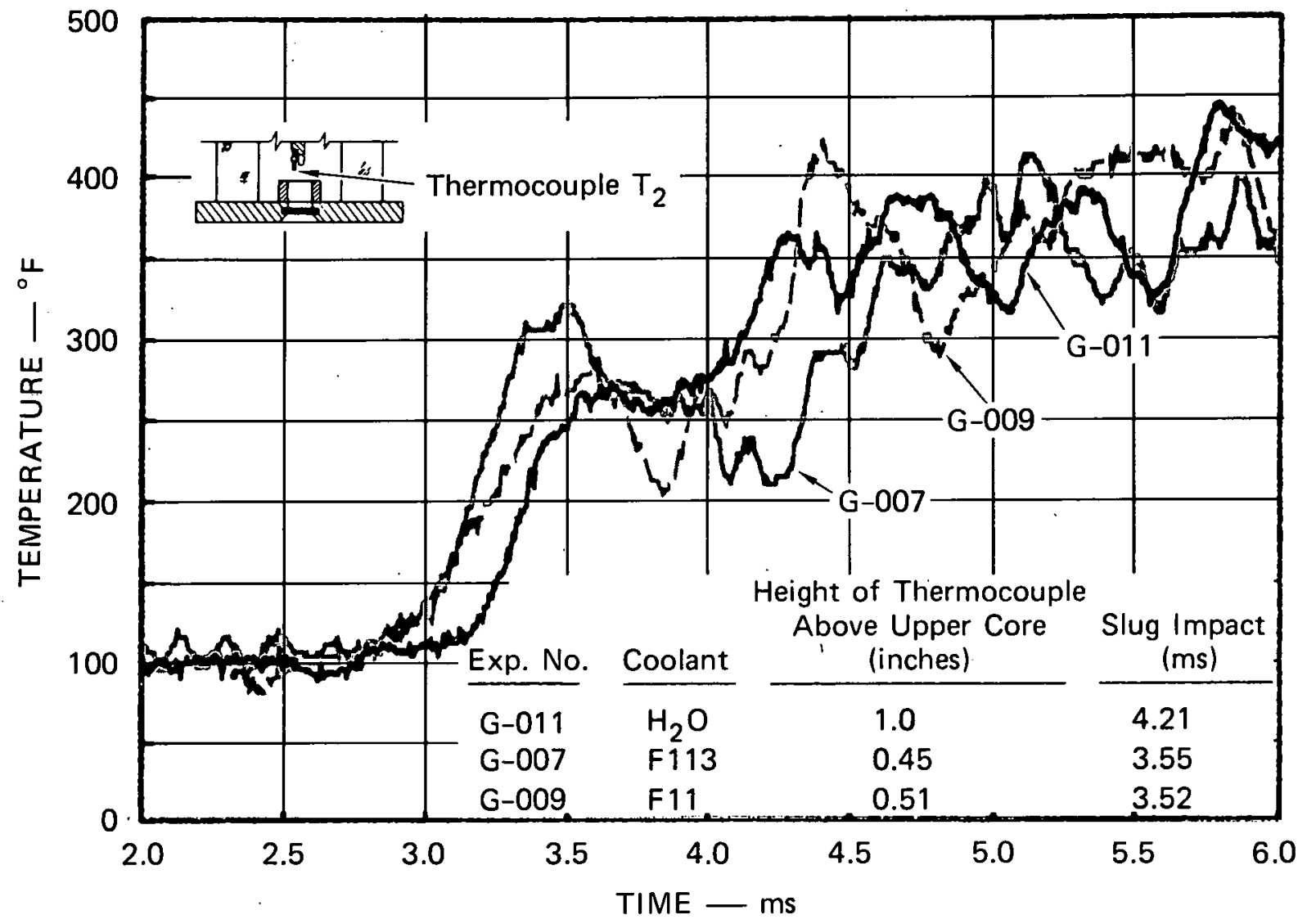

MA-3929-506

FIGURE 25 BUBBLE TEMPERATURE MEASUREMENTS IN THE CONSTANT MASS EXPERIMENTS

to a saturation pressure for water of about 280 psi. The pressure measured in the upper core at this postimpact time is also about 280 psi.

Figures 26(a) and (b) give the relative position of the thermocouple and bubble at several times before slug impact. We see that within about $0.2 \mathrm{~ms}$ of bubble arrival, the thermocouple measures a rising temperature. As the bubble moves past the gage, the temperature rises rapidly. At slug impact, the thermocouple is recording temperatures of around 320 to $350^{\circ} \mathrm{F}$. The temperature rise as the bubble passes the thermocouple indicates an axial temperature gradient through the bubble. The temperature increases. from 100 to $350^{\circ} \mathrm{F}$, which is much cooler than the estimated temperature of steam leaving the lower core of $500^{\circ} \mathrm{F}$ (saturation at $700 \mathrm{psi}$ ). 


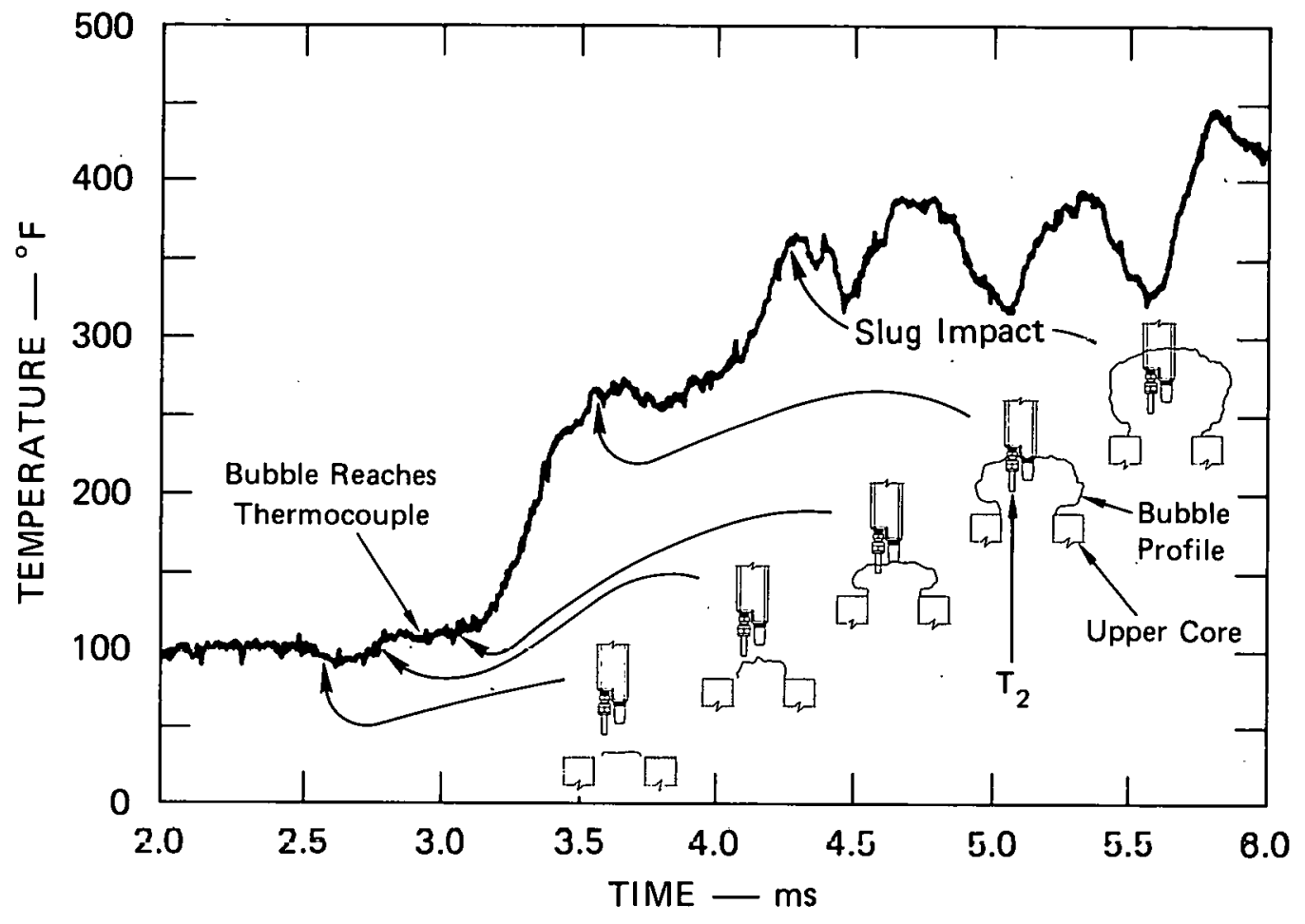

(a) WATER COOLANT (G-011)

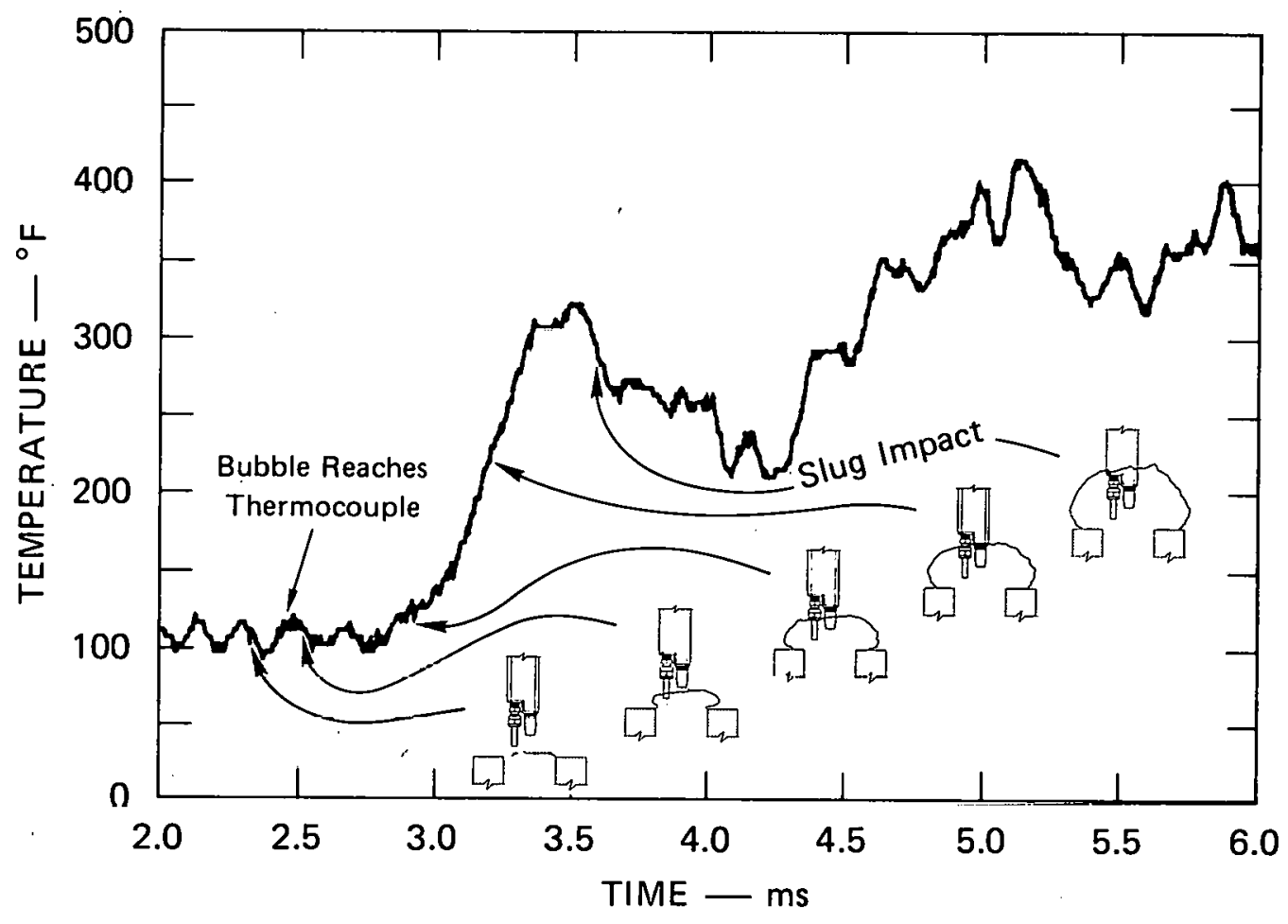

(b) FREON 113 COOLANT (G-007)

MA-3929-504

FIGURE 26 RELATION BETWEEN MEASURED BUBBLE TEMPERATURE AND THERMOCOUPLE $T_{2}$ POSITION WITHIN THE BUBBLE 
The dynamic character of the thermocouple measurements and their close correlation with the dynamic events in these experiments leads us to conclude that the HCDA bubble consists of a fairly thick mixing layer inside the bubble boundary that is much cooler than the steam leaving the lower core. Further work is needed to map the bubble structure in more detail.

\section{Cover Pressure and Impulse}

The primary slug impact pulses in the constant mass experiments are compared in Figure 27. Slug impact occurs about $0.7 \mathrm{~ms}$ sooner in the Freon experiments. Only a small portion of this difference can be accounted for by the variation indicated in the initial cover gas gap. At a representative coolant surface speed of $1.5 \mathrm{inch} / \mathrm{ms}$, the gap variation would account for less than $0.15 \mathrm{~ms}$. The reason for this gap variation among tests was mentioned at the beginning of this section and is explained in detail in Appendix B. As was shown in Section III for the nitrogen-source experiments, slug impact should occur no more than about $0.1 \mathrm{~ms}$ sooner in a Freon constant mass experiment than in the water experiment because of geometrical effects. We are, therefore, led to conclude by the significantly earlier slug impact that the higher upper core and bubble pressures seen in the Freon experiments are due to vaporization of the more volatile coolant and result in a higher coolant slug velocity and an earlier slug impact time. This conclusion is supported by the higher impact pressures seen in the Freon experiments in Figure 27. The impact pressure should be lower in Freon experiments for equal impact velocities, because of its lower acoustic impedance. The Freon experiments must

therefore have a higher slug impact velocity. Impact pressure is discussed further in Section VII.

Slug impact impulse is also discussed in Section VII. It will be shown that in constant mass experiments, the slug impact impulse should vary as the slug impact velocity varies. The impulse is independent of the fluid density and acoustic impedance. In Table 7, the impulse on the vesse1 cover is tabulated for the constant mass experiments. The impulse calculation begins when the pressure on the cover exceeds 200 psi and ends 


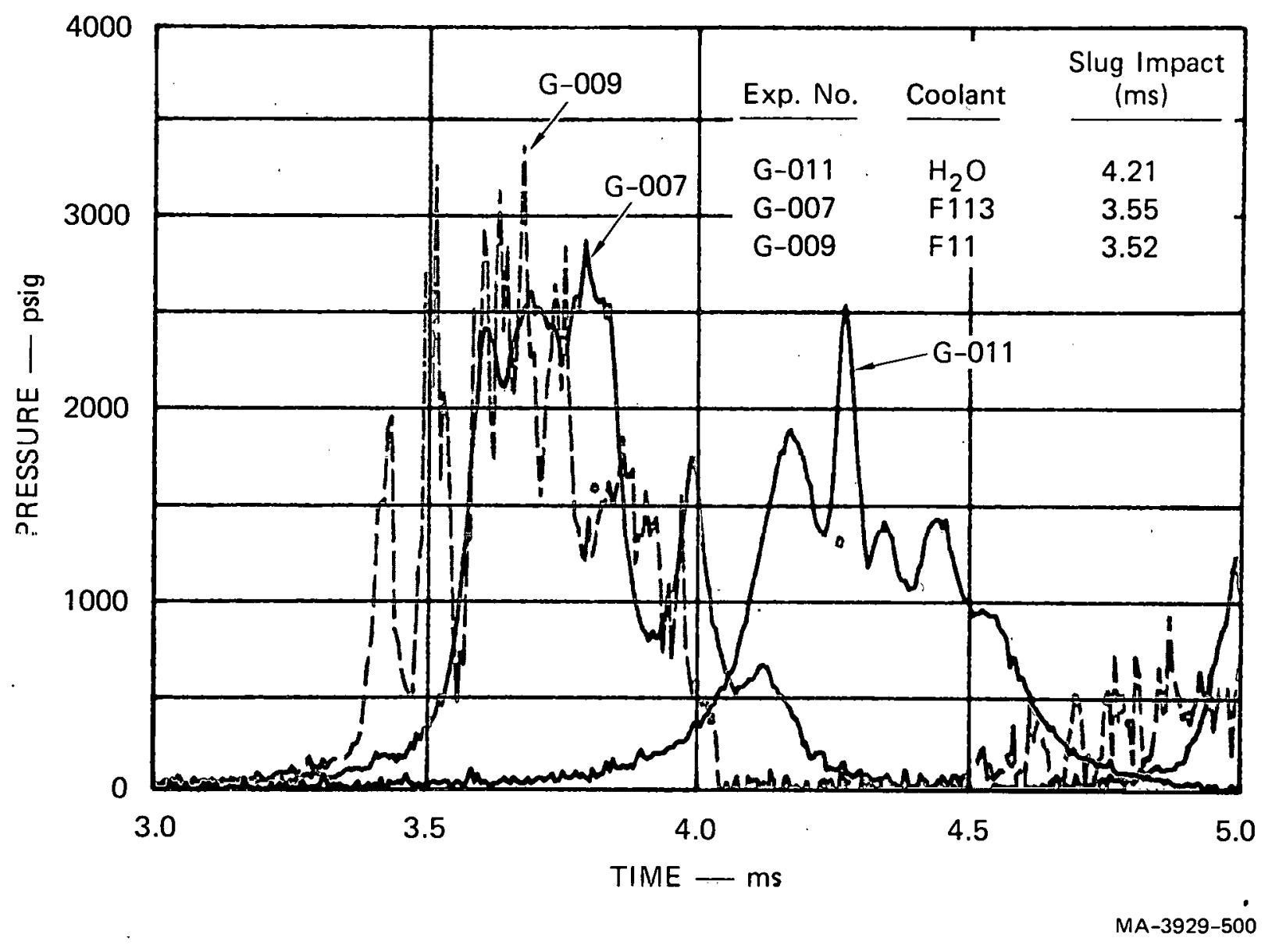

FIGURE 27 PRIMARY SLUG IMPACT PRESSURE $\left(P_{5}\right)$ PULSE IN THE CONSTANT MASS EXPERIMENTS

when the pressure drops below this level. The impulse in the Freon experiments is seen to be higher and is consistent with the conclusion above that higher coolant velocities occur in the Freon experiments.

B. Coolant Surface and Bubble Motion

1. Coolant Surface Visplacement

The coolant surface displacement shown in Figure 28 is an integral measure of the velocity and acceleration of the coolant slug. We see in Figure 28 that a given surface displacement is reached on the order of $0.5 \mathrm{~ms}$ earlier in the Freon experiments during the later stage 
Table 7

\section{IMPULSE ON THE VESSEL COVER FROM THE FIRST SLUG IMPACT PULSE, CONSTANT MASS EXPERIMENTS}

\begin{tabular}{|c|c|c|c|}
\hline Experiment & Coolant & $\begin{array}{c}\text { Initial Cover } \\
\text { Gas Gap } \\
\text { (inch) }\end{array}$ & $\begin{array}{c}\text { Impulse* } \\
\text { (Ibf-s) }\end{array}$ \\
\hline G-002 & $\mathrm{H}_{2} \mathrm{O}$ & 0.89 & 40.8 \\
\hline G-011 & $\mathrm{H}_{2} \mathrm{O}$. & 0.86 & 38.9 \\
\hline G-007 & $F 113$ & 0.77 & 51.1 \\
\hline G-009 & F11 & 0.84 & 51.9 \\
\hline
\end{tabular}

"Average of all cover pressure measurements in a given experiment.

of the expansion to slug impact. From the discussion in Section A.5above, at most $0.25 \mathrm{~ms}$ can be attributed to experiment geometry. or a smaller initial gap. The remainder is due to the effects of coolant volatility on the upper core and bubble pressure; these effects produce higher acceleration of the coolant pool. From Figure 28, we estimate that the average velocity of the coolant pool over its last 0.7 inch of motion is 0.55 inch/ms in G-011 (water), 0.67 inch/ms in G-007 (F113), and 0.73 inch/ms in G-009 (F1l). We note that $1 \mathrm{inch} / \mathrm{ms}$ equals $83.3 \mathrm{feet} / \mathrm{s}$.

2. Bubble Profiles and Volume

Figure 29 compares the growth of the HCDA bubble in a water and Freon experiment. These profiles, were obtained from each frame of the 


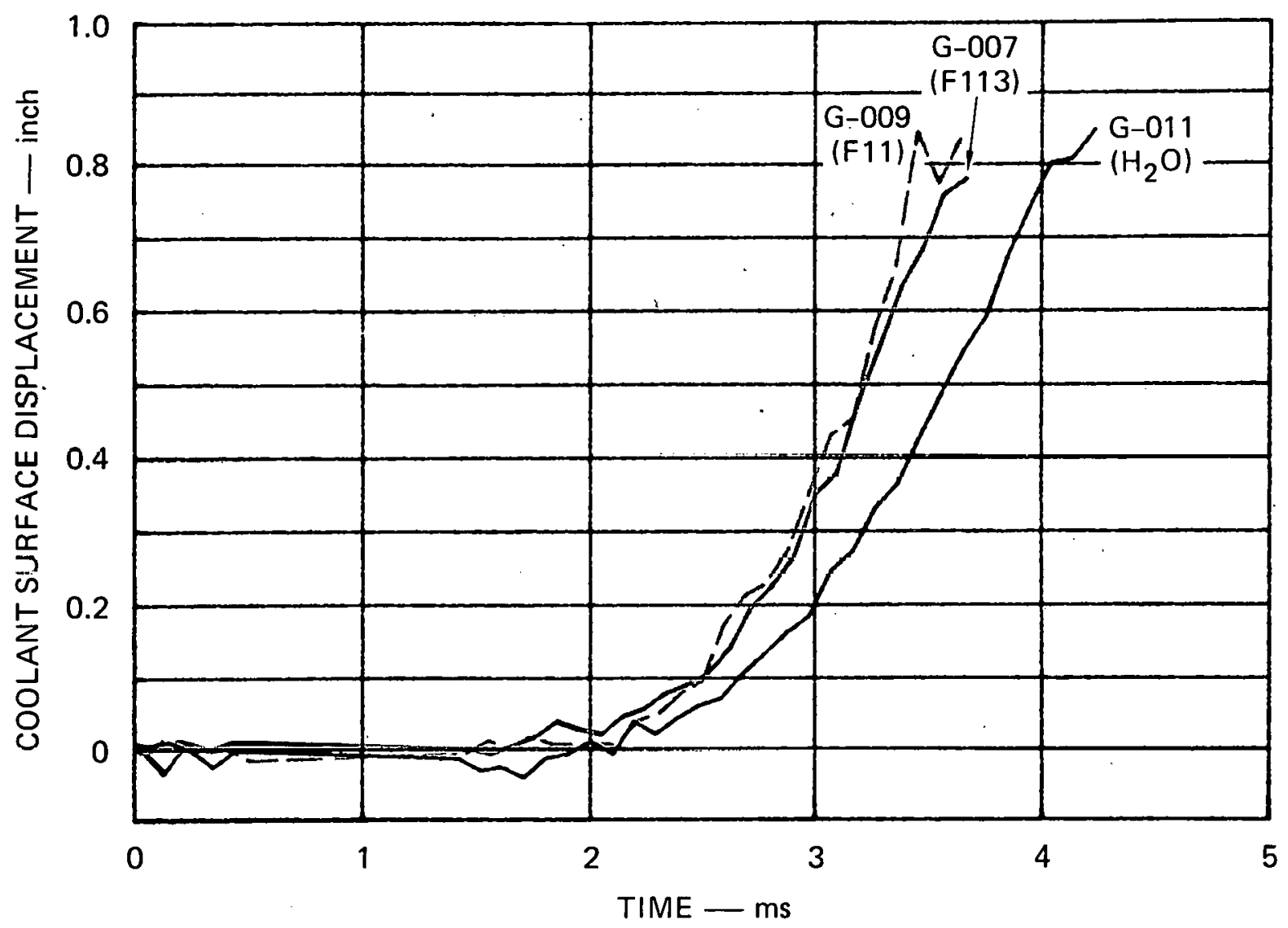

MA-3929-495

FIGURE 28 EFFECT OF COOLANT VOLATILITY ON COOLANT SURFACE DISPLACEMENT IN CONSTANT MASS EXPERIMENTS

high-speed movies. The bubble volume in each frame is obtained by mathematically rotating each half of the bubble profile around the central axis of the apparatus and averaging the two values obtalned.

A comparison of the profile in the water and Freon 113 experiments for a coolant surface displacement of 0.75 inch is shown in Figure 30 . We see that the upper surface of the mushroom-like bubble has the same shape in both experiments. The penetration of the bubble into the coolant pool is about 0.6 inch further in the water experiment. The larger bubble volume in the water experiment (indicated in the figure) is due to this penetration as well as the larger volume of the upper core (also indicated). The actual photographs of the bubble at slug impact are compared in Figure 31. 


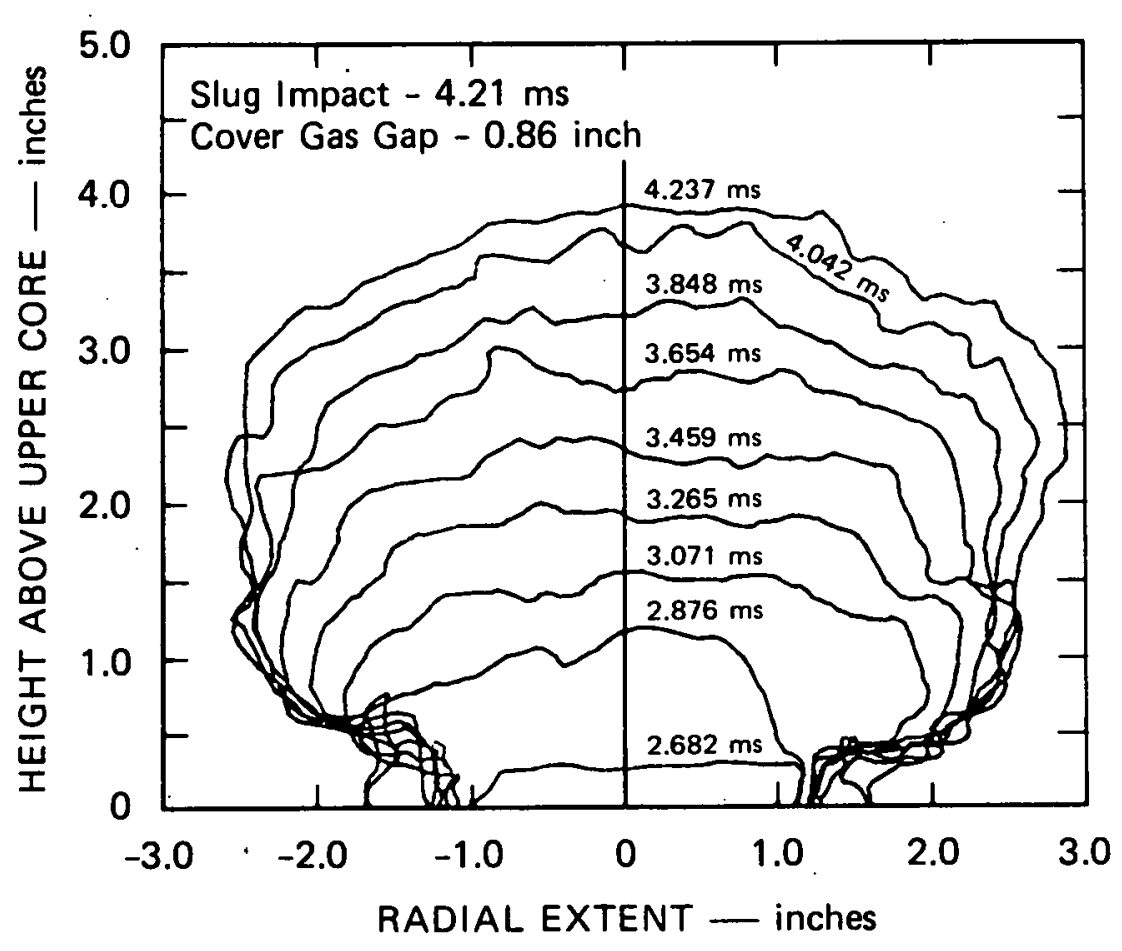

(a) WATER COOLANT (G-011)

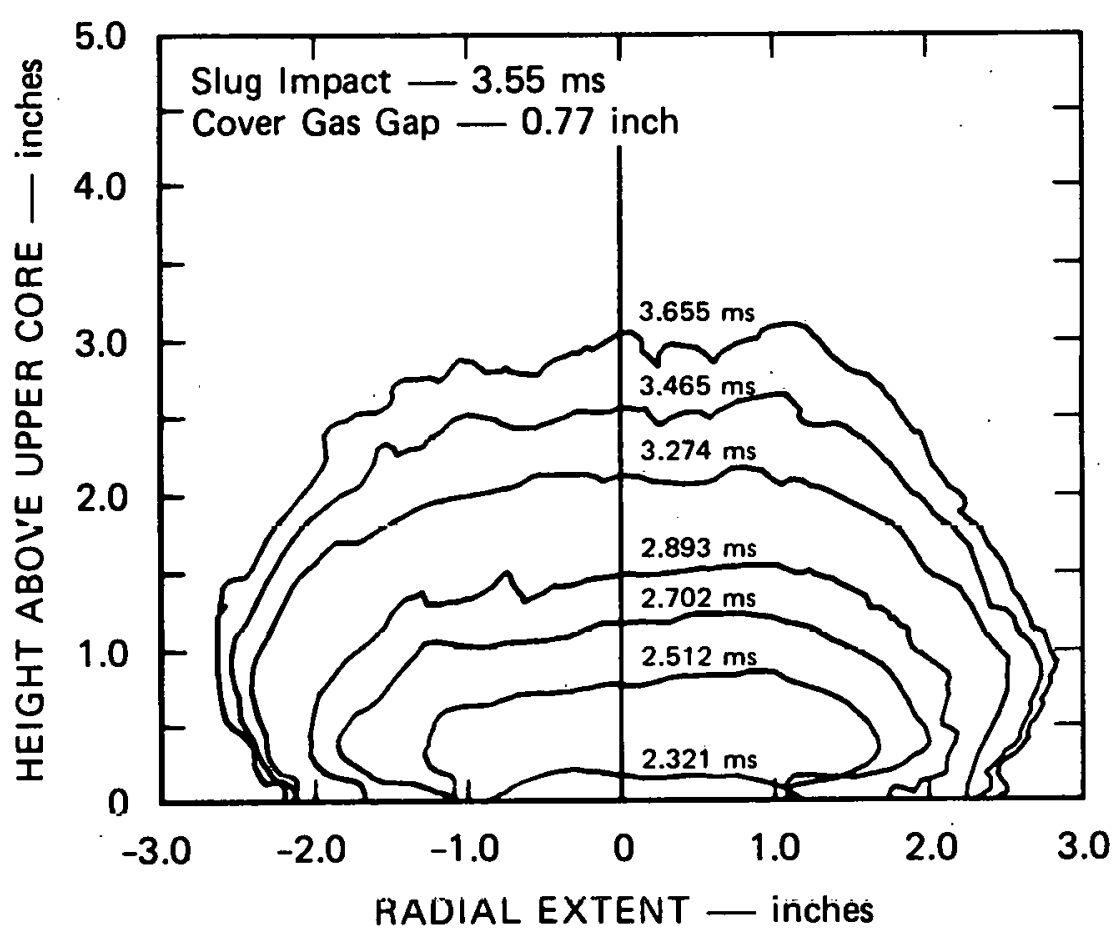

(b) FREON 113 COOLANT (G-007)

MA-3929-579

FIGURE 29 BUBBLE GROWTH PROFILES IN CONSTANT MASS EXPERIMENTS 


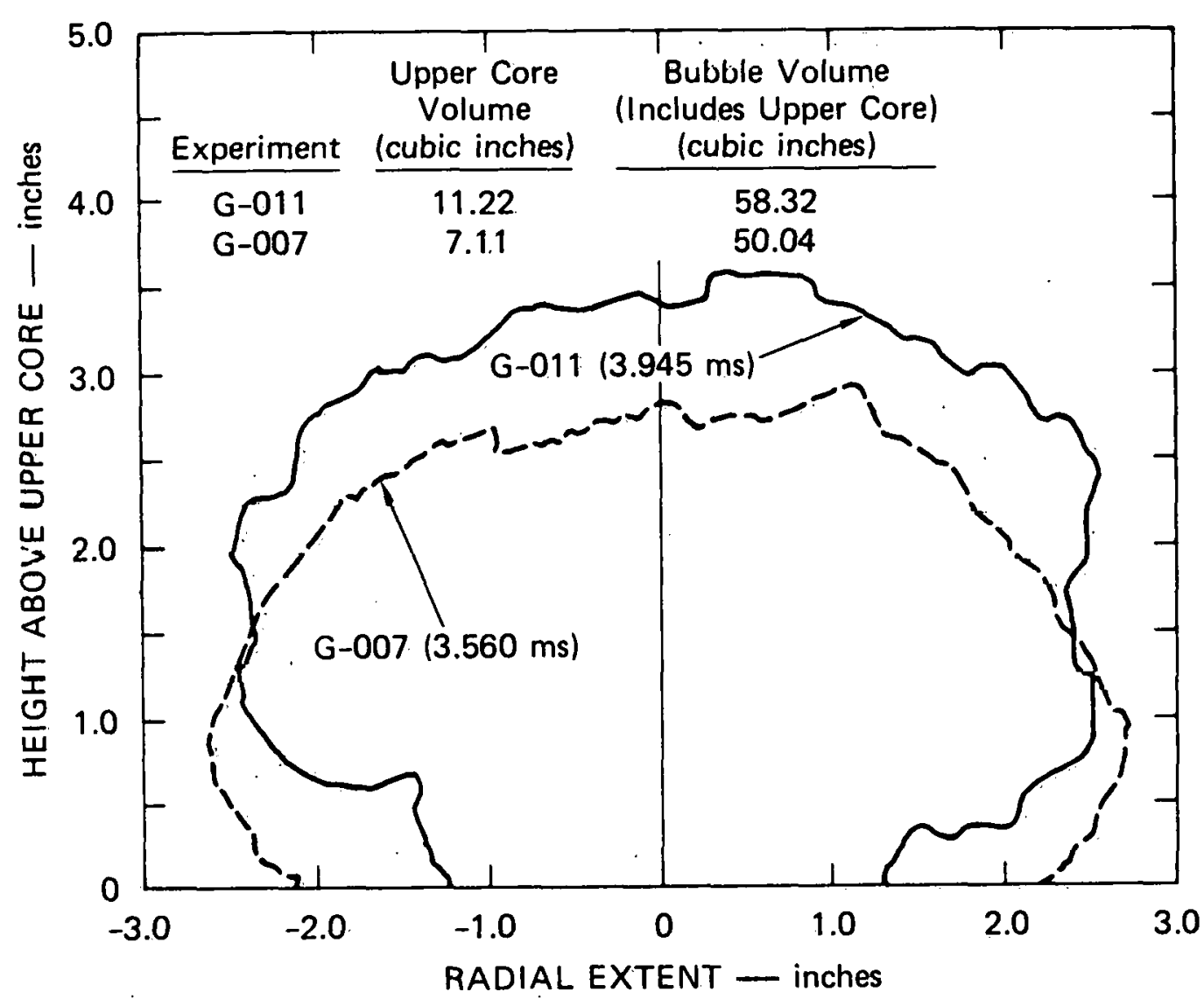

MA-3929-580

FIGURE 30 COMPARISON OF THE BUBBLE PROFILE IN G-011 (WATER) AND G-007 (FREON 113) AT A COOLANT SURFACE DIEPLACEMENT OF 0.75 INCH

The time histories of the bubble volume in the constant mass experiments are compared in Figure 32. A given bubble volume is reached sooner in the Freon experiments than in the water experiments and the growth rate appears to increase with increasing coolant volatility.

\section{Lintrainment}

The entrainment of liquid within the HCDA bubble is calculated at any time as the difference between llie bubble volume and the volume displaced by the coolant surface motion. The entrained volume and the entrainment as a percentage of bubble volume are presented in Figures 33(a) 


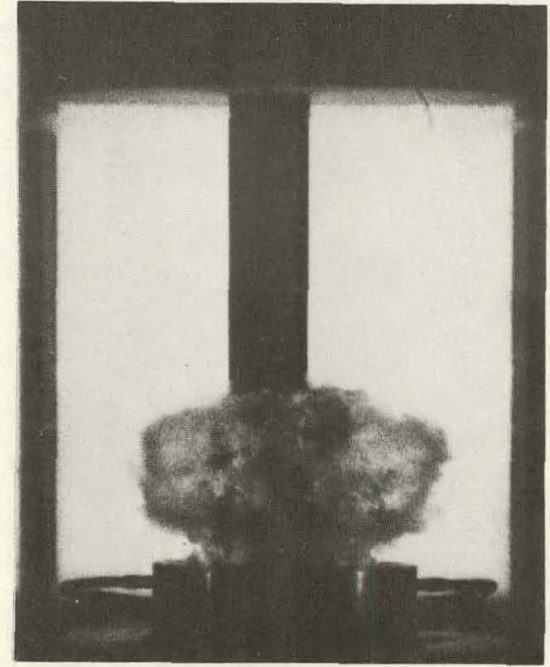

(a) WATER COOLANT (EXPERIMENT G-011)

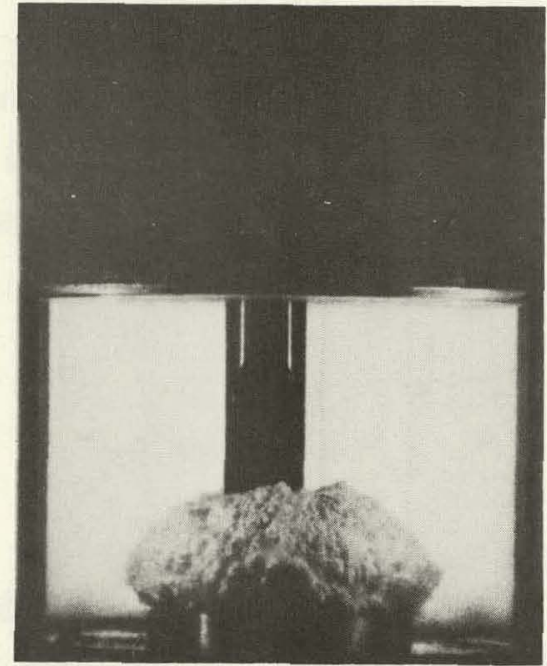

(b) FREON 113 COOLANT (EXPERIMENT G-007)

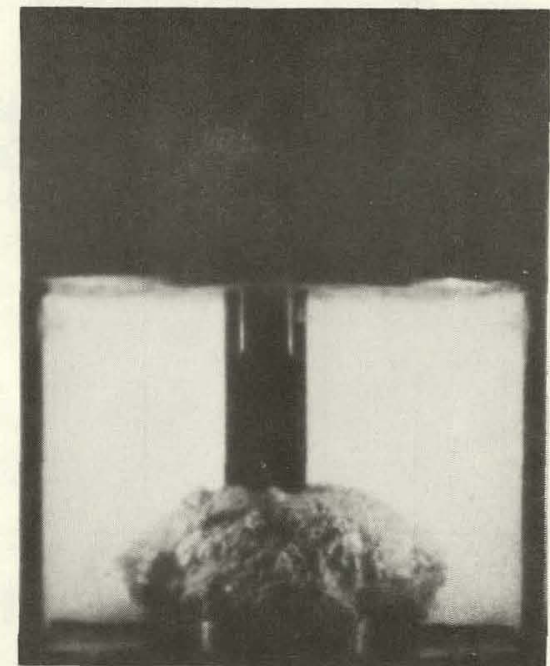

(c) FREON 11 COOLANT (EXPERIMENT G-009)

$\mathrm{MA}-3929-58$

FIGURE 31

HDCA BUBBLE PHOTOGRAPHS AT SLUG IMPACT IN THE CONSTANT MASS FLASHING WATER BUBBLE SOURCE EXPERIMENTS 


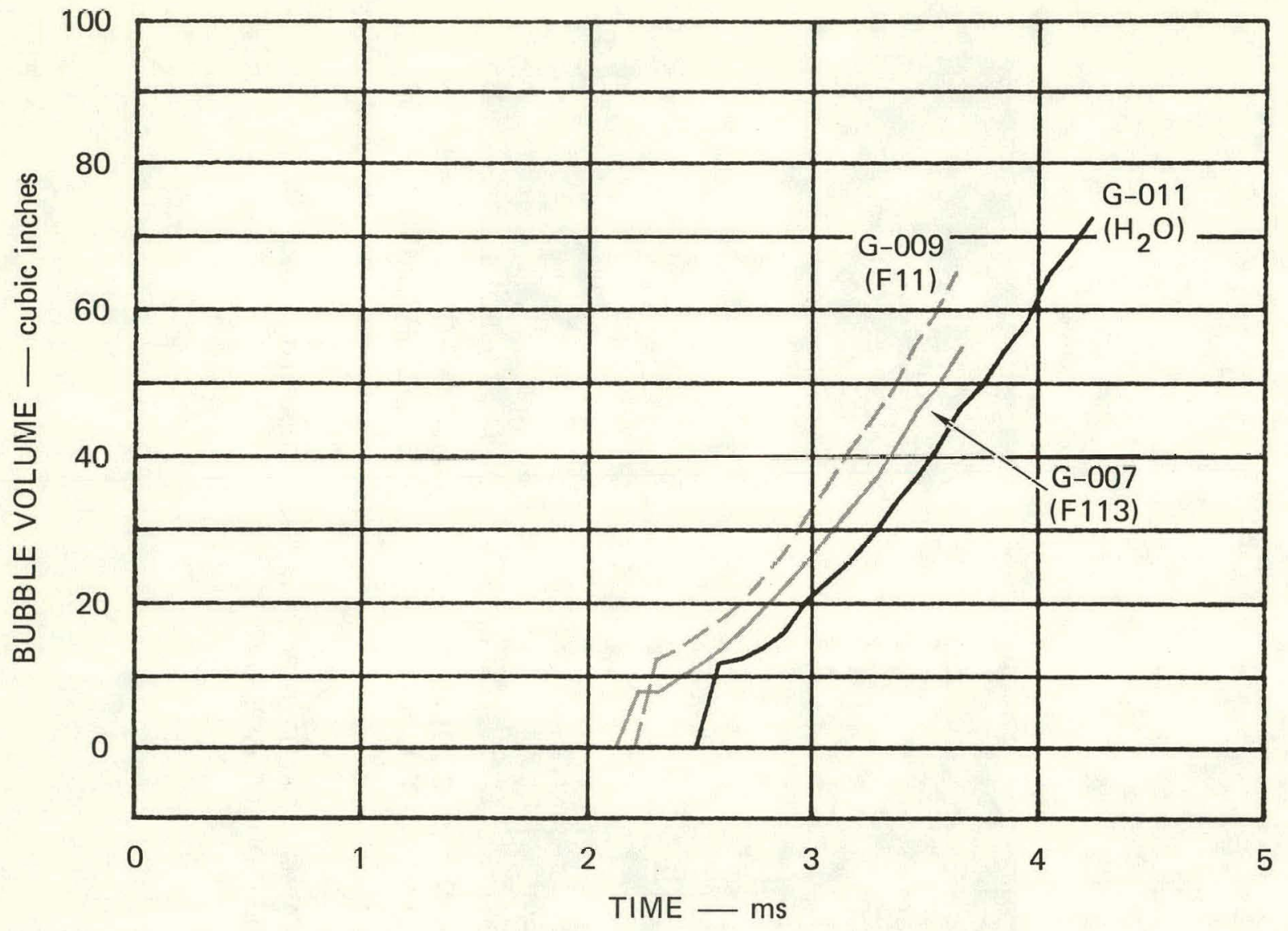

MA-3929-496

FIGURE 32 EFFECT OF COOLANT VOLATILITY ON BUBBLE VOLUME IN CONSTANT MASS EXPERIMENTS

and (b), respectively. No trend with increasing volatility can be seen in these curves. The differences seen in the curves are not substantial. In all four constant mass experiments as well as in our earlier flashing water source experiments, ${ }^{1}$ the slug impact entrainment is about $30 \% \pm 10 \%$ of the bubble volume.

C. Flashing Source Expansion

1. Pressure-Volume Increase

To evaluate the expansion work done in driving the coolant slug to the vessel cover, we need to know the histories of pressure acting on 


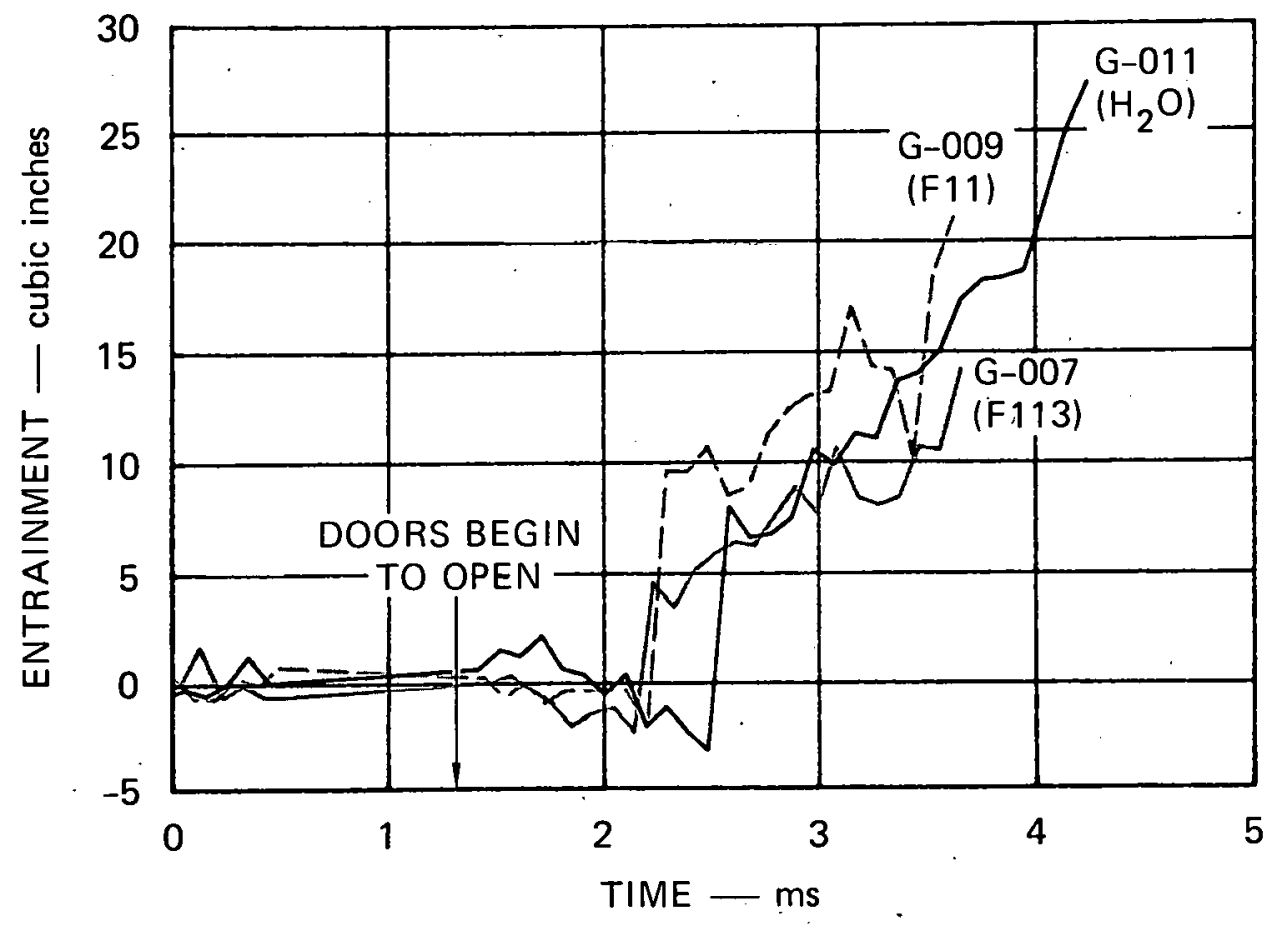

(a) ENTRAINED VOLUME

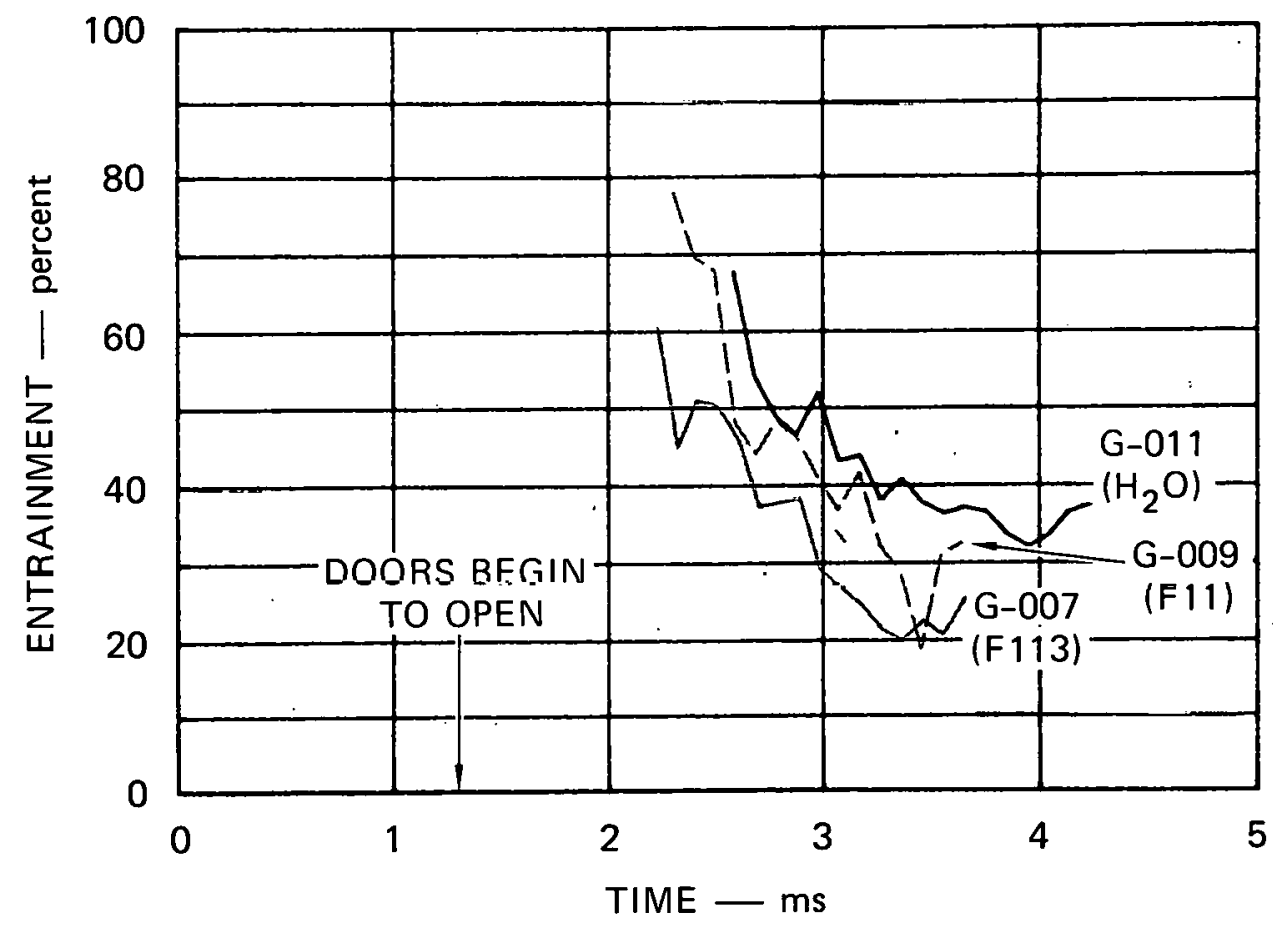

(b) ENTRAINMENT AS A PLICENTAGE OF BUBBLE VOLUME

MA-3929-497

FIGURE 33 EFFECT OF COOLANT VOLATILITY ON ENTRAINMENT IN THE EXPANDING BUBBLE OF CONSTANT MASS EXPERIMENTS 
the slug and the slug displacement. Since the bubble-slug boundary is a moving boundary, we have no pressure transducer that measures the pressure at this boundary. We, therefore, must construct an estimate of the desired pressure from the three stationary pressure transducer locations in the lower core, upper core, and bubble. Figure 34 (a) shows the composite pressure acting on the coolant slug in water experiment G-011.

When the composite pressure is cross-plotted against the volume displaced by the coolant slug (from the coolant surface displacement), the pressure-volume change curve can be drawn as shown in Figure $34(\mathrm{~h})$. Since the area under this curve is the expansion work [Figure 35(c)], we see that essentially all of the work done on the slug is done after the upper core is emptied. The majority of the work is done after the bubble has expanded enough to reach transducer $\mathrm{P}_{8}$.

Similar curves for Freon 113 experiment G-007 are shown in

Figure 35. Higher pressures acting on the coolant slug, Figures 35 (a) and (b), result in greater expansion work done earlier in time, Figure 35 (c).

Figure 36 presents the composite pressures for constant mass experiments with the three coolants. The effect of volatility on the driving pressure can be seen in Figure 36. The upper core $\mathrm{P}_{3}$ (or $\mathrm{P}_{4}$ ) and bubble $\left(\mathrm{P}_{8}\right)$ pressures before slug impact increase in value as the volatility increases from water to Freon 113 to Freon 11 as coolant.

\section{Expansion Work}

The expansion work for experiments. G-011 and G-007 is shown plotted against time in Figures $34(\mathrm{c})$ and $35(\mathrm{c})$. The expansion work for all the constant mass experiments is shown plotted against the coolant surface displaced volume in Figure 37. The trends are fairly linear. For a given displaced volume, the Freon experiments have yielded slightly higher expansion work. Table 8 summarizes the expansion work at slug impact and at an expansion volume of 35 cubic inches. Since the initial cover gas gap and, therefore, the coolant pool displacement differ in each experiment, 
(a) PRESSURE ACTING ON THE COOLANT SLUG

(b) PRESSURE-VOLUME CHANGE

(c) EXPANSION WORK
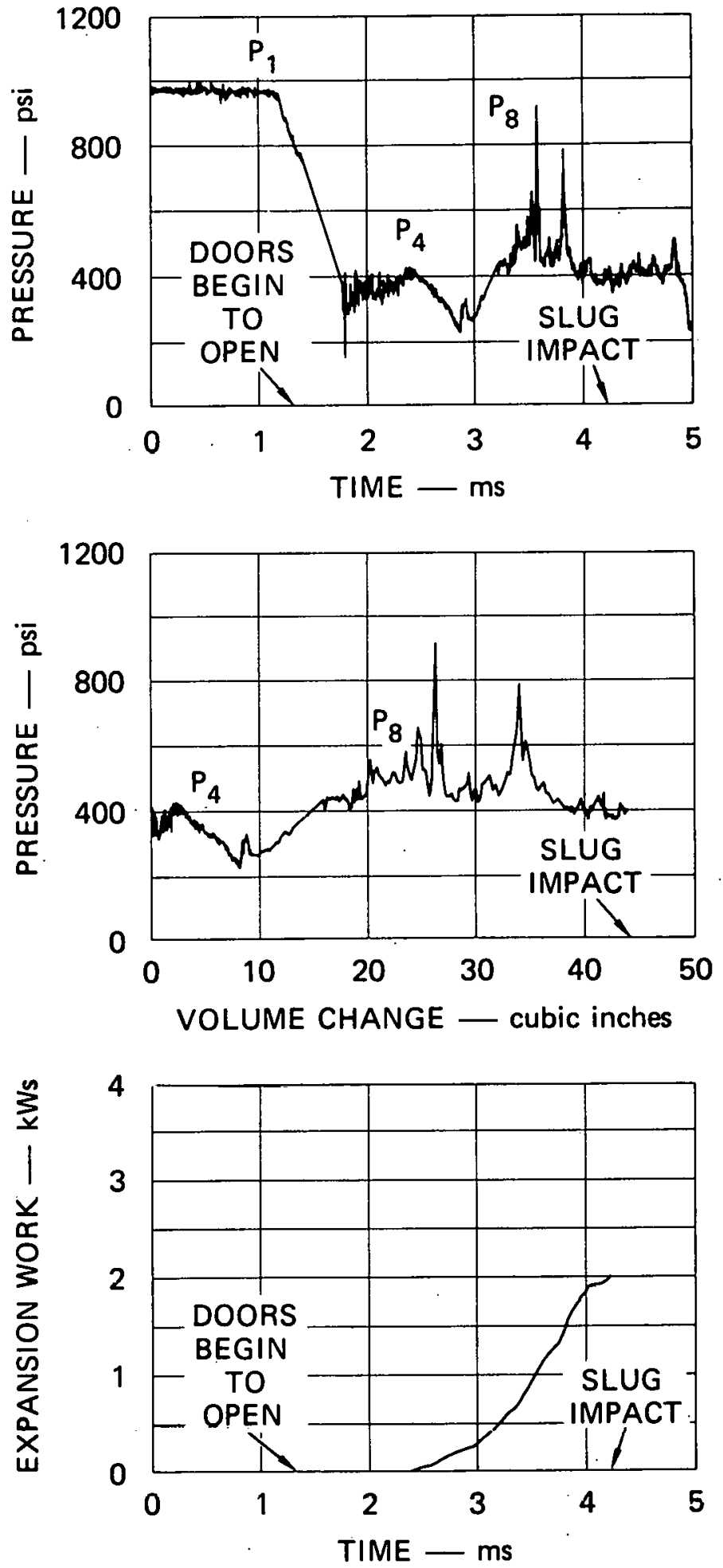

MA-3929-501

FIGURE 34 EXPANSION WORK DONE IN MOVING THE COOLANT SLUG, EXPERIMENT G-011 (WATER) 
(a) PRESSURE ACTING ON THE COOLANT SLUG

(b) PRESSURE-VOLUME CHANGE
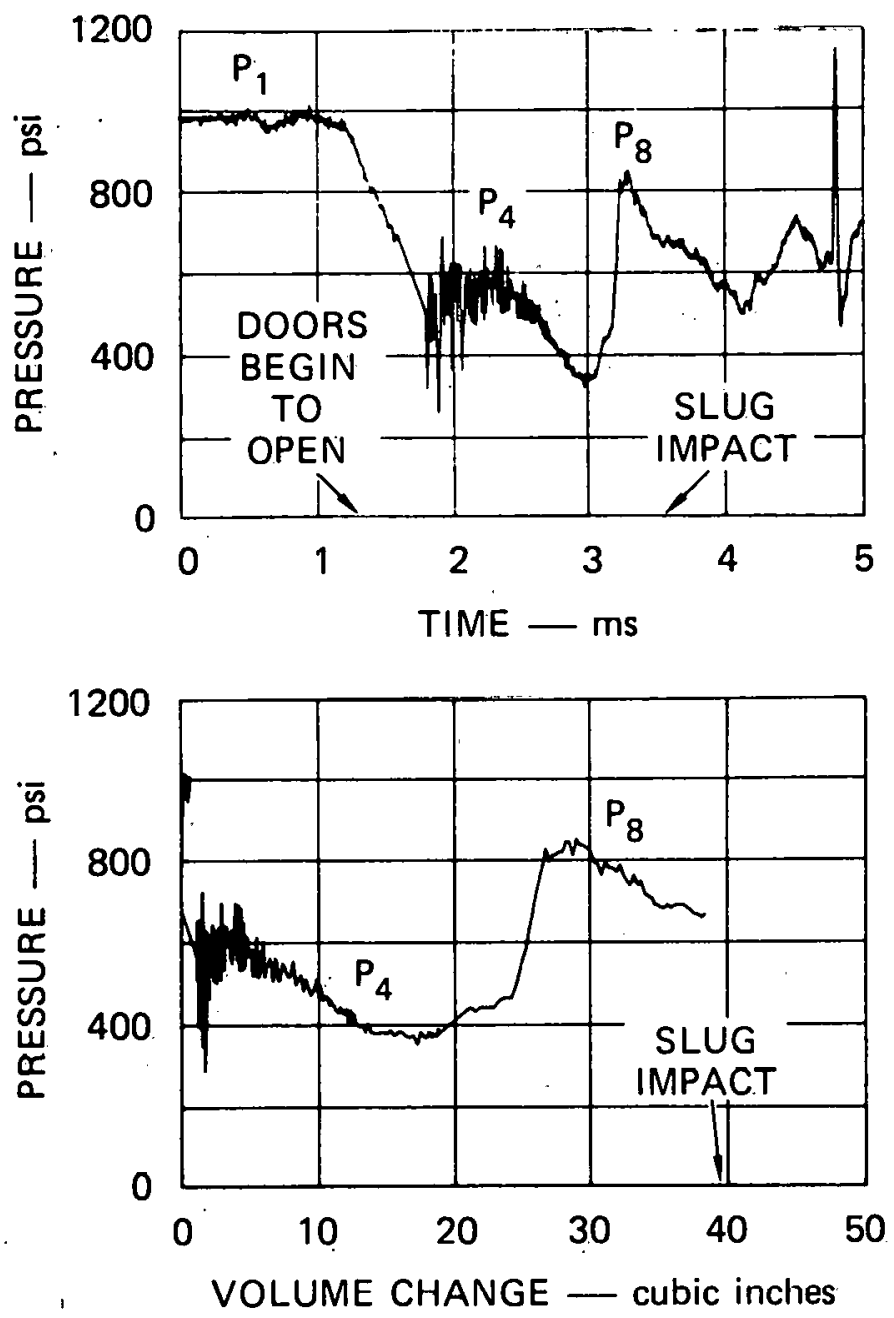

(c) EXPANSSION WORK

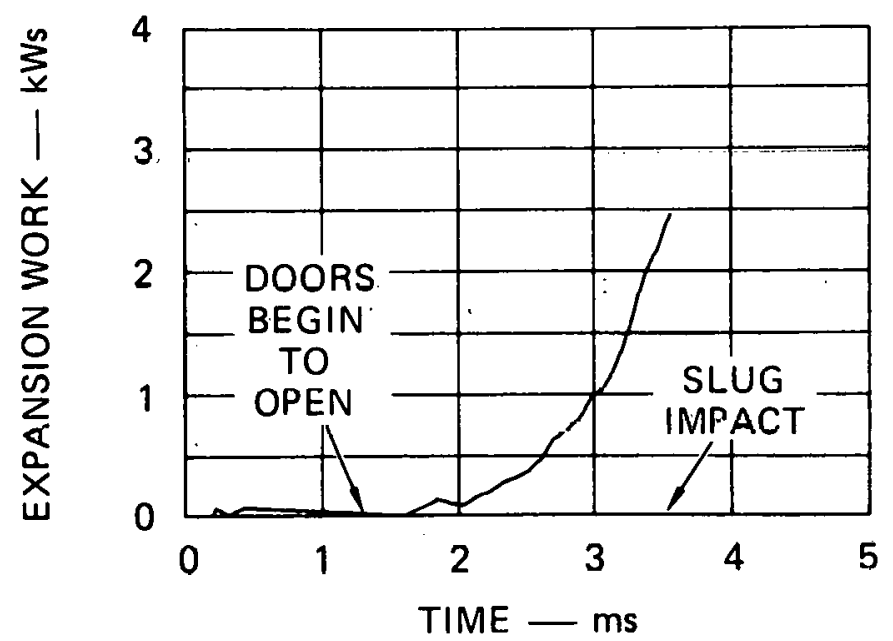

MA-3929-586

FIGURE 35 . EXPANSION WORK DONE IN MOVING THE COOLANTT SLUG, EXPERIMENT G-007 (FREON 113) 
(a) G-002 (Water)

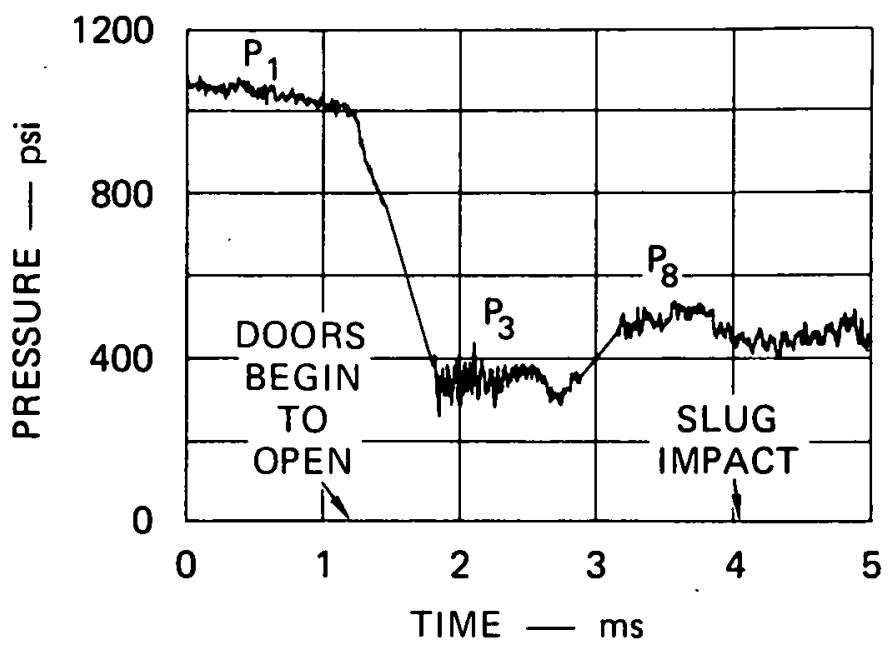

(b) G-007 (Freon 113)

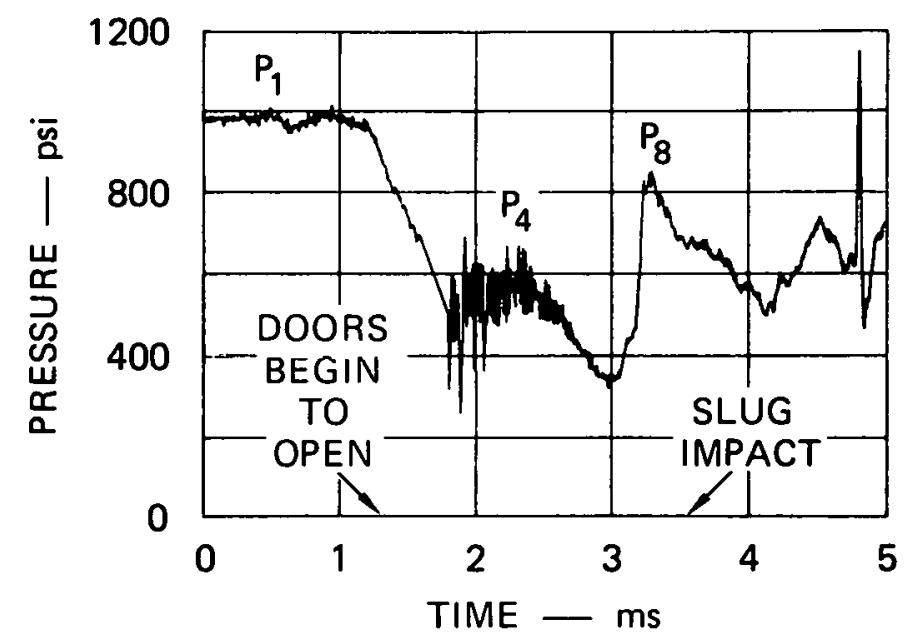

(c) G-009 (Freon 11)

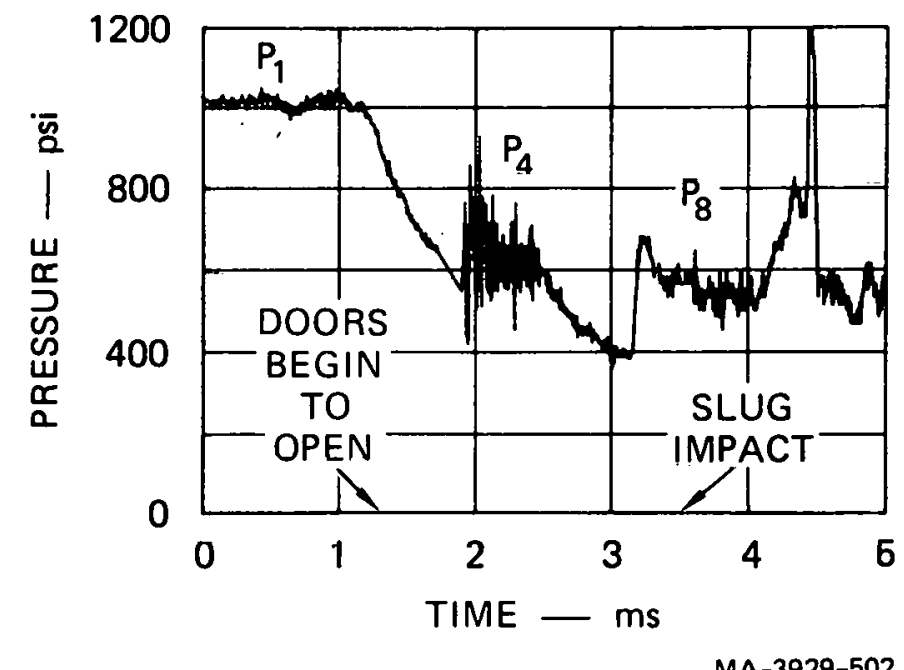

FIGURE 36 COMPOSITE PRESSURE ACTING ON THE COOLANT SLUG IN CONSTANT MASS EXPERIMENTS G-002, G-007, AND G-009 


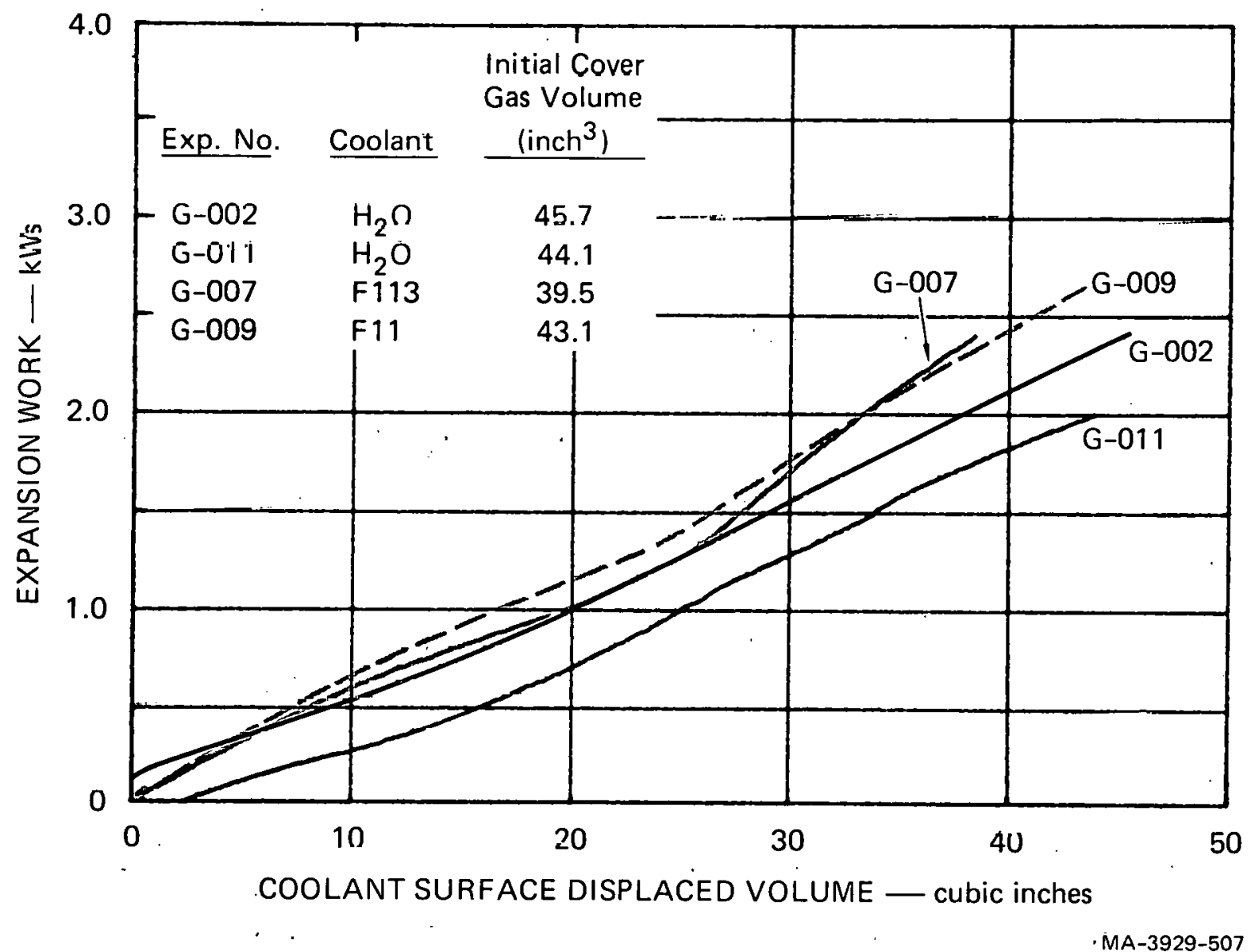

FIGURE 37 EXPANSION WORK AS A FUNCTION OF COOLANT SLUG MOTION IN THE CONSTANT MASS EXPERIMENTS 
the comparison at a given expansion volume is the most appropriate way to compare the expansion work done in these experiments. We see in Table 8 that the expansion work in the two Freon experiments (at $\Delta V=35$ inch ${ }^{3}$ ) is about $25 \%$ higher than in the average of the two water experiments.

Table 8

EXPANSION WORK CONSTANT MASS EXPERIMENTS

\begin{tabular}{|c|c|c|c|c|}
\hline Experiment & Coolant & $\begin{array}{l}\text { Initial Cover } \\
\text { Gas Gap } \\
\text { (inch) } \\
\end{array}$ & $\begin{array}{c}\text { Expansion Work } \\
\text { at } \Delta V=35 \text { inches } \\
(\mathrm{kWs})\end{array}$ & $\begin{array}{c}\text { Expansion Work } \\
\text { at Slug Impact } \\
\text { (kWs) }\end{array}$ \\
\hline & & & & . \\
\hline G-002 & $\mathrm{H}_{2} \mathrm{O}$ & 0.89 & 1.85 & 2.42 \\
\hline G-011 & $\mathrm{H}_{2} \mathrm{O}$ & 0.86 & 1.57 & 2.00 \\
\hline G-007 & F113 & 0.77 & 2.14 & 2.40 \\
\hline G-009 & F11 & 0.84 & 2.11 & 2.58 \\
\hline
\end{tabular}

$67=68$ 
$\mathrm{V}$ RESULTS OF THE FLASHING WATER CONSTANT GEOMETRY

EXPERIMEN'I'S WITHOUT INTERNAL STRUCTURES

In the 1/30-scale geometry, two experiments were performed with water as the coolant and two with Freon 113 as the coolant. The results from experiments G-002 (water) and G-003 (Freon 113) are compared here. Reproducibility is discussed in Appendix $E$. We note here that the cover gas gap was significantly different in these two experiments; 0.89 inch in G-002 and 0.58 inch in G-003. As mentioned at the beginning of section IV, the reason for this difference is that the coolant pool expands (to a greater degree with Freon) when heat from the lower core conducts through the sliding doors and heats the pool before the experiment is initiated.

\section{A. Pressure Measurements}

\section{Lower Core Pressure}

The lower core pressure in experiments G-002 and G-003 is shown in Figure 38(a). The doors begin to open at about $1.20 \mathrm{~ms}$ and slug impact occurs around $4 \mathrm{~ms}$ in both experiments. In the interval between these times, the records are quite similar, varying at most by $60 \mathrm{psi}$.

\section{Upper Core Pressure}

The upper core pressure is shown in Figure $38(\mathrm{~b})$. The records have been filtered through a low pass filter at $10 \mathrm{kHz}$ to facilitate comparison. The unfiltered records are presented in Appendix D. Near the time of emergence of the bubble into the pool ( $3 \mathrm{~ms})$, the upper core pressure is higher in the Freon experiment, reaching essentially the same pressure as in the lower core, 600 psia. The higher pressure in the Freon experiment is due to both the coolant volatility and to the heavier coolant slug being moved. In these experiments, it is difficult to sort out the relative contribution of each of these factors. Comparison of Figure $38(b)$ with Figure 23 (constant mass experiments) leads us to conclude that volatility is the dominant factor leading to the higher pressure in G-003. 


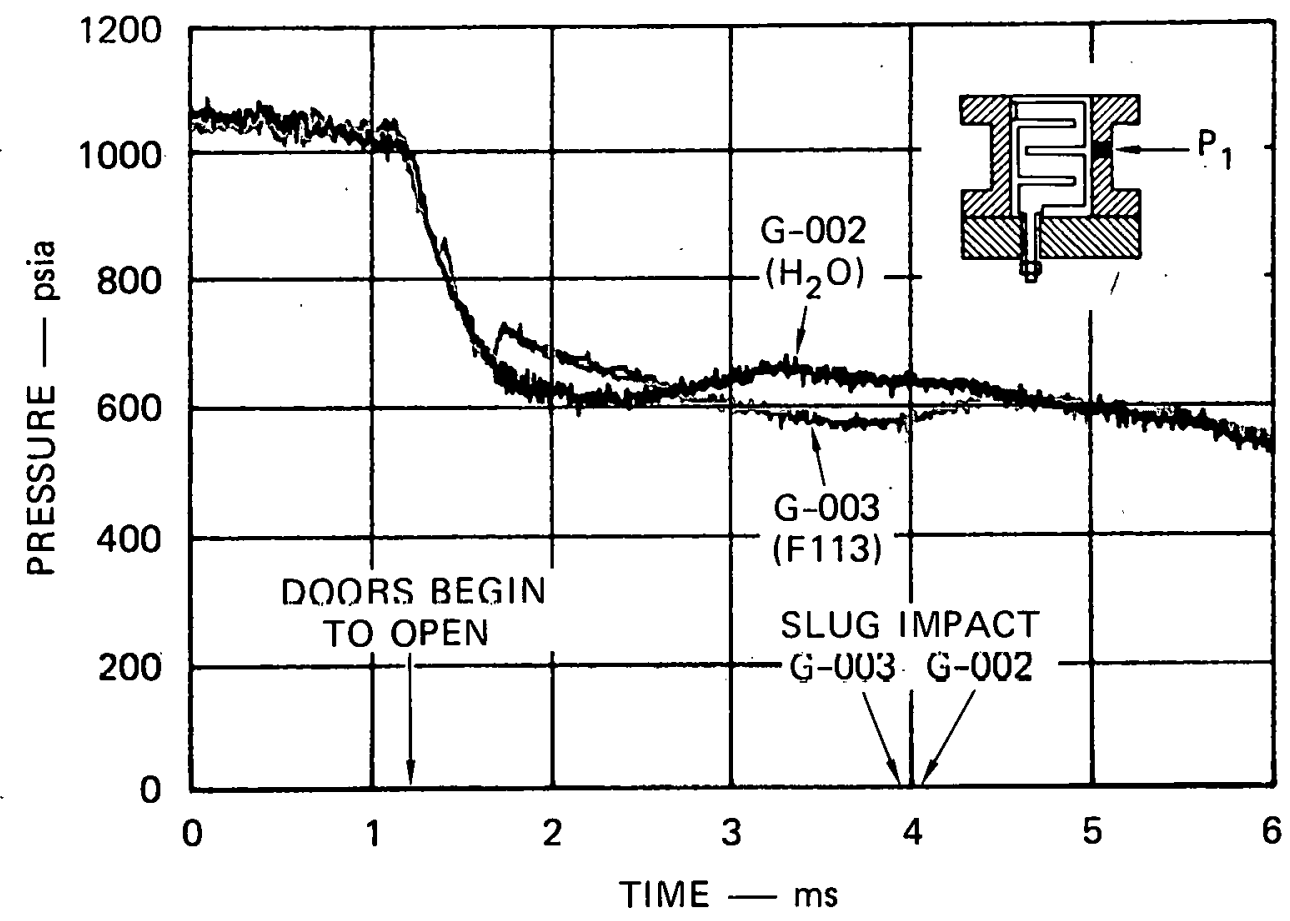

(a) LOWER CORE PRESSURE $\left(\mathrm{P}_{1}\right)$

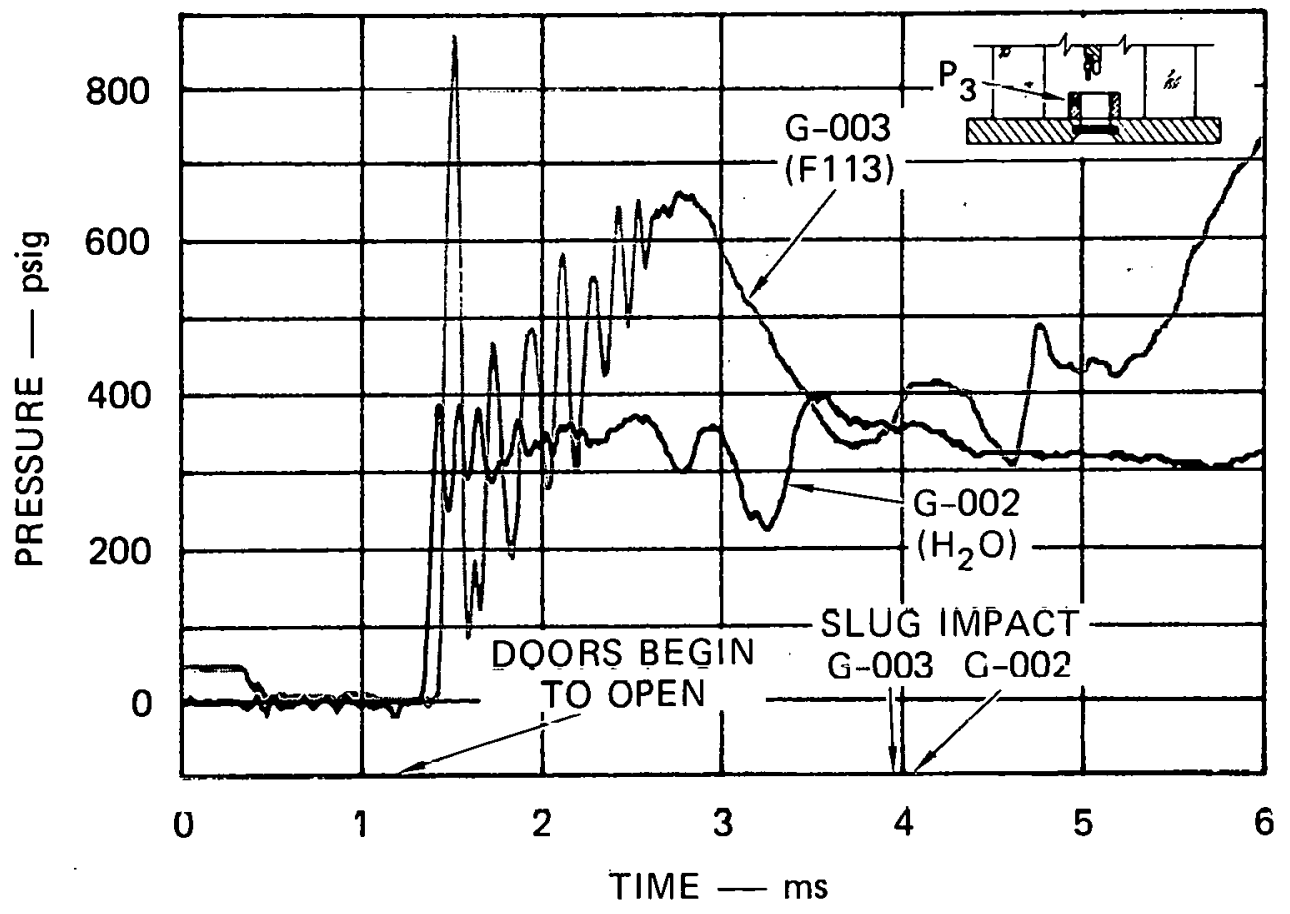

(b) UPPER CORE PRESSURE $\left(P_{3}\right)$ LOW PASS FILTERED AT $10 \mathrm{kHz}$

MA-3929-510

FIGURE 38 LOWER AND UPPER CORE PRESSURES IN THE CONSTANT GEOMETRY EXPERIMENTS WITHOUT INTERNAL STRUCTURES 


\section{Pool and Bubble Pressure}

The pressure measured by transducer $\mathrm{P}_{8}$ in experiments G-002 (water) and G-003 (Freon 113) is shown in Figure 39(a). The record from G-002 is quite similar to that of its duplicate test G-011 (Figure 24) except that the peak at $3 \mathrm{~ms}$ is somewhat broader and higher. The record for G-003 (constant geometry) is quite similar to that of its constant mass counterpart, G-007 (Figure 24) except that the first pressure peak is shifted from 2-1/2 ms in Figure 24 to $3 \mathrm{~ms}$ in Figure 39. This slowing of the expansion is due to the heavier pool in G-003. The pressure peaks and valleys in G-003 are the same in magnitude as in G-007 (Figure 24). The pressure drops in Figure 39 around the time that the bubble reaches the transducer are also similar in magnitude to those in Figure 24. Slug impact does not result in any increase in pressure in the water experiment but is easily seen as a large rise in pressure in the Freon experiment. This feature was also seen in the constant mass experiments (Figure 24). The difference in response of the bubble to compression from the slug impact shock is due to a difference in the composition of the bubble in the water and Freon experiments--namely, the presence of Freon vapor in the bubble in the Freon experiments.

\section{Cover Pressure and Impulse}

Cover pressure $P_{5}$ for experiments G-002 (water) and G-003 (Freon 113) is shown in Figure 39(b). Slug impact occurred at $4.06 \mathrm{~ms}$ in G-002 and $3.95 \mathrm{~ms}$ in G-003. The impact times are so close because of the different initial cover gas gaps. If the gaps were the same, slug impact would occur much later in G-003 because of the heavier coolant pool.

The impact pressure in G-003 is about the same as in G-002. If the gaps were the same, the impact pressure in G-003 would have been higher than in C-002. The impar.t impulses for all four constant geometry experiments are shown in Table 9. Despite the difference in the gaps, the impulses in the Freon experiments are $1-1 / 2$ to 2 times larger than those in the water experiments. This increase is due partly to the longer duration of the pulse in G-003. Further discussion of the slug impact pressure and impulse is presented in Section VII. 


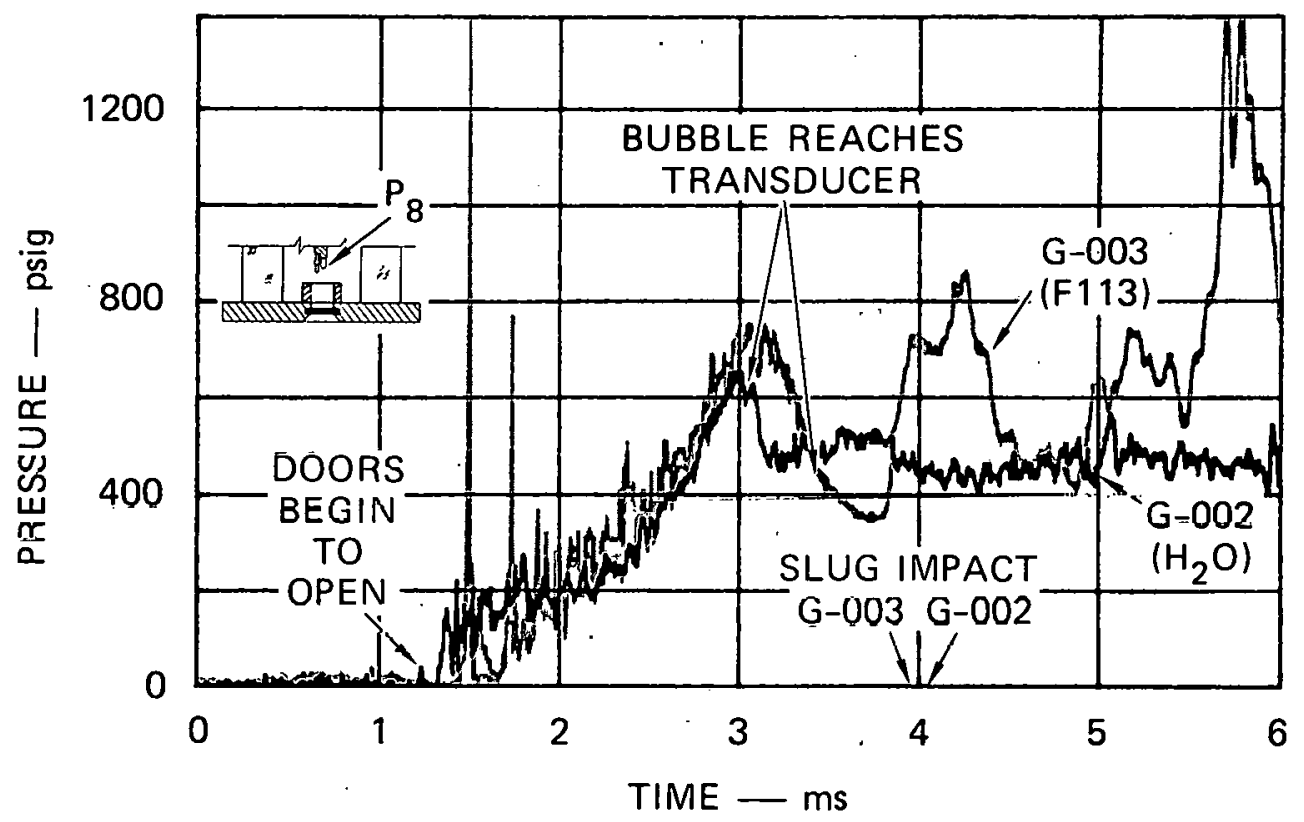

(a) POOL AND BUBBLE PRESSURE $\left(\mathrm{P}_{8}\right)$

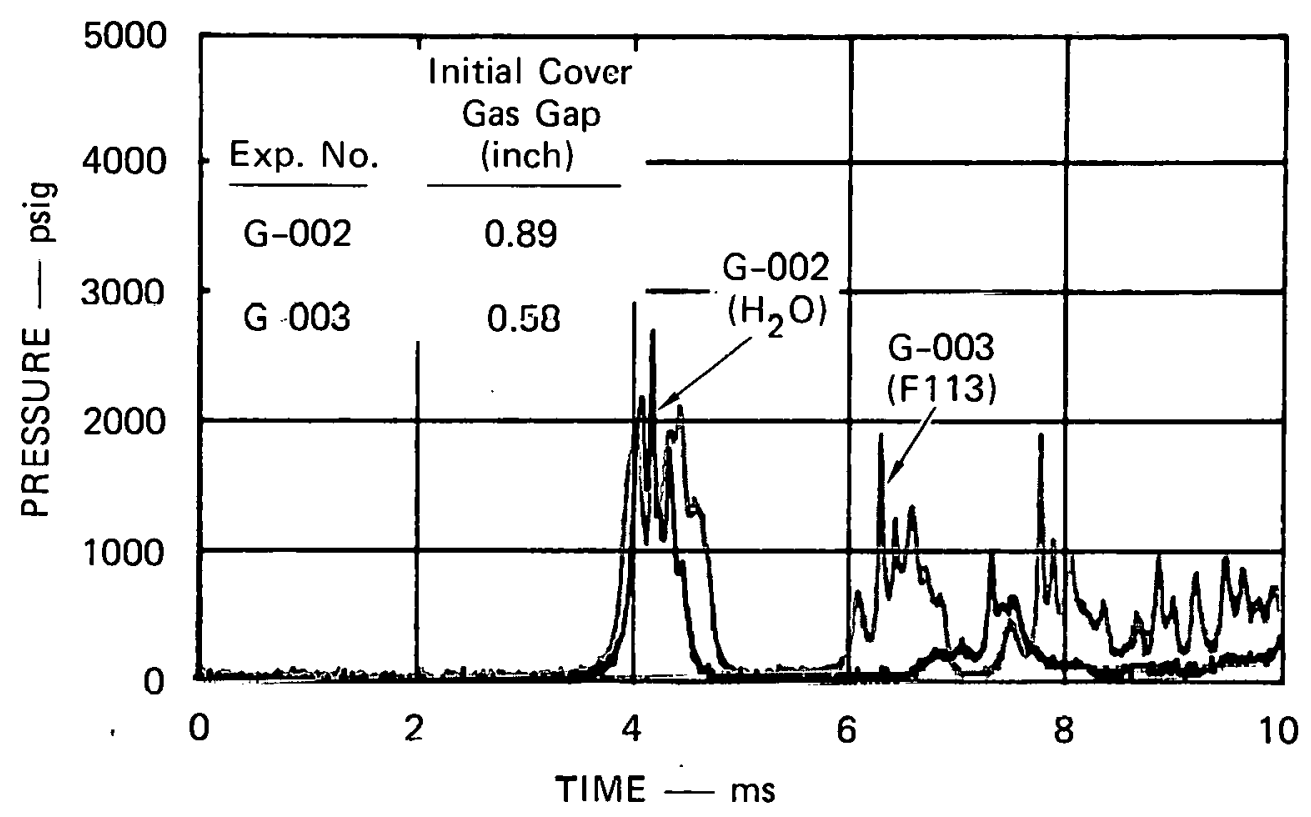

(b) COVER PRESSURE $\left(P_{5}\right)$

MA-3929-511

FIGURE 39 POOL, BUBBLE AND SLUG IMPACT PRESSURE IN THE CONSTANT GEOMETRY EXPERIMENTS WITHOUT INTERNAL STRUCTURES 
Table 9

\section{IMPULSE ON THE VESSEL COVER \\ FROM THE FIRST SLUG IMPACT PULSE, CONSTANT GEOMETRY EXPERIMENTS WITHOUT INTERNAL STRUCTURES}

\begin{tabular}{|c|c|c|c|}
\hline Experiment & Coolant & $\begin{array}{l}\text { Initial Cover } \\
\text { Gas Gap } \\
\text { (inch) }\end{array}$ & $\begin{array}{c}\text { Impulse* } \\
\text { (lbf-s) }\end{array}$ \\
\hline G-002 & $\mathrm{H}_{2} \mathrm{O}$ & 0.89 & 40.8 \\
\hline G-011 & $\mathrm{H}_{2} \mathrm{O}$ & 0.86 & 38.9 \\
\hline G-003 & F113 & 0.58 & 67.9 \\
\hline G-004 & F113 & 0.73 & 75.7 \\
\hline
\end{tabular}

\section{B. Coolant Surface and Bubble Motion}

1. Coolant Surface Displacement

The coolant surface displacement for the two constant geometry experiments under discussion are shown in Figure 40. We see here that the heavier pool dominates over the effects of volatility. The displacement in the Freon experiment proceeds more slowly than that in the water experiment. The slopes of the curves in Figure 40 indicates a characterietic pool velority of 0.65 inch/ms in G-002 (water) and 0.61 inch/ms in G-003 (Freon 113).

2. Bubble Profiles and Volume

Bubble growth profiles from the high-speed movies are shown for experiments G-002 and G-003 in Figure 41. As with the constant mass experiments, 


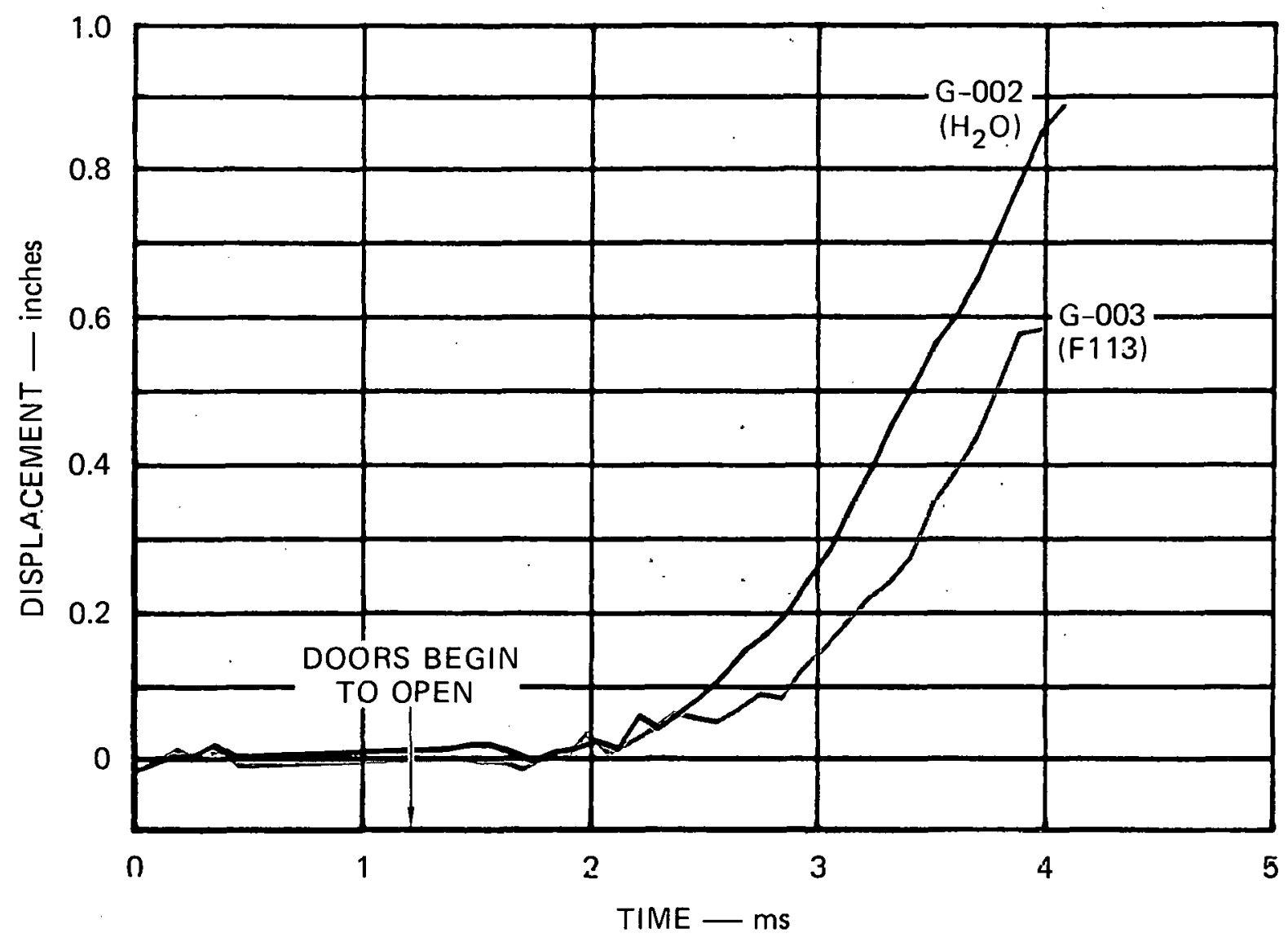

MA-3929-508

FIGURE 40 COOLANT SURFACE DISPLACEMENT IN CONSTANT GEOMETRY EXPERIMENTS WITHOUT INTERNAL STRUCTURES

the Freon bubble does not penetrate as far as into the pool. In contrast to the constant mass experiment, the upper surface of the bubble is not the same shape in these constant geometry experiments. In G-003 with the heavier Freon pool, the bubble is flatter.

The bubhle valime lisisury. In C-002 and $\ddot{6} 003$, determined from the bubble profiles, is shown in Figure 42. The slower motion of the coolant seen in Figure 40 is also seen in Figure 42 . 


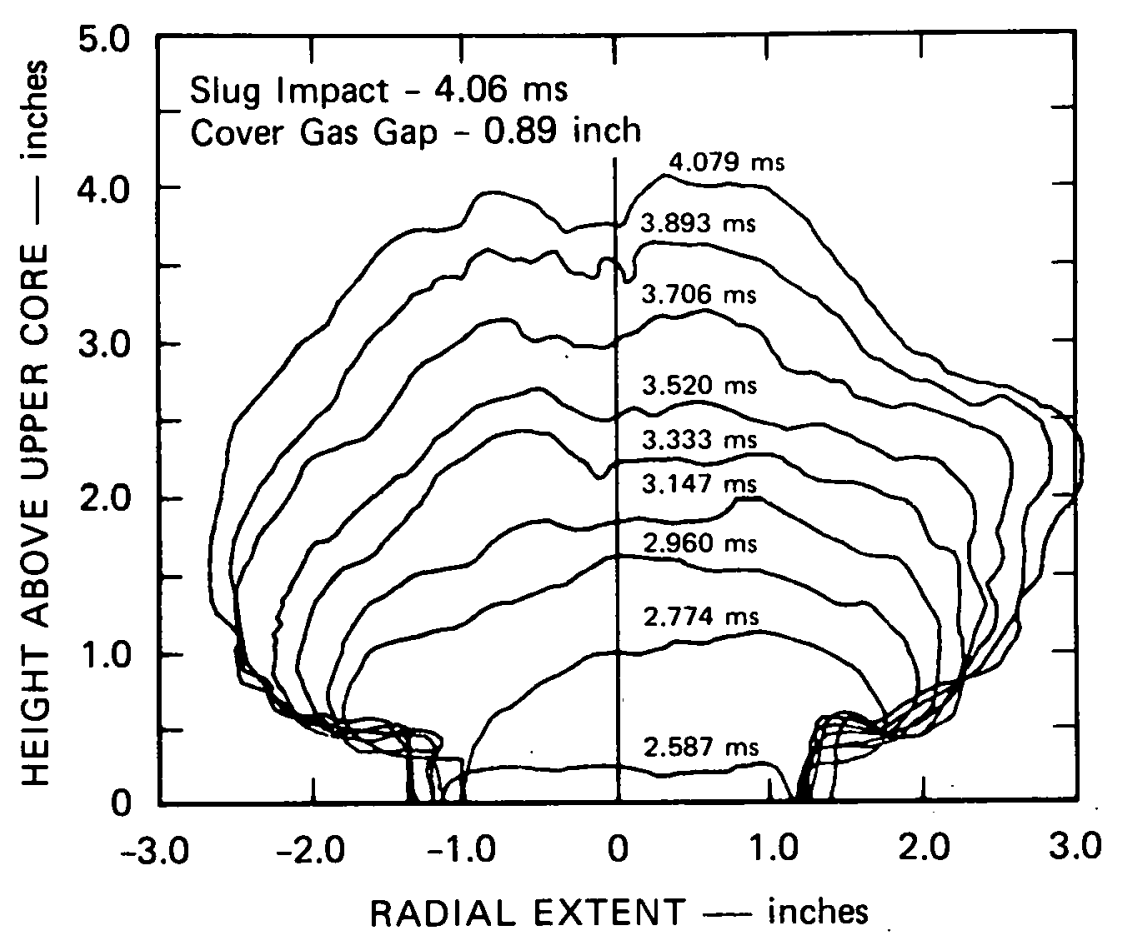

(a) WATER COOLANT (G-002)

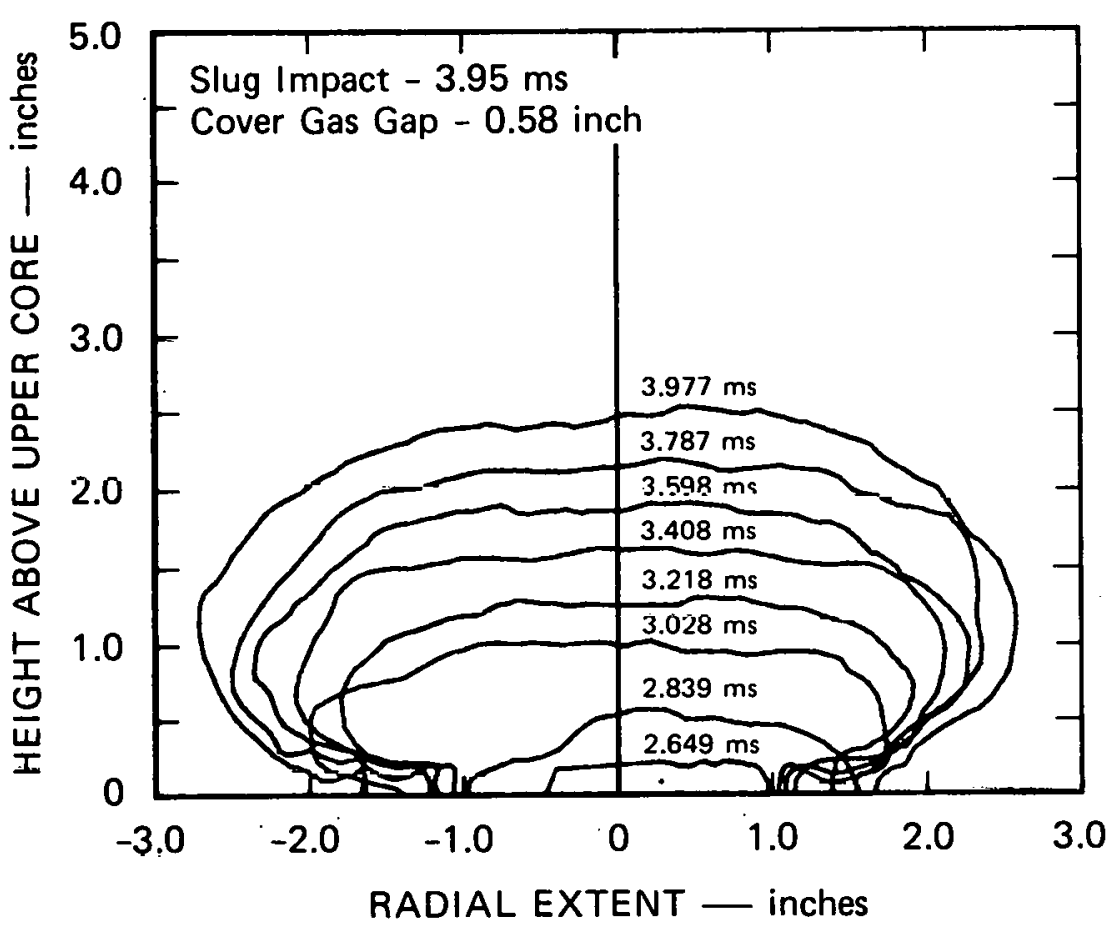

(b) FREON 113 COOLANT (G-003)

MA-3929-585

FIGURE 41 BUBBLE GROWTH PROFILES IN THE CONSTANT GEOMETRY EXPERIMENTS 


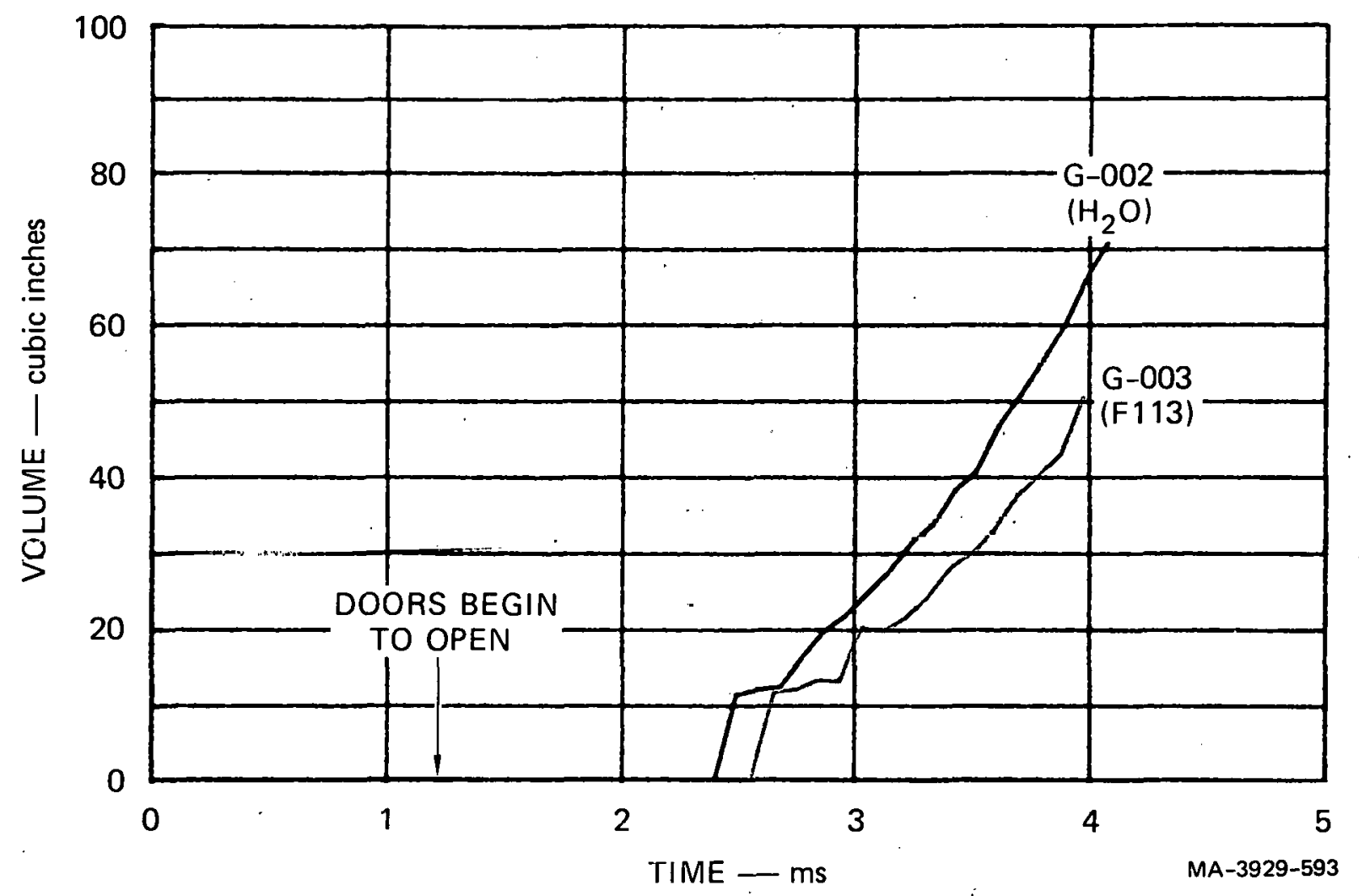

FIGURE 42 BUBBLE VOLUME IN CONSTANT GEOMETRY EXPERIMENTS WITIIOUT INTERNAL STRUCTURES

\section{Entrainment}

The entrainment volumes, Figure 43(a), in these constant geometry experiments are similar and the valnes for entrainment as a percentage of bubble volume, Figure $43(\mathrm{~b})$, are within the spread that we usually see. In the constant mass experiments (Figure 33), the Freon tests had a lower entrainment. Here, the Freon test has a higher entrainment. In all. fnur. constant geometry experiments, the entrainment at slug impact is between $30 \%$ and $40 \%$ of bubble volume. 


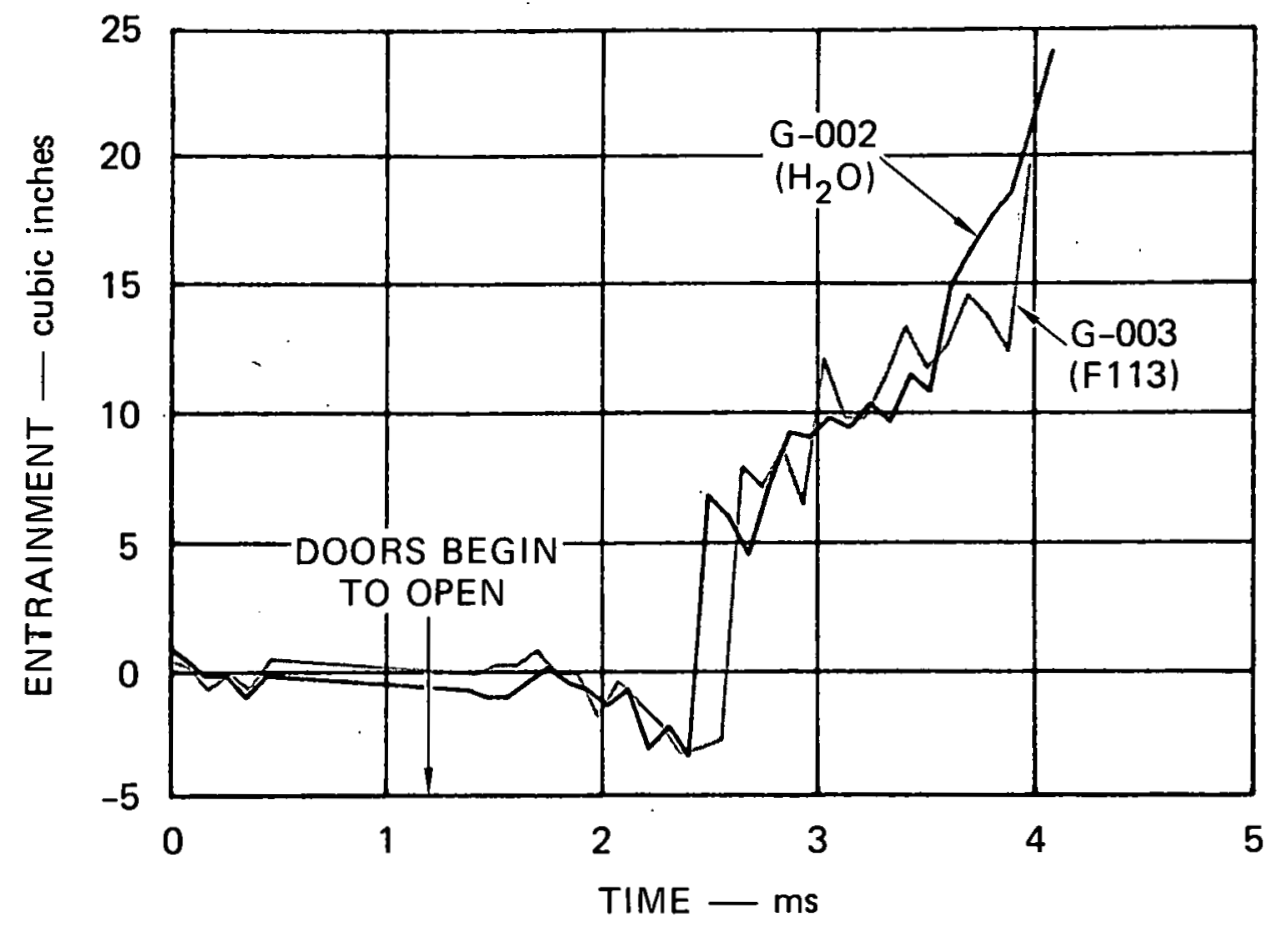

(a) ENTRAINED VOLUME

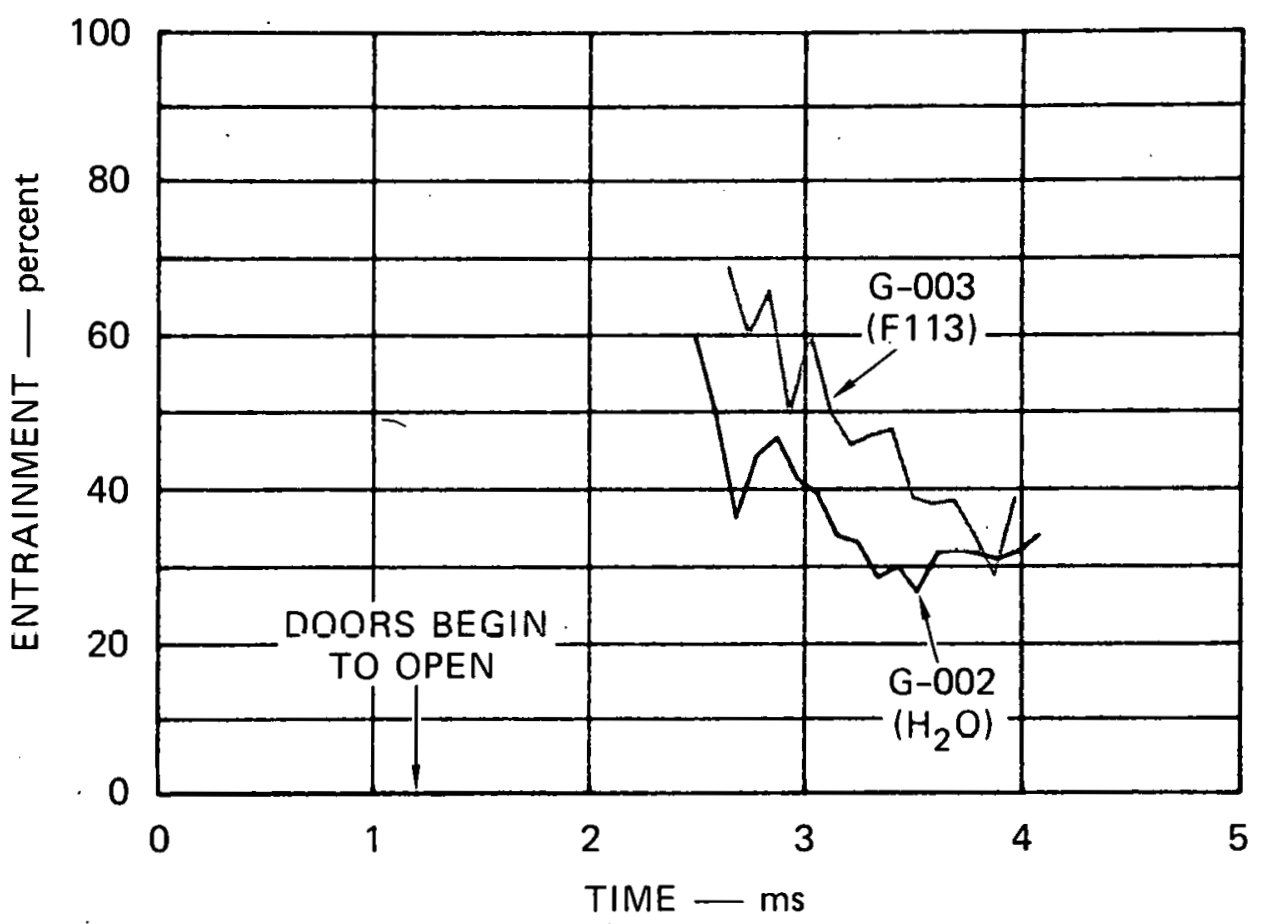

(b) ENTRAINMENT AS A PERCENTAGE OF BUBBLE VOLUME

MA-3929-509

FIGURE 43 ENTRAINMENT IN THE EXPANDING BUBBLE IN CONSTANT GEOMETRY EXPERIMENTS WITHOUT INTERNAL STRUCTURES 


\section{EFFECT OF INTERNAL VESSEL STRUCTURES IN FLASHING WATER CONSTANT GEOMETRY EXPERIMENTS}

Three experiments with Freon 113 as the coolant are compared in this section.

\begin{tabular}{ccc} 
Experiment & Internal Structures & $\begin{array}{c}\text { Initial Lower } \\
\text { Core Pressure } \\
\text { (psia) }\end{array}$ \\
\cline { 2 - 2 } & None & 1040 \\
G-006 & UCS \& UIS & 998 \\
G-005 & UCS \& UIS & 501
\end{tabular}

In the experiment matrix G-005 and G-006 were to be duplicate experiments, but G-005 was found to have an initial pressure low by a factor of 2 from nominal. Comparison between G-004 and G-006 reveals the effects of internal structures. Comparison between G-005 and G-006 reveals the effect of initial pressure. These latter two are the first flashing water source experiments we have conducted in which the initial pressure varies by a factor of 2 .

\section{A. Lower Core Pressure}

The lower core pressure in these three experiments is shown in Figure 44. The pressures in G-004 and G-006 differ by no more than about 50 psi. Comparing experiments G-005 and G-006, we see that both the initial pressures and the presaurc plateau which occurs after the sliding doors open and until slug impact differ by a factor of 2 .

\section{B. Coolant Surface Displacement}

In Figure 45(a), the coolant surface displacement in experiments with and without internal structures is compared for both Freon 113 and water as the coolant. The experiments with water as the coolant, E-001 and E-003, are from earlier work. ${ }^{l}$ We see that the effect of internal structure is qualitatively similar with either coolant. The expansion 


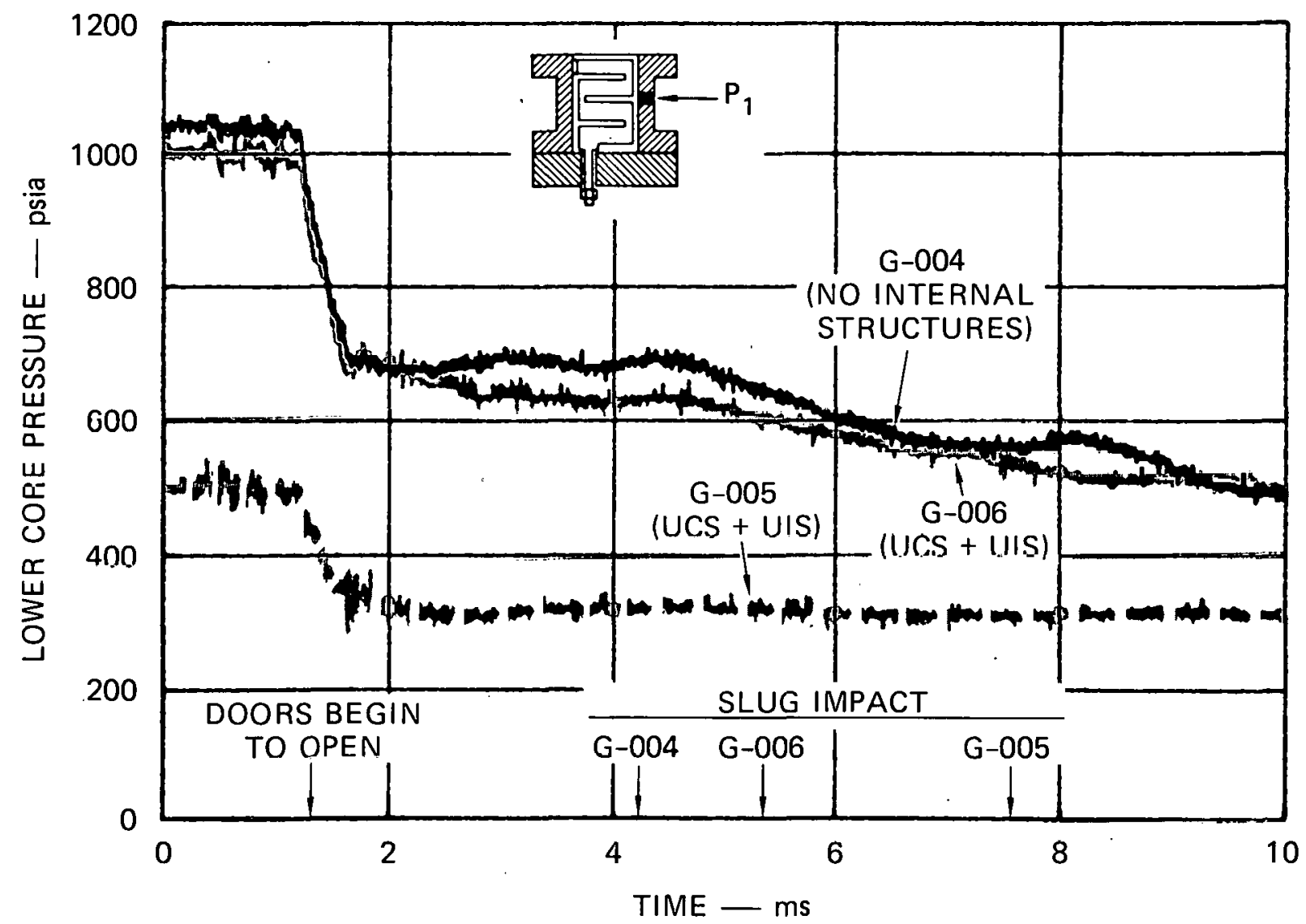

MA-3929-528

FIGURE 44 LOWER CORE PRESSURE $\left(P_{1}\right)$ IN EXPERIMENTS G-004 (NO INTERNAL STRUCTURES). G-005 (UCS + UIS), AND G-006 (UCS + UIS)

time scale is increased by 1 to $1-1 / 2 \mathrm{~ms}$. The average coolant pool velocities [from the slopes in Figure $45(\mathrm{a})$ ] are $0.61 \mathrm{inch} / \mathrm{ms}$ for E-001, 0.57 inch/ms for G-004, $0.38 \mathrm{inch} / \mathrm{ms}$ in E-003, and $0.29 \mathrm{inch} / \mathrm{ms}$ in G-006.

Figure 46(a) shows the effect of initial pressure on the expansion with internal structures. Reducing the lower core pressure by a factor of 2 changes the coolant pool velocity from 0.29 inch/ms in r-0.6 to 0.24 inch/ms in G-005.

\section{c. Bubble Profilcs}

The HCDA bubble photographs at slug impact are compared in Figures 47. and 48. Figure 47 shows that the effect of internal structures alters 


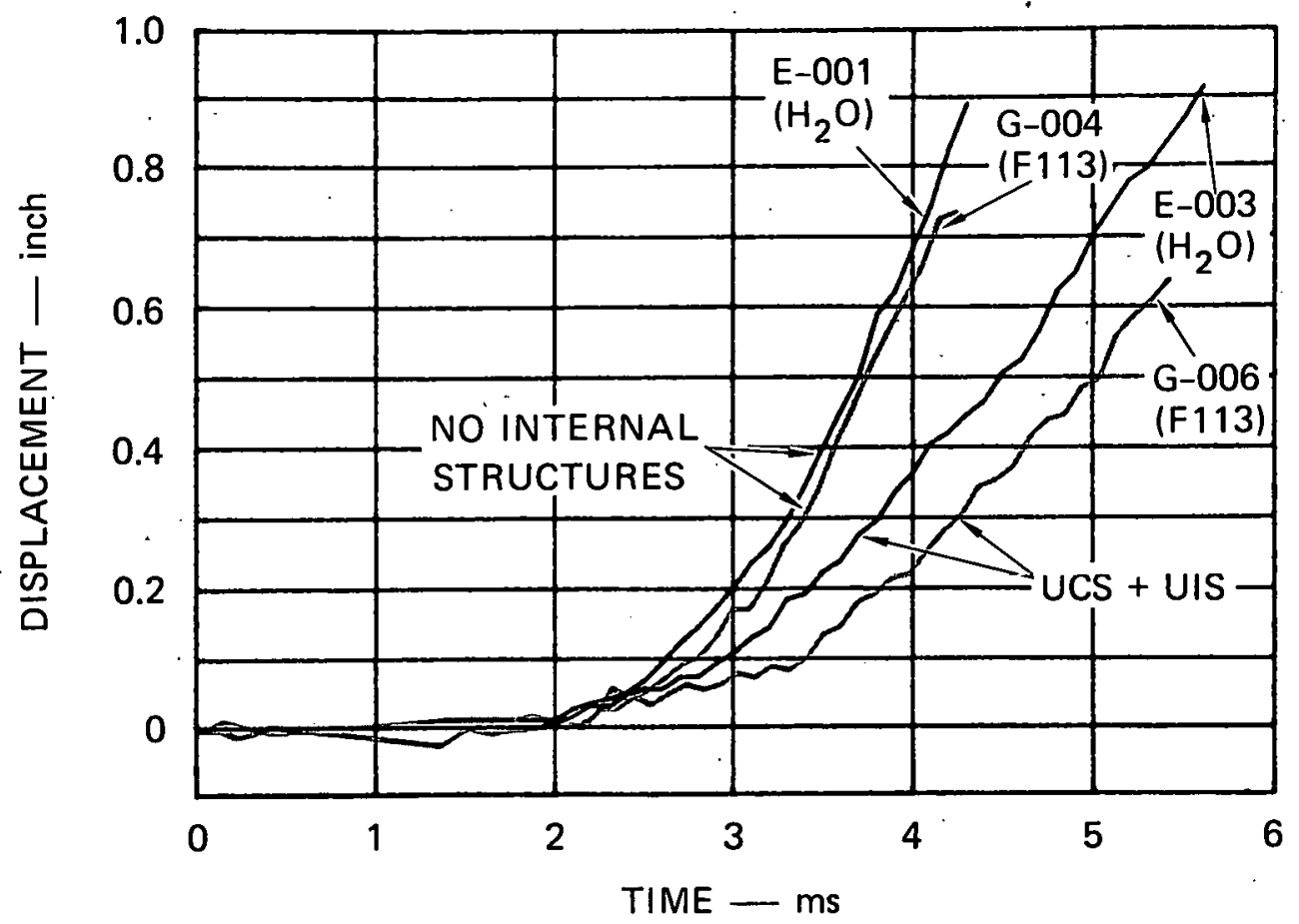

(a) COOLANT SURFACE DISPLACEMENT

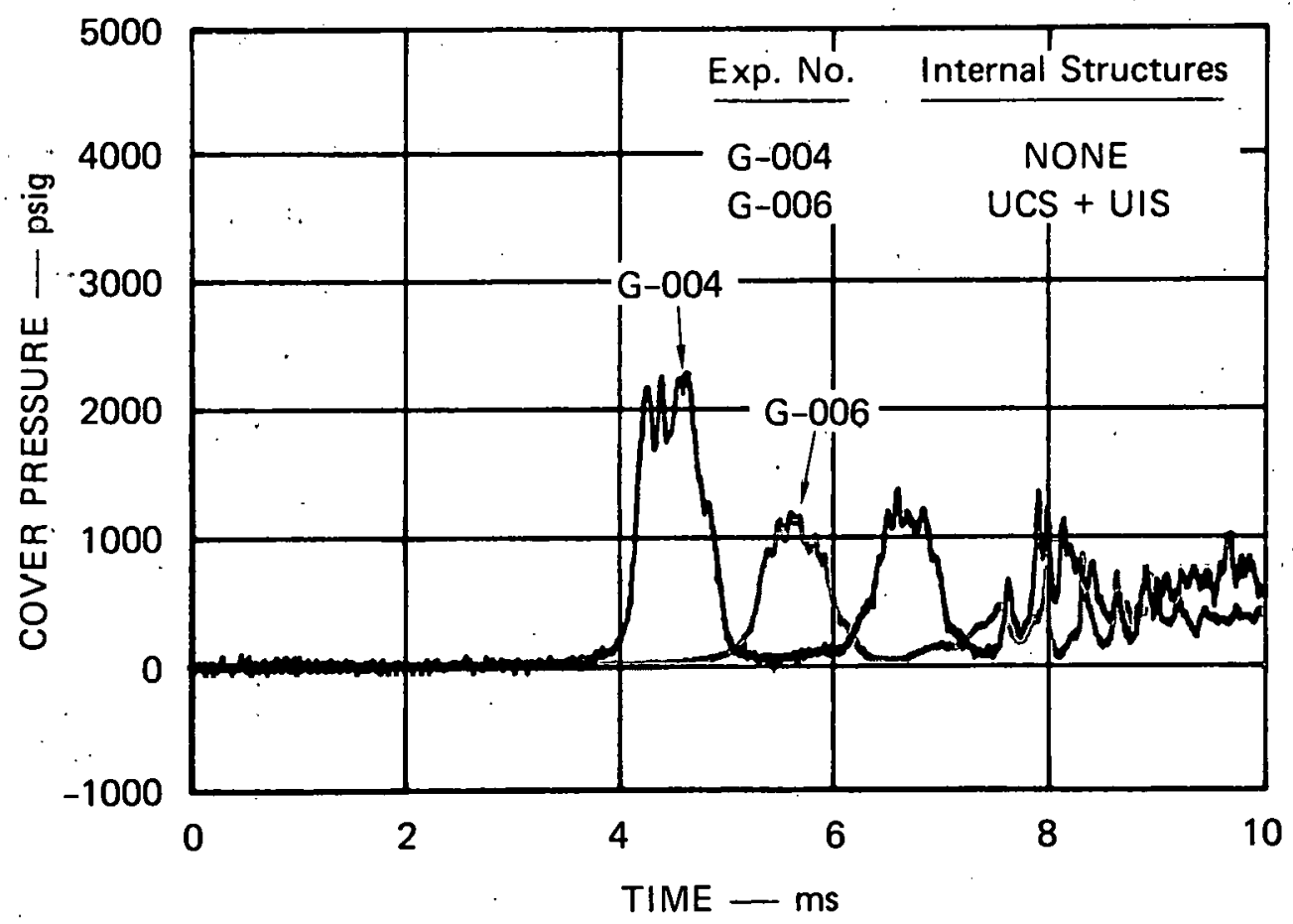

(b) SLUG IMPACT PRESSURE $\left(P_{5}\right)$ IN THE FREON 113 EXPERIMENTS

MA-3929-503

FIGURE 45 EFFECT OF INTERNAL VESSEL STRUCTURES AND COOLANT VOLATILITY IN 1/30-SCALE HCDA SIMULATIONS 


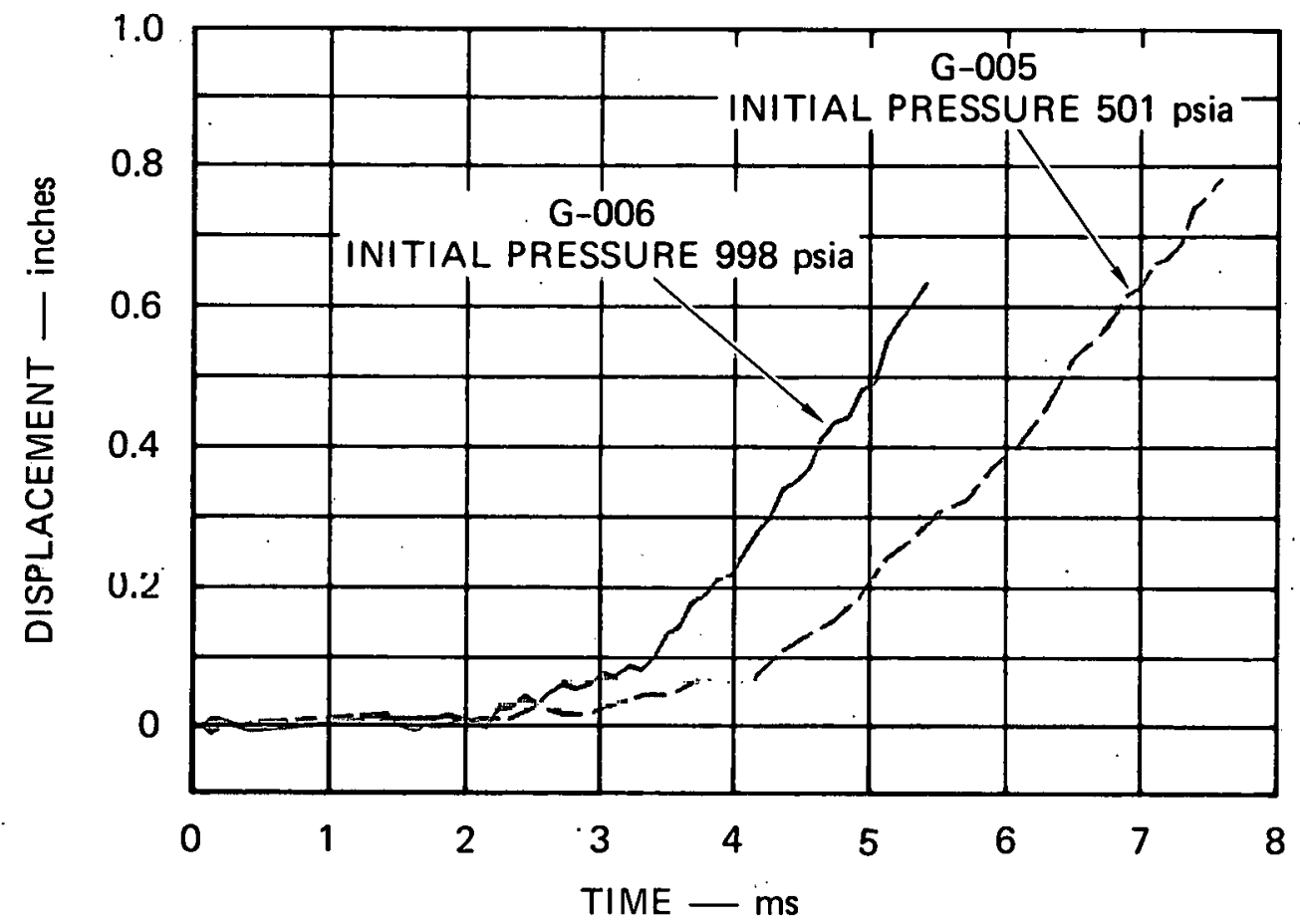

(a) COOLANT SURFACE DISPLACEMENT

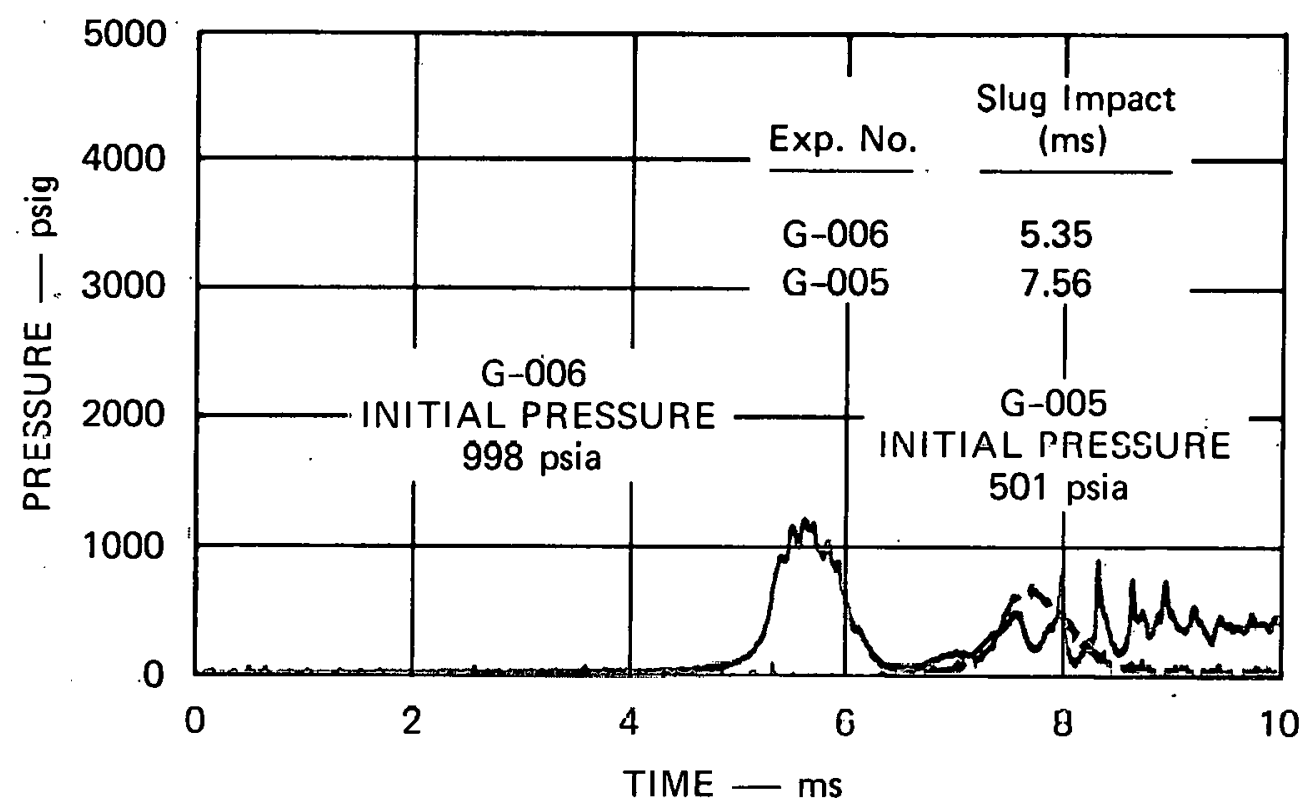

(b) SLUG IMPACT PRESSURE $\left(\mathbf{P}_{5}\right)$

$M \wedge$ 3028-612

FIGURE 46 EFFECT OF LOWER CORE PRESSURE IN EXPERIMENTS WITH BOTH A UCS AND UIS 


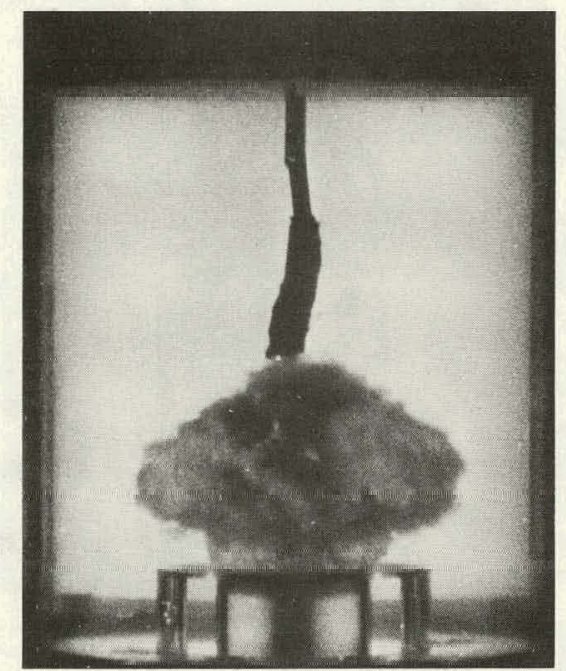

(a) WATER COOLANT (E-001) NO STRUCTURES

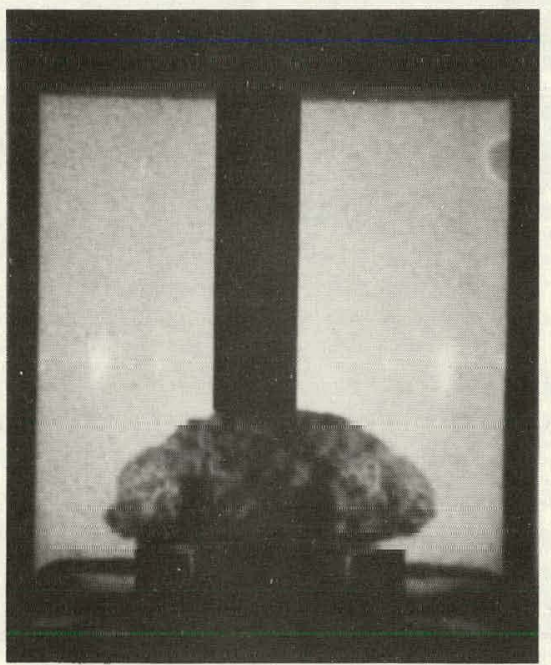

(c) FREON 113 COOLANT (G-004) NO STRUCTURES

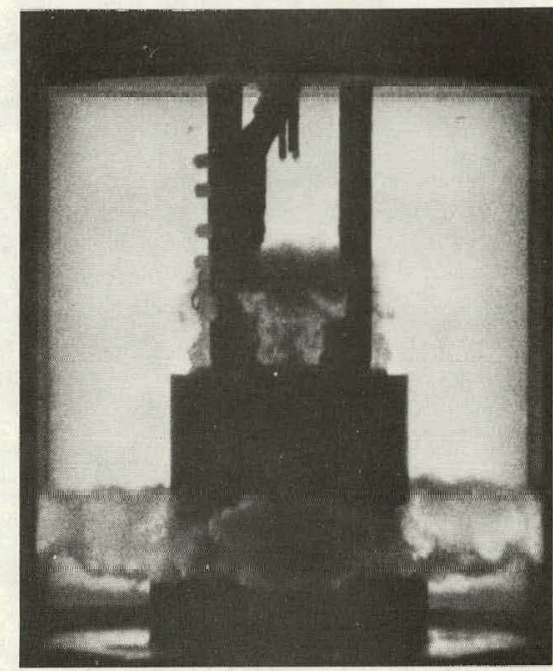

(b) WATER COOLANT (E-003) UPPER CORE AND UPPER INTERNAL STRUCTURES

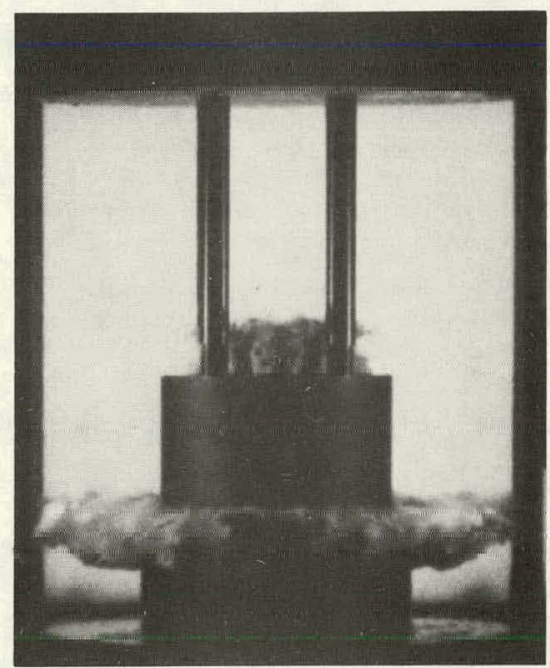

(d) FREON 113 COOLANT (G-006) UPPER CORE AND UPPER INTERNAL STRUCTURES

MA-3929-582

FIGURE 47 HCDA BUBBLE PHOTOGRAPHS AT SLUG IMPACT SHOWING THE EFFECT OF INTERNAL VESSEL STRUCTURES 


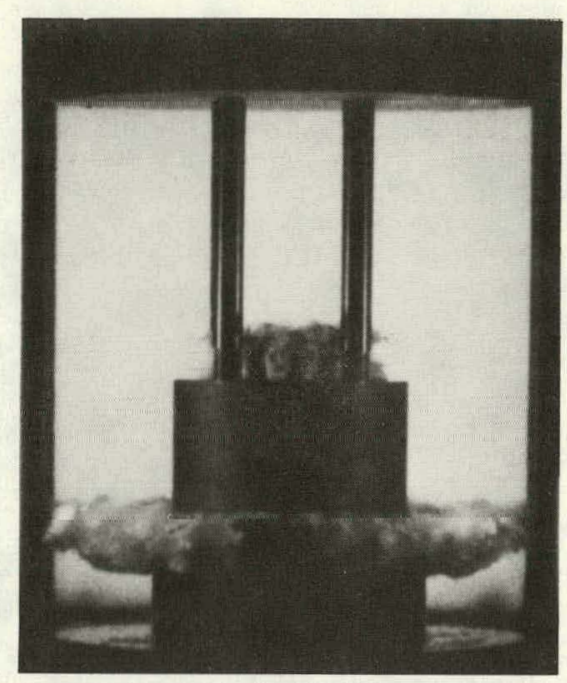

(a) G-006

INITIAL PRESSURE 998 psia

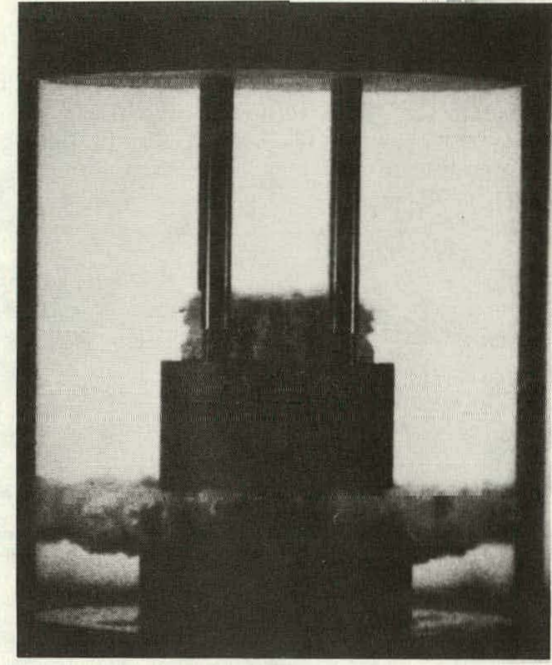

(b) G-005

INITIAL PRESSURE 501 psia

MP-3929-583

FIGURE 48 HCDA BUBBLE PHOTOGRAPHS AT SLUG IMPACT SHOWING THE EFFECT OF INITIAL PRESSURE

the bubble shape in the same way whether the coolant is water or Freon 113. In Figure 48, we see that the expansion time frame due to different initial pressures does not noticeably change bubble shape.

\section{Cover Pressure and Impulse}

The effect of internal vessel structures on the cover pressure is shown in Figure 45(b). As in earlier work with water as coolant, ${ }^{1}$ a noticeable reduction in slug impact pressure occurs due to the attenuating effects of internal structures. In Figure $46(\mathrm{~b})$, the effect of different lower core pressures is demonstrated. The impulse on the vessel cover in the four Freon 113 experiments with and without internal structures is summarized in Table 10. Internal structures reduce the impulse by $44.9 \%$ from $71.8 \mathrm{lbf}-\mathrm{s}$ (average of G-003 and G-004) to $39.6 \mathrm{lbf}-\mathrm{s}$ (G-006). Reducing the lower core initial pressure by half reduces the impulse by $42.4 \%$ from $39.6 \mathrm{lbf}-\mathrm{s}$ in G-006 to $22.8 \mathrm{lbf}-\mathrm{s}$ in $\mathrm{G}-005$. 
Table 10

\section{EFFECT OF INTERNAL VESSEL STRUCTURES \\ ON THE IMPULSE FROM THE FIRST \\ SLUG IMPACT PULSE}

\begin{tabular}{|c|c|c|c|c|}
\hline Experiment & $\begin{array}{c}\text { Structures } \\
\text { Present }\end{array}$ & $\begin{array}{l}\text { Initial } \\
\text { Pressure } \\
\text { (psia) }\end{array}$ & $\begin{array}{c}\text { Initial Cover } \\
\text { Gas Gap } \\
\text { (inch) }\end{array}$ & $\begin{array}{c}\text { Impulse* } \\
\text { (lbf-s) }\end{array}$ \\
\hline G-003 & None & 1038.9 & 0.58 & 67.9 \\
\hline G-004 & None & 1039.7 & 0.73 & 75.7 \\
\hline G-006 & UCS + UIS & 998.0 & 0.63 & 39.6 \\
\hline G-005 & UCS + UIS & 501.2 & 0.78 & 22.8 \\
\hline
\end{tabular}

"Average of all cover pressure measurements in a given experiment. 
THIS PAGE

\section{WAS INTENTIONALLY \\ LEFT BLANK}

86 


\section{INTERPRETATION OF RESULTS}

In Sections III through VI, we reported the data obtained in these experiments. Distinguishable effects of coolant volatility have been shown, as have the effects of internal structures. In this section, we review the integral measures of the expansion dynamics, e.g., the coolant surface displacement and the cover loading. The coolant surface displacement is an integral measure of the axial acceleration and velocity history of the coolant slug that should correspond to the effects of coolant volatility seen in individual pressure measurements. The cover loading is a measure of the slug impact velocity.

Our discussion of the coolant surface displacement involves a comparison of the experimental measurements in constant mass and constant geometry experiments with predictions based on a simple mathematical model of the expansion. The model is shown in Figure 49. A constant pressure source accelerates the coolant liquid in the upper core and coolant poul until the coolant surface travels a distance equal to the cover gas height. The expansion occurs in two phases. In phase $A$, the upper core is emptied and the mass of liquid in regions 1 and 2 varies with time. During phase $B$, the coolant slug of constant mass in region 2 is driven upward by the source pressure.

The fluid dynamics of the expanding source is not modeled. In our experiments, we often measure a lower pressure in the bubble than in the lower core. In our model we, therefore, allow the pressure driving the slug upward to differ in phases $A$ and $B$. The pressure in phase $A$ acts over the diameter $d_{1}$, and the pressure in phase $B$ acts over the diameter $\mathrm{d}_{2}$. Some simple calculations based on this model are presented in Figure 50. The mathematical model is described in more detail in Appendix F. In Figure 50(a), the effects of experiment geometry and coolant density are demonstrated by using a phase A driving pressure of 650 psia and a phase B driving pressure of 450 psia in the three cases shown. The choice of 650 psia for phase $A$ was based on the lower core pressure data shown in 


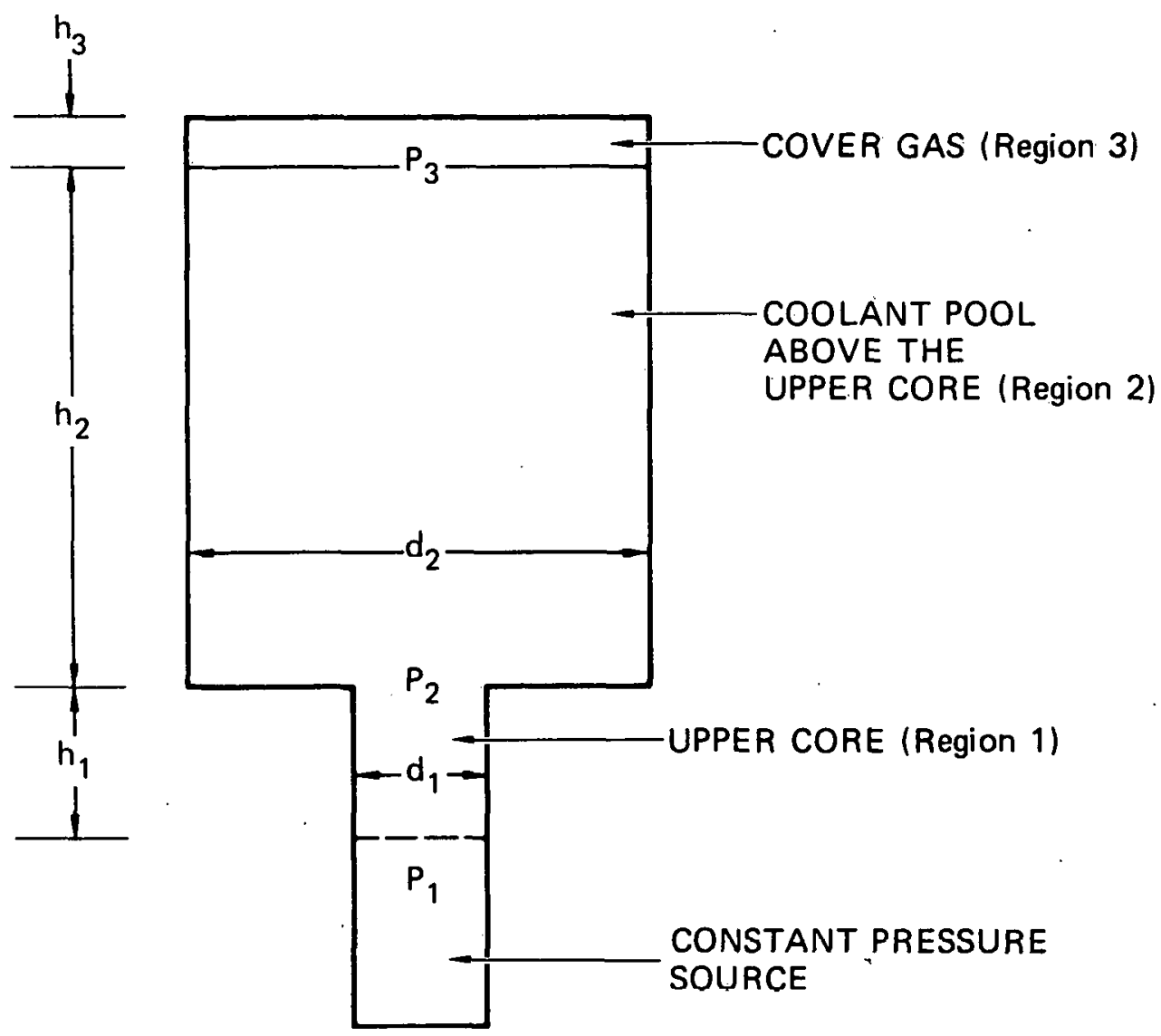

MA-3929-493

FIGURE 49 SIMPLE EXPANSION MODEL

Figure 22. The choice of 450 psia for phase $B$ was based on pressure data in Figure 24 for experiment G-011 after the bubble reached the transducer. In Figure $50(\mathrm{~b})$, the additional effects of coolant volatility are demonstrated by having the phase B driving pressure equal to 650 psia in the Freon 113 cases. This cholce was based on the higher pressure seen in Figure 24 in Freon 113 experiment G-007. Five calculations are presented in Figure 50. The reference case in parts $a$ and $b$ of the figure is our standard 1/30-scale geometry with water as the coolant. The expansion in these calculations begins at $1.25 \mathrm{~ms}$, when conceptual sliding doors open, to permit comparison of our experimental measurements. 


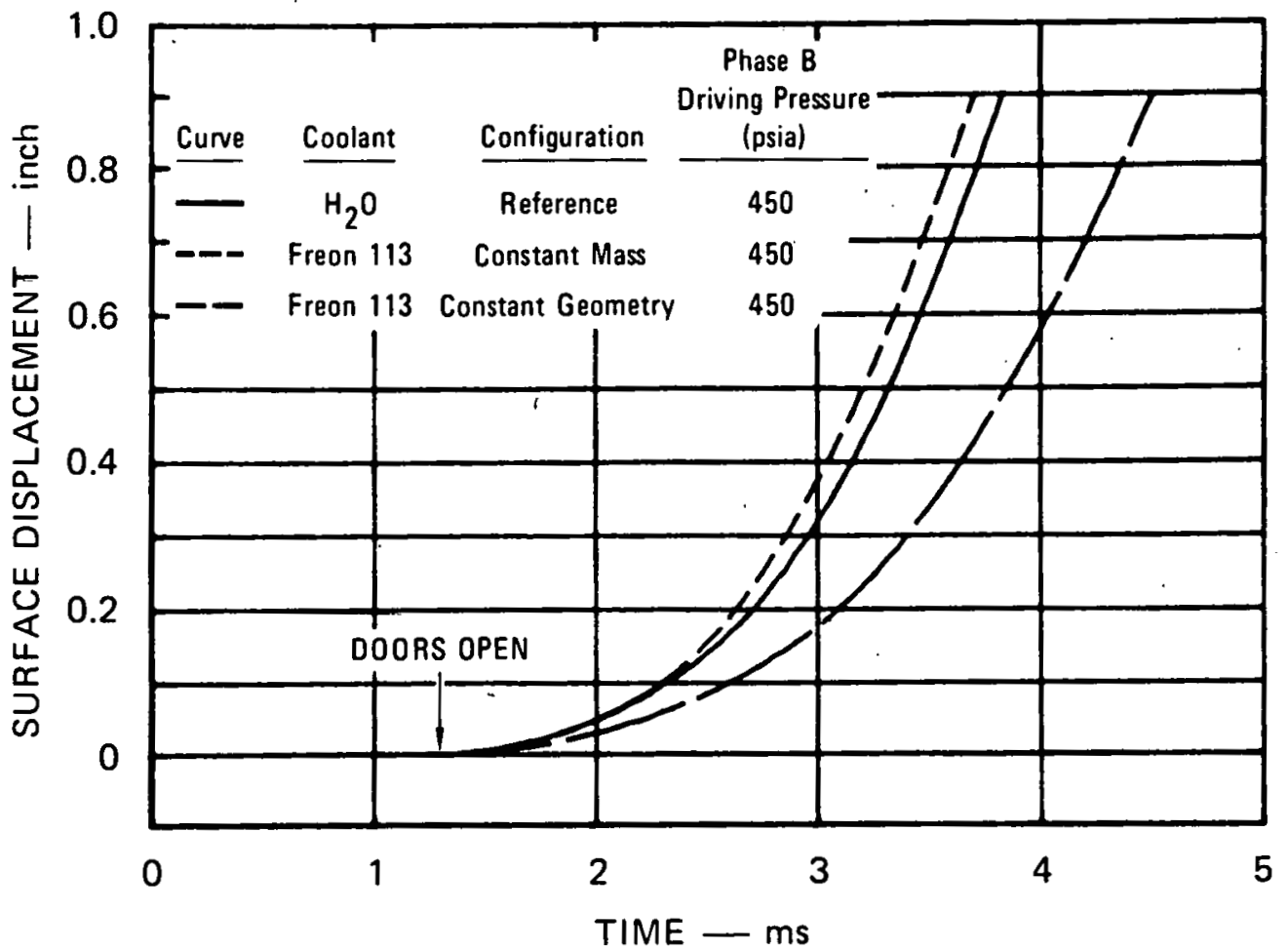

(a) GEOMETRY EFFECTS

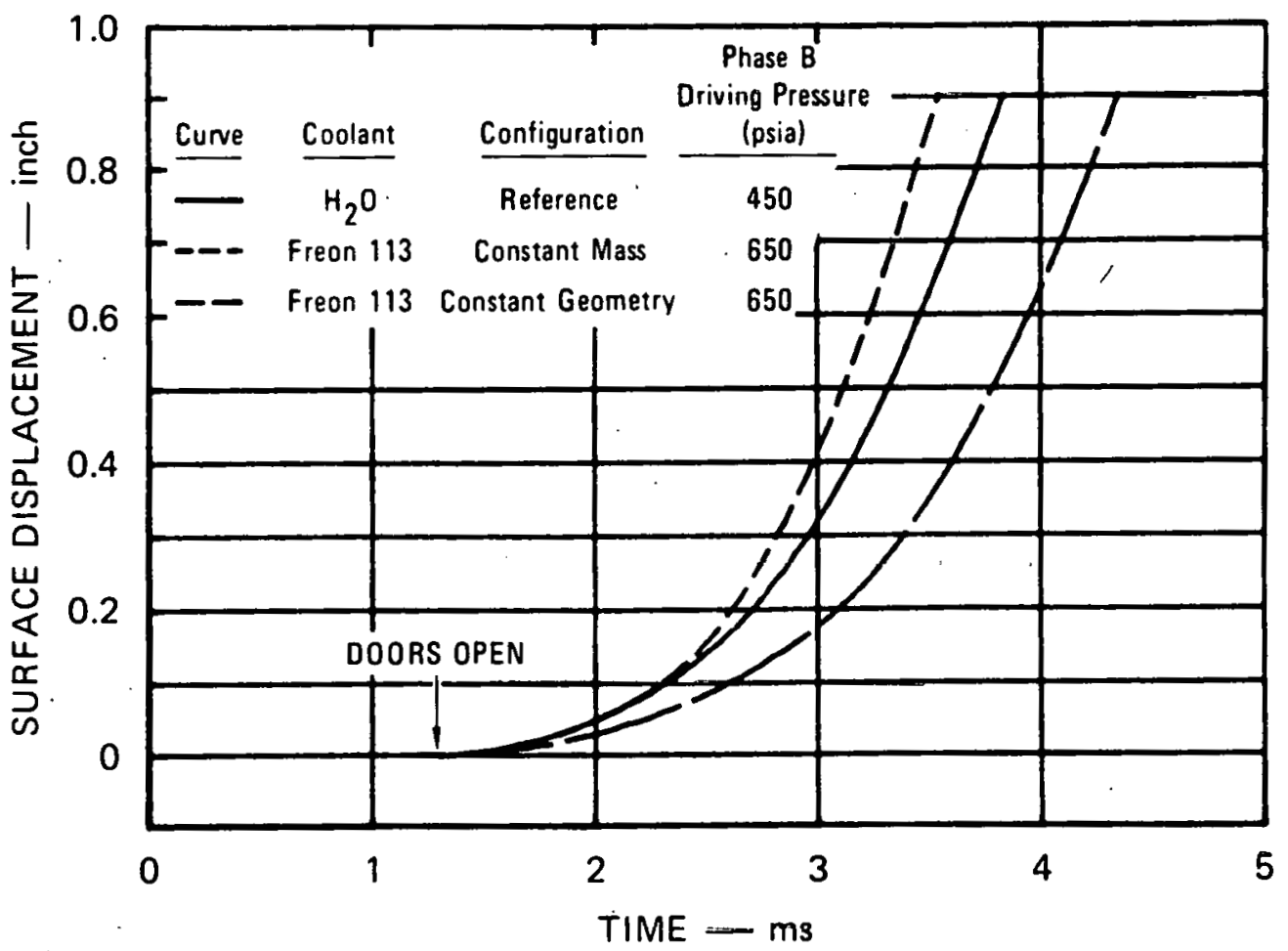

(b) VOLATILITY EFFECTS

MA-3929-527

FIGURE 50 COOLANT SURFACE DISPLACEMENT PREDICTIONS FROM SIMPLE MODEL WITH PHASE A DRIVING PRESSURE OF 650 nsia 
In Figure 50(a), we see that the coolant surface displacement in the constant mass case is similar to the reference case, whereas the constant geometry expansion with the heavier liquid proceeds more slowly. The constant mass case does not exactly reproduce the reference case because, although the initial acceleration is the same for each case, the shorter height of the upper core and the higher acceleration at a given time during phase $A$ of the constant mass expansion results in an earlier emptying of the upper core, i.e., a shorter phase A duration. Phase $A$ is $1.49 \mathrm{~ms}$ long in the reference case and $1.18 \mathrm{~ms}$ long in the constant mass case. Figure 50 (a) demonstrates the effert of experiment geometry on the coolant surface displacement with coolants of different density.

Figure 50(b) demonstrates the effect of coolant volatility. The pressure driving phase $B$ in the Freon expansion is increased from 450 psia to 650 psia to represent the higher bubble pressure seen in the Freon experiments (Figure 24). Relative to the Freon cases with a 450psia phase B driving pressure [Figure 50(a)], the Freon curves in Figure 50 (b) are shifted to the left; that is, these expansions proceed more rapidly. This demonstrates the additional effect of coolant volatility on the coolant surface displacement.

These calculations were made to get a qualitative sense of the independent effects of experiment geometry and coolant volatility. Experimental measurements of coolant surface displacement are shown in Figure 51. Quantitative comparison of slopes and times in Figures 50 and 51 should not be made because of the simple nature of the mathematical model used to generate Figure 50. Qualitative comparison should be made between the trend demonstrated in Figures 50 (a) and (b) and the trend demonstrated in Figures 51 (a) and (b).

In Flyurg 51 (d), the effecte of crperiment gcometry and coolant density are shown in the nitrogen bubble source experiments. The nitrogen source is not a constant pressure source (Figure D.7), so direct comparison between Figures $50(\mathrm{a})$ and $51(\mathrm{a})$ should not be made. The qualitative features of Figures $50(\mathrm{a})$ and 51 (a) are the same. The constant mass expansion is about $0.1 \mathrm{~ms}$ earlier than the reference expansion; the constant geometry expansion is about $0.5 \mathrm{~ms}$ later. 


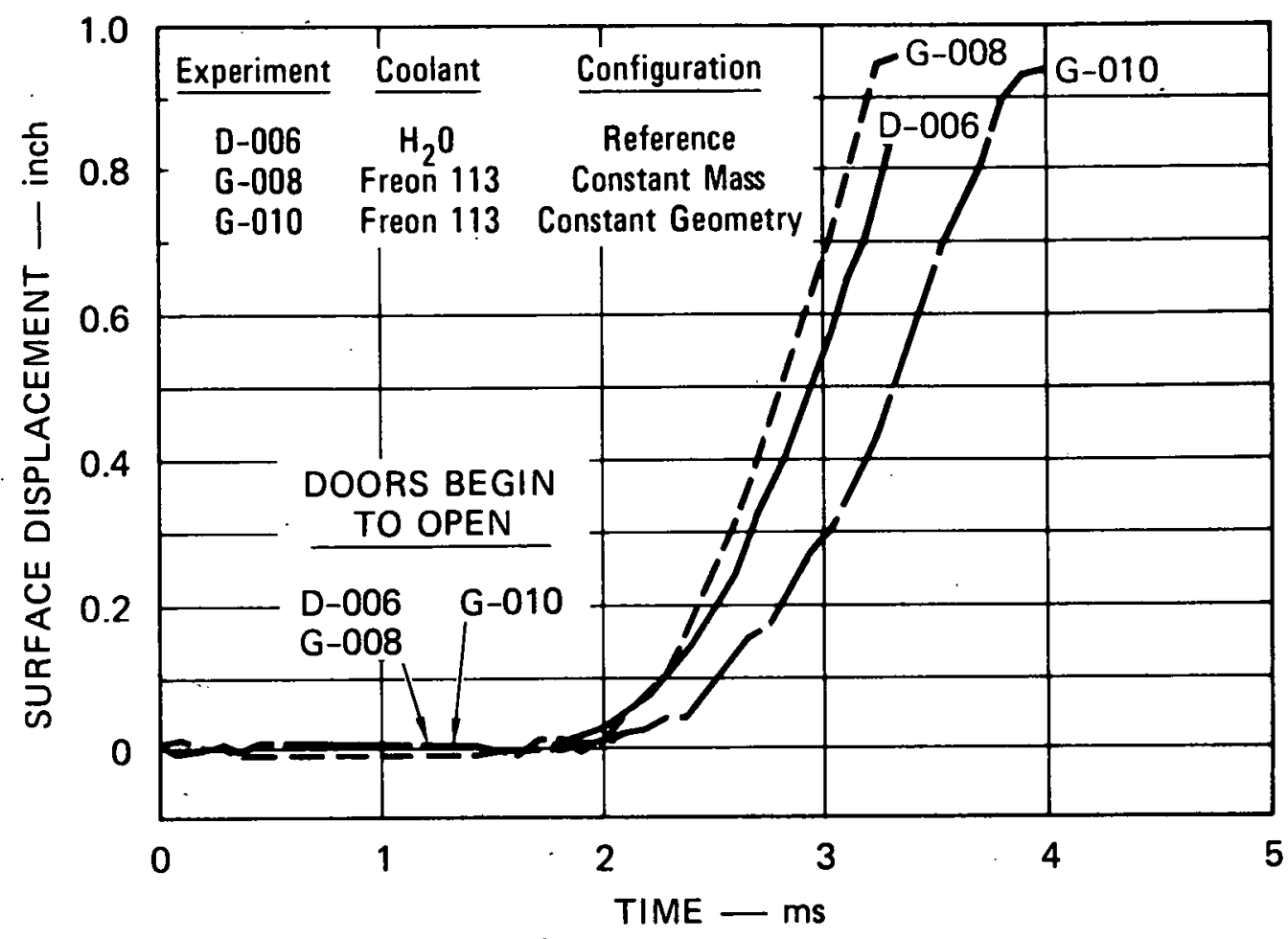

(a) GEOMETRY EFFECTS (Nitrogen Source)

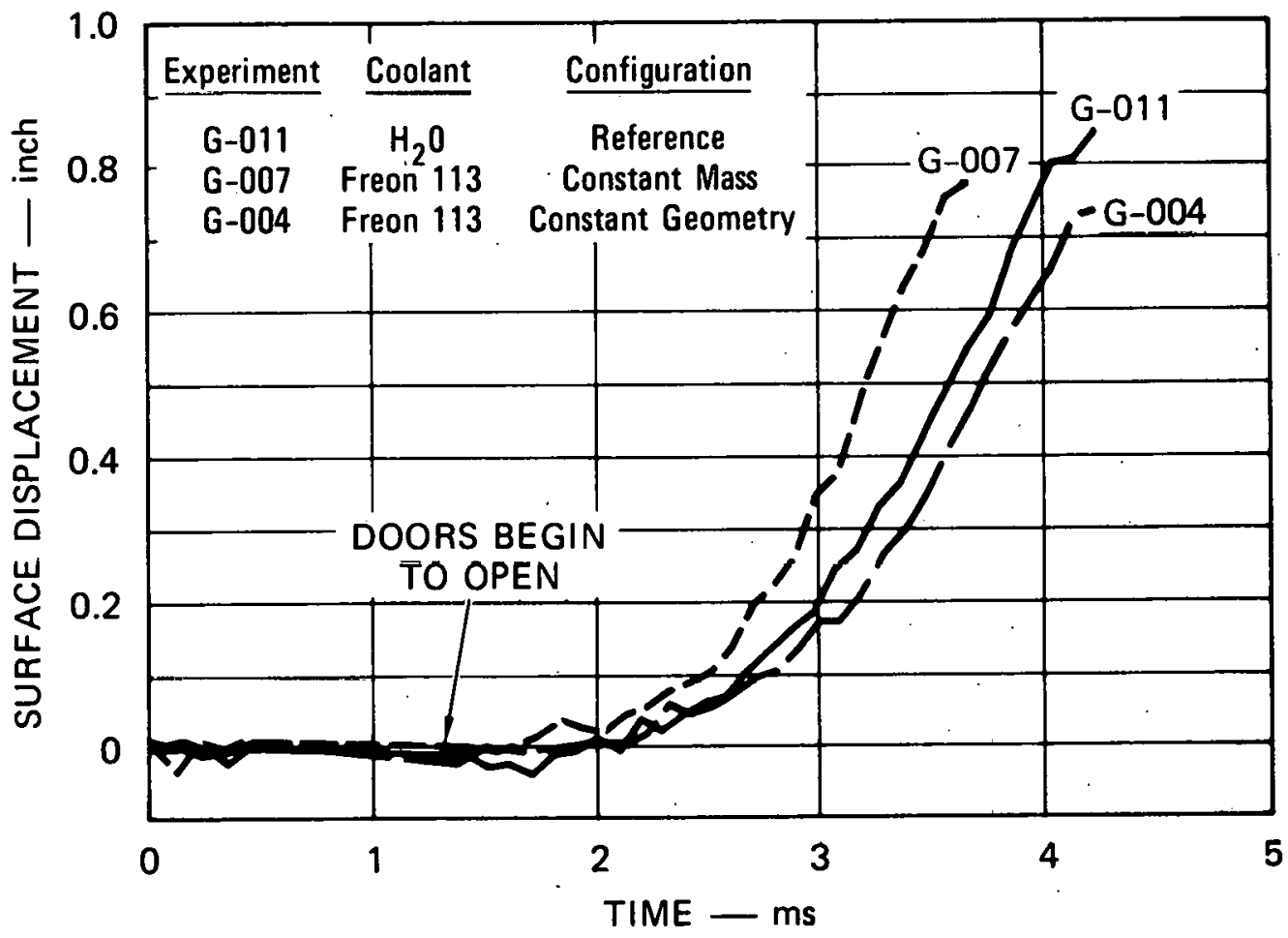

(b) VOLATILITY EFFECTS (Flashing Water Source)

MA-3929-526

FIGURE 51 COMPARISON OF GEOMETRY EFFECTS AND VOLATILITY EFFECTS ON COOLANT SURFACE DISPLACEMENT 
Figure 51(b) demonstrates the experimental effect of coolant volatility on the results of the flashing water bubble source experiments. In contrast to the nitrogen experiments, the constant mass experiment in Figure 51(b) is farther to the left of the reference than the constant mass is to the right. This earlier shift in time of the Freon experiments results from the higher pressures produced by the vaporization of the Freon. This shifting earlier in time was seen in the calculations in Figure 50(b) when compared with 50(a). Figures 50 and 51 thus demonstrate the separate effects of experiment geometry, coolant density, and coolant volatility. Together, they support our expectation that the higher pressures seen in the Freon experiments should have a demonstrable effect on the coolant surface displacement.

To consider the slug impact pressure and impulse, we view the coolant slug as a compressible material impacting on the completely rigid vessel cover with velocity $V_{I}$. The acoustic relation

$$
P_{I}=\rho c V_{I}
$$

where $\rho=$ coolant density and $c=$ coolant sound speed, can then be used to predict the impact pressure $P_{I}$. In two experiments with the same velocity but different coolant acoustic impedance, $\rho c$, different impact pressures would be expected. Table 11 compares the acoustic impedance of Freons 113 and 11 with that of water. Since the acoustic impedance of the Freons is $24 \%$ lower, the Freon experiments will produce lower impact pressure unless the impact velocity is at least $32 \%$ higher than in the water experiments. The following relations hold for these three coolants:

$$
\begin{array}{lll}
\mathrm{H}_{2} \mathrm{O}: & \mathrm{P}_{\mathrm{I}}(\mathrm{psi}) & =5360 \mathrm{~V}_{\mathrm{T}} \text { (inch/ms) } \\
\text { F113: } & \mathrm{P}_{\mathrm{I}} & =4069 \mathrm{~V}_{\mathrm{I}} \\
\mathrm{F11}: & \mathrm{P}_{\mathrm{I}} & =4086 \mathrm{~V}_{\mathrm{I}}
\end{array}
$$

It is desirable to compare predictions from the above relations with experimental measurements. Unfortunately, it is difficult to obtain good values for the slug impact velocity. and the slug impact pressure. The 


\section{Table 11}

\section{ACOUSTIC IMPEDANCE OF COOLANT SIMULANTS}

\begin{tabular}{|c|c|c|c|c|}
\hline Material & $\begin{array}{c}\text { Density, } \rho, \\
\text { at } 70^{\circ} \mathrm{F} \\
\left(\mathrm{lbm} / \mathrm{ft}^{3}\right) \\
\end{array}$ & $\begin{array}{c}\text { Sound Speed, c, } \\
\text { at } 68^{\circ} \mathrm{F} \\
(\mathrm{ft} / \mathrm{s}) \\
\end{array}$ & $\begin{array}{c}\text { Acoustic } \\
\text { Impedance,oc } \\
\left(\mathrm{lbm} / \mathrm{ft}^{2}-\mathrm{s}\right) \\
\end{array}$ & $\frac{\rho \mathrm{c}}{\rho \dot{\mathrm{c}}_{\mathrm{H}_{2} \mathrm{O}}}$ \\
\hline $\mathrm{H}_{2} \mathrm{O}$ & $62.3^{*}$ & $4860^{\oint}$ & $3.03 \times 10^{5}$ & 1.0 \\
\hline F113 & $98.3^{\dagger}$ & $2344^{* *}$ & $2.30 \times 10^{5}$ & 0.76 \\
\hline F11 & $92.7^{\ddagger}$ & $2489^{* *}$ & $2.31 \times 10^{5}$ & 0.76 \\
\hline
\end{tabular}

\footnotetext{
"From Reference 7.

tFrom Reference 9.

fFrom Reference 10.

$\oint$ From Reference 11.

**From Reference 12.
}

measured coolant surface displacement can be used to determine a coolant slug veloctty. However, since the displacement is obtained every $0.1 \mathrm{~ms}$ and since the coolant slug is decelerated by compression of the cover gas in less time than the $0,1 \mathrm{~ms}$ before slug impact, we do not have the date needed to calculate a slug impact velocity from the surface displacement. The coolant slug velocity before impact is certainly an upper bound on the impact velocity, although it is subject to about $20 \%$ error. The slug impact pressure pulse has many peaks, valleys, and spikes (see, for example, Figures 27 and 39), making it difficult to objectively characterize the impact pressure. The best approach to characterizing the impact pressure is to calculate the slug impact impulse as the area under the pressuretime curve for the first slug impact pulse and to model the pulse as an isosceles trapezoid with equal length sides and a width at the top onethird the width of the base. 
Table 12 compares the slug impact pressure and velocity based on the slug impact impulse and the coolant surface displacement. We see in the table that the coolant slug velocity provides an upper bound on the impact pressure. Characterizing the slug impulse by a shape different than the isosceles trapezoid shown will result in somewhat different numbers, but the coolant pool velocity will still provide an upper bound on the expected impact pressure. This is because (1) the impact velocity is lower than the measured slug velocity before impact, (2) the cover has a finite not an infinite acoustic impedance, and (3) the surface may not be perfectly flat. With the water coolant, the finite acoustic impedance of the cover reduces the impact pressure by about $10 \%$.

Table 12

\section{COMPARISON OF SLUG IMPACT PRESSURE AND VELOCITY, CONSTANT MASS EXPERIMENTS}

\begin{tabular}{|c|c|c|c|c|}
\hline \multirow[b]{2}{*}{ Experiment } & \multicolumn{2}{|c|}{$\begin{array}{c}\text { FROM: SLUG IMPACT } \\
\text { IMPULSE }\end{array}$} & \multicolumn{2}{|c|}{$\begin{array}{l}\text { FROM COOLANT SURFACE } \\
\text { DISPLACEMENT* }\end{array}$} \\
\hline & $\begin{array}{l}\text { Calculated } \\
\text { Impact } \\
\text { Pressuret } \\
\text { (psi) } \\
\end{array}$ & $\begin{array}{c}\text { Cálcuilàtèd } \\
\text { Impact } \\
\text { Velocity }{ }^{\ddagger} \\
\text { (in./ms) } \\
\end{array}$ & $\begin{array}{c}\text { Calculated } \\
\text { Impact } \\
\text { Pressure }{ }^{\prime} \\
\text { (nsi) } \\
\end{array}$ & $\begin{array}{c}\text { Coolant } \\
\text { Slug } \\
\text { Velocity } \phi \\
\text { (in./ms) } \\
\end{array}$ \\
\hline $\mathrm{G}-011\left(\mathrm{H}_{2} \mathrm{O}\right)$ & 1475 & $0: 28$ & 2950 & 0.55 \\
\hline G-007 (F113) & 2117 & 0.52 & 2725 & 0.67 \\
\hline G-009.(F11) & 2658 & 0.65 & 2985 & 0.73 \\
\hline \multicolumn{5}{|c|}{ "Yields an upper bound on the calculated impact pressure. } \\
\hline \multicolumn{5}{|c|}{$\begin{array}{l}{ }^{\dagger} \text { Assumes pressure pulse is an isosceles trapezoid with the width } \\
\text { at the top } 1 / 3 \text { the width of the base. }\end{array}$} \\
\hline
\end{tabular}


The slug impact impulse depends on the duration and shape of the slug impact pulse. This duration is primarily dependent on the time it takes for the slug impact shock to propagate from the cover down to the top of the bubble and return to the cover as an expansion wave. In other words, it depends on the sound speed, $c$, in the coolant (Table 5) and the distance between the cover and the bubble, $h$. If we express this mathematically, we can see how the impulse will vary in constant mass and constant geometry Freon experiments relative to $1 / 30$-scale water experiments.

$$
I \sim P_{I} \frac{h}{c} A
$$

where $A$ is the area of the vessel cover. From our discussion above, the impact pressure depends on the impact velocity, $V_{I}$, and the acoustic impedance; therefore,

$$
\mathrm{I} \sim \rho \mathrm{V}_{\mathrm{I}} \mathrm{hA}
$$

Since the product $\mathrm{phA}$ is approximately the mass, $\mathfrak{m}_{c}$, of coolant above the bubble at the time of slug impact, we expect that:

(1) In constant mass experiments

$$
I \sim \mathrm{V}_{\mathrm{I}}
$$

(2) In constant geometry experiments

$$
I \sim \mathrm{m}_{c} \mathrm{~V}_{\mathrm{I}}
$$

Based on the impulse values in Table 13, the Freon constant mass experiments had about a $29 \%$ higher impact velocity and the Freon constant geometry experiments had about a $20 \%$ higher impact velocity than the reference water experiments. These results--along with the coolant surface displacement comparison (Figures 50 and 51 ), the higher impact velocities obtained from the coolant surface displacements, and the higher impact pressures in the Freon experiments--combine to make a consistent and strong case for the measurable effects of coolant volatility on simulated HCDA bubble expansions. 
Table 13

SLUG IMPACT IMPULSE IN CONSTANT MASS

AND CONSTANT GEOMETRY EXPERIMENTS

\begin{tabular}{|c|c|c|c|c|}
\hline Configuration & Experiment & Coolant & $\begin{array}{c}\text { Initial Cover } \\
\text { Gas Gap } \\
\text { (inch) }\end{array}$ & $\begin{array}{c}\text { Impulse } \\
\text { (lbf-s) }\end{array}$ \\
\hline \multirow{3}{*}{$\begin{array}{l}\text { Constant } \\
\text { Mass }\end{array}$} & G-002 & $\mathrm{H}_{2} \mathrm{O}$ & 0.89 & 40.8 \\
\hline & G-011 & $\mathrm{H}_{2} \mathrm{O}$ & 0.86 & 38.9 \\
\hline & G-007 & $F 113$ & 0.77 & 51.1 \\
\hline . & G-000 & $F 11$ & 0.84 & 51.9 \\
\hline \multirow{4}{*}{$\begin{array}{l}\text { Constant } \\
\text { Geometry }\end{array}$} & G-002 & $\mathrm{H}_{2} \mathrm{O}$ & 0.89 & 40.8 \\
\hline & G-011 & $\mathrm{H}_{2} \mathrm{O}$ & 0.86 & 38.9 \\
\hline & G-003 & $F 113$ & 0.58 & 67.9 \\
\hline & G-004 & F11 & 0.73 & 75.7 \\
\hline
\end{tabular}




\section{CONCLUSIONS AND RECOMMENDATIONS}

In Sections III through VI, we have presented and characterized the measurements achieved in this experiment series. A summary of these results is presented in Table 14. In the table, the expansion time (siug impact time) and slug impact impulse are presented along with the initial lower core pressure and cover gas gap for the ten experiments. For convenience, the reference water experiments (G-002 and G-011) appear more than once. Comparisons among these experiments and a few experiments from our earlier work ${ }^{l}$ have provided conclusive evidence that the thermodynamic interaction of fuel and coolant influences the expansion dynamics and cover loading of simulated HCDAs. Vaporization of some of the coolant that is entrained in the bubble and mixes with hot steam contributes a partial pressure to the bubble and thereby increases the pressure pushing the coolant slug upward to the vessel cover.

Pressure measurements in the flashing water constant mass experiments provide the strongest direct evidence of this conclusion. Pressure in the upper core and expanding bubble of the Freon experiments was on the order of $50 \%$ higher than in the water experiments. When these pressures were used in conjunction with the displacement history of the coolant surface to derive the expansion work done on the coolant slug, it was found that the expansion work was about $25 \%$ higher in the Freon experiments. Little difference was found between the results of the Freon 113 alld Fieun 11 experiments.

In Section VII, the coolant surface displacement and cover loading in all the experiments without internal structures were compared. These are integral measures of the expansinn history. Comparison between the coolant surface displacement in nitrogen source experiments, in which volatility effects are absent, with flashing water source experiments, in which they are present, provided strong evidence that volatility effects accelerate the expansion and shift the surface displacement curves earlier in time. Support for this conclusion was provided by the use of a simple 
Table 14

\section{SUMMARY OF EXPERIMENTAL RESULTS}

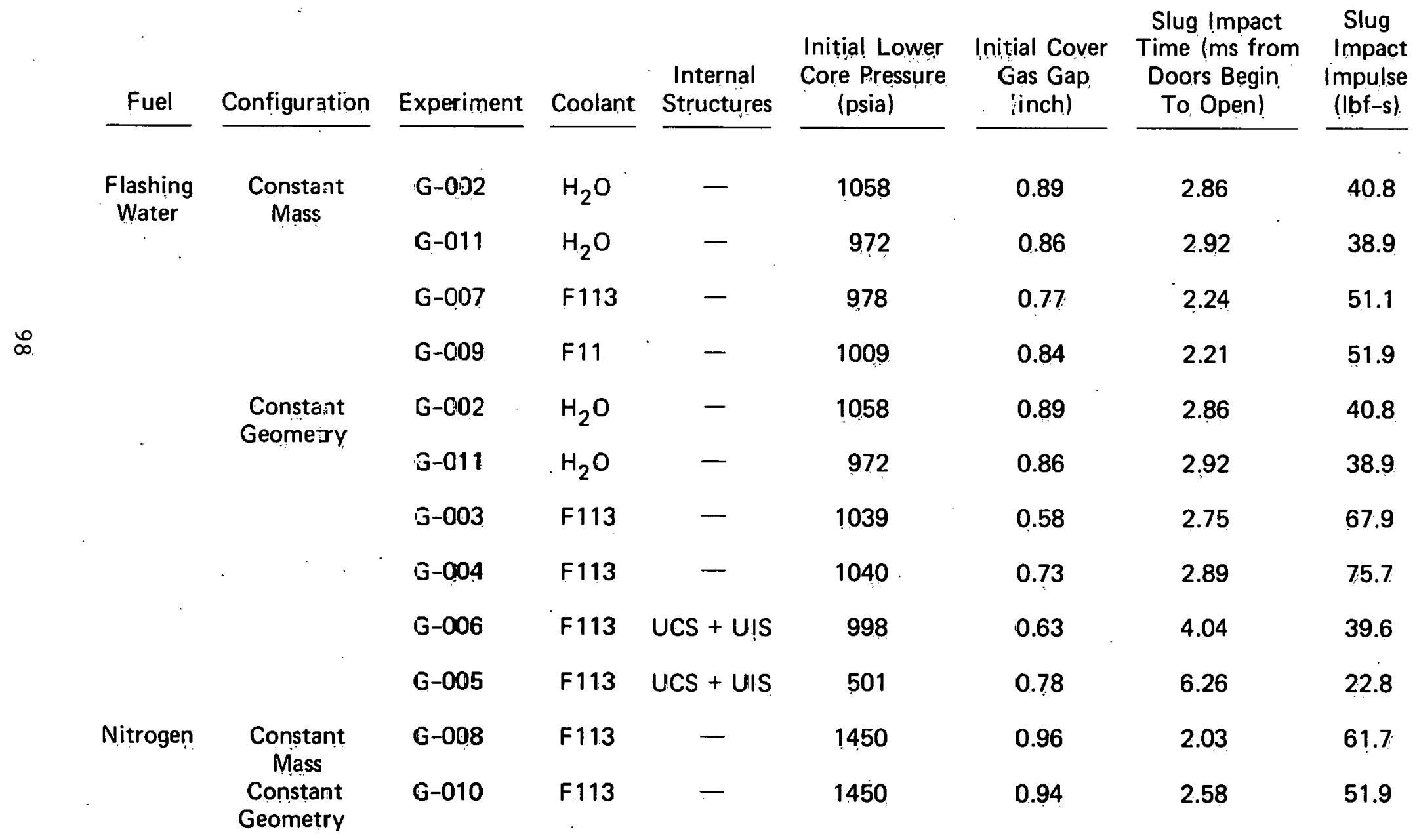


mathematical model of the expansion. Evidence for the higher impact velocities associated with the faster displacements was obtained from the slug impact pressures and slug impact impulses. The impact impulse was $29 \%$ higher in the Freon constant mass experiments than in the water experiments. This implies an approximately $29 \%$ higher impact velocity in these Freon experiments.

The bubble volume and entrainment within the bubble were within the range typical of our previous HCDA simulations. ${ }^{1,3}$ Entrainment is at least $60 \%$ of the bubble volume as the bubble emerges from the upper core into the pool. Entrainment in the upper core is certainly even higher. Entrainment at slug impact ranges from $20 \%$ to $40 \%$ of the bubble volume. The percentage of entrainment decreases during the expansion because the bubble grows faster than liquid is entrained into it. Although percentage entrainment decreases during the expansion, the entrained volume of liquid increases from about 5 cubic inches as the bubble enters the pool to about 20 to 30 cubic inches at slug impact. Entrainment in the upper core is due to the significant mixing that occurs as the sliding doors open. Entrainment in the pool occurs in the dissipating vortex at the lateral periphery of the bubble and at the bubble-coolant interface.

The location of vortices within the coolant pool depends on the geometry of the internal structures. With an open upper core, a vortex ring forms just above the upper core due to convection from the upper core into the pool of a viscous liquid layer that forms at the wall of the upper core. This vortex is engulfed by the bubble and entrains liquid into the bubble by the circulation it creates at the lateral periphery of the bubble. With a UCS or a UIS, other vortices are tormed, which entrain coolant into the bubble.

Temperature measurements in the HCDA bubble of flashing water source experiments were attempted for the first time in this experiment series. The thermocouple was located approximately $1 / 2$ to 1 inch above the core depending on the experiment and approximately 0.7 inch off-axis. The measured temperature increases with time as the bubble passes over the thermocouple, indicating a temperature gradient through the bubble and providing evidence for a fairly thick mixing layer inside the bubble 
boundary. Temperatures in the bubble varied between $100^{\circ} \mathrm{F}$ when the bubble reached the thermocouple and $350^{\circ} \mathrm{F}$ at slug impact. This compares with a steam temperature no higher than $500^{\circ} \mathrm{F}$ for saturated steam emerging from the lower core at $700 \mathrm{psi}$. Further measurements are needed to map the bubble temperature field and structure.

The effect of upper core and upper internal structures on the expansion dynamics and cover loading is qualitatively the same whether the coolant is Freon 113 or water. The structures slow the expansion and thereby reduce the coolant surface velocity, slug impact pressure, and slug impact impulse. The presence of both structures reduced the slug impact impulse $56 \%$ in the water case and $45 \%$ in the Freon case. In two experiments with Freon 113 coolant and both internal structures, reducing the pressure in the lower core by a factor of 2 reduced the impulse on the cover by $42 \%$. We predict that in constant mass Freon experiments with a UCS and a UIS, the attenuating effects of internal structure would reduce cover loads on the order of $50 \%$.

The major conclusions can be summarized as follows:

- In the constant mass flashing water bubble source experiments:

- The upper core and bubble pressures were on the order of $50 \%$ higher than in the water experiment.

... The expansion work at a coolant surface displaced volume of 35 cubic inches was $25 \%$ higher than in the water experiment.

- The slug impact impulse was on the order of $29 \%$ higher than in the water experiment.

- The temperature in the bubble varied between $100^{\circ} \mathrm{F}$ when the bubble reached the thermocouple and $350^{\circ} \mathrm{F}$ at slug impact.

- In all txpeiments without internal atrur.turcc, the entrainment at slug impact was $20 \%$ to $40 \%$ of the bubble volume.

- Internal vessel structures reduced the slug impact impulse by $45 \%$ using Freon 113 coolant compared with $56 \%$ using water as the coulant.

- In experiments with internal vessel structures, reducing the lower core pressure by a factor of 2 reduced the slug impact impulse by $42 \%$. 
Future work in this area should entail 1/30-scale experiments that address aspects of the expansion dynamics about which the most questions remain. These areas include the forces on the UCS and UIS and on the wall of the acrylic vessel, the mechanisms of mixing and entrainment in the upper core and bubble, the composition of the bubble, the attenuation effects of heat transfer with a more prototypic upper core structures, and the temperature distribution in the bubble. Questions also still remain about the scaling of thermodynamic phenomena observed in these experiments and application of our results to the demonstration size LMFBR and the newly proposed 1000-MW plant. 
THIS PAGE

\section{WAS INTENTIONALLY \\ LEFT BLANK}

102 


\section{REFERENCES}

1) Tobin, R. J., and Cagliostro, D. J., "Effects of Vessel Internal Structures on Simulated HCDA Bubble Expansions," Technical Report 5, SRI International Project PYU-3929, Menlo Park, CA (November 1978).

2) Romander, C. M., and Cagliostro, D. J., "Experimental Simulation of a Hypothetical Core Disruptive Accident in 1/20-Scale Models of the Clinch RIver Breeder Reactor," Technical Report 4, SRI International Project PYU-3929, Menlo Park, CA (October 1978).

3) Ploeger, D. W., and Cagliostro, D. J., "Development and Characterization of a Liquid-Vapor Bubble Source for Modeling HCDA Bubbles," Technical Report 2, SRI International Project PYU-3929, Menlo Park, CA (March 1977).

4) Booth, D. L., "Fireball-P.V.T., A Computer Program for the Thermodynamics of a Substance Instantaneously Heated to a Very High Temperature," United Kingdom Atomic Energy Authority, Nuclear Design and Construction Limited (NDC-RI16, FRPC/RSWP/P (67) 130).

5) "Radlological Assessment Models, Eighth Quarterly Report, JuneAugust 1976," GE-FBRD, September 1976 (GEAP-14034-8).

6) Fink, J. K., and Liebowitz, L., "Thermophysical Properties of Sodium," ANL-CEN-RSD-79-1 (May 1979).

7) ASME Steam Tables, 3rd Edition (1977).

8) Freon Fluorocarbons: Properties and Applications, E. I. du Pont Pub1. B-2 (1969).

9) Thermodynamic Properties nf "Freon 113," E.I. du Pont Pub1. T-113A (1938).

10) Thermodynamic Properties of "Freon 11," E.I. du Pont Pub1. T-11 (1965).

11) Baumeister, T., et. al., Mark's Standard Handbook of Mechanical Engineers, Eighth Ed., McGraw-Hil1. (1978).

12) Meyer, K. J., "The Connection Between Sound Velocity and Heat Conductivity of Liquid Flouro-chloro-derivatives of Methane and Ethane," Kä1tetechnik-K1imatisierung, Vo1. 21, No. 9 (1969). 
Appendix A

APPARATUS AND INSTRUMENTATION

\section{Lower Core}

The lower core, which contains the bubble source material, is shown in detail in Figure $\Lambda .1$. The lower core is designed according to ASME pressure vessel codes for a maximum of 3000 psi at $700^{\circ} \mathrm{F}$. The interior is 3.75 inches in diameter and 5 inches long with a total measured volume of 59.9 cubic inches (including the passage in the rigid base plate and with all internal pieces in place). The interior is chrome-plated to prevent corrosion.

The heating element is made from 718 Inconel sheet, 0.021 inch thick, with a total surface area of 50.25 square inches. It is supported by three stainless steel stands with alumina insulators at each mounting point. The electrical feedthroughs are 1/2-inch-diameter copper.: A hard-anodized aluminum block insulates the lower feedthrough from the vessel. Power is supplied by a $400 \mathrm{~A}, 40-\mathrm{V}$ dc welding generator. The welder permits fine control of the temperature in the vessel. The vessel is completely filled with water during the heating process. Heating from room temperature to $600^{\circ} \mathrm{F}$ requires approximately five minutes.

Figure A.2 is a schematic of the heating and pressurization system used in the experiments. The water pressure is controlled by nitrogen gas with a manostat. The manostat consists of two pressure chambers separated by a movable piston and rolling diaphragm. The bottom chamber is connected to the lower core pressure vessel, and the top chamber is pressurized with nitrogen by the system shown in Figure A.2. The manostat has an effective piston area of 26.0 square inches and a total stroke of 5.42 inches for a maximum volume change of 141 cubic inches. It, too, is built to ASME code specifications for $3000 \mathrm{psi}$ at $700^{\circ} \mathrm{F}$. The maximum allowable pressure differential across the diaphragm itself is 250 psi. 


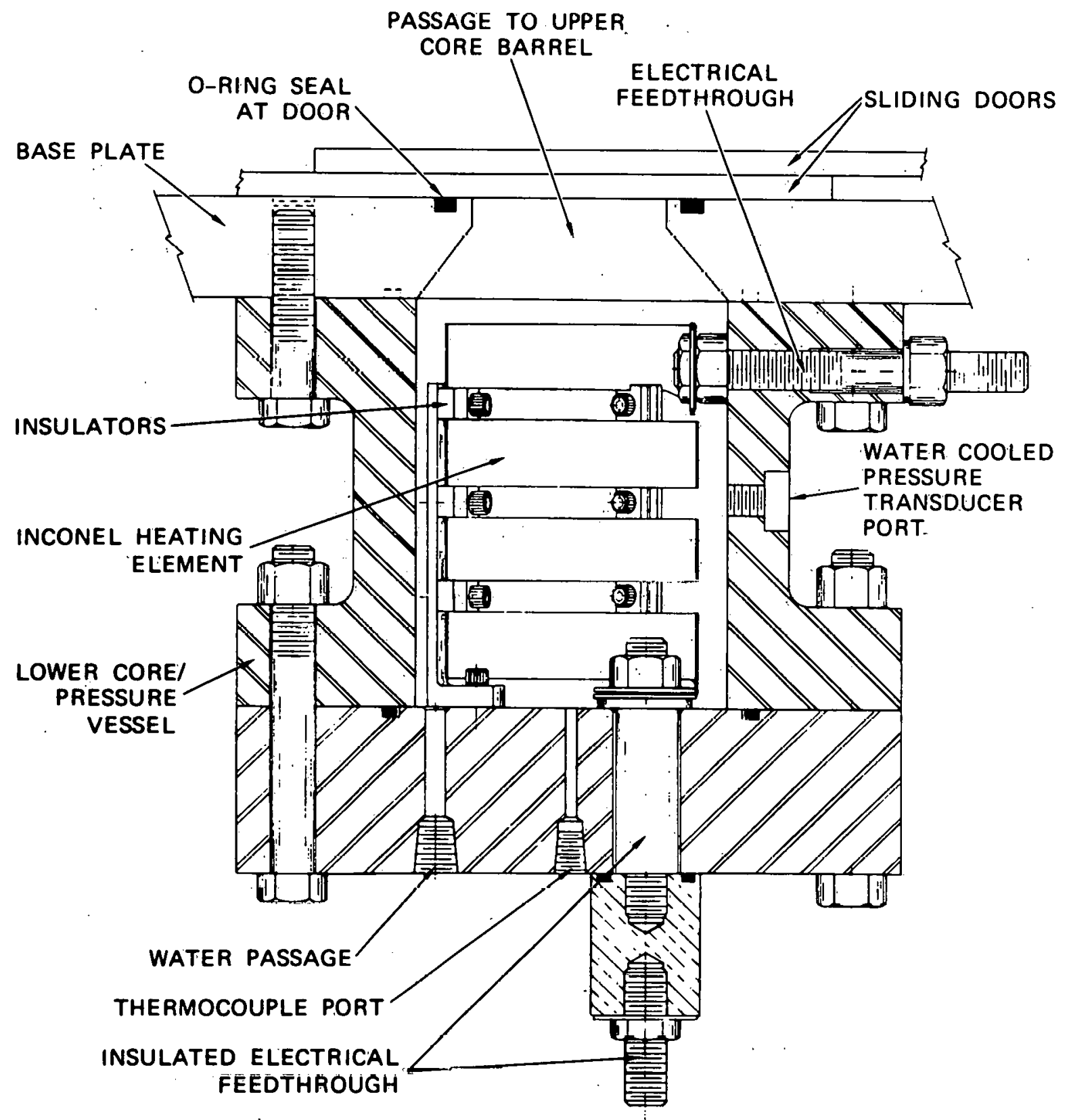

MA-3929-70A

FIGURE A.1 LOWER CORE DETAIL 


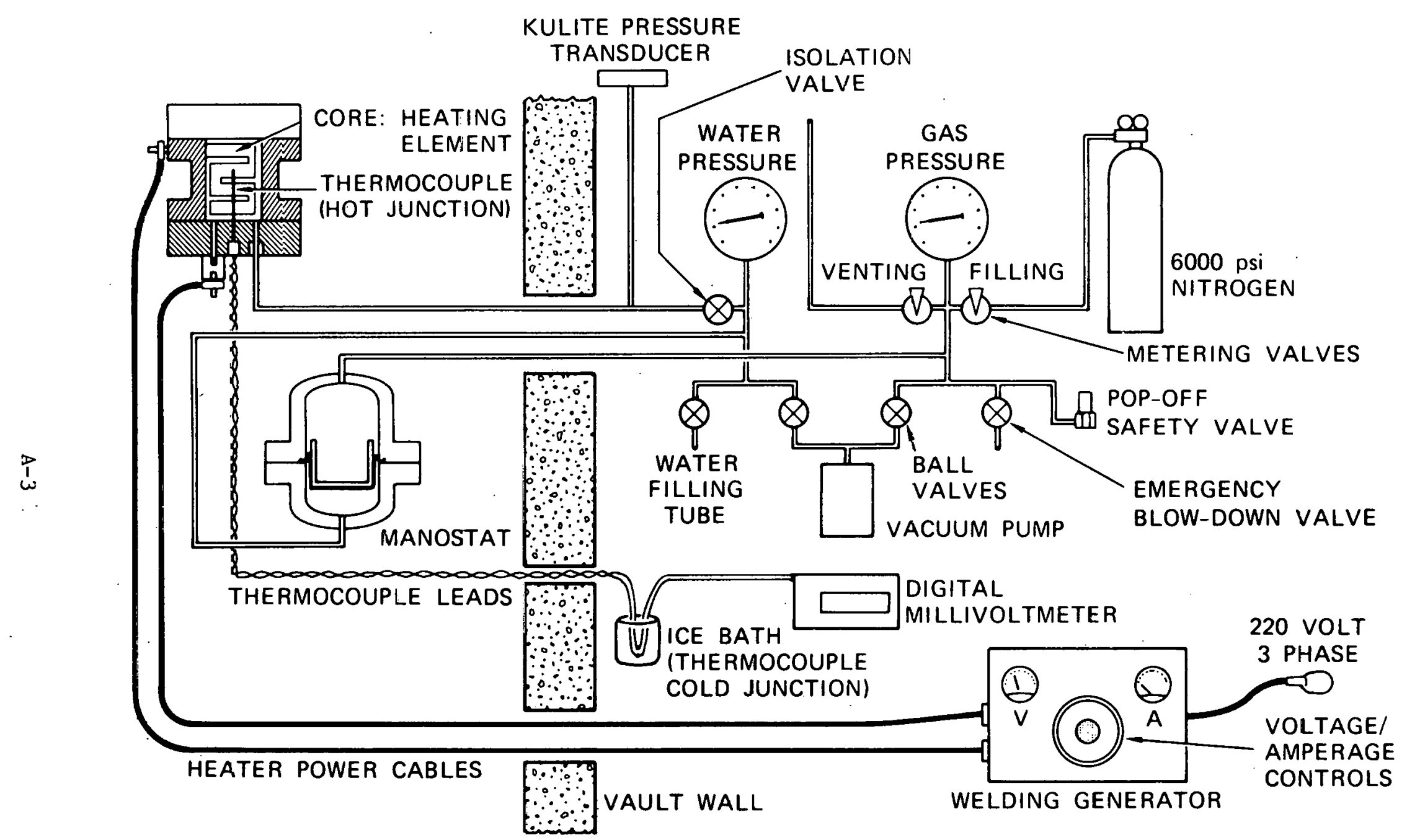

$M A-3929-65 A$

FIGURE A.2 HEATING AND PRESSURE CONTROL SYSTEM 
Nitrogen gas is supplied by a 6000-psi bottle and rcgulator. All. the pressure lines are 1/4-inch-outside-diameter, 0.028-inch-wall, stainless steel tubing with a maximum pressure rating of 6000 psi. The fittings and valves are stainless steel. A pop-off safety valve set to 3100 psi is mounted on the gas piping system to prevent overpressure. The valves, gages, bottle, and regulator are mounted on a portable control panel. The lower core pressure vessel and the manostat are isolated from the operator in a separate room; as shown in Figure A.2.

With a nitrogen source, a gas bottle was used to fill the lower core to the desired pressure. With a saturated zero-quality high-pressure water source, the water for the bubble was brought to the desired initial. state by heating it under pressure. Figure A.3 is a pressure-specific volume diagram for water showing the procedure used to heat the bubble material. To reach any zero quality ${ }^{*}$ initial state (saturated liquid; point D, Figure A.3.), the water pressure is first raised, at room temperature, from atmospheric pressure (point A.) to a pressure slightly higher than the desired pressure (point B). The water is then heated to the desired initial temperature (point $C$ ) while the pressure is kept constant by bleeding gas out the top chamber of the manostat. The pressure is lowered at constant temperature to the desired value for the experiment (point D).

If the experiment requires a higher quality steam as the initial state (point D', for example), a. slightly different procedure is followed. The water is pressurized to a point ( $\left.\bar{B}^{\prime}\right)$ above the critical pressure and heated at that pressure to a predetermined temperature that gives the desired speclfic volume ( $\left.C^{\prime}\right)$ for the initial statc. The waler is then cooled at constant specific volume until the desired initial pressure 13 reached $\left(D^{\prime}\right)$.

* When a substance exists as part liquid and part vapor at the saturation temperature, its quality is defined. as the ratio of the mass of vapor to the total mass. Quality has meaning only when the substance is in a saturated state, i.e., at saturation pressure and temperature. 


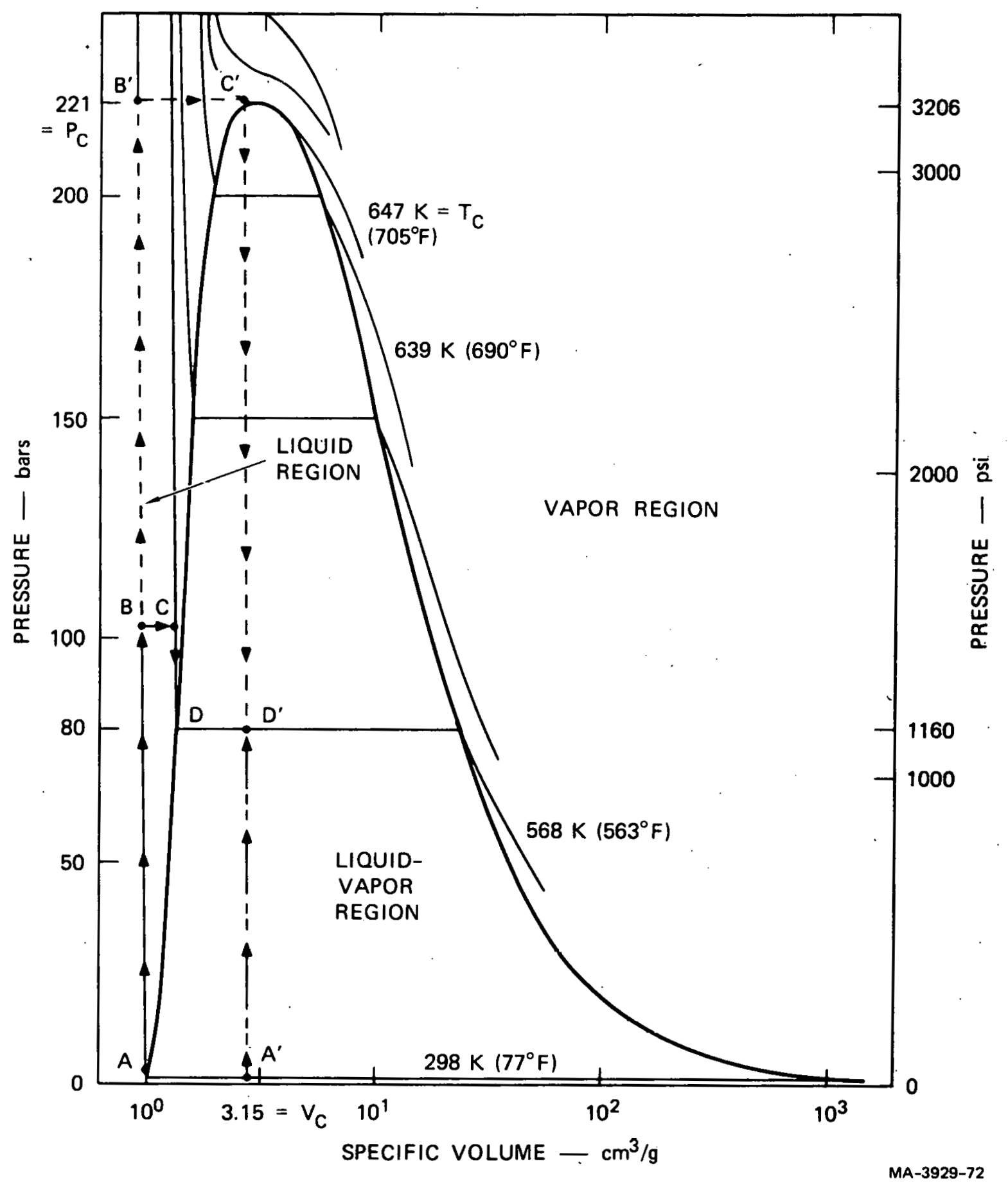

FIGURE A.3 WATER HEATING DIAGRAM 
This heating method has the advantages of:

- Keeping the bubble material liquid while it is being heated, which allows more efficient heat transfer between the heating element and the bubble material than would a two-phase or an all-vapor mixture.

- Making the temperature, pressure, and specific volume easier to control than other schemes, such as heating a measured mass of water to a precise final temperature in a vessel of fixed, measure volume, as shown by line $A^{\prime}-D^{\prime}$ in Figure A.3.

\section{Sliding Door Pressure Release Mechanism}

Before the experiment can begin, the heated, pressurized water in the lower core must be released into the upper core barrel by opening the passage between them. The passage must be opened completely in a time much shorter than the expansion time of the bubble in the vessel to ensure that the expansion of the bubble will not be affected by the way the passage is opened. An opening time one-tenth of the expansion time of the bubble in the vessel was considered adequate. Additionally, the pressure release mechanlsm must not interfere with the flow out of the lower core or release any debris into the vessel.

The bubble material in the lower core is released by opening the passage between the lower and upper core barrel shown in Figure A.1. The passage is sealed by two flat doors, one atop the other, that can slide in opposite directions. Each door is attached to a piston in a cylinder driven by the pressure from the detonation of low density explosive. The cylinders are mounted rigidly in a frame to which the base plate of the reactor is attached. Figure A.4 is a schematic of the door-piston-cylinder assembly.

The doors used in the experiments are made of 7075-T6 aluminum, and are 3.2 inches wide and 0.285 inch thick. They slide between the base plate and the bottom plate of the reactor model as shown in Figure A.1. Spacers set the proper clearance, 0.003 inch, between the doors. Sealing is achieved with Viton 0-rings on the bottom side of the lower door and the top side of the upper door. 


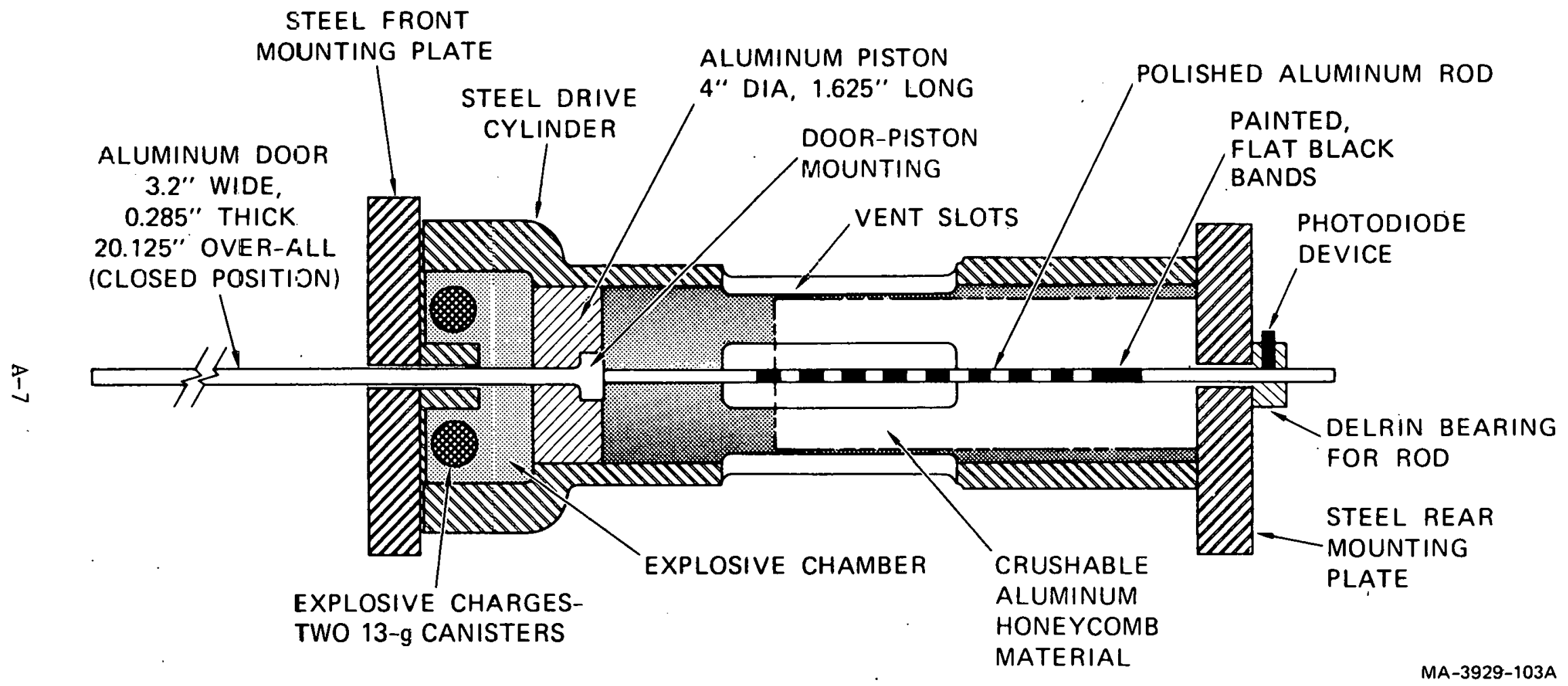

FIGURE A.4 DOOR-PISTON-CYLINDER ASSEMBLY 
As seen in Figure A.4, a boss on the leading edge of the dour fits into a slot in the front of the piston, providing a lightweight attachment. The piston is 4.0 inches in diameter and 1.625 inches Iong. The door serves to stabilize the piston in the cylinder. The cylinder has a hard-chrome-plated bore to minimize scoring.

The explosive is a mixture of $90 \mathrm{wt} \%$ PETN $^{*}$ explosive powder and 10 wt\% plastic microspheres. A $26-g$ charge (in two $13-g$ paper canisters, one on each side of the door) is used in each cylinder. Each 13-g canister is connected to its mate by Detasheet ${ }^{\dagger}$ fuse, 0.25 inch wide and 0.042 inch thick. The charges in each cylinder are linked with equal lengths of Detasheet fuse to a common point for detonation.

Figure A.5(a) shows the piston-door assemblies in the closed position. Detonation of the low-density explosive drives the pistons outward. As the pistons move apart, the doors are pulled one over the other and out the passage.

The doors slide 3 inches before they begin to reach the high velocity needed for adequate opening times, with relatively low acceleration levels. The 26-g explosive charge yields a maximum pressure of 5780 psi and a maximum acceleration of $6.1 \times 10^{6} \mathrm{in} . / \mathrm{sec}^{2}$. The average velocity during the opening is $4800 \mathrm{in.} / \mathrm{sec}$ for an opening time of $230 \mathrm{\mu sec}$. Figure A.5(b) shows the doors as they begin to open the passage between the lower and upper cores. Once the passage is open, Figure A.5(c), after a total motion of 4.14 inches, the piston uncovers slots in the side of the cylinder that vent the explosive gages to the atmosphere. The energy of the piston door assembly is absorbed through crushing aluminum honeycomb material in the rear portion of the cylinder.

${ }_{\text {PETN }}\left(\mathrm{C}_{5} \mathrm{H}_{8} \mathrm{O}_{12} \mathrm{~N}_{4}\right)$ pentaerythritol tetranitrate.

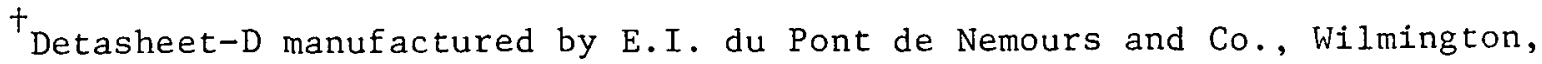
Delaware. 
(a)

CLOSED POSITION

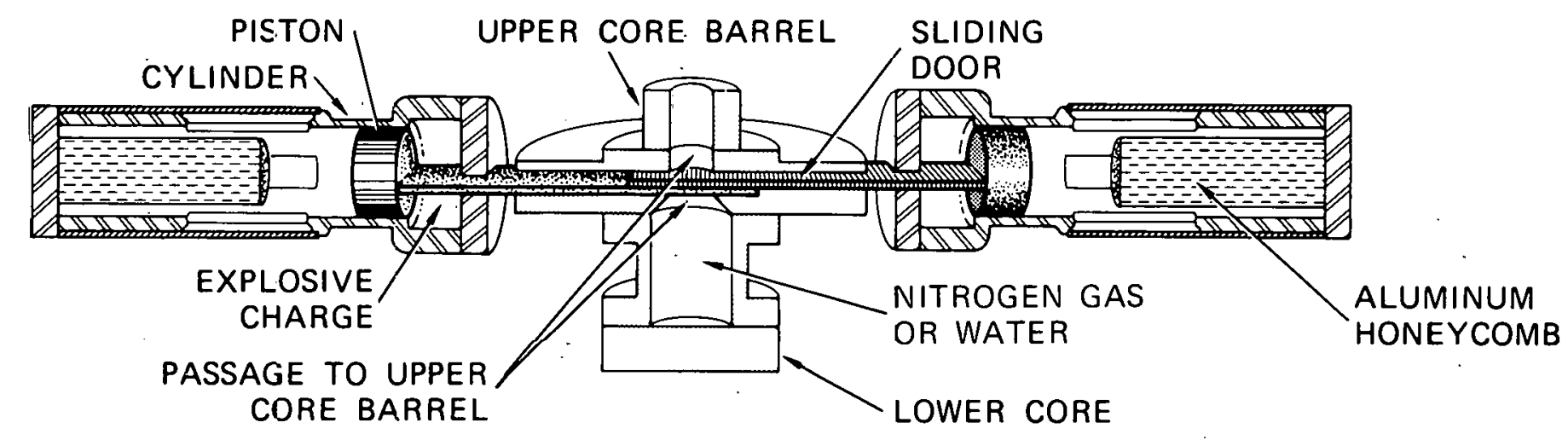

(b)

DOORS BEGIN TO OPEN .

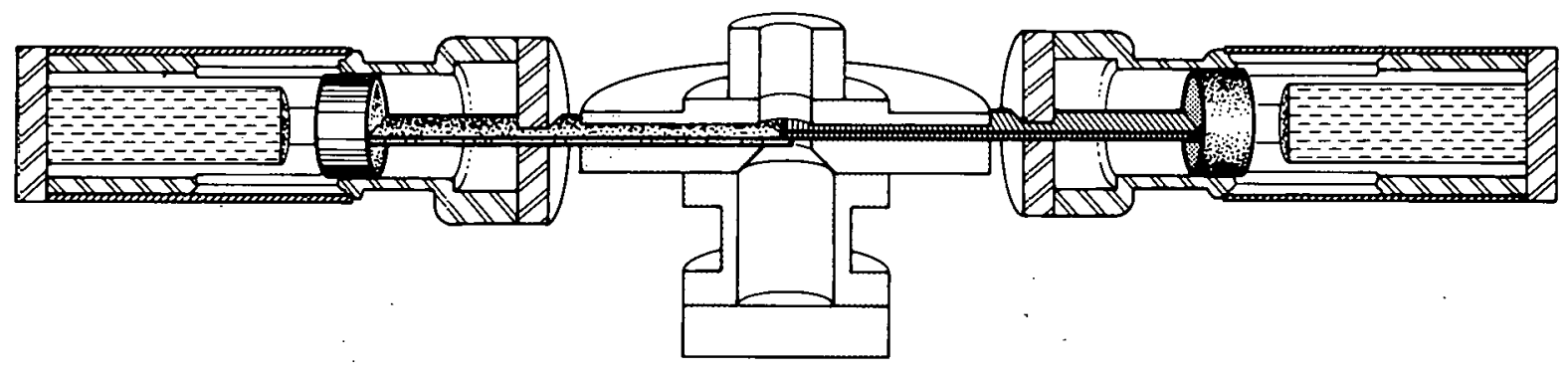

(c)

OPEN POSITION

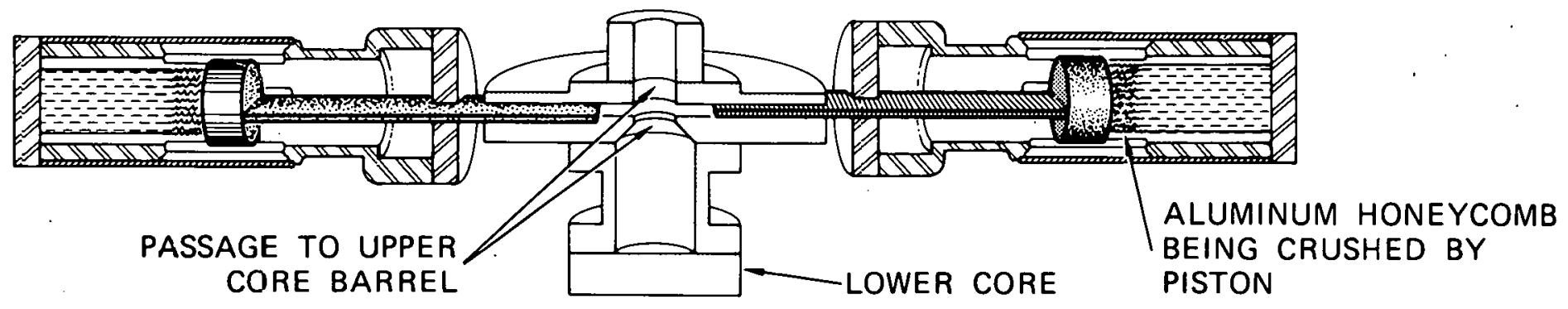


Analysis of the nitrogen experiment results includes consideration of the work performed by the lower core gas. As the sliding doors move, they make available volume, which the high pressure lower core gas can fill in a free expansion (constant energy) process. This reduces the lower core pressure and alters the history of work performed on the upper core and pool fluids. Analysis of these experiments as well as the flashing water bubble source experiments requires a consideration of the influence of this door volume on the experiment dynamics. Figure A.6 presents the nominal door opening sequence. Representative measurements of the sliding door displacement are plotted and tabulated in Figure A. $\overline{7}$ and Table A.1, respectively.

\section{Instrumentation}

The door opening time is measured by a photodiode device that can detect differences in the reflectivity of a surface. A polished aluminum rod mounted to the front of the piston runs through a hole in the cylinder mounting plate and slides in a Delrin bearing mounted to the end-plate (shown in Figure A.4). The photodiode is mounted to the bearing so that it can measure the reflectivity of the rod surface. A dull black band painted around the rod is positioned so that when the door begins to open, the front of the band is at the photodiode and when the opening is complete, the end of the band is at the photodiode. Additional 1/2-inch-1ong bands spaced $1 / 2$ inch apart allow measurement of the door displacement history. A large change in the photodiode output (3 to 4 volts) results when moving from the polished to the dull black surface. Thus, the output of the photodiode during an experiment is a series of square pulses that start when the door opening begins and stop when the opening is complete. The output is recorded on both an oscilloscope and a high-speed Bell and Howell tape recorder. 


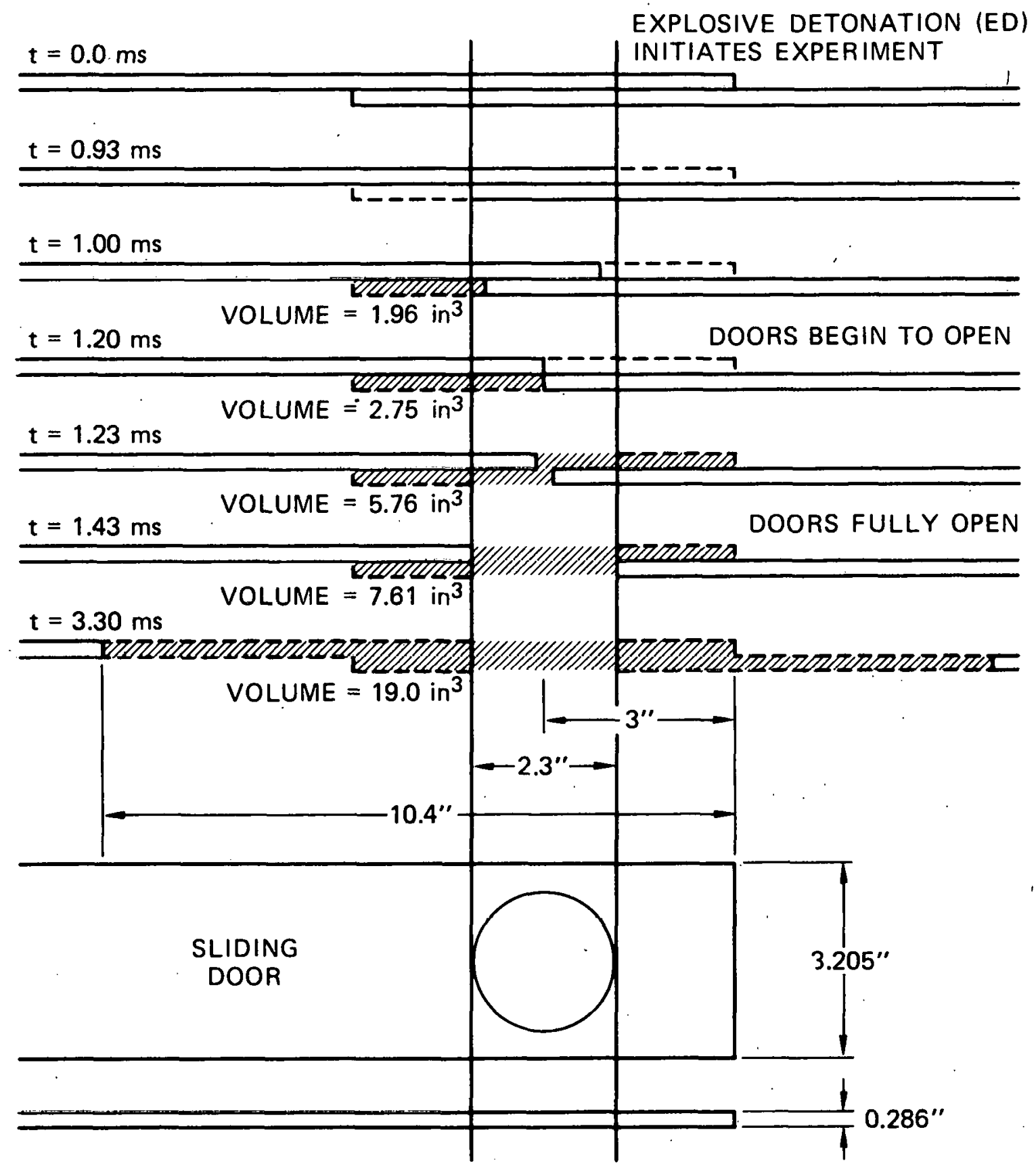

MA-3929-324A

FIGURE A.6 NOMINAL DOOR OPENING SEQUENCE 


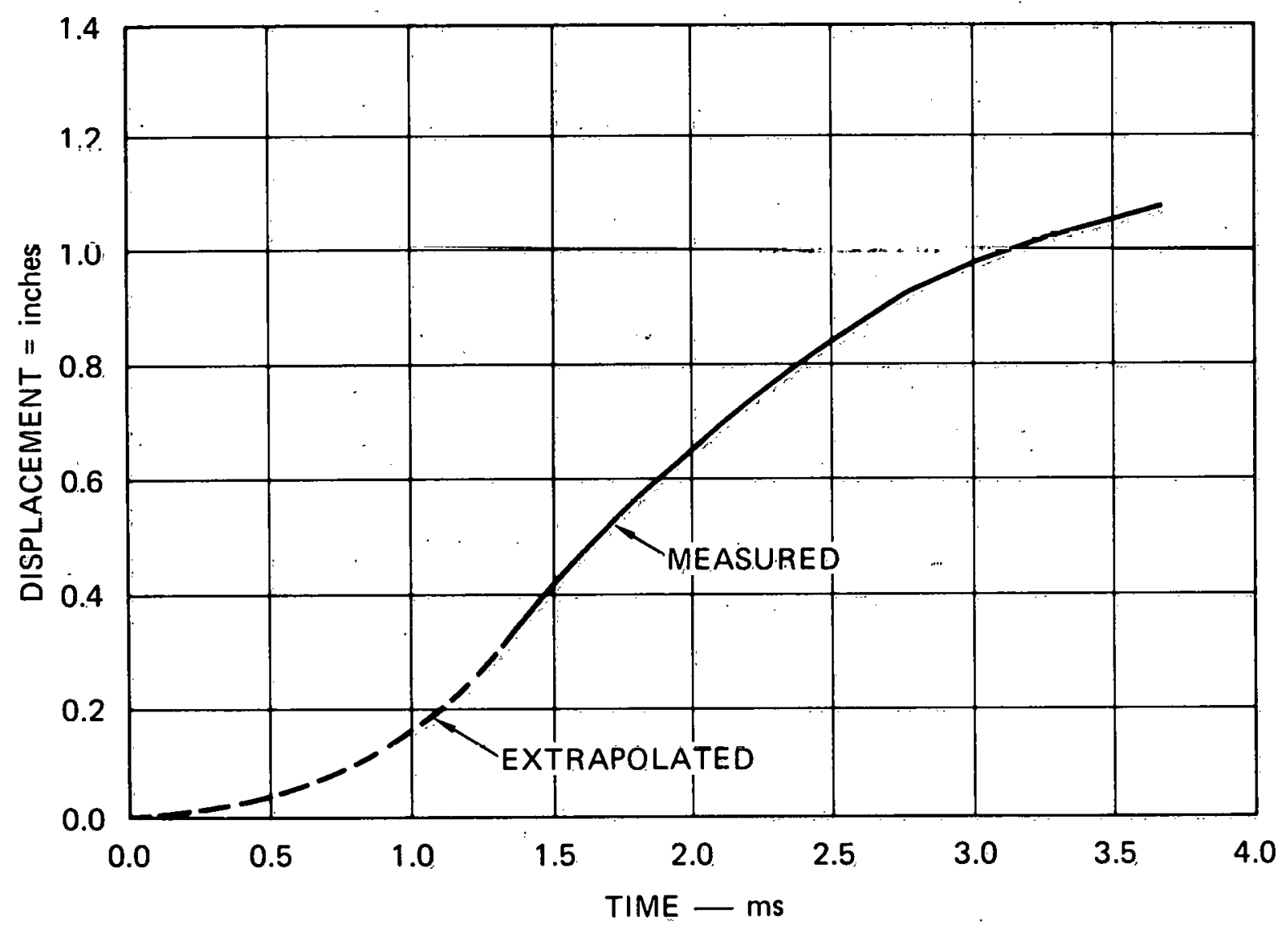

MA-3929-517

FIGURE A.7 REPRESENTATIVE SLIDING DOOR DISPLACEMENT HISTORY

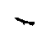

A- 12 
Table A.1

REPRESENTATIVE SLIDING DOOR DISPLACEMENT

(Photodiode 1, Experiment G-011)

Time

(ms)

0.0

1.306

1.503

1.600

1.703

1.809

1.925

2.038

2.169

2.294

2.444

2.600

2.759

2.978

3.269

3.656
Displacement

(inches)

0.0

3.00

4.15

4.66

5.16

5.67

6.17

6.68

7.18

7.69

8.19

8.70

9.20

9.71

10.21

10.72 
The instrument sting in which thermocouple $\mathrm{T}$ and pressure transducer $P$ are mounted was shown full scale in Figure 10. The volume of the pool occupied by the sting is shown in Table A.2. The HCDA bubble volumes presented in this report include a correction for the volume of the sting contained within the bubble. Table A.2 should be useful to those who may wish to describe our experiment geometry in computer code predictions of our experiments. 
Table A.2

\section{INSTRUMENT STING VOLUME}

EXPERIMENT G-0_-

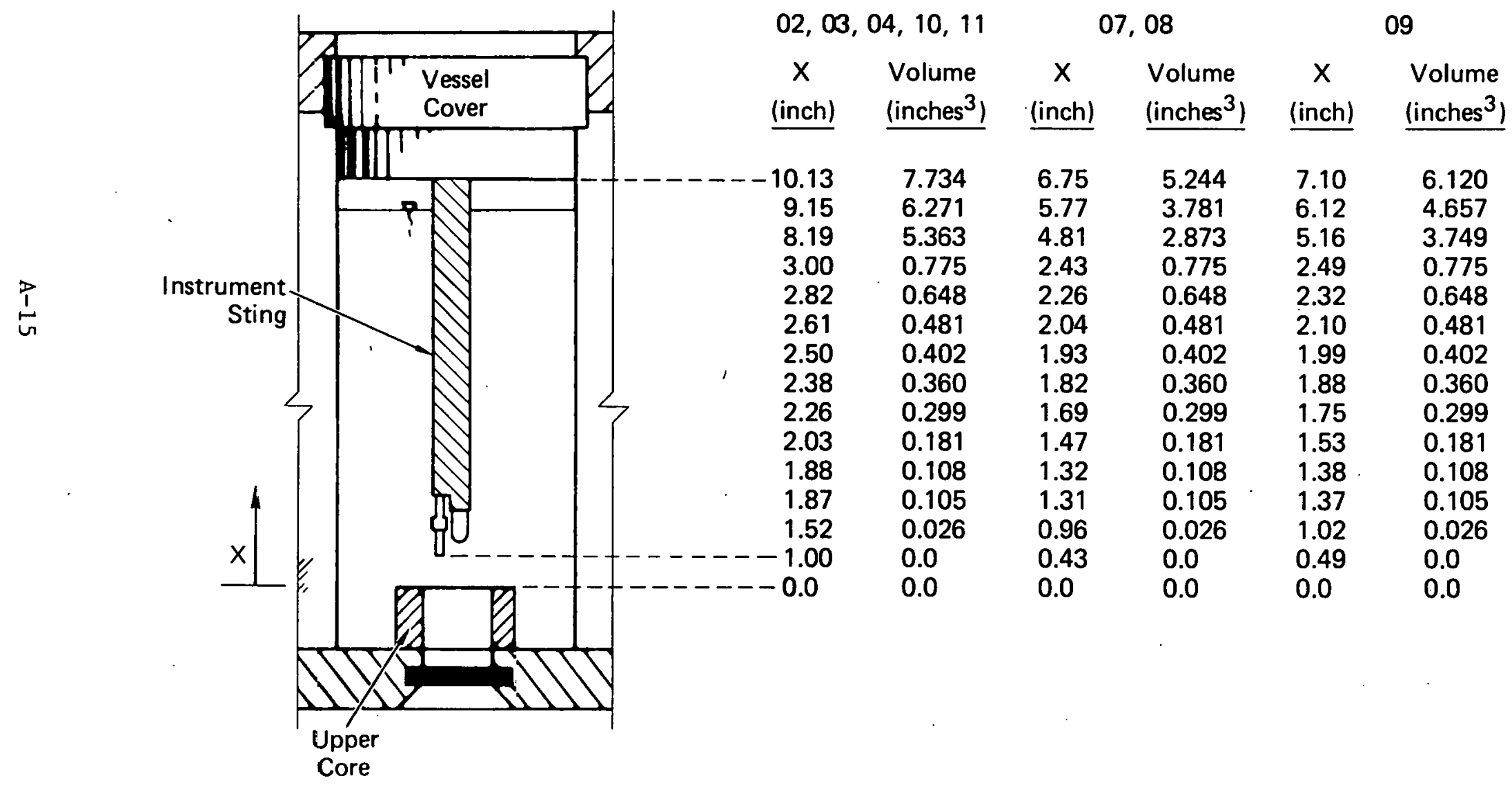


Appendix B

EXPERIMENT INITIAL CONDITIONS

The initial conditions in the experiments consist of the state of the fuel simulant in the lower core, the magnitude of the cover gas gap, and the cover gas pressure at time zero (the time at which the fuse to the sliding door explosives is detonated). The flow path separating the lower core and upper core is opened as the sliding doors are carried by the pistons being driven by the explosives. The flow path nominally begins to open at $1.20 \mathrm{~ms}$ and is nominally fully open at $1.43 \mathrm{~ms}$. The bubble source expansion begins and the experiment proceeds as the sliding doors are opening.

For the nitrogen bubble source experiments, the lower core was pressurized using a regulated gas bottle. Once established, this pressure remained constant and thus was the same at time zero as initially set, 1450 psia.

The nominal water initial conditions in the lower core during the flashing water source experiment were:

$\begin{array}{ll}\text { Pressure } & -1160 \mathrm{psia} \\ \text { Temperature } & -563^{\circ} \mathrm{F} \\ \text { Quality } & -0 \%\end{array}$

The nominal thermodynamic path used to establish a saturated zero-quality liquid state in the flashing source was described in Appendix $A$ and is. represented in Figure B.1. Figure B.2 is a characterization of the analog records of the Kulite pressure transducer and thermocouple $\mathrm{T}_{1}$ used to establish the initial conditions in the flashing source. Points $A, B, C$, and $D$ on the thermodynamic path of Figure B.1 are shown in Figure B.2. Pressurization at room temperature to 1700 psia (points A to B) is followed by heating to $563^{\circ}$ (points $B$ to $C$ ) at a constant pressure of 1700 psia $\left(\mathrm{T}_{\text {sat }}=629^{\circ} \mathrm{F}\right)$. The pressure is then reduced at constant temperature until saturated liquid conditions are reached at point D. Following point 


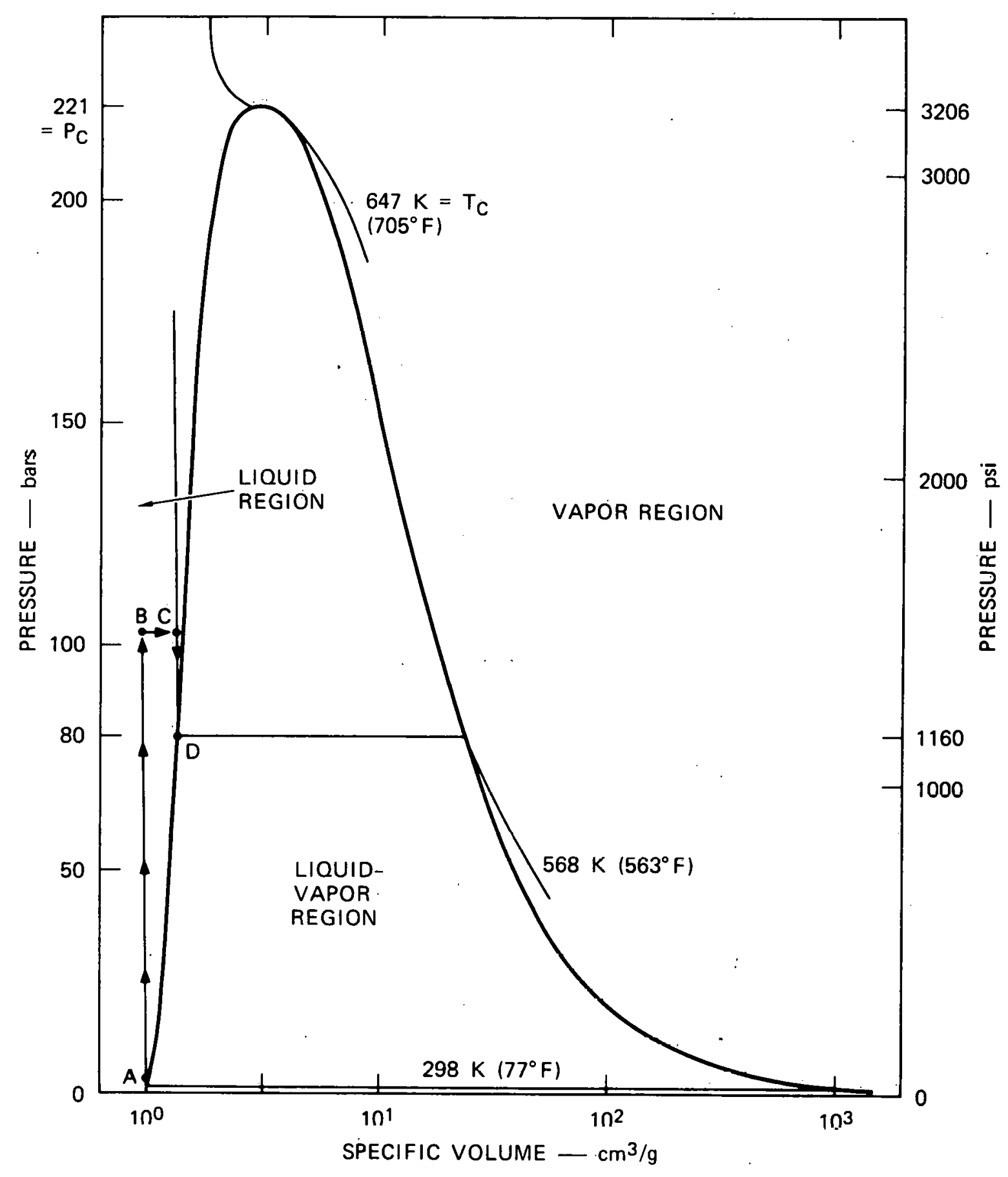

MA-3929-72A

FIGURE B.1 WATER HEATING DIAGRAM 


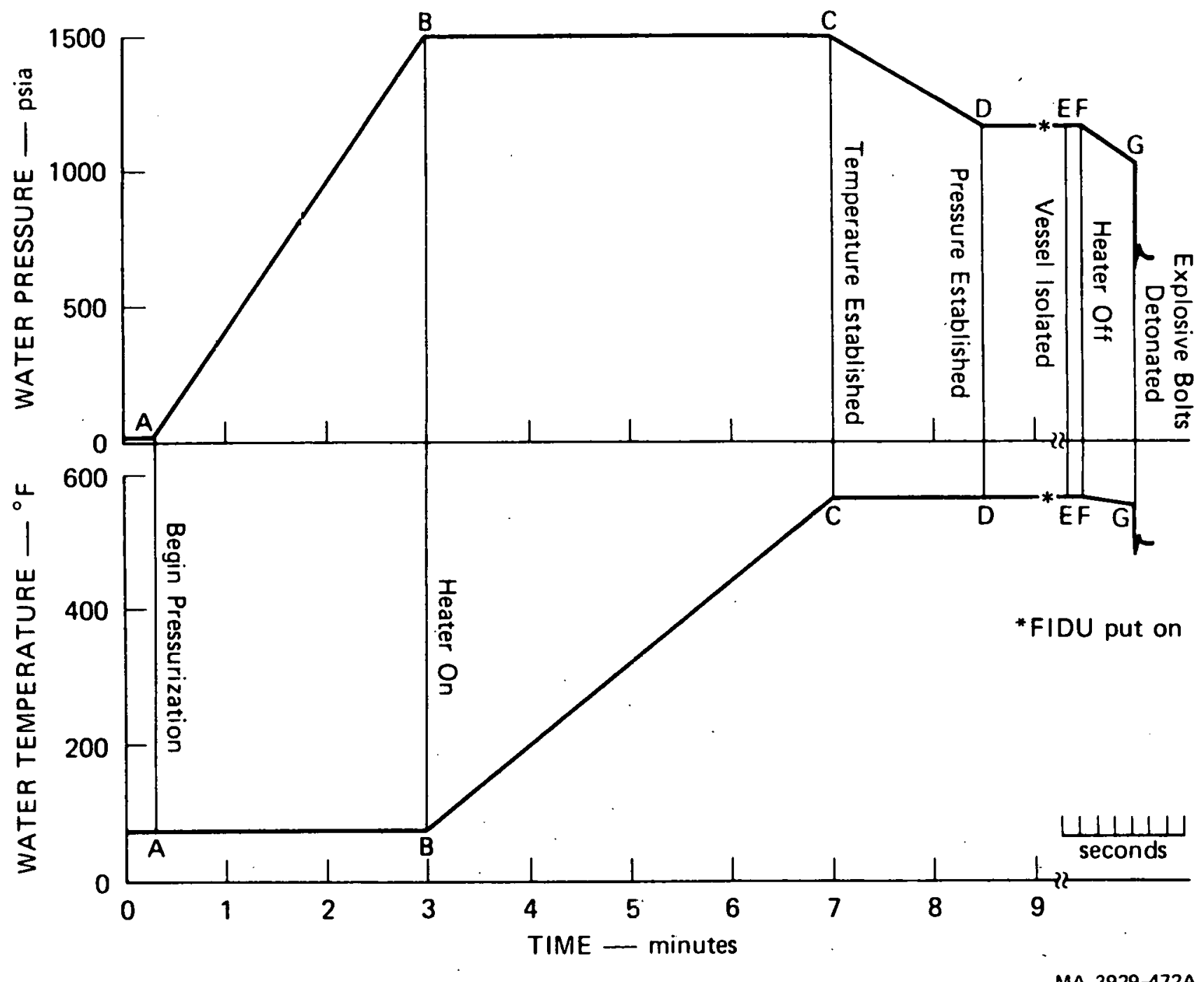

FIGUFE B.2 CHARACTERIZATION OF EXPERIMENT INITIATION 
D on Figure B.2 are several features of the actual procedure not represented on Figure B.1.

Once the desired conditions at point $D$ are established, the liquid must be isolated in the flashing source before initiating the expansion with the explosive bolts. The vessel is first isolated (point E), as shown in Figure B.2, by closing the "isolation valve" shown in Figure B.3. Power to the heating element is then shut off as indicated on Figure B.2. Once the heater is off (point F), heat transfer from the hot apparatus to the room temperature air and supporting structure is no longer being compensated for; hence the liquid cools and the pressure falls (points $F$ to $G$ ). At point $G$, the explosive bolts are detonated, initiating the expansion. Pressure and temperature changes during the expansion are measured using other fast-response instruments. The conditions at point $G$ are the initial experimental conditions.

In these experiments, the Kulite pressure transducer and thermocouple $\mathrm{T}_{1}$ were recorded on an EMI tape recorder at 30 inches per second. In addition, they were input to two Nicolet digital storage oscilloscopes. When both the temperature and pressure were established (between points $\mathrm{D}$ and E, Figure B.2), a manual triggering device was used to simultaneously put a fiducial mark on the tape recorder channels (the asterisk in Figure B.2) and trigger the Nicolet oscilloscopes. The pressure and temperature at the fiducial mark could be directly read on the oscilloscopes following the experiment. The initial conditions at point $G$ would then be determined by subtracting from these values at the fiducial the pressure drop and temperature drop that occur between the fiducial and point $G$ on the calibrated tape recording. The values of the initial pressure $\left(P_{9}\right)$ and initial temperature $\left(\mathrm{T}_{1}\right)$ in the lower core at time zero are presented in Table B.1. For six of the eight experiments, the measured temperature is within 2 degrees of the saturation temperature at the measured pressure. Also shown in the table is the average lower core pressure at $t=1.2 \mathrm{~ms}$ just before the opcning of the sliding doors. 'lhese values are determined for each experiment by subtracting from $P_{9}$ the average pressure drop in $P_{1}$ and $\mathrm{P}_{2}$ between 0 and $1.20 \mathrm{~ms}$. A typical lcwer core pressure trace during this early period of the expansion is shown in Figure B.4. 


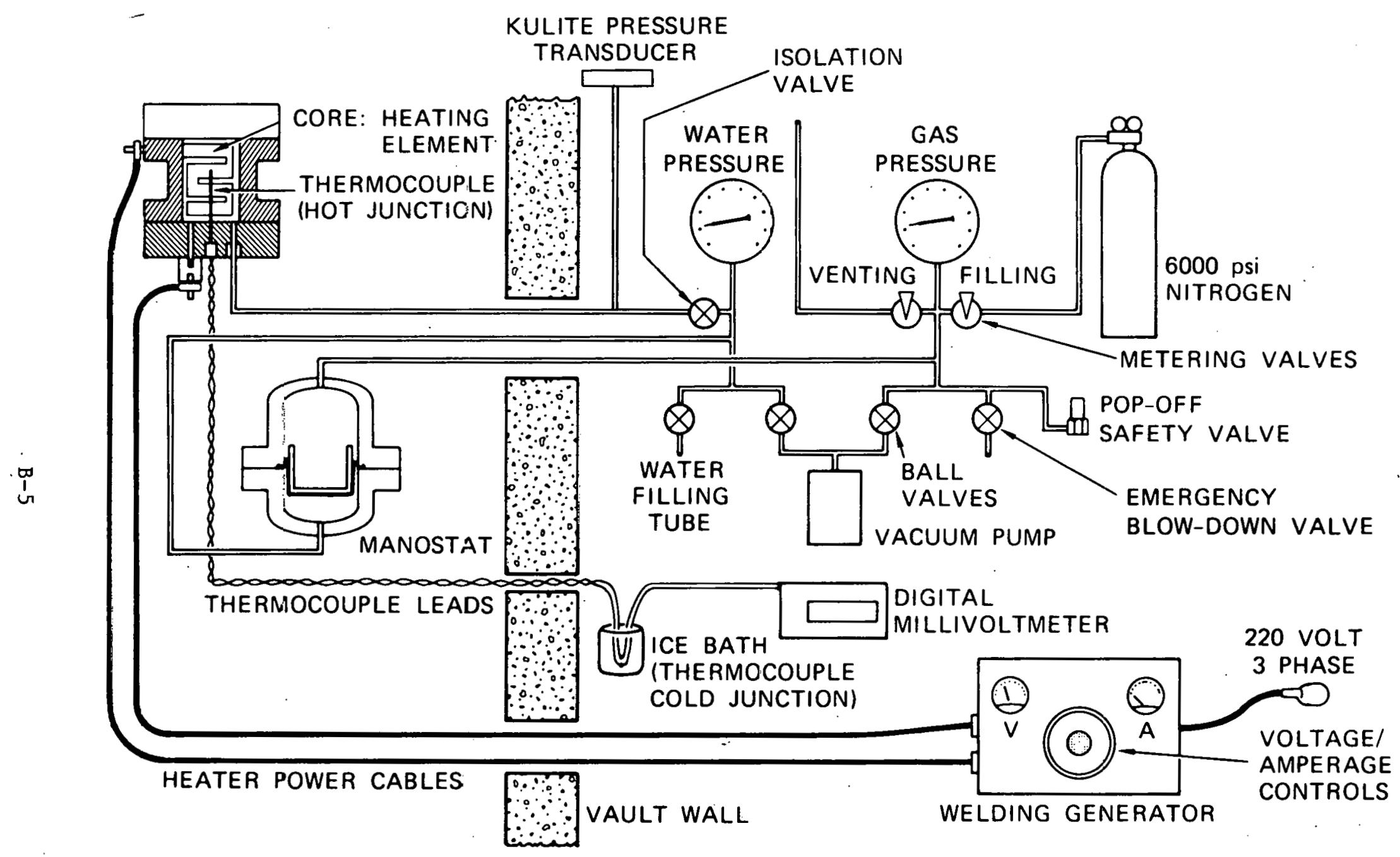

MA-3929-65A

FIGURE B.3 HEATING AND PRESSURE CONTROL SYSTEM 
Table B.1

\section{MEASURED LOWER CORE INITIAL CONDITIONS, FLASHING WATER SOURCE EXPERIMENTS}

\begin{tabular}{|c|c|c|c|c|}
\hline \multirow[b]{2}{*}{ Experlment } & \multicolumn{3}{|c|}{$\mathrm{t}=0.0 \mathrm{~ms}$} & \multirow{2}{*}{$\begin{array}{c}t=1.2 \mathrm{~ms}^{\dagger} \\
P^{\dagger} \\
\underline{\text { psla })}\end{array}$} \\
\hline & $\begin{array}{c}P_{9} \\
\text { (psia) }\end{array}$ & $\begin{array}{l}T_{1} \\
\left({ }^{n} \mathrm{~F}\right) \\
\end{array}$ & $\begin{array}{c}\mathrm{T}_{\mathrm{SAT}}\left(\mathrm{P}_{9}\right) \\
\left({ }^{\circ} \mathrm{F}\right) \\
\end{array}$ & \\
\hline $\begin{array}{l}\text { G-002 } \\
\text { G-0033 } \\
\text { G-004 } \\
\text { G-005 } \\
\text { G-006 } \\
\text { G-007 } \\
\text { G-009 } \\
G-011\end{array}$ & $\begin{array}{r}1058 \\
1039 \\
1040 \\
501 \\
998 \\
978 \\
1009 \\
972\end{array}$ & $\begin{array}{l}551 \\
549 \\
548 \\
458 \\
539 \\
543 \\
544 \\
543\end{array}$ & $\begin{array}{l}552 \\
549 \\
549 \\
467 \\
544 \\
542 \\
546 \\
541\end{array}$ & $\begin{array}{r}1015 \\
1 \cap 31 \\
1028 \\
484 \\
988 \\
953 \\
989 \\
947\end{array}$ \\
\hline Just prior $t$ & or openin & & & \\
\hline
\end{tabular}

The cover gas gap in each experiment was set within 0.01 inch of the nominal value of 0.90 inch a few hours before the experiment. The procedure used involved filling the apparatus to its final coolant level with a small volume syringe. A sharply pointed metal rod was hung from the vessel cover within 0.01 inch of the nominal gap. When the coolant surface just touched the pointed metal rod, as indicated by a dimple in the surface, the syringe was removed and the vessel was sealed.

The composition of the cover gas was not measured. Since Freon vapor is denser than air, we expect that the cover gas in the Freon experiments consisted solely of Freon vapor. The air above the rising coolant surface would have been displaced by Freon vapor coming from this surface as the acrylic vessel was filled. 


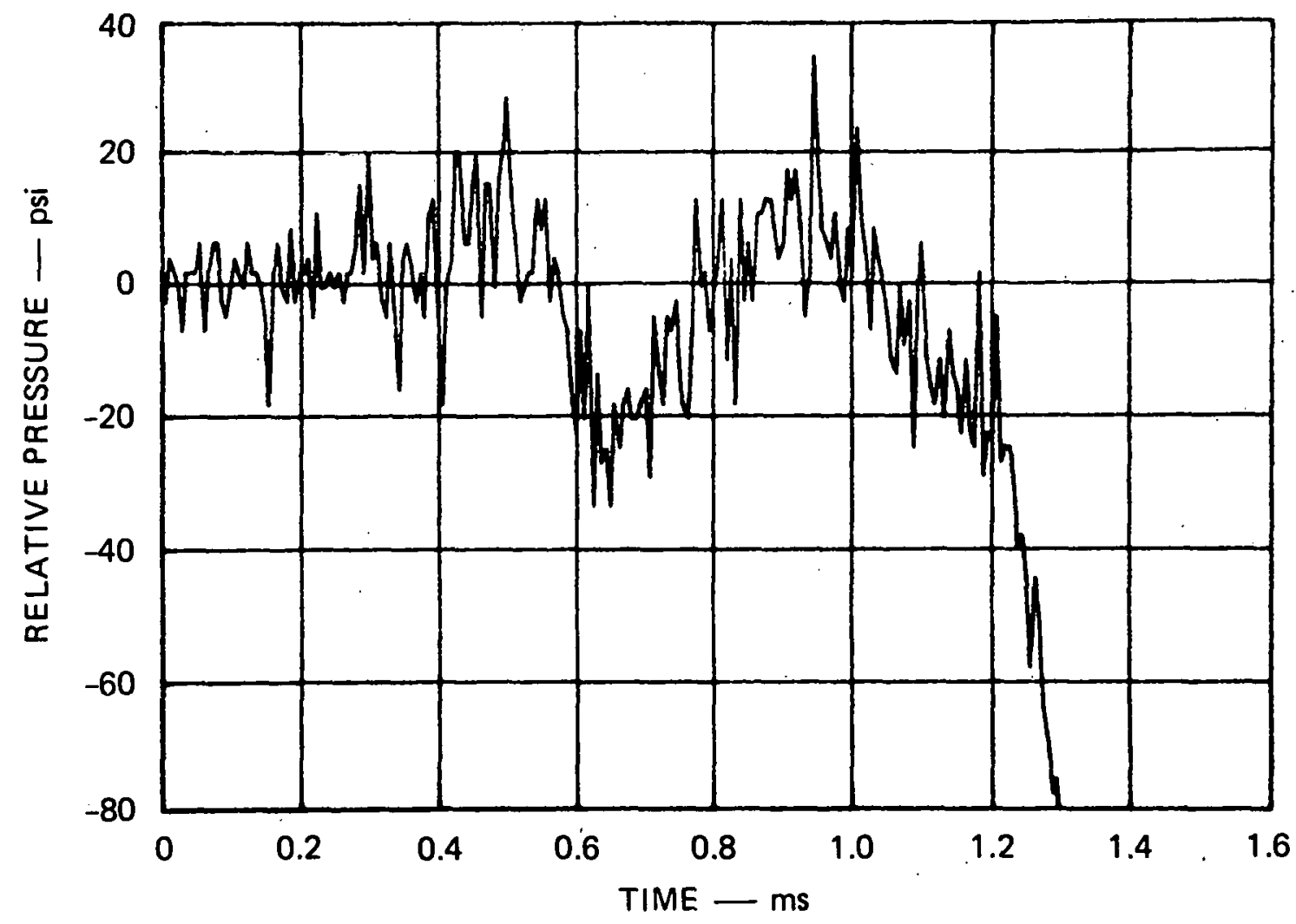

MA-3929-568

FIGURE B.4 TYPICAL EARLY LOWER CORE PRESSURE HISTORY ( $P_{1}$, EXPERIMENT G-007)

To establish the initial conditions in the lower core during the flashing source experiments, we used the pressurization and heating procedures just described. Heating of the fuel simulant in the lower core heated the sliding doors and the coolant above the sliding doors. In the flashing source tests, the temperature in the coolant pool indicated by thermocouple $\mathrm{T}_{2}$ was about $100^{\circ} \mathrm{F}$ a few seconds before experiment initiation. If overall the coolant pool is at about this temperature, the coolant density would have decreased somewhat from the time the cover gas gap was set. The reduced coolant density would result in a larger coolant volume and a reduced cover gas gap. In Table B.2, the gap at a coolant temperature of $100^{\circ} \mathrm{F}$ is compared with the nominal gap and the gap measured from the high-speed movies for representative experiments. The trend is consistent and is convincing evidence that coolant heating was responsible for the different measured initial gaps. 
Table B.2

\section{EFFECT OF COOLANT HEATING' ON INITIAL COVER GAS GAP}

\begin{tabular}{|c|c|c|c|c|c|c|}
\hline Coolant & Configuration* & $\begin{array}{l}\text { Density } \\
\text { at } 70^{\circ} \mathrm{F} \\
\left(\mathrm{lbm} / \mathrm{ft}^{3}\right)\end{array}$ & $\begin{array}{l}\text { Density } \\
\text { at } 100^{\circ} \mathrm{F} \\
\left(\mathrm{lbm} / \mathrm{ft}^{3}\right)\end{array}$ & $\begin{array}{l}\text { Gap } \\
\text { at } 70^{\circ} \mathrm{F} \\
\text { (inch) }\end{array}$ & $\begin{array}{l}\text { Gap } \\
\text { at } 100^{\circ} \mathrm{F} \\
\text { (inch) }\end{array}$ & $\begin{array}{l}\text { Initial Gap (Experiment) } \\
\text { (inch) }\end{array}$ \\
\hline $\mathrm{H}_{2} \mathrm{O}$ & C.G. & 62.31 & 62.00 & 0.90 & 0.85 & $\begin{array}{l}0.89(G-002) \\
0.86(G-011)\end{array}$ \\
\hline$F 113$ & C.G. & 98.26 & 95.79 & 0.90 & 0.63 & $\begin{array}{l}0.58(G-003) \\
0.73(G-004)\end{array}$ \\
\hline$F 113$ & C:M. & 98.26 & 95.79 & 0.90 & 0.74 & 0.77 (G-007) \\
\hline F11 & C.M. & 92.72 & 90.20 & 0.90 & 0.71 & 0.84 (G-009) \\
\hline
\end{tabular}

We also desired to know the initial cover gas pressure with more volatile coolant simulants. Once the vessel is sealed after setting the cover gas gap and the lower core is heated, the cover gas should pressurize. When the vessel is sealed, the cover gas pressure is 14.7 psia and the coolant temperature is, say, $70^{\circ} \mathrm{F}$. At experiment initiation, the coolant is at about $100^{\circ} \mathrm{F}$ and the increase in the cover gas pressure should correspond to the increase in vapor pressure from $70^{\circ} \mathrm{F}$ to $100^{\circ} \mathrm{F}$. A differential pressure transducer with one side open to the atmosphere was used to measure the cover gas pressure. The measured values are compared in Table B.3 with values based on the coolant temperature measured by thermocouple. $\mathrm{T}_{2}$. The measurement method could be improved, but the measurements are consistent with our expectations. 
Table B.3

INITIAL COVER GAS PRESSURE

FLASHING SOURCE EXPERIMENTS

\begin{tabular}{|c|c|c|c|c|}
\hline Experiment & Coolant & $\begin{array}{c}\text { Temperature } \\
\mathrm{T}_{2} \text { Measured } \\
\text { Several Seconds } \\
\text { Before Zero Time } \\
\left({ }^{\circ} \mathrm{F}\right)\end{array}$ & $\begin{array}{c}\text { Vapor Pressure } \\
\text { at } \mathrm{T}_{2} \\
\text { Relative } \\
\text { to } 70^{\circ} \mathrm{F} \\
\text { (psi) }\end{array}$ & $\begin{array}{c}\text { Measured } \\
P_{10} \\
\text { (psig) }\end{array}$ \\
\hline G-002 & $\mathrm{H}_{2} \mathrm{O}$ & 93 & 0.4 & NA \\
\hline G-003 & $F 113$ & 107 & 6.5 & NA \\
\hline G-004 & F113 & 92 & 3.4 & NA \\
\hline G-005 & F113 & NA & NA & NA \\
\hline G-006 & F113 & NA & NA & 3.3 \\
\hline G-007 & $F 113$ & 107 & 6.5 & 7.3 \\
\hline G-009 & F11 & 99 & 7.3 & 8.5 \\
\hline G-011 & $\mathrm{H}_{2} \mathrm{O}$ & 101 & 0.6 & 1.9 \\
\hline
\end{tabular}




\section{Appendix C \\ EXPER IMENT INSTRUMENTATION}

A general description of the experiment instrumentation was presented in Section II-D and shown in Figure 16. Additional information on the instrumentation techniques was presented in Appendix B. This appendix gives the actual instrumentation specific to each experiment. Figure C.1 presents schematics of each experiment, including all working instrumentation, internal structures (if any), and apparatus dimensions. The instrumentation for all experiments is summarized in Table C.1. Instrumentation schematics are presented in Figures C.2 through C.4. 


\section{EXPERIMENT G-002}

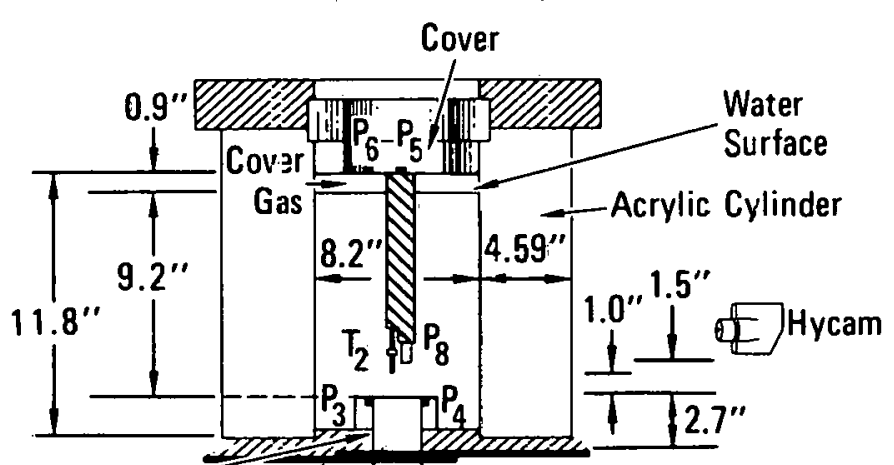

Upper Core

Sliding B́oors Heating Element

Lower Core'

$\left(60.9\right.$ in. $\left.{ }^{3}\right)$

\section{EXPERIMENT G-004}

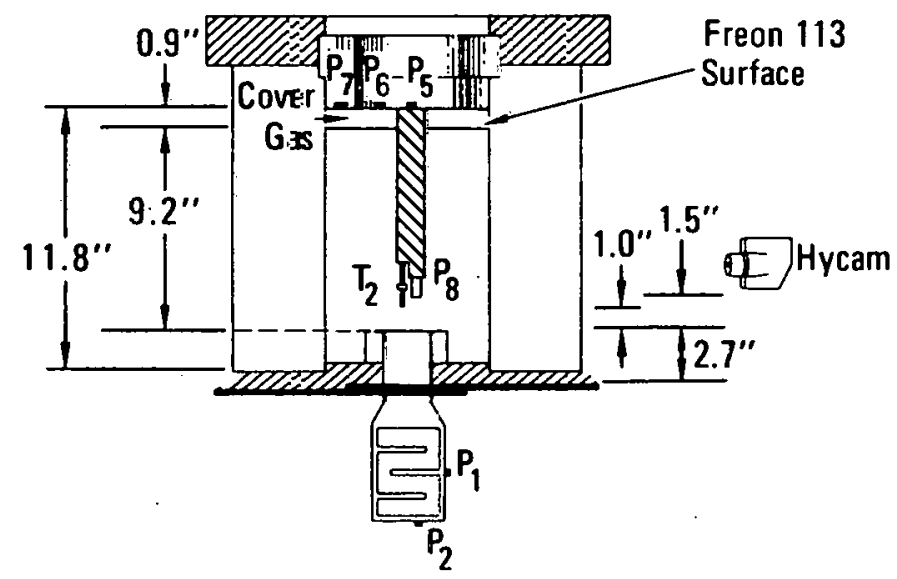

EXPERIMENT G-003

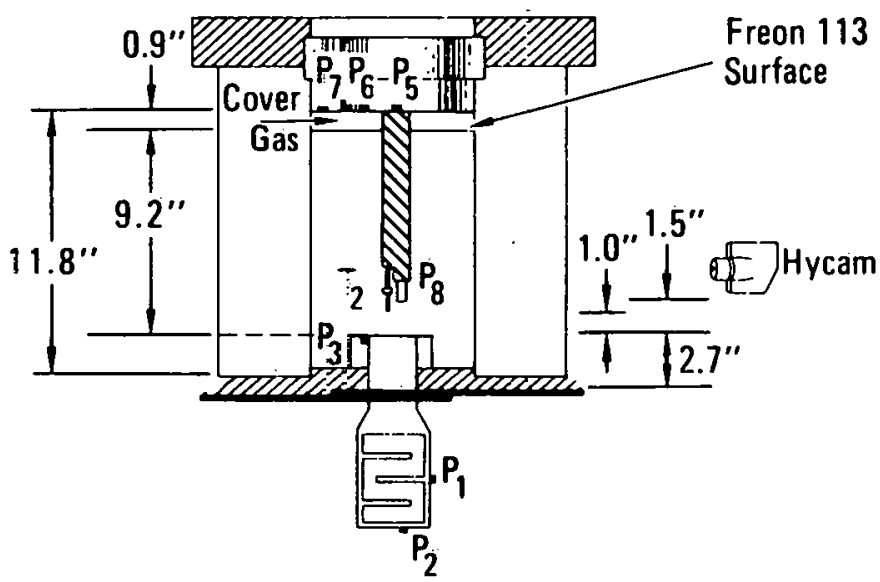

EXPERIMENT G-005

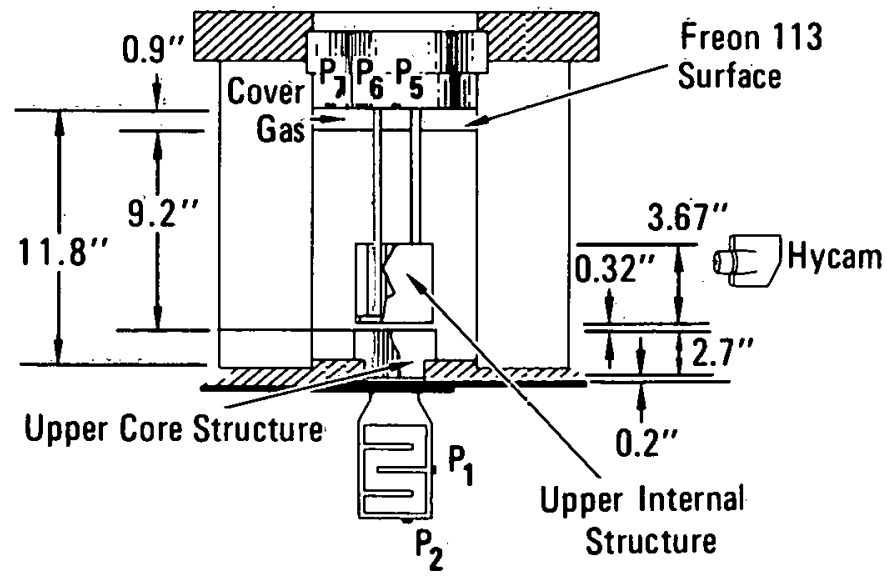




\section{EXPERIMENT G-006}

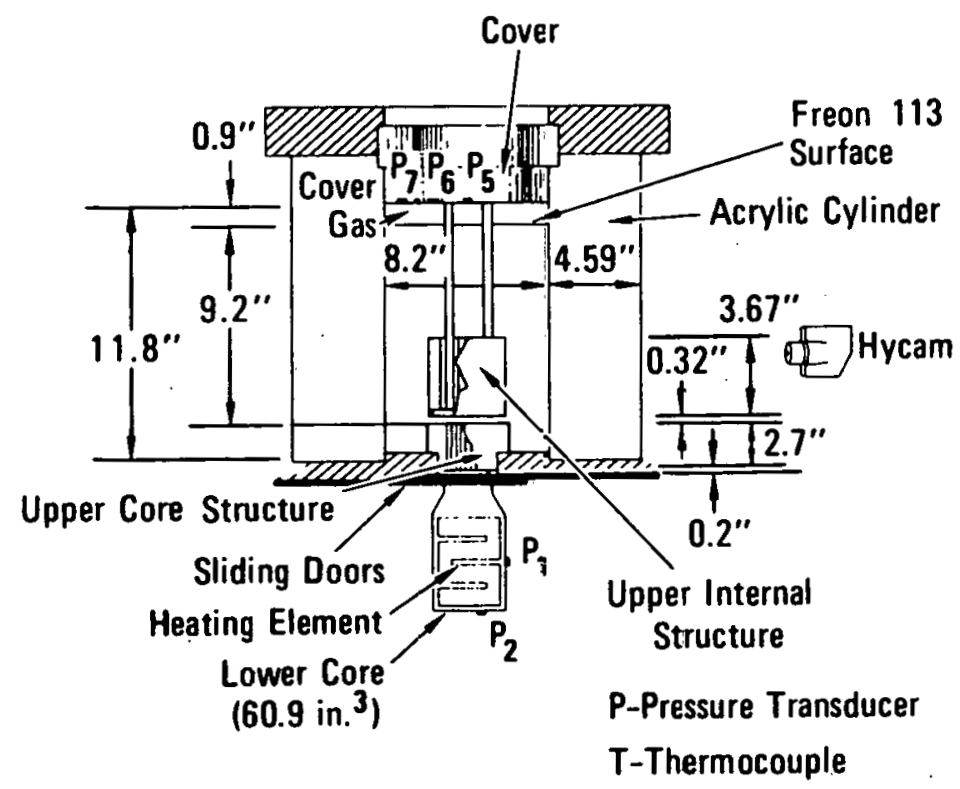

$\stackrel{?}{\omega}$
EXPERIMENT G-007

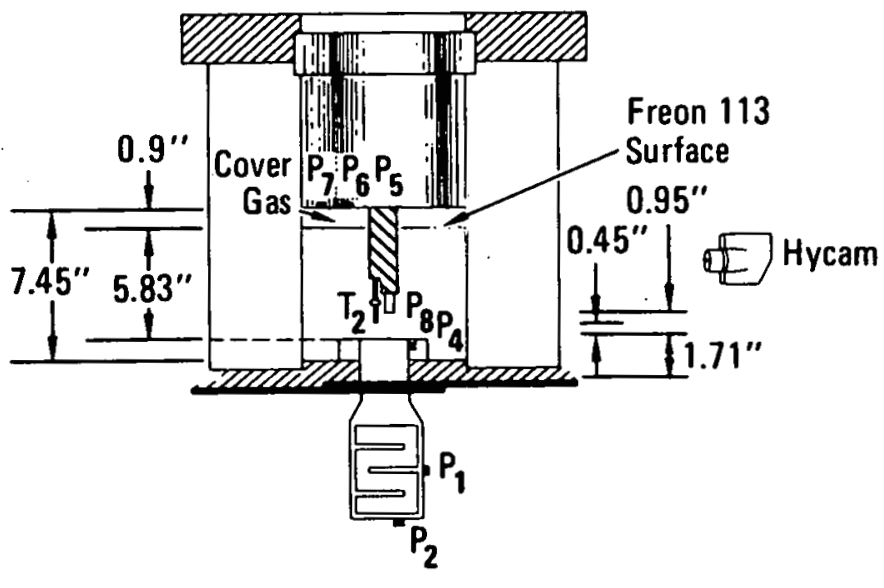

EXPERIMENT G-009

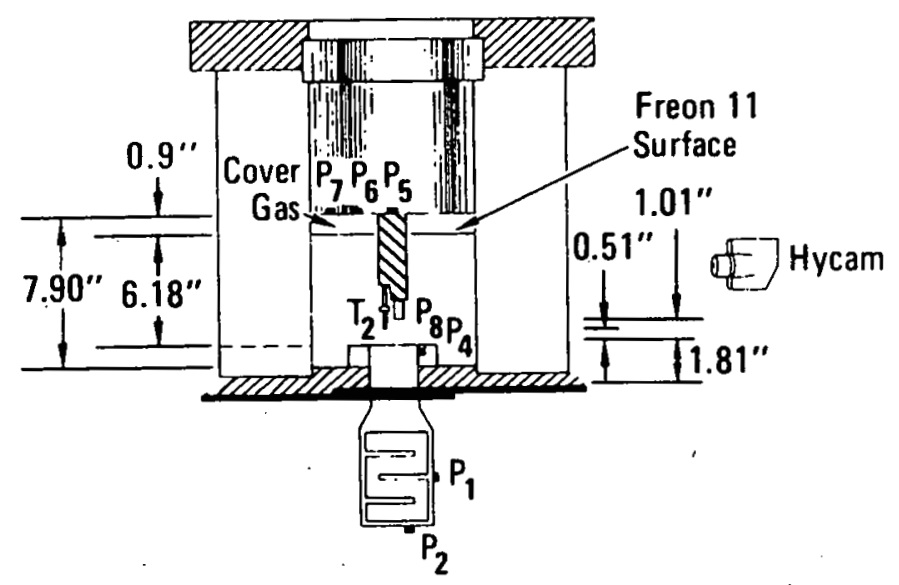

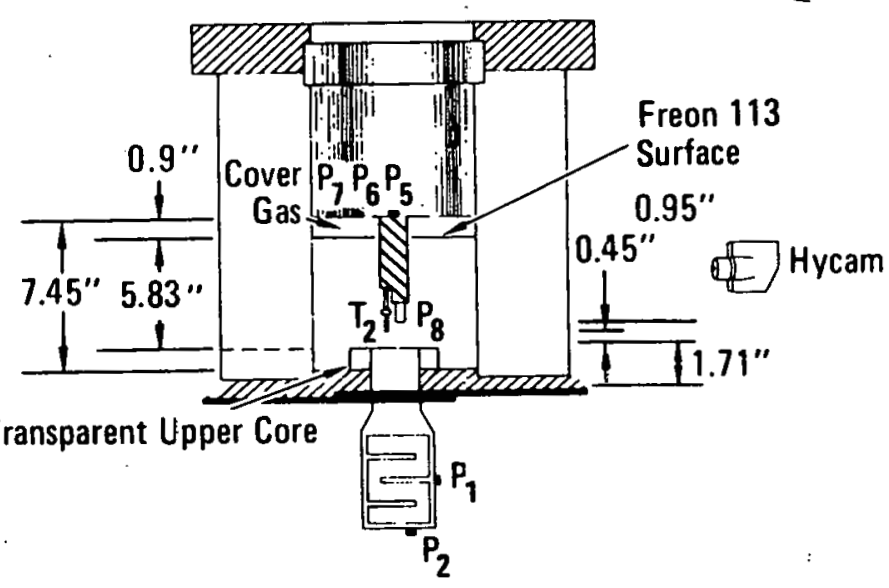




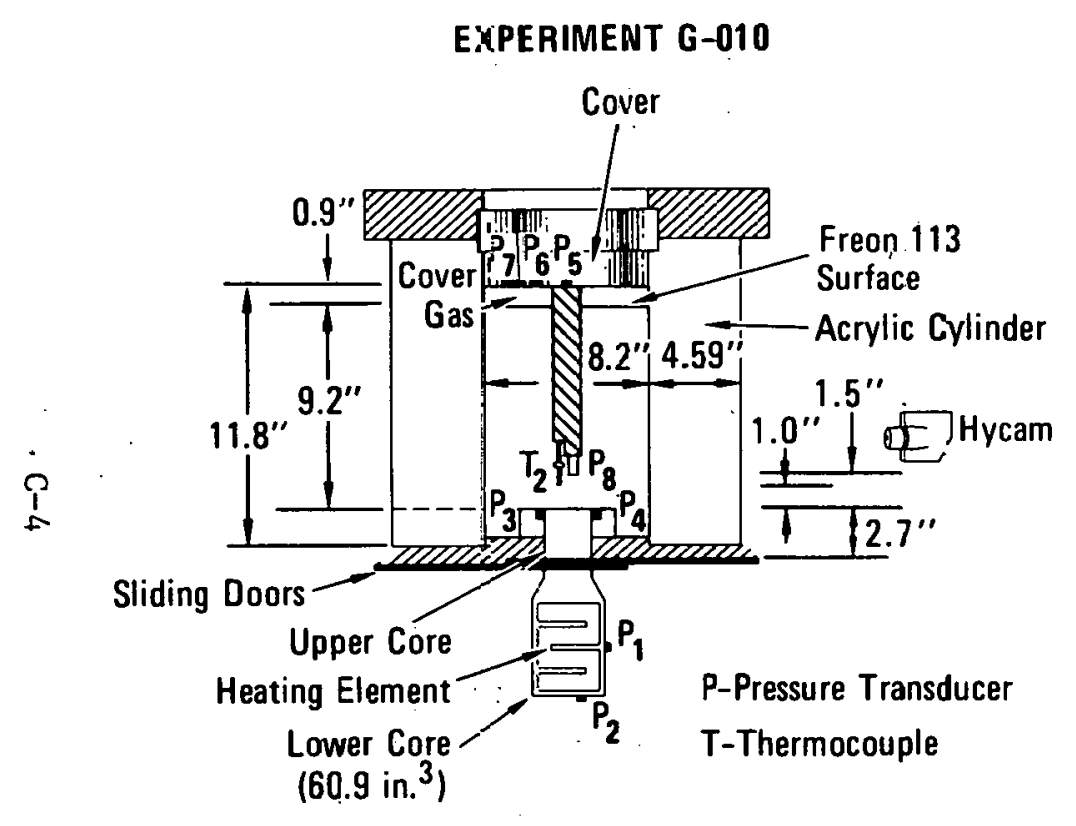

\section{EXPERIMENT G-011}

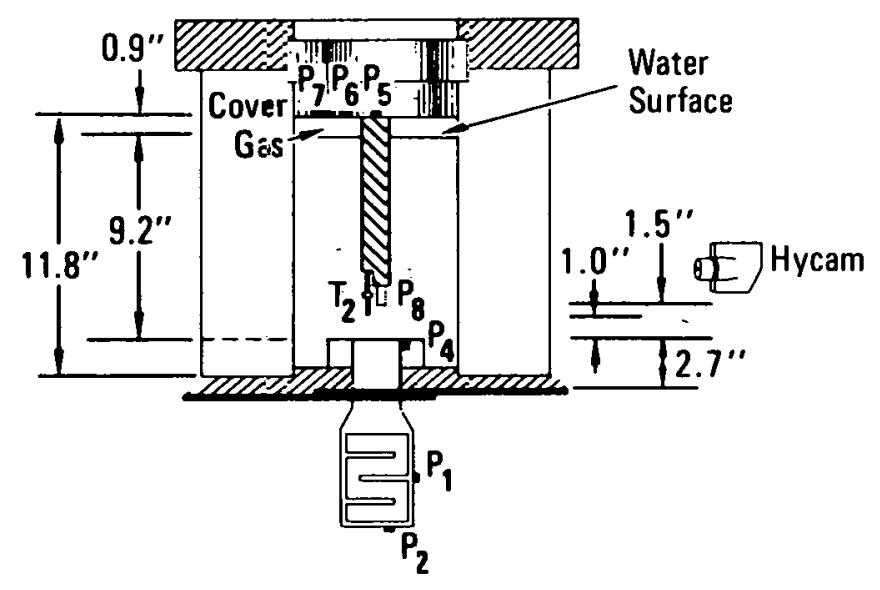

MA-3929-516

FIGURE C.1 EXPERIMENT GEOMETRY AND WORKING INSTRUMENTATIION (Concluded) 
Table C.1

\section{EXPERIMENT INSTRUMENTATION}

\begin{tabular}{|c|c|c|c|c|c|c|c|c|c|c|c|c|c|c|}
\hline Expt. No. & $P_{1}$ & $P_{2}$ & $\mathrm{P}_{3}$ & $\mathrm{P}_{4}$ & $P_{5}$ & $P_{6}$ & $P_{7}$ & $\mathrm{P}_{8}$ & $T_{2}$ & Film & $\mathrm{D}_{1}$ & $\mathrm{D}_{2}$ & $P_{10}$ & $\underline{P_{9}}$ \\
\hline G-002 & * & * & * & * & * & * & $*$ & * & * & * & * & $*$ & $*$ & * \\
\hline G-003 & * & * & * & * & * & * & * & * & * & * & * & * & * & * \\
\hline G-004 & * & * & $\neq$ & * & * & * & * & * & * & * & * & * & * & * \\
\hline G-005 & * & * & NU & NU & * & * & * & NU & NU & * & * & * & $\neq$ & * \\
\hline G-006 & * & * & NU & NU & * & * & * & NU & NU & * & * & * & * & * \\
\hline G-007 & * & * & $*$ & $*$ & * & * & * & * & * & * & * & * & * & * \\
\hline G-008 & * & * & NU & NU & * & * & * & * & * & * & * & * & NU & NU \\
\hline G-009 & * & * & * & * & * & * & * & * & * & * & * & * & * & * \\
\hline G-010 & * & * & * & * & * & * & * & * & * & * & * & * & NU & NU \\
\hline G-011 & * & * & $\neq$ & * & * & * & * & * & * & * & * & * & * & * \\
\hline
\end{tabular}

\section{Instrumentation Symbols}

Use Notation

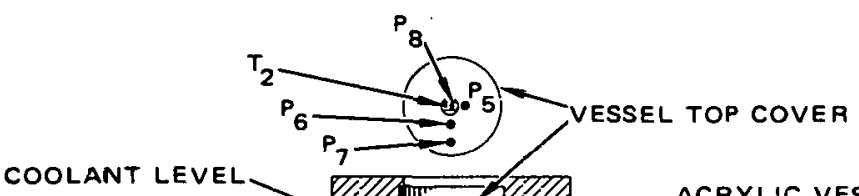

COOLANT LEVEL

DIFFUSER- CACRYLIC VESSEL

(b) InSTRUMENT STING LIGHTS

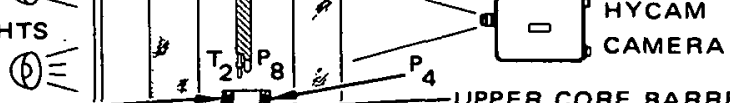

SLIDING DOCRS -

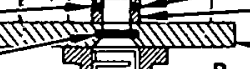

UPPER CORE BARREL

P - Pressure Transducer

T - Thermocouple

D1, D2 - Sliding Door Photodiodes

P9 - Lower Core Pressure, Pretest

T1 - Lower Core Temperature, Pretest

P10 - Cover Gas Pressure, Pretest
* Used

* Used but invalid/ malfunctioned

NU Not Used

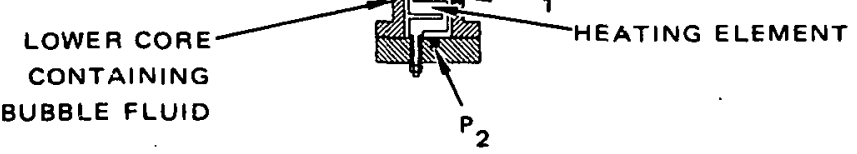




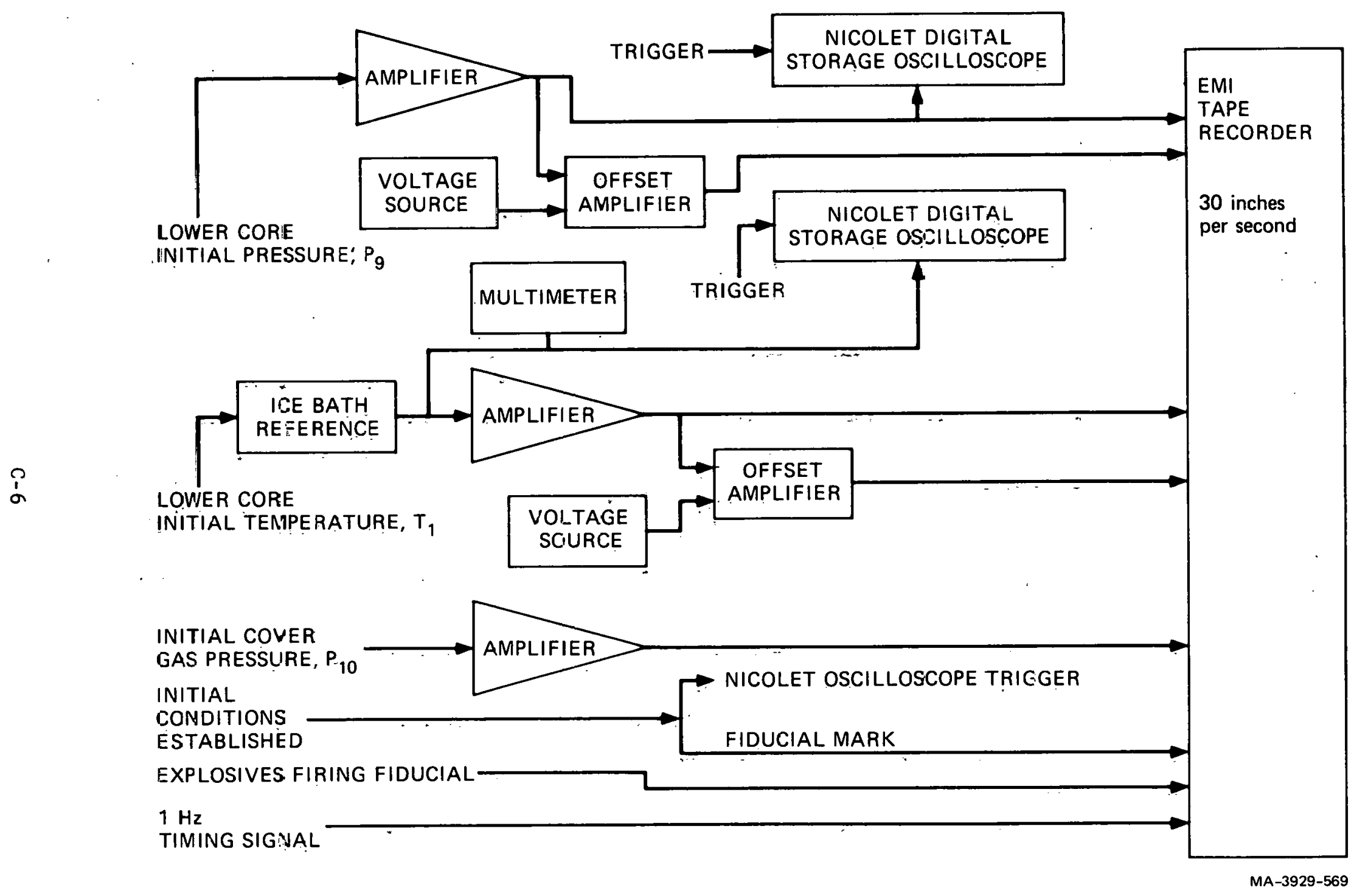

FIGURE C.2 INITIAL CONDITION RECORDING SYSTEM 


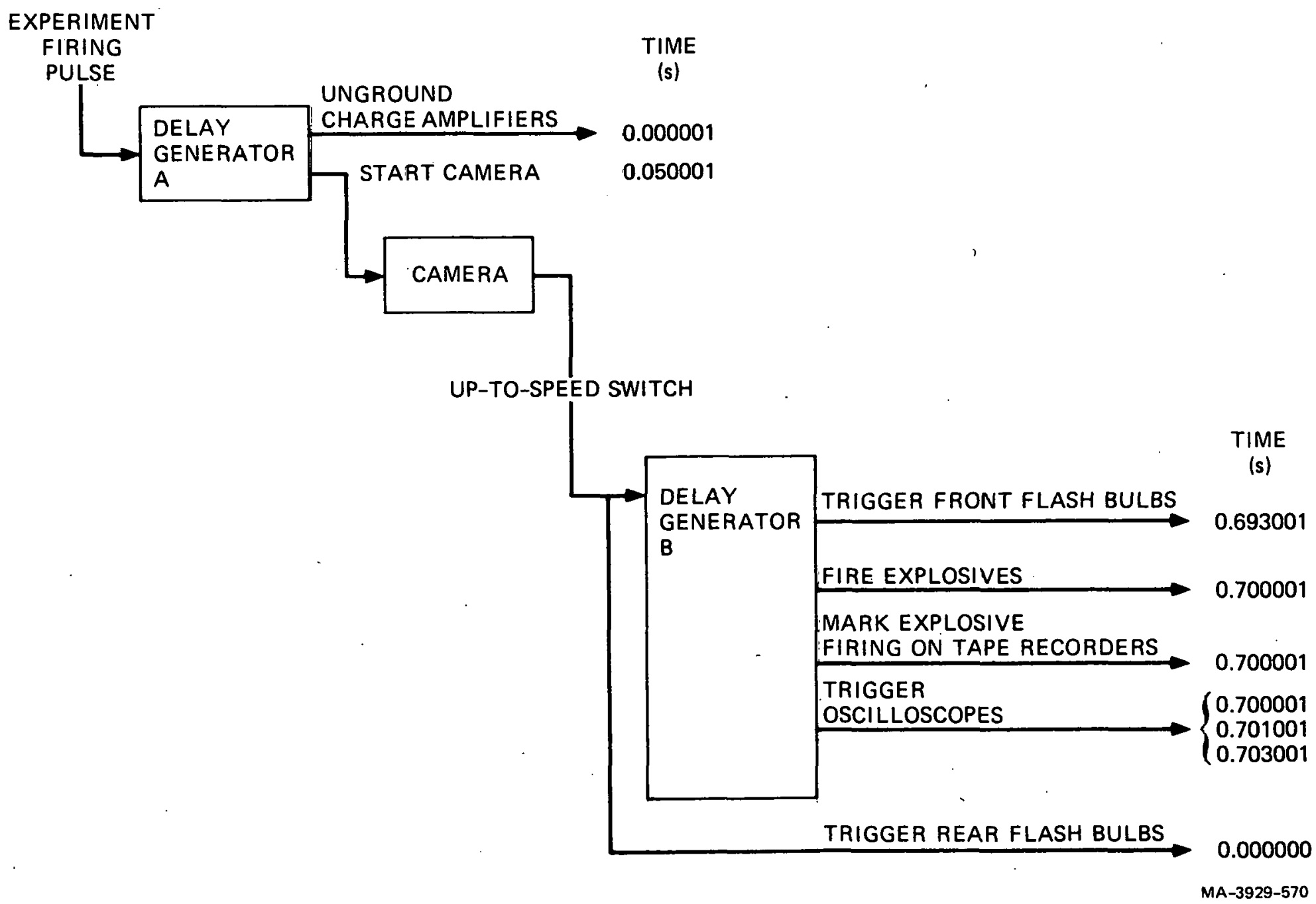

FIGURE C.3 EXPERIMENT TRIGGERING SYSTEM 


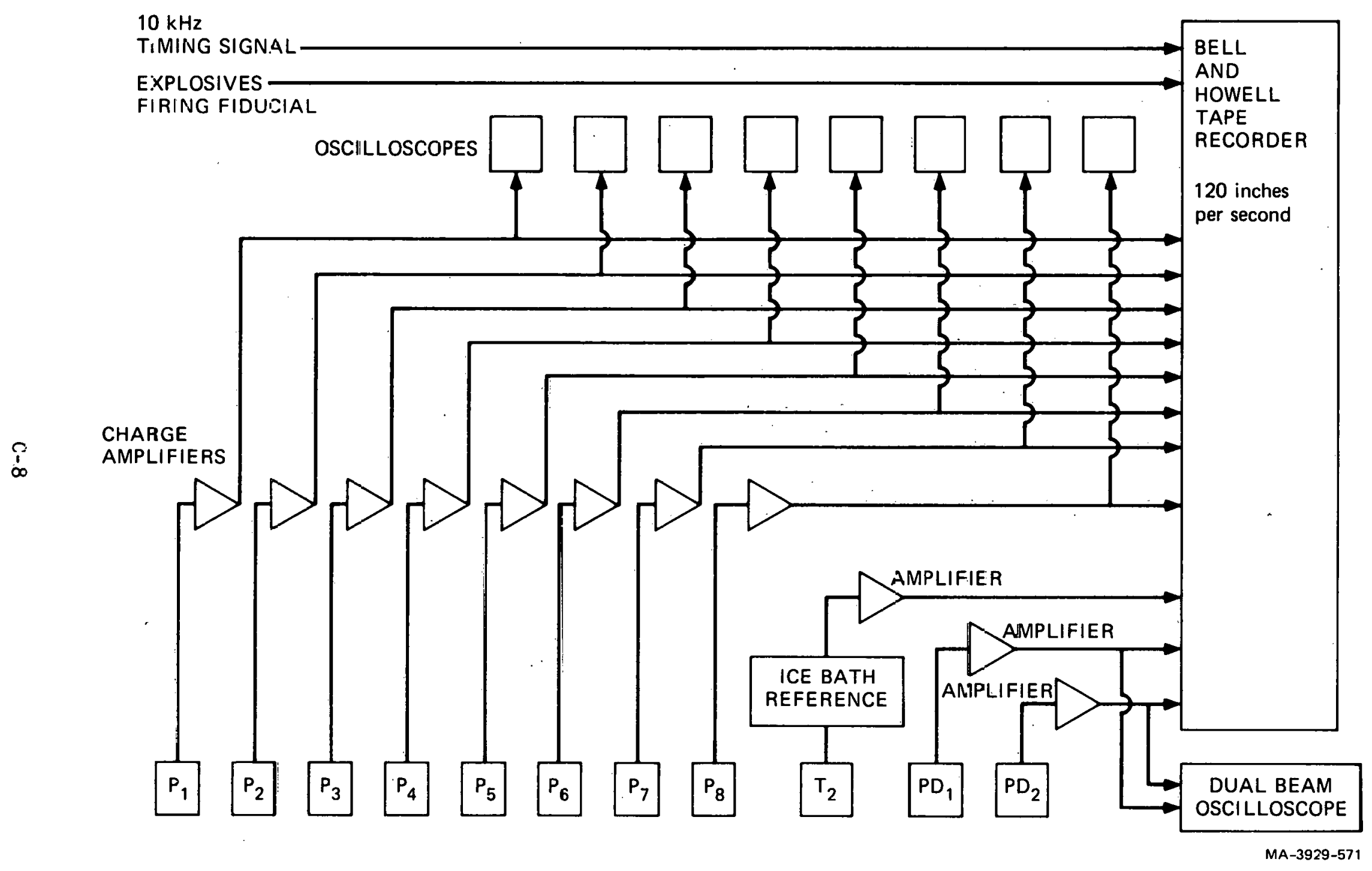

FIGURE C.4 DYNAMIC INSTRUMENTATION RECORDING SYSTEM 
Appendix D

EXPERIMENTAL DATA

This appendix contains a complete set of data from the ten experiments performed. Table D.1 gives the sliding door opening time and the volume created by the door motion. A representative door displacement history was presented in Figure A.7 and Table A.1. Table D.2 presents the slug impact time relative to time zero and relative to when the sliding doors begin to open for each experiment. Included for each experiment in Figures D.1 to D.10 are:

- Dynamic pressure measurements from all working pressure transducers (indicated by an asterisk in Table C.1)

- Bubble temperature (for flashing water bubble source experiments without internal structures)

- Coolant surface displacement measured from the high-speed movies

- Bubble volume measured from the high-speed movies (for experiments without internal structures)

- A sequence of ten movie frames characterizing the bubble expansion.

The pressure and temperature data are presented for a $10-\mathrm{ms}$ window. The reader should refer to Table D.2 to identify the span of time associated with the expansion from door opening to slug impact.

In experiment G-009, the acrylic vessel fractured at slug impact and broke into several pieces. The dynamic measurements are valid only through the slug impact time, $3.52 \mathrm{~ms}$. The data beyond this time should be disregarded.

Determination of the initial conditions for the experiments was described in $\Lambda$ ppendix $B$. 
Table D.1

SLIDING DOOR OPENING TIME AND VOLUME CREATED
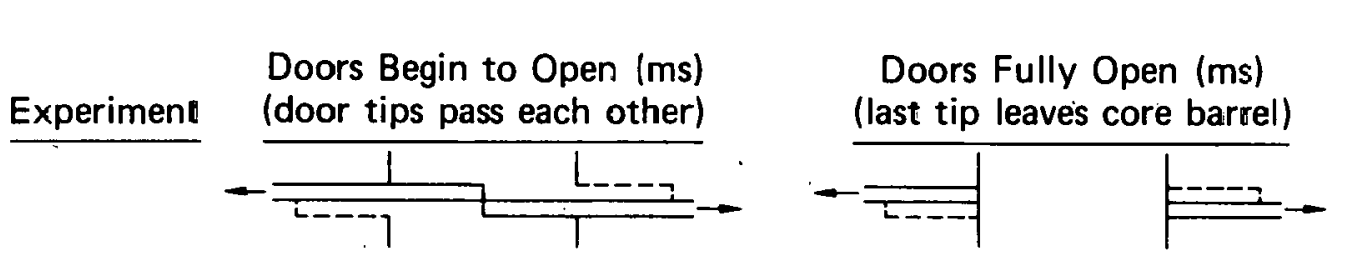

$\begin{array}{cc}\text { Opening } & \text { Total Volume } \\ \text { Time } & \text { Created }\end{array}$

1.194

1.413

219

18.88

$\stackrel{.1}{N}$

G-003

1.199

1.434

235

19.11

G-004

1.315

1.513

198

19.08

G-005

1.302

1.509

207

18.94

G-006

1.313

1.519

206

18.65

G-007

1.309

1.516

207

19.05

G-008

1.199

1.459

260

19.46

G-009

1.313

1.519

206

18.61

G-010

1.300

1.497

197

19.16

G-011

1.292

1.503

211

19.31 
Table D.2

SLUG IMPACT TIME

\begin{tabular}{|c|c|c|c|}
\hline \multirow[b]{2}{*}{ Experiment } & \multirow[b]{2}{*}{$\begin{array}{l}\text { Doors Begin } \\
\text { To Open } \\
\text { (ms) }\end{array}$} & \multicolumn{2}{|c|}{ SLUG IMPACT TIME } \\
\hline & & $\begin{array}{c}\text { From Time } \\
\text { Zero } \\
\text { (ms) }\end{array}$ & $\begin{array}{l}\text { From Doors } \\
\text { Begin to Open } \\
(\mathrm{ms})^{*}\end{array}$ \\
\hline G-002 & 1.194 & 4.06 & 2.86 \\
\hline G-003 & 1.199 & 3.95 & 2.75 \\
\hline G-004 & 1.315 & 4.20 & 2.89 \\
\hline G-005 & 1.302 & 7.56 & 6.26 \\
\hline G-006 & 1.313 & 5.35 & 4.04 \\
\hline G-007 & 1.309 & 3.55 & 2.24 \\
\hline G-008 & 1.199 & $3.23^{\prime}$ & 2.03 \\
\hline G-009 & 1.313 & 3.52 & 2.21 \\
\hline G-010 & 1.300 & 3.88 & 2.58 \\
\hline G-011 & 1.292 & 4.21 & 2.92 \\
\hline curacy & & & \\
\hline
\end{tabular}




\section{EXPERIMENT G-002}

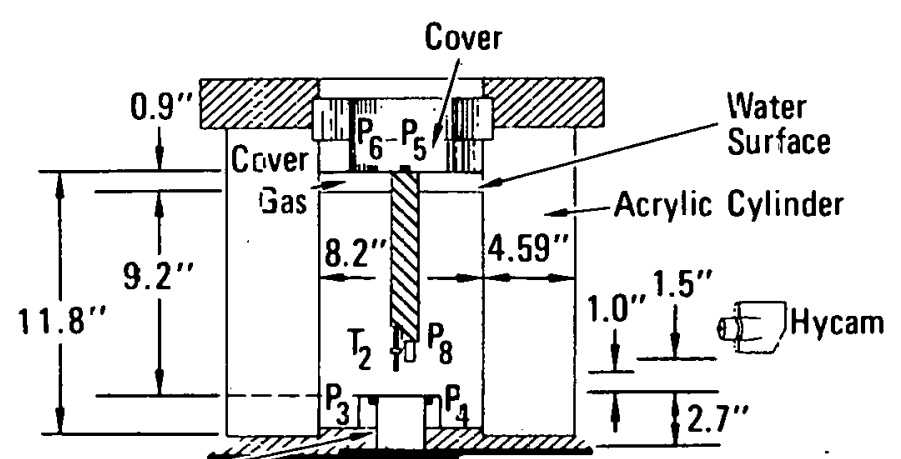

Upper Core

Sliding Doors Heating Element Lower Core $\left(60.9\right.$ in. $\left.{ }^{3}\right)$

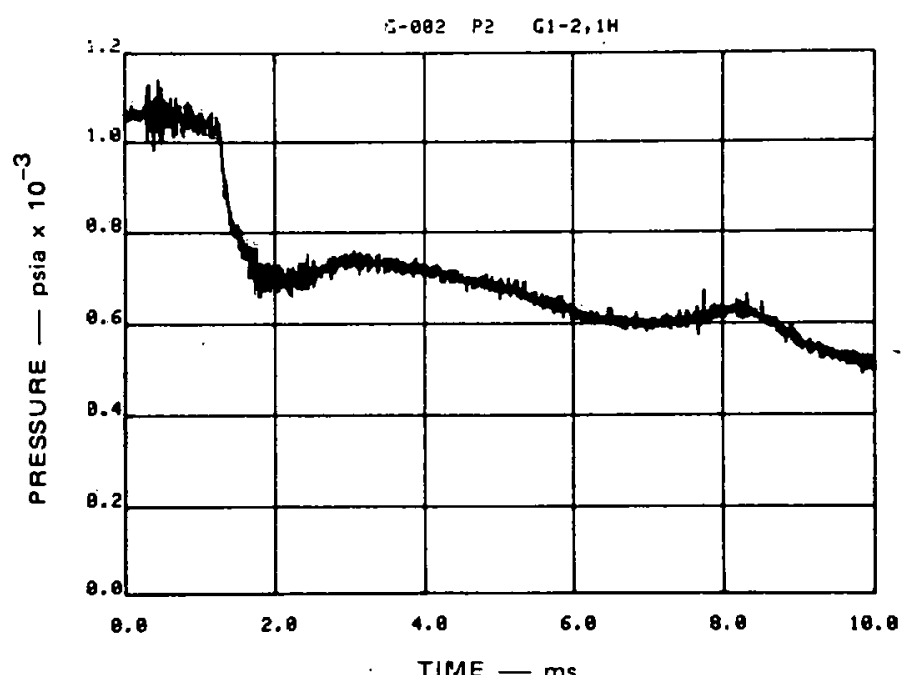

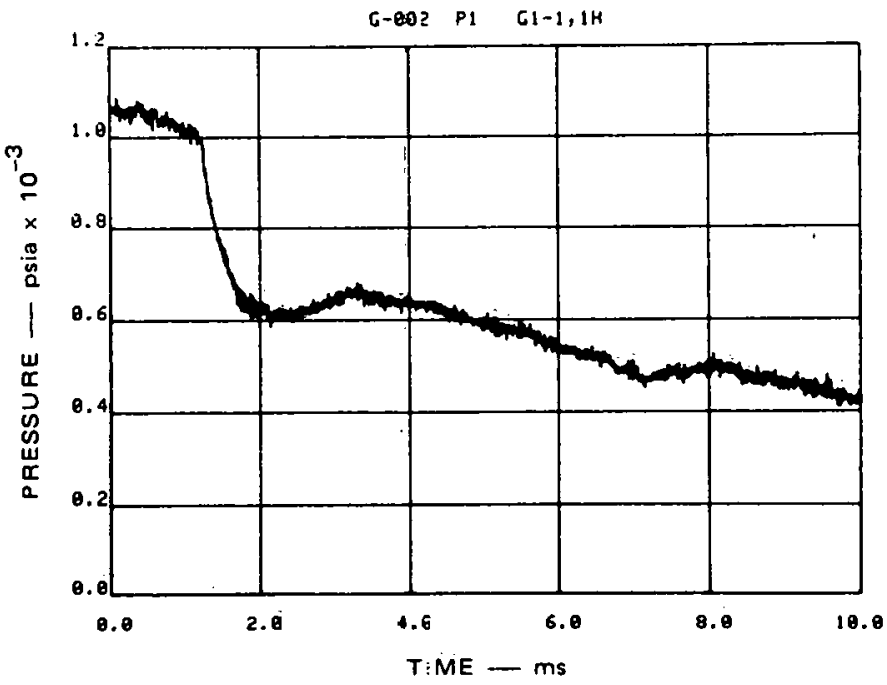

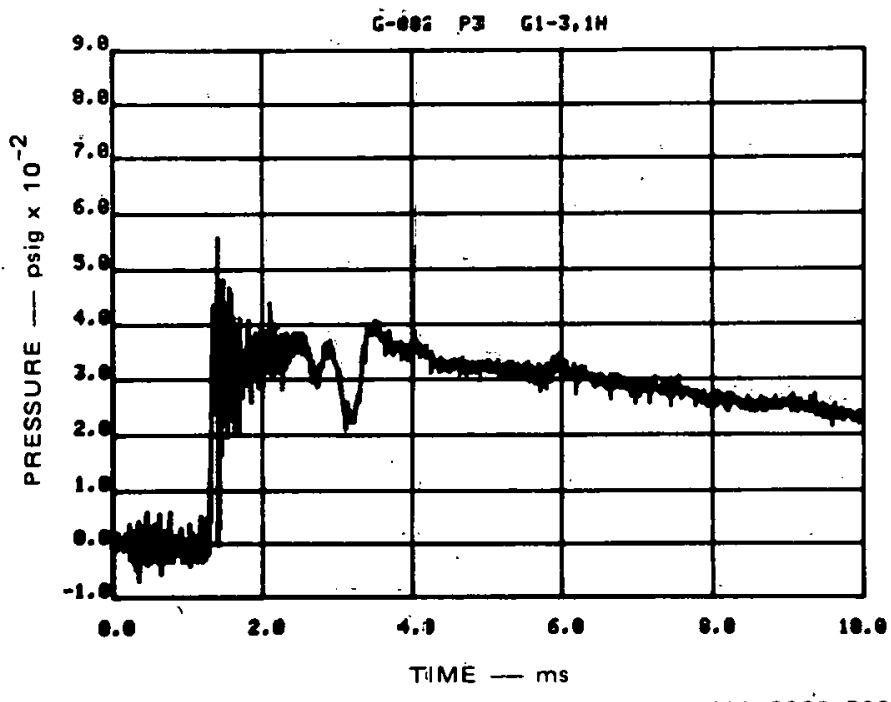

MA-3929-530

FIGURE D.1 EXPERIMENT G-002, FLASHING WATER BUBBLE SOURCE 

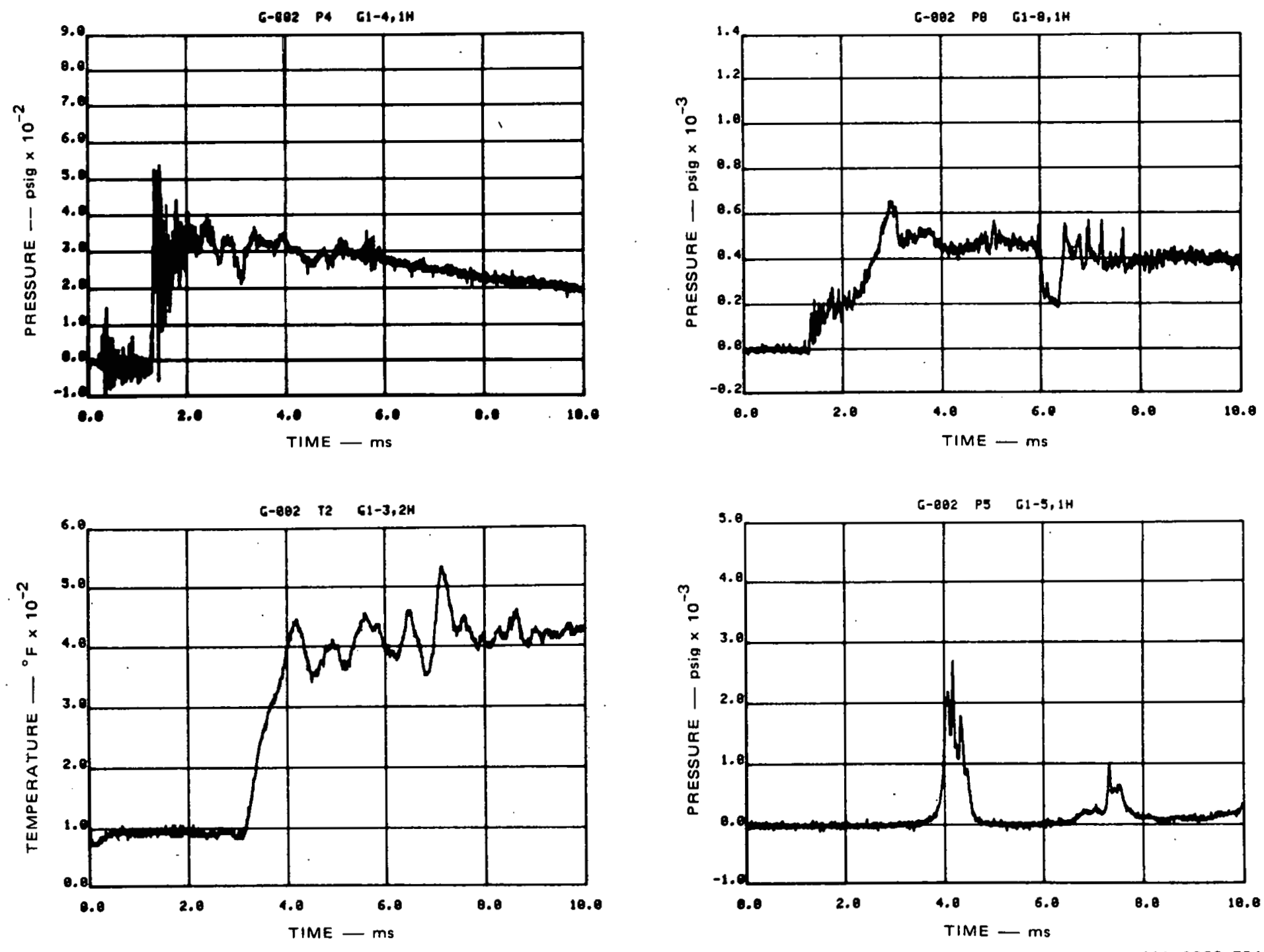

MA-3929-531

FIGURE D.1 EXPERIMENT G-002 (Continued) 

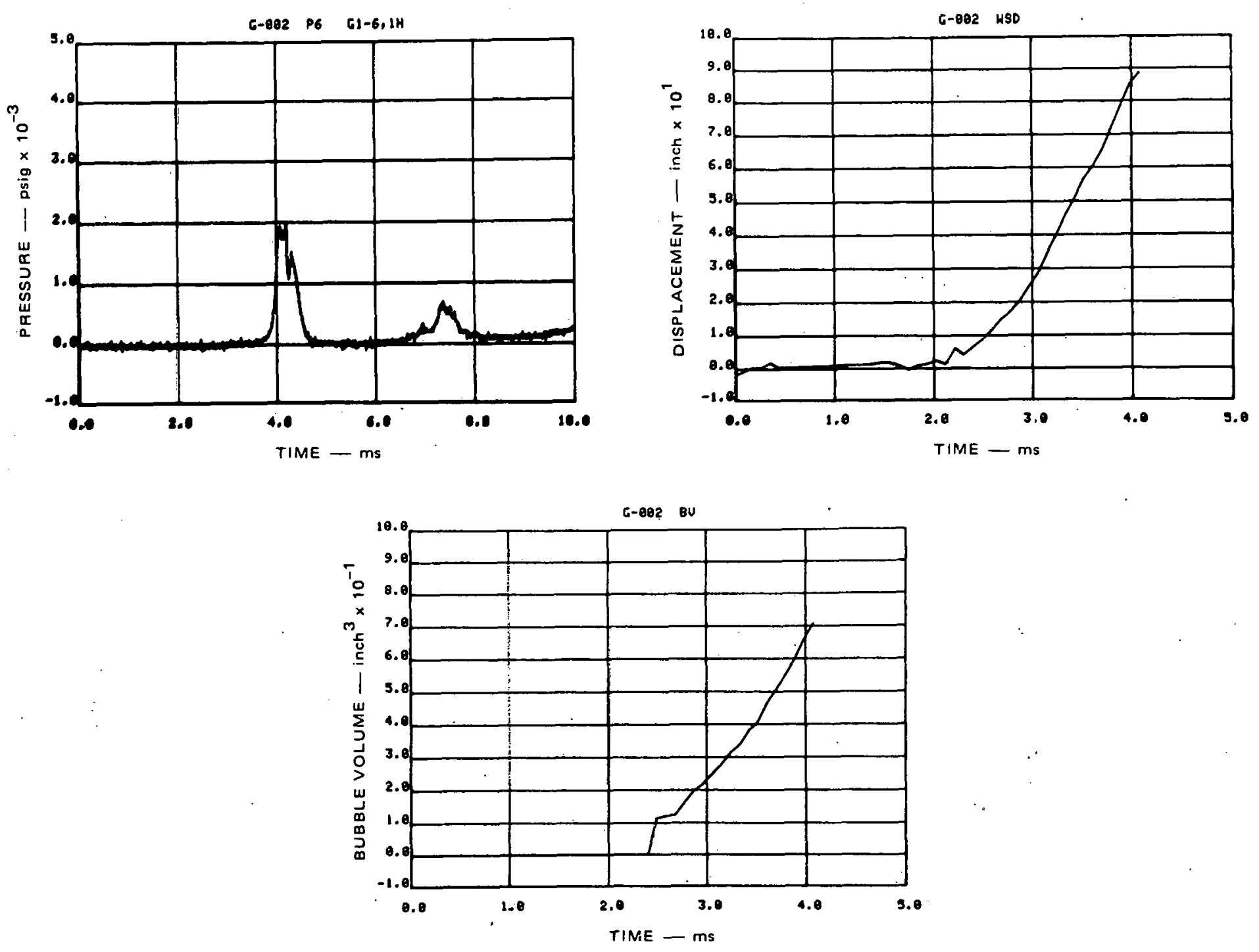

FIGURE D.1 EXPERIMENT G-002 (Continued) 


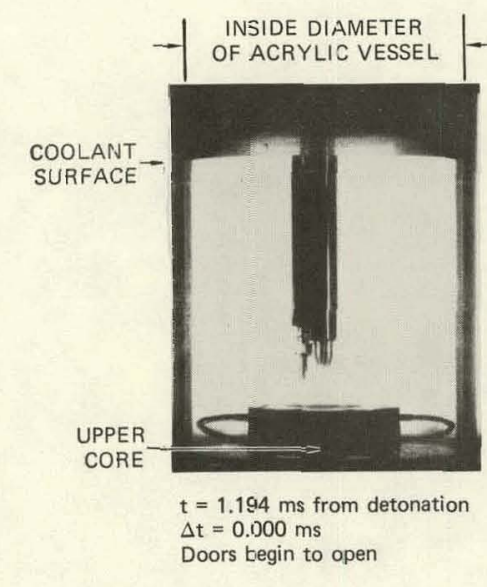

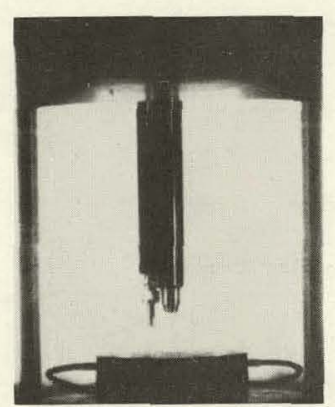

$\mathrm{t}=1.842 \mathrm{~ms}$

$\Delta \mathrm{t}=0.648 \mathrm{~ms}$

barrel openirg

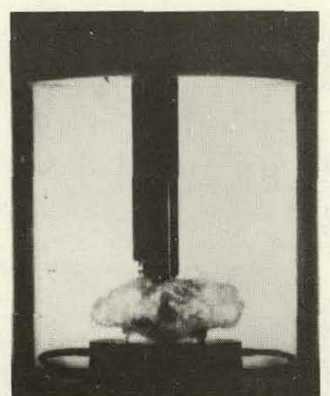

$\mathrm{t}=3.428 \mathrm{~ms}$

$\Delta \mathrm{t}=2.234 \mathrm{~ms}$
Bubble continues to grow

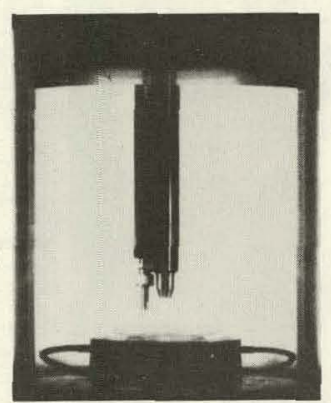

$\mathrm{t}=2.495 \mathrm{~ms}$

$\Delta \mathrm{t}=\cdot .301 \mathrm{~ms}$
Bubble emerges into pool

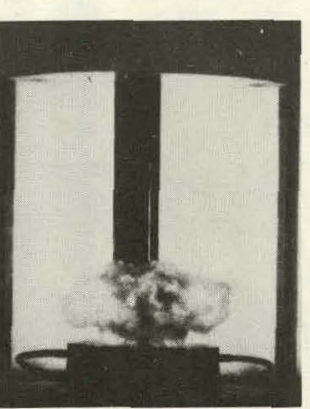

$\mathrm{t}=3.708 \mathrm{~ms}$

$\Delta \mathrm{t}=2.514 \mathrm{~ms}$

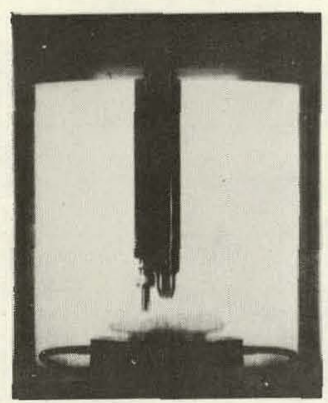

$\mathrm{t}=2.775 \mathrm{~ms}$

$\Delta \mathrm{t}=1.581 \mathrm{~ms}$

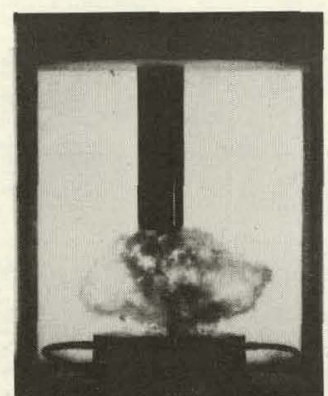

$\mathrm{t}=4.081 \mathrm{~ms}$

$\Delta \mathrm{t}=2.887 \mathrm{~ms}$
Slug impact

Slug impact
at $\Delta t=2.86 \mathrm{~ms}$

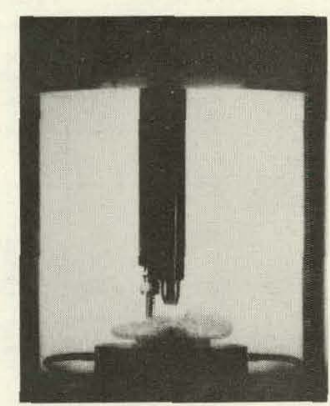

$\mathrm{t}=2.868 \mathrm{~ms}$

$\Delta t=1.674 \mathrm{~ms}$ thermocouple

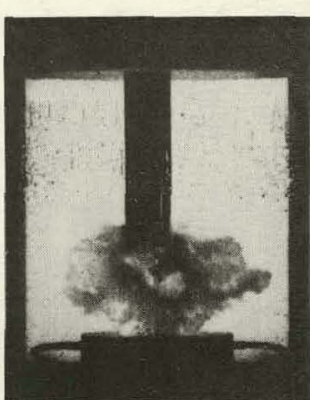

$\mathrm{t}=4.825 \mathrm{~ms}$

Post impact cavitation cavitation

FIGURE D.1 EXPERIMENT G-002, PHOTO SEQUENCE (Concluded) 


\section{EXPERIMENT G-003}

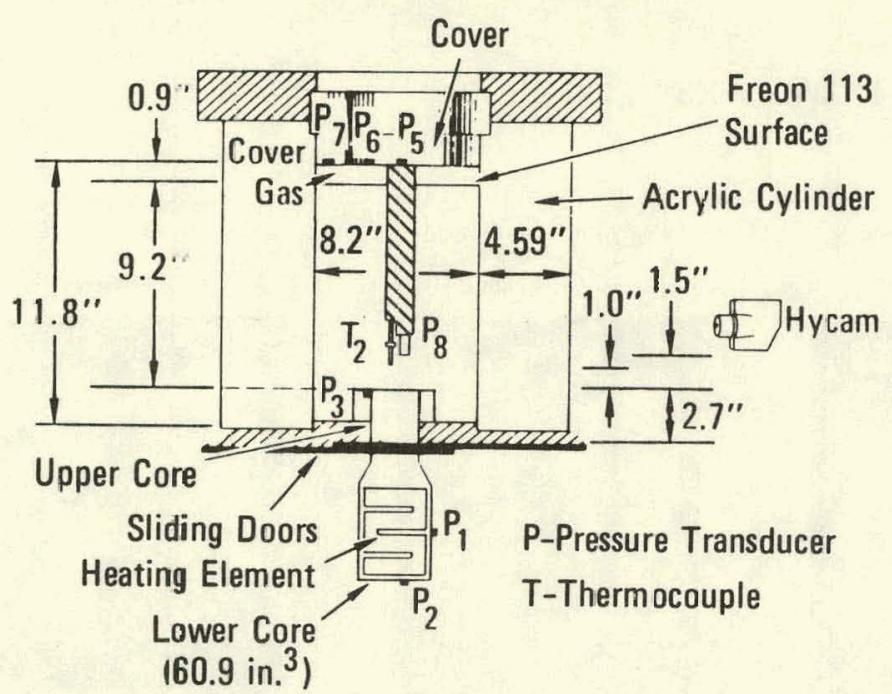

1
1
$\infty$

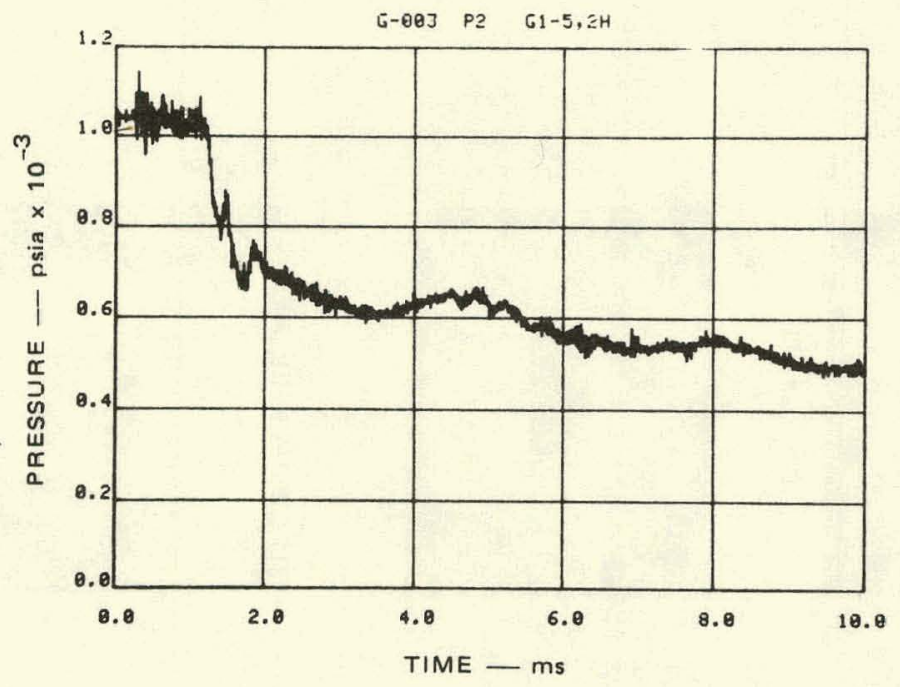

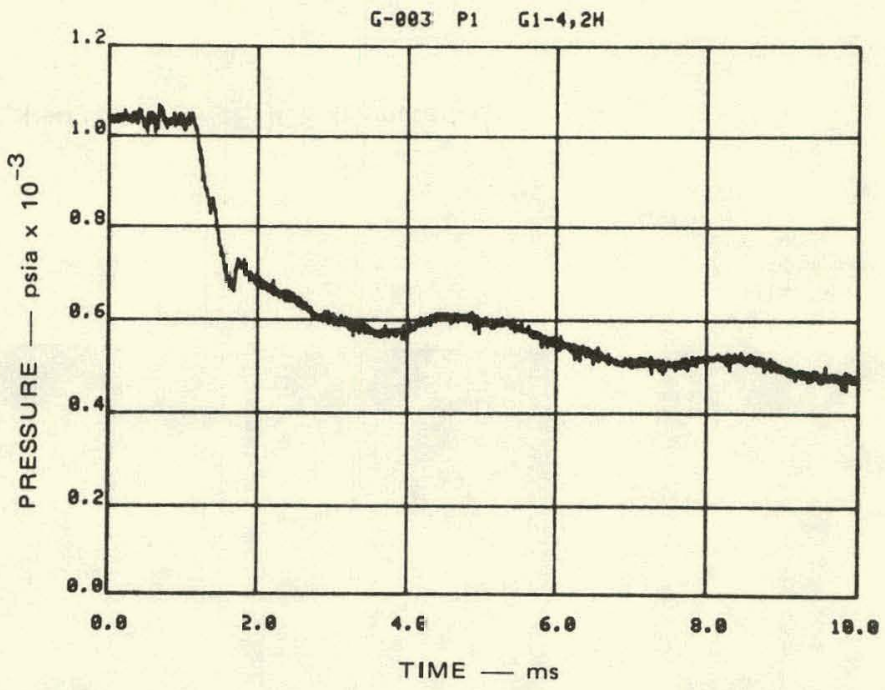

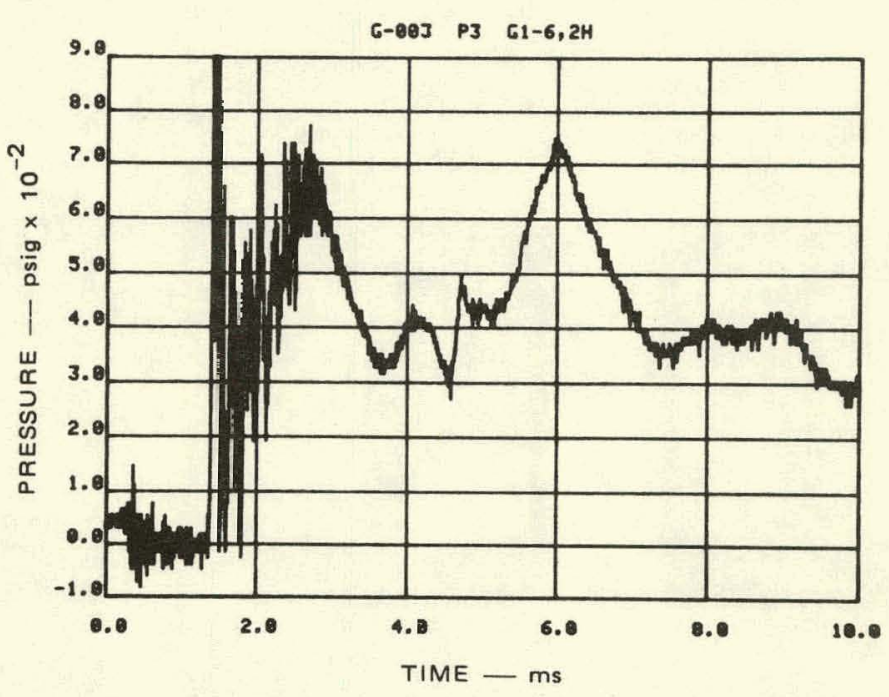

MA-3929-534

FIGURE D.2 EXPERIMENT G-003, FLASHING WATER BUBBLE SOURCE 

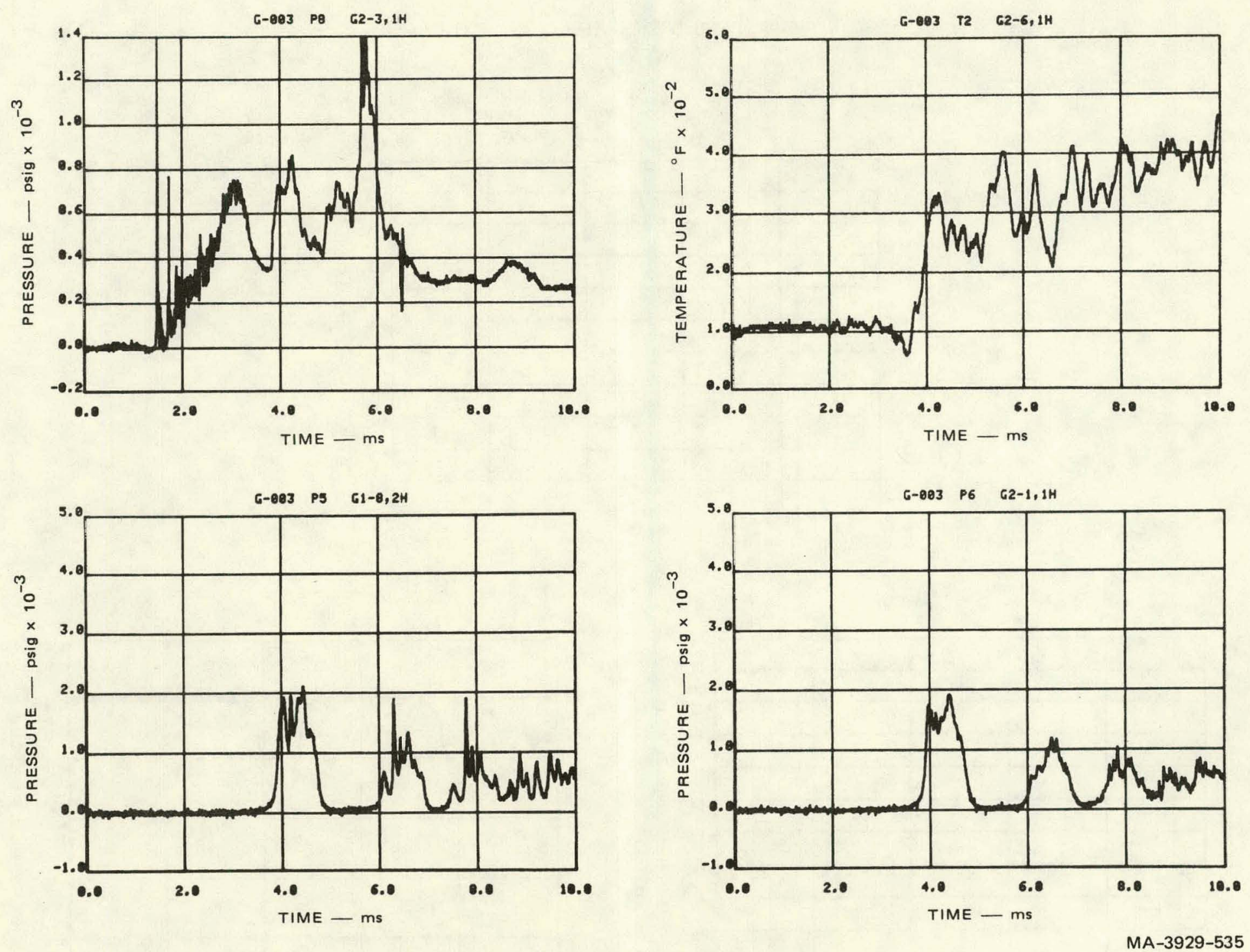

FIGURE D.2 EXPERIMENT G-003 (Continued) 

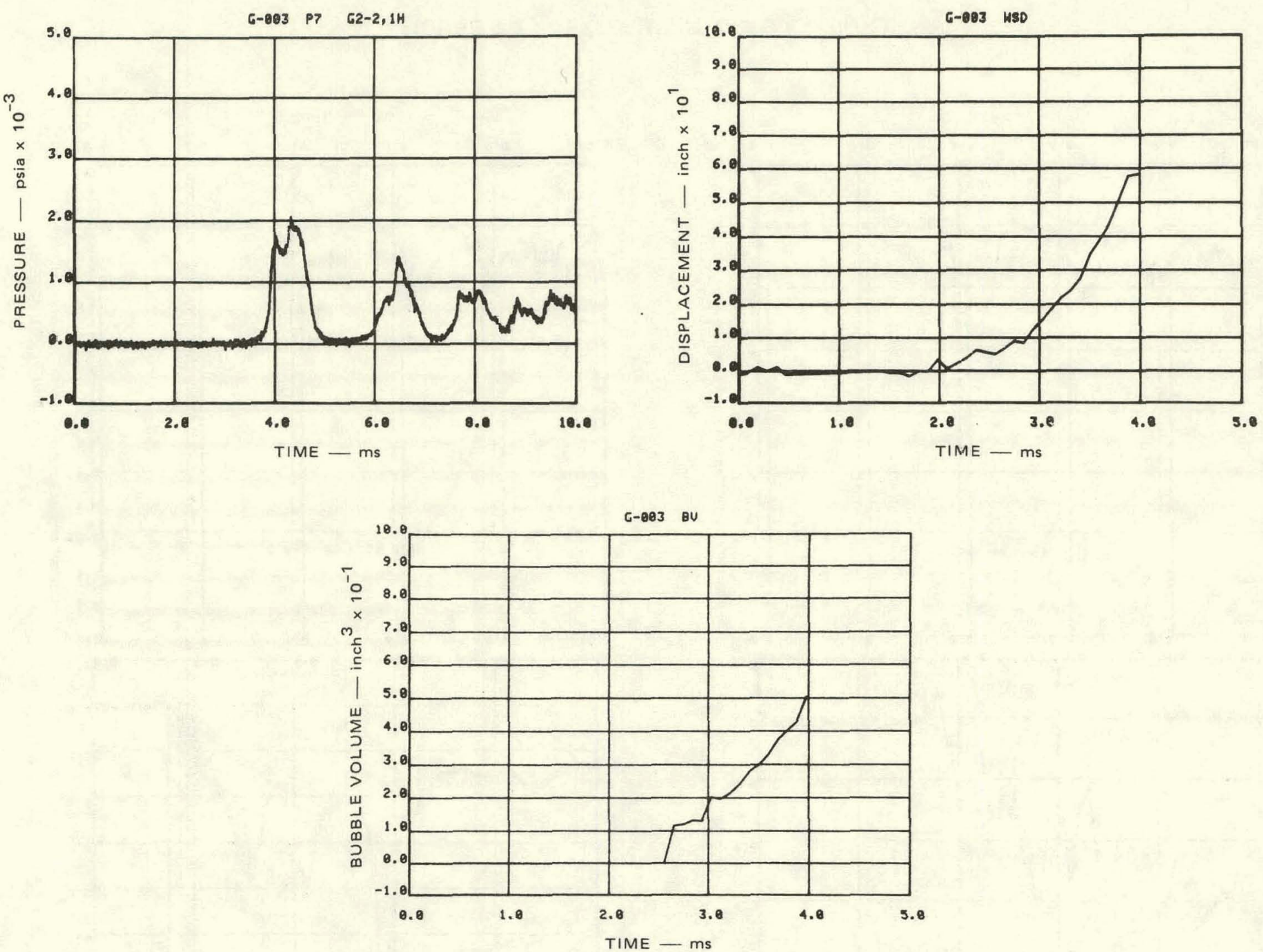

FIGURE D.2 EXPERIMENT G-003 (Continued) 


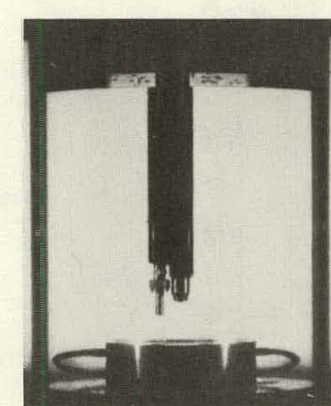

. $=1.199 \mathrm{~ms}$ from detonation It $=0.000 \mathrm{~ms}$

Joors begin to open

$\stackrel{\ominus}{\mapsto}$

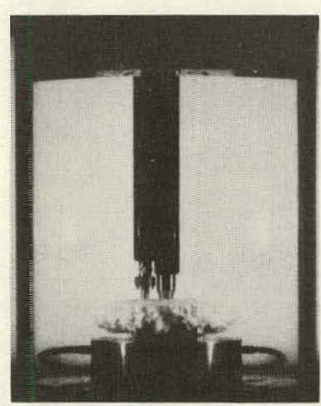

$\mathrm{t}=3.409 \mathrm{~ms}$

$\Delta \mathrm{t}=2.21 \mathrm{C} \mathrm{ms}$
Bubble reazh

pressure transducer

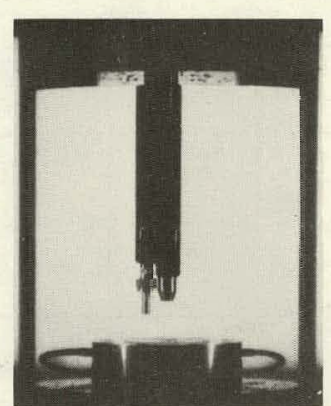

$\mathrm{t}=1.891 \mathrm{~ms}$

$\Delta \mathrm{t}=0.692 \mathrm{~ms}$

at core berrel opening

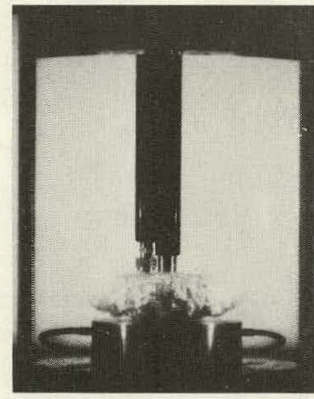

$\mathrm{t}=3.59 \subseteq \mathrm{ms}$

$\Delta \mathrm{t}=2.400 \mathrm{~ms}$
Bubble continues to graw

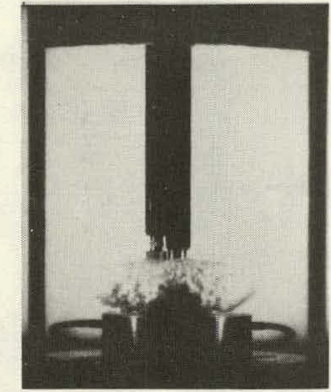

$\mathrm{t}=3.789 \mathrm{rs}$

$\Delta t=1.546 \mathrm{~ms}$
Bubble emerges into pool

$\Delta \mathrm{t}=2.590 \mathrm{~ms}$

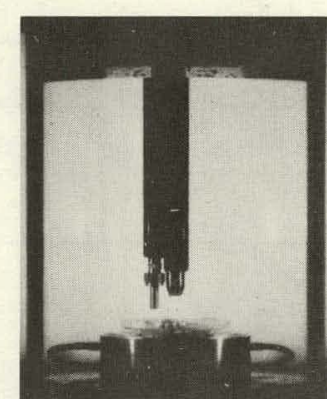

$\mathrm{t}=2.934 \mathrm{~ms}$

$\Delta \mathrm{t}=1.735 \mathrm{~ms}$

Bubble rises through vortex

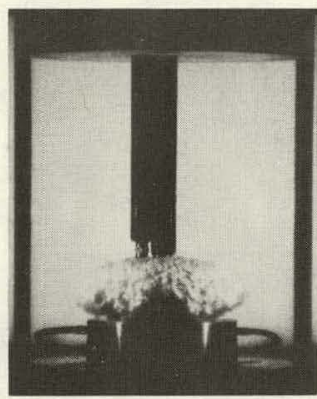

$\mathrm{t}=3.978 \mathrm{~ms}$

$\Delta t=2.779 \mathrm{~ms}$

Slug impact

at $\Delta \mathrm{t}=2.75 \mathrm{~ms}$

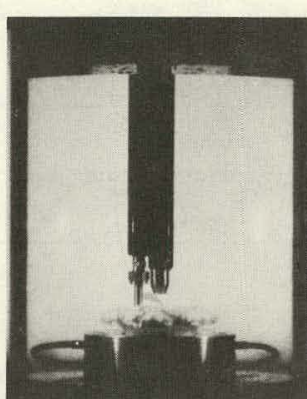

$\mathrm{t}=3.124 \mathrm{~ms}$

$\Delta \mathrm{t}=1.925 \mathrm{~ms}$
Bubble reaches thermosouple

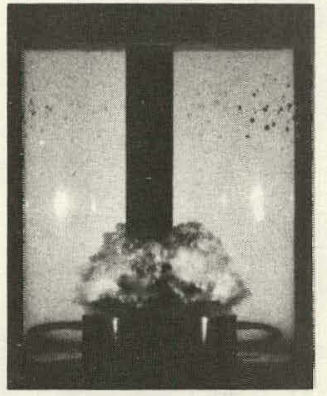

$\mathrm{t}=4.926 \mathrm{~ms}$
$\Delta \mathrm{t}=3.727 \mathrm{~ms}$

Post impact cavitation

MP-3929-537

FIGURE D.2 EXPERIMENT G-003, PHOTO SEQUENCE (Concluded) 

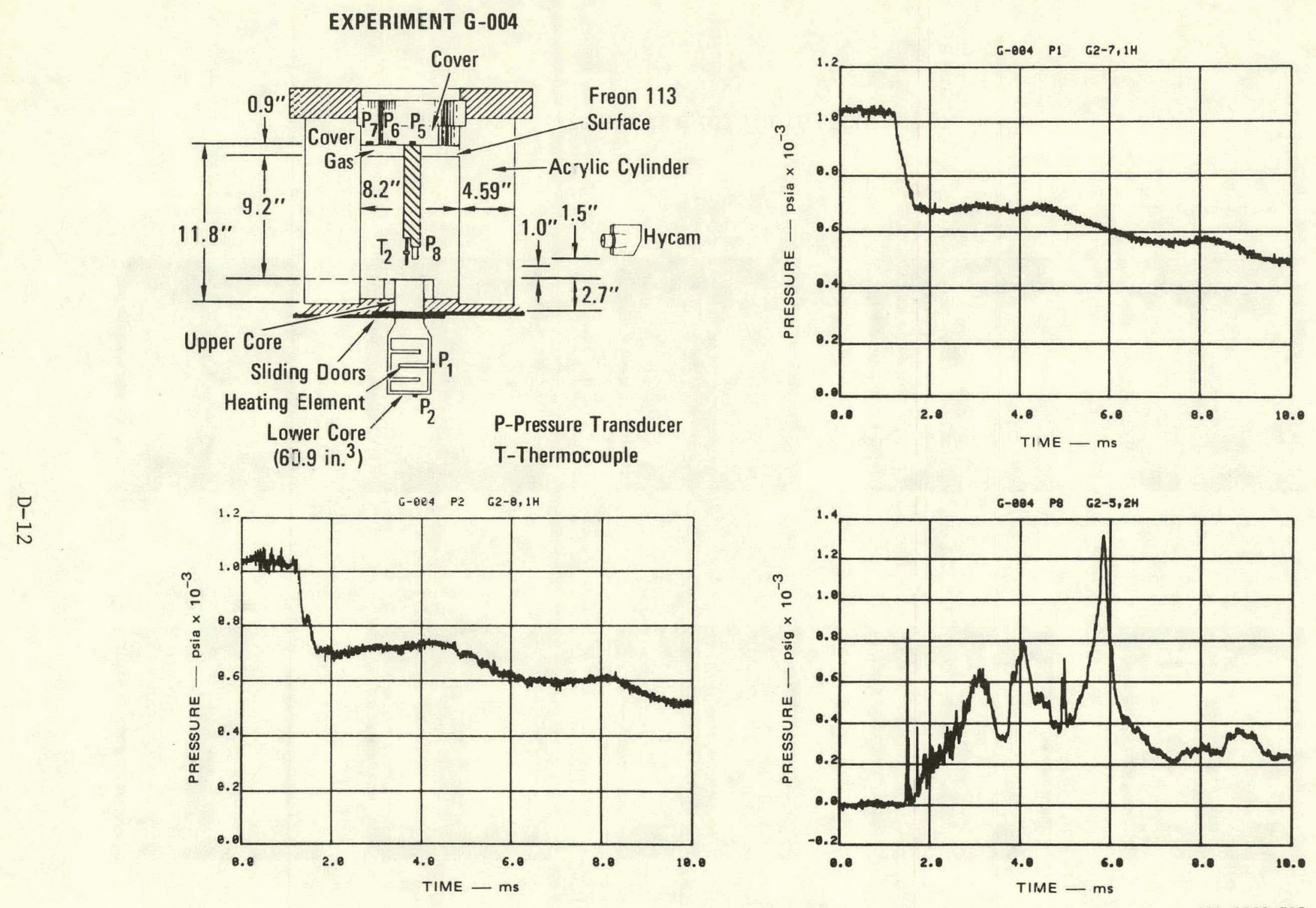

FIGURE D.3 EXPERIMENT G-004, FLASHING WATER BUBBLE SOURCE 

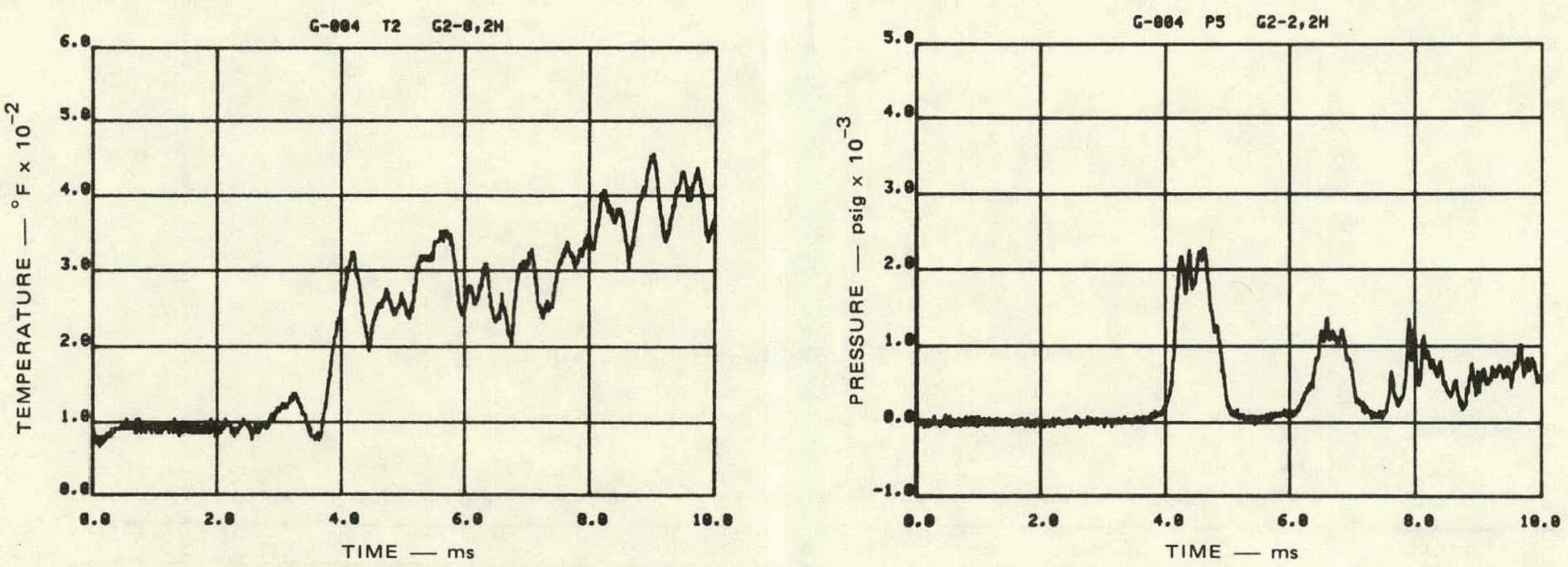

$\stackrel{\emptyset}{\stackrel{1}{\omega}}$
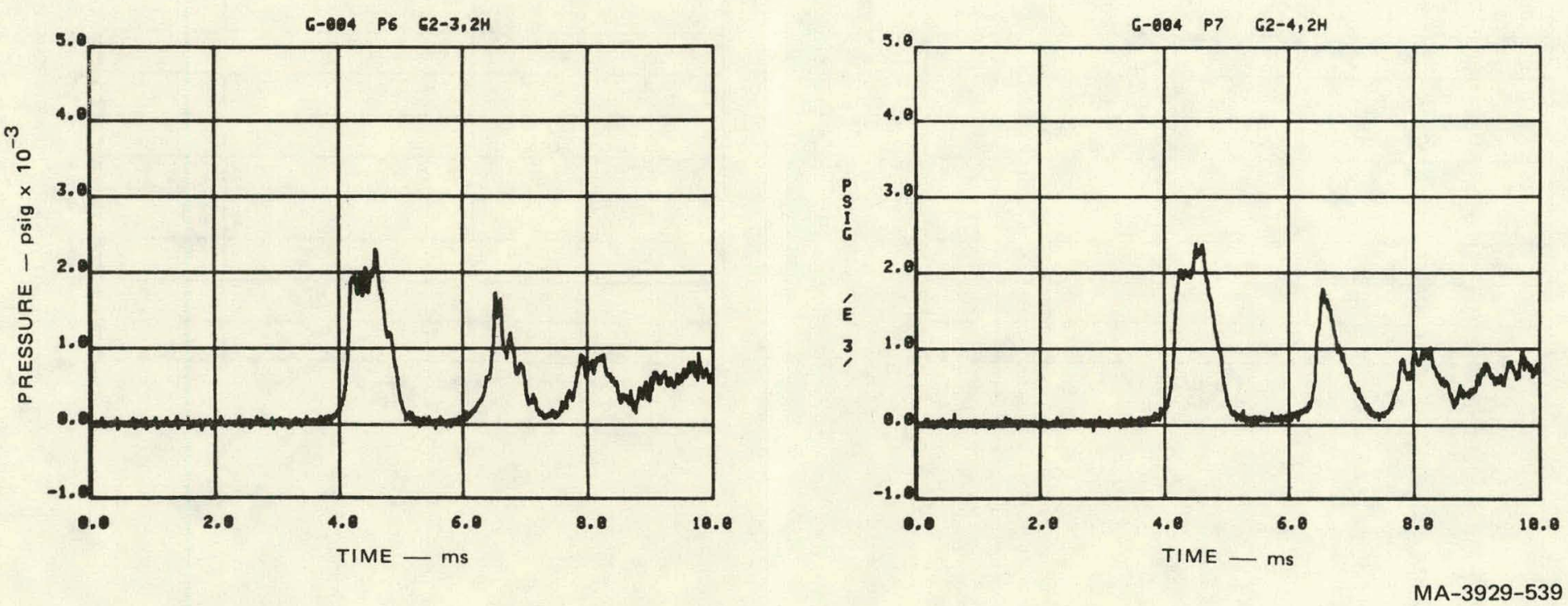

FIGURE D.3 EXPERIMENT G-004 (Continued) 

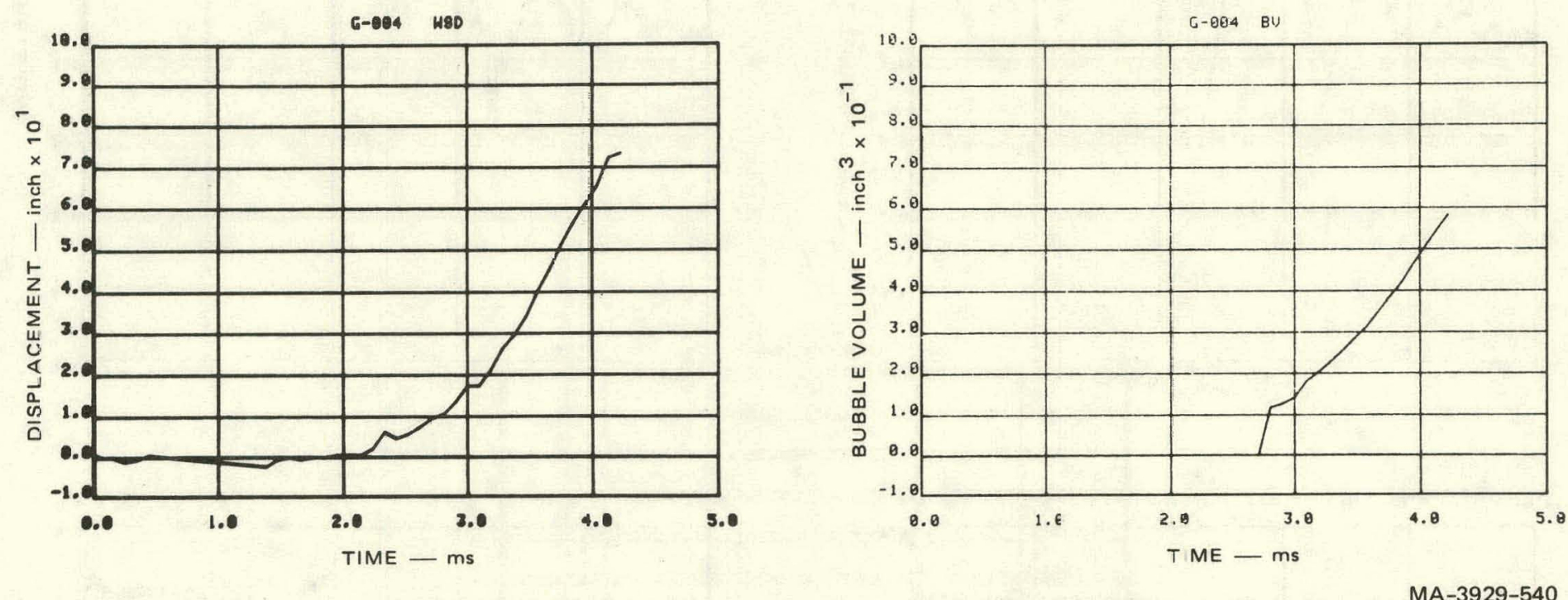

FIGURE D.3 EXPERIMENT G-004 (Continued) 


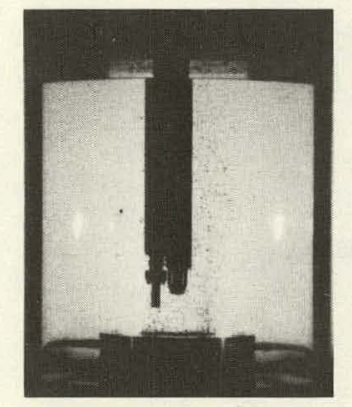

$\mathrm{t}=1.315 \mathrm{~ms}$ from cetonation Doors begin to ope

v

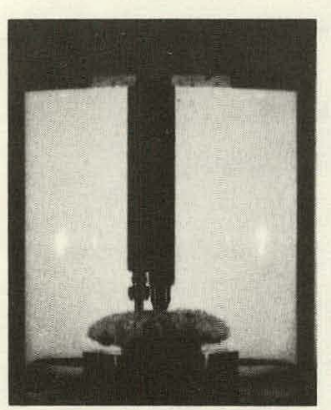

$\mathrm{t}=3.375 \mathrm{~ms}$

$\Delta t=2.060 \mathrm{~ms}$

pressure transdıcer

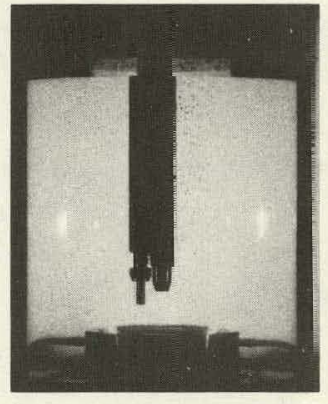

$\mathrm{t}=2.142 \mathrm{~ms}$

$\Delta \mathrm{t}=0.827 \mathrm{~ms}$

a: core barrel opening

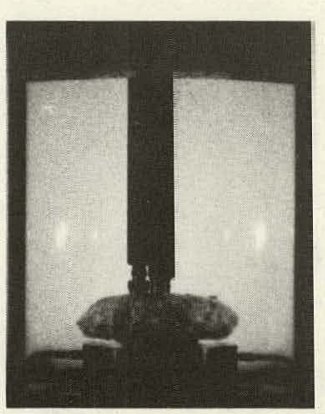

$\mathrm{t}=3.659 \mathrm{~ms}$ $\Delta \mathrm{t}=2.344 \mathrm{~ms}$ to grow

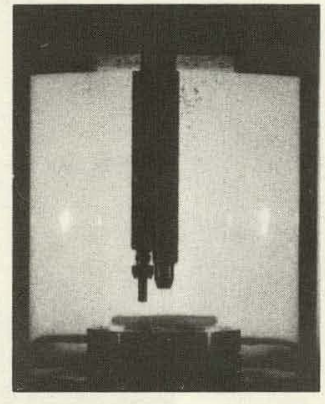

$\mathrm{t}=2.711 \mathrm{~ms}$

Bubble emerges into pool

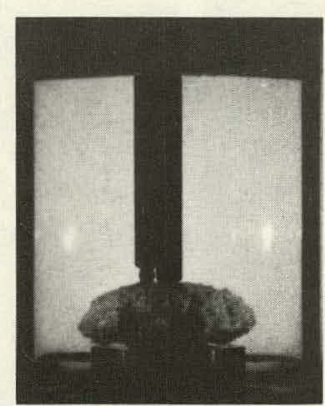

$\mathrm{t}=3.943 \mathrm{~ms}$

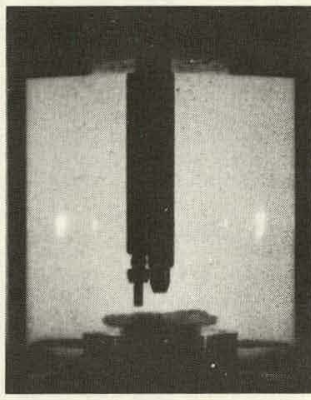

$\mathrm{t}=2.995 \mathrm{~ms}$

Eubble engulfs vortex

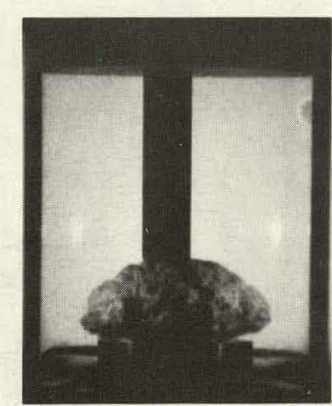

$\mathrm{t}=4.228 \mathrm{~ms}$

$\Delta \mathrm{t}=2.913 \mathrm{~ms}$

at $\Delta \mathrm{t}=2.89 \mathrm{~ms}$

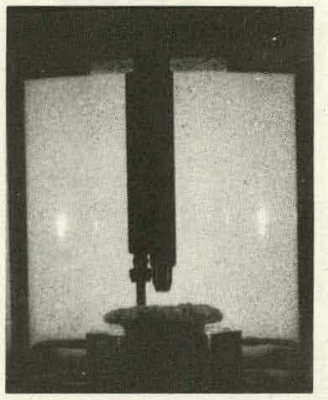

$\mathrm{t}=3.090 \mathrm{~ms}$

$\Delta t=1.775 \mathrm{~ms}$
Bubble reaches thermocouple

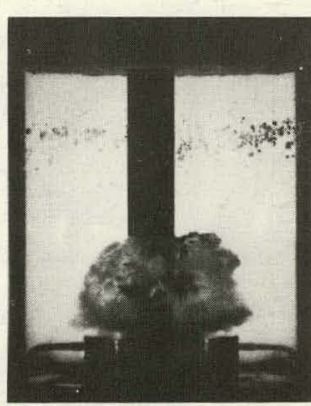

$\mathrm{t}=5.175 \mathrm{~ms}$

Post impact cavitation

MP-3929-541

FIGURE D.3 EXPERIMENT G-004, PHOTO SEQUENCE (Concluded) 

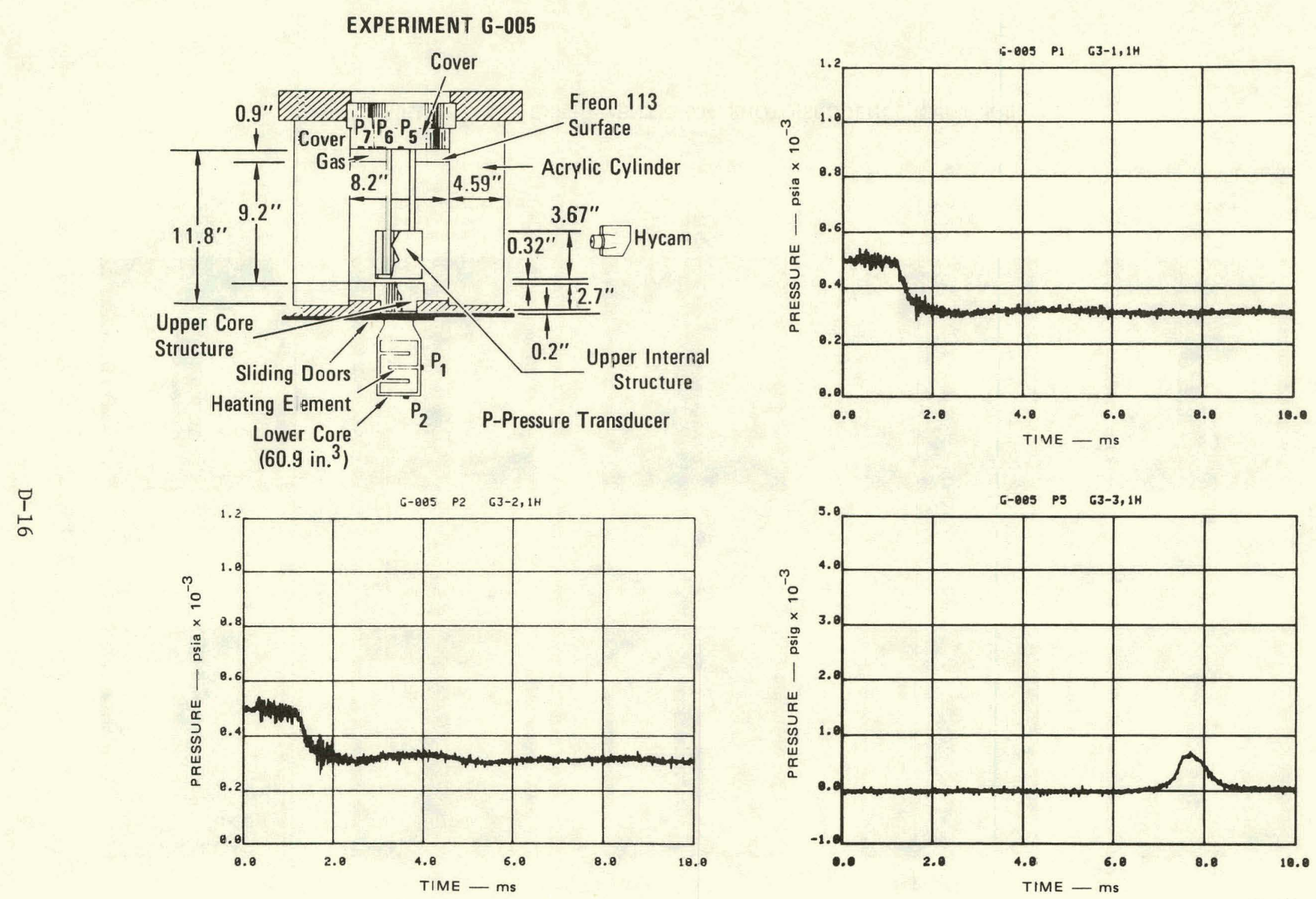

MA-3929-542

FIGURE D.4 EXPERIMENT G-005, FLASHING WATER BUBBLE SCURCE 

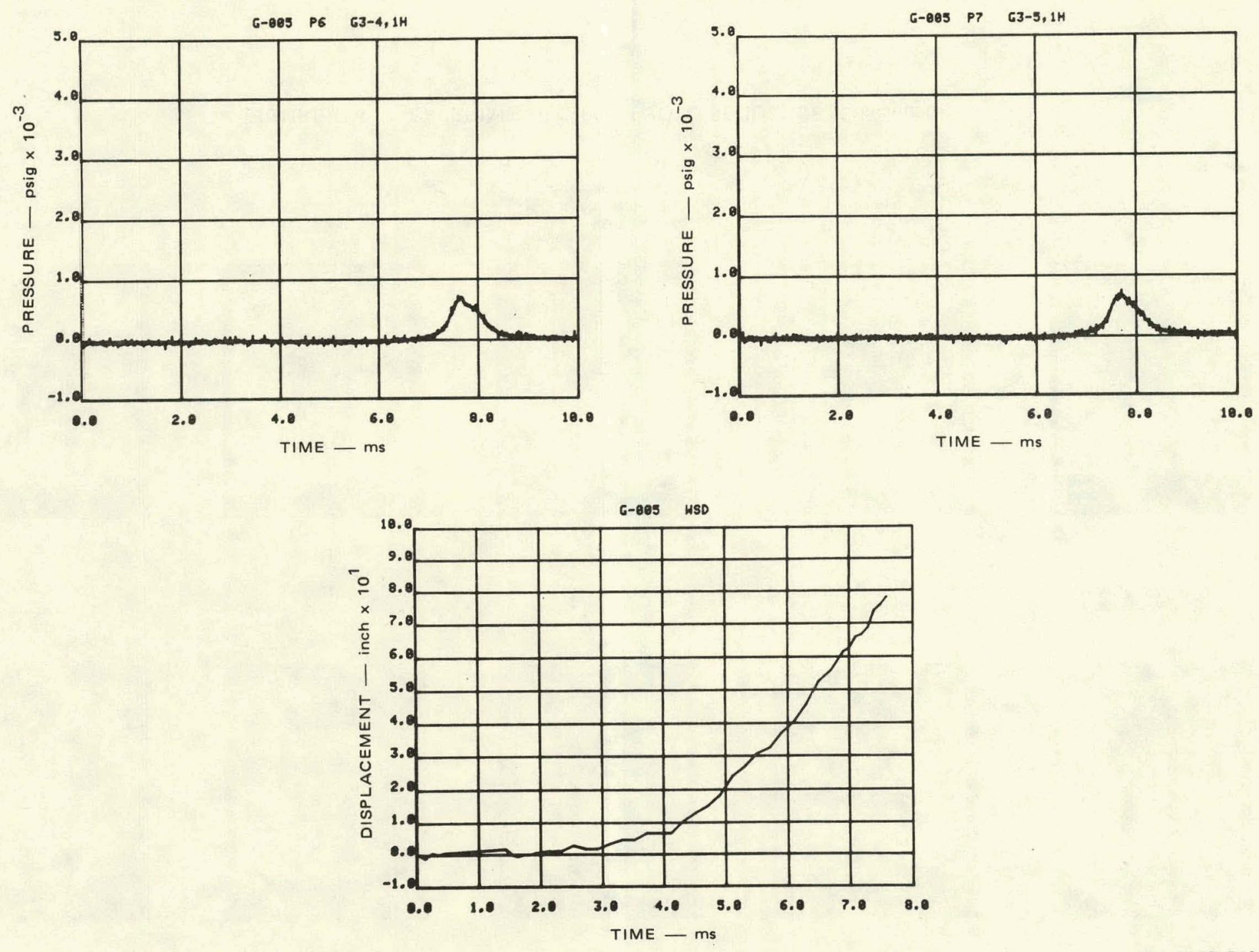

FIGURE D.4 EXPERIMENT G-005 (Continued) 


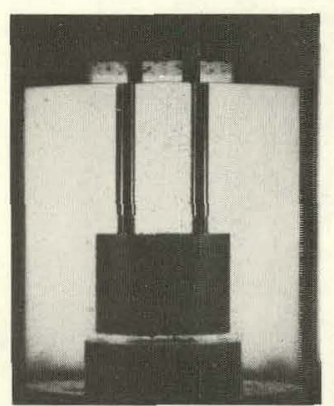

$\mathrm{t}=1.302 \mathrm{~ms}$ from detonaticr $\Delta \mathrm{t}=0.000 \mathrm{~ms}$

$\stackrel{\bullet}{!}$

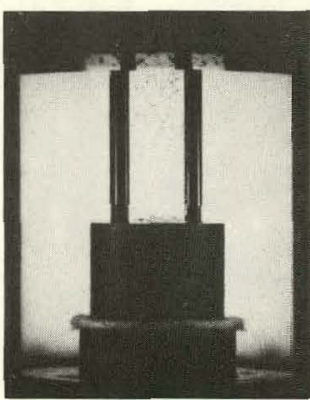

$\mathrm{t}=4.810 \mathrm{~ms}$ $\Delta \mathrm{t}=3.508 \mathrm{~ms}$
Vortices form above UIS

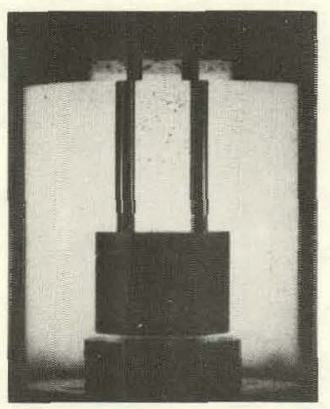

$\mathrm{t}=3.123 \mathrm{~ms}$

Vortices form above UCS

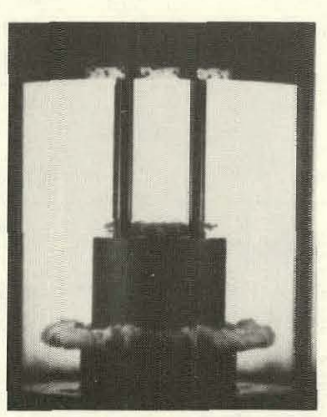

$\mathrm{t}=5.901 \mathrm{~ms}$

$\Delta \mathrm{t}=4.599 \mathrm{~ms}$

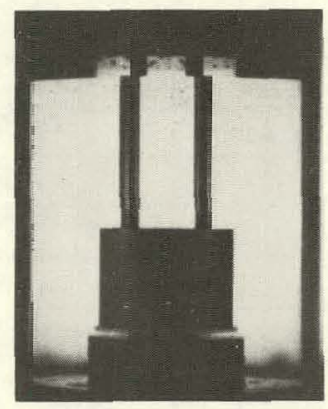

$\mathrm{t}=3.818 \mathrm{~ms}$

$\Delta \mathrm{t}=2.51 \mathrm{~m} \mathrm{~ms}$

of UIS

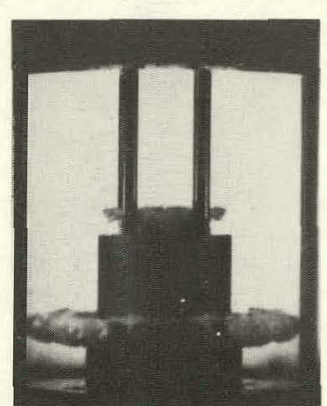

$\mathrm{t}=6.893 \mathrm{~ns}$ $\Delta \mathrm{t}=5.59 \mathrm{~ms}$
3ubble reaches yessel wall

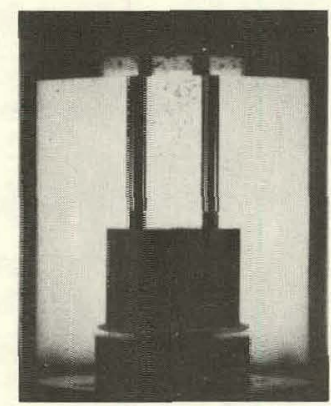

$\mathrm{t}=\angle .115 \mathrm{~ms}$ Votex grows

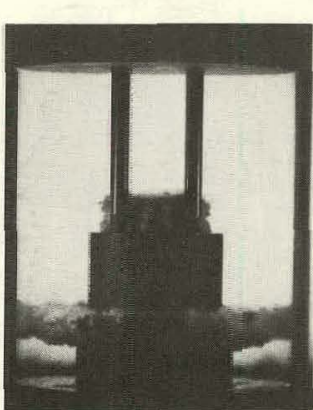

$\mathrm{t}=7.587 \mathrm{~ms}$ $\Delta \mathrm{t}=6.285 \mathrm{~ms}$ at $\angle:=6.26 \mathrm{~ms}$

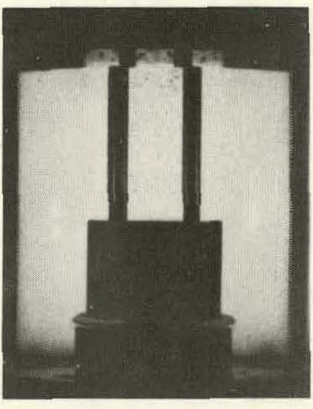

$\mathrm{t}=4.512 \mathrm{~ms}$

Bubble emerges

between UCS and UIS

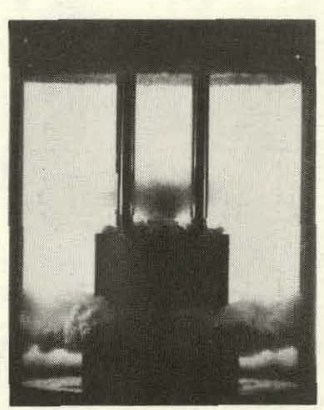

$\mathrm{t}=8.877 \mathrm{~ms}$ $\Delta t=7.575 \mathrm{~ms}$ 

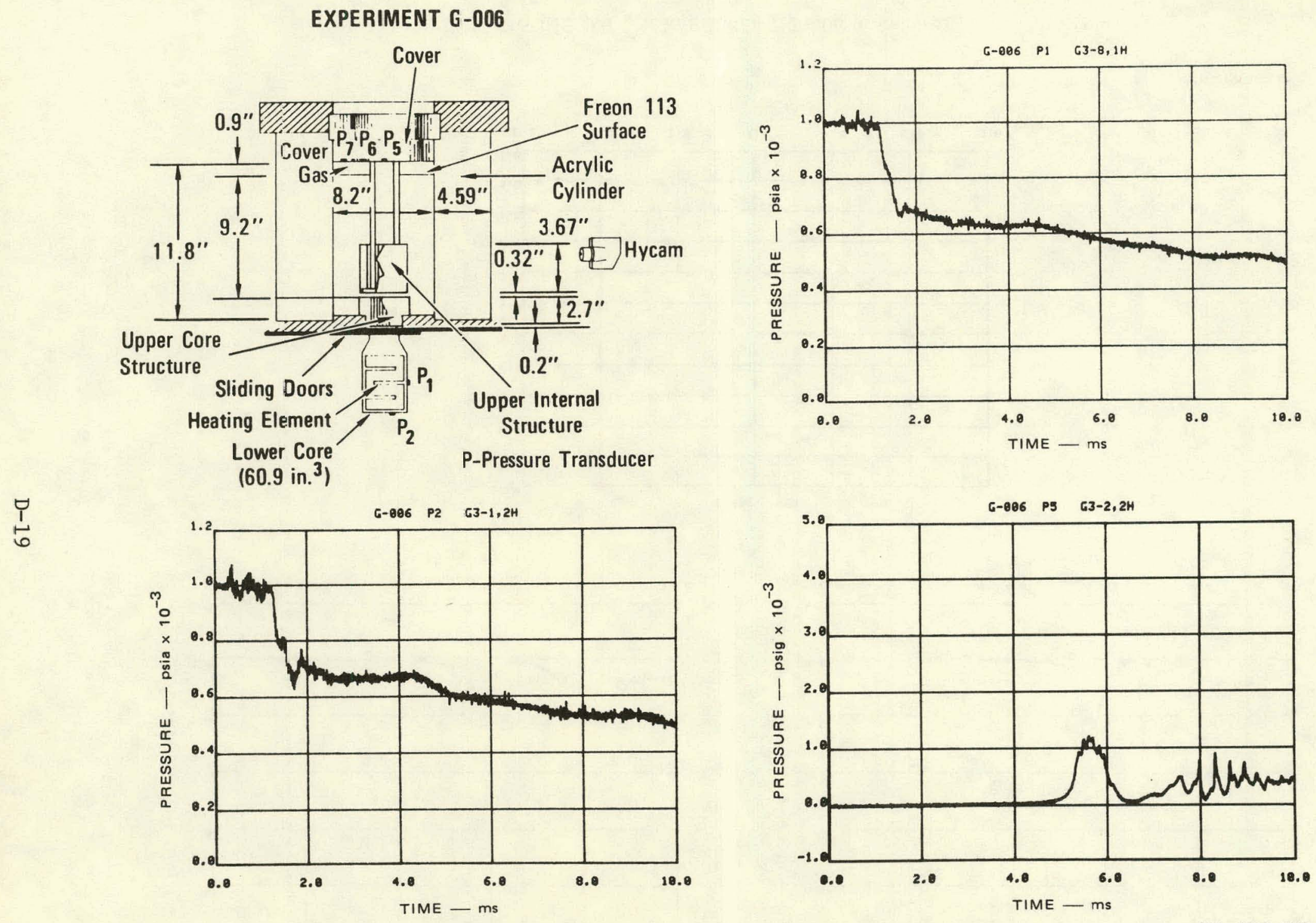

FIGURE D.5 EXPERIMENT G-006, FLASHING WATER BUBBLE SOURCE 

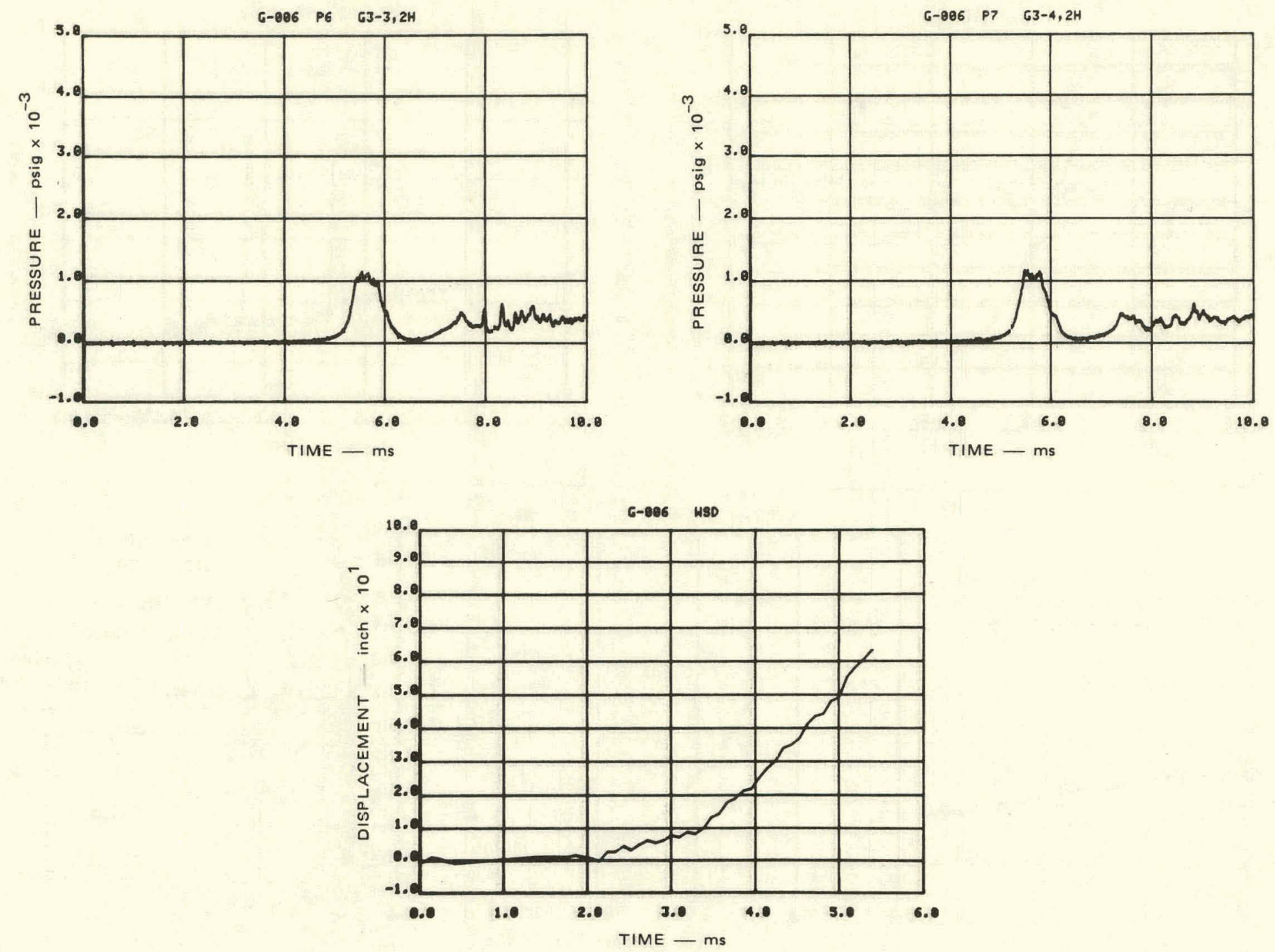

FIGURE D.5 EXPERIMENT G-006 (Continued) 


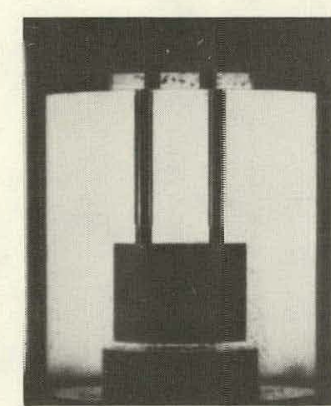

$t=1.313 \mathrm{~ms}$ from detonation

$\Delta \mathrm{t}=0.000 \mathrm{~ms}$

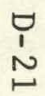

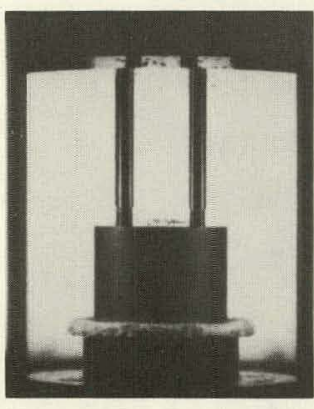

$\mathrm{t}=3.667 \mathrm{~ms}$

$\Delta t=2.354 \mathrm{~ms}$
Vortices form abcve UIS

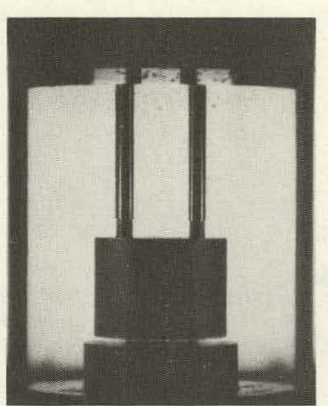

$t=2.523 \mathrm{~ms}$

$\Delta \mathrm{t}=1.210 \mathrm{mis}$
Vortices form above UCS

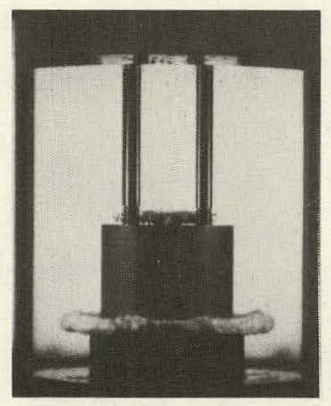

$\mathrm{t}=4.04 \mathrm{sm}$ $\Delta \mathrm{t}=2.736 \mathrm{~ms}$

Bubble emerges
through UIS

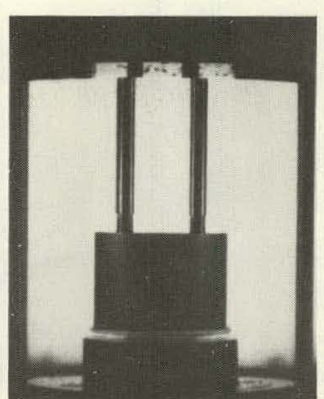

$\mathrm{t}=2.809 \mathrm{~ms}$

$\Delta t=1.496 \mathrm{~ms}$

Vortex forms at bas

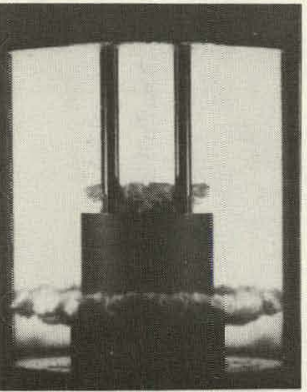

$\mathrm{t}=5.098 \mathrm{~ms}$ $\Delta \mathrm{t}=3.785 \mathrm{~ms}$ vessel wall

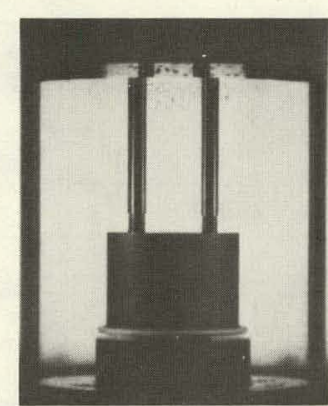

$\mathrm{t}=3.095 \mathrm{~ms}$

$\Delta \mathrm{t}=1.782 \mathrm{~m}$

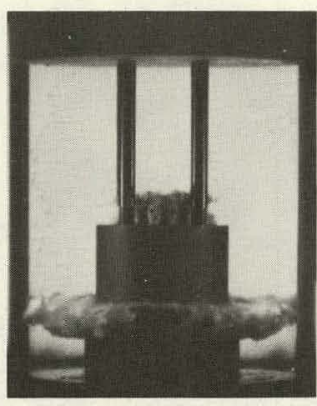

$\mathrm{t}=5.384 \mathrm{~ms}$

$\Delta \mathrm{t}=4.071 \mathrm{~ms}$

at $\Delta \mathrm{t}=4.04 \mathrm{~ms}$

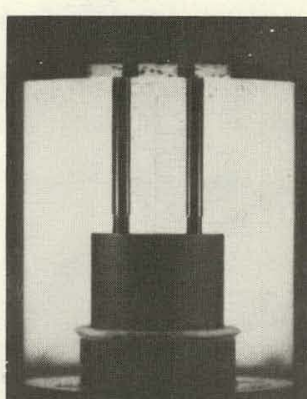

$\mathrm{t}=3.381 \mathrm{~ms}$

$\Delta \mathrm{t}=2.068 \mathrm{~ms}$

Bubble emerges

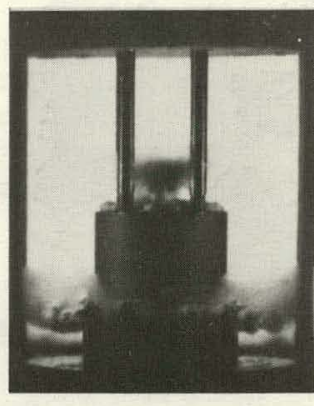

$\mathrm{t}=6.623 \mathrm{~ms}$ $\Delta \mathrm{t}=5.310 \mathrm{~ms}$
Post impact

FIGUR D D.5 EXPERIMENT G-006, PHOTO SEQUENCE (Concluded) 

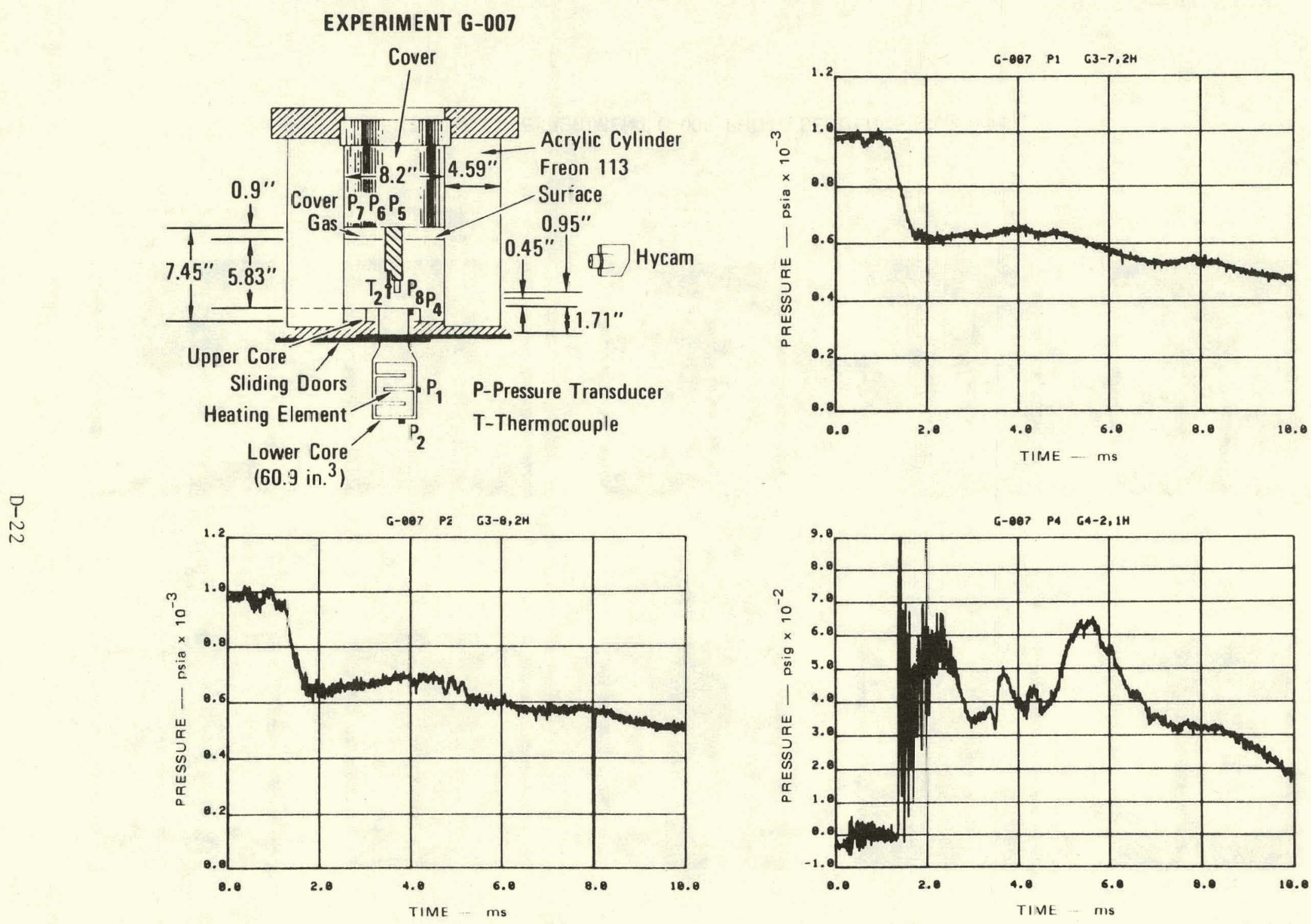

MA-3929-548

FIGURE D.6 EXPERIMENT G-007, FLASHING WATER BUBBLE SCURCE 

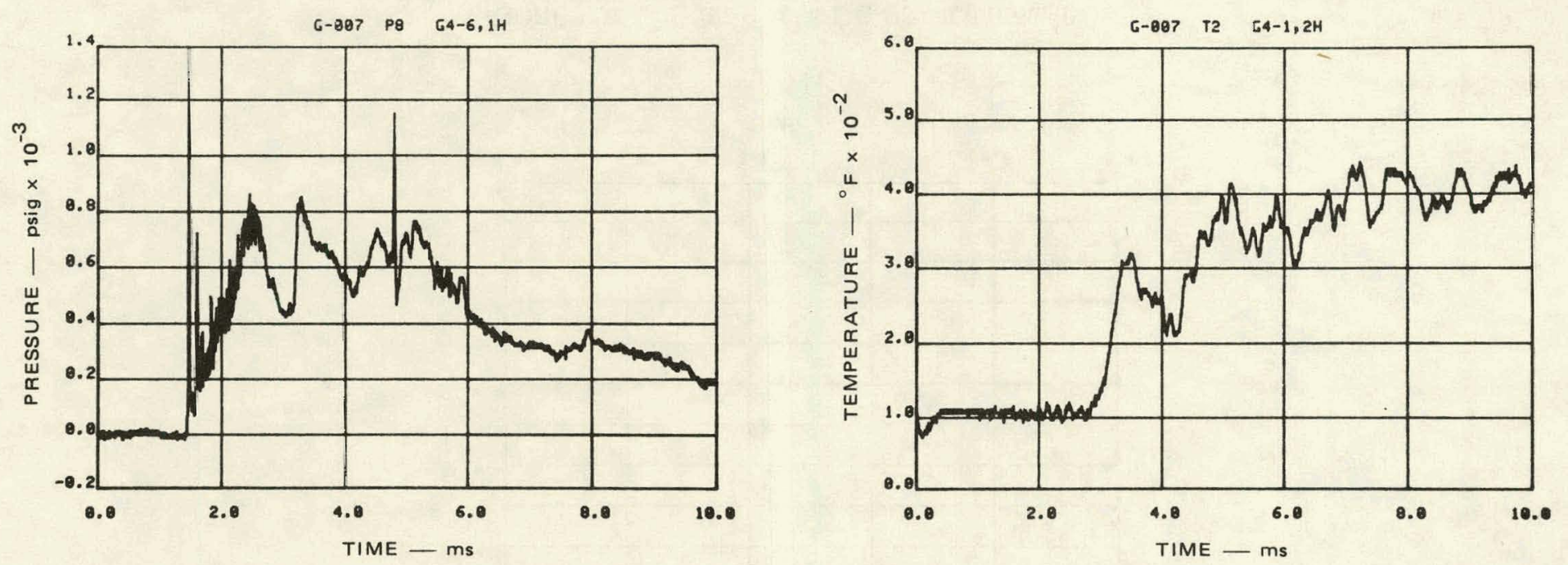

$\forall$
$\sim$
$\omega$
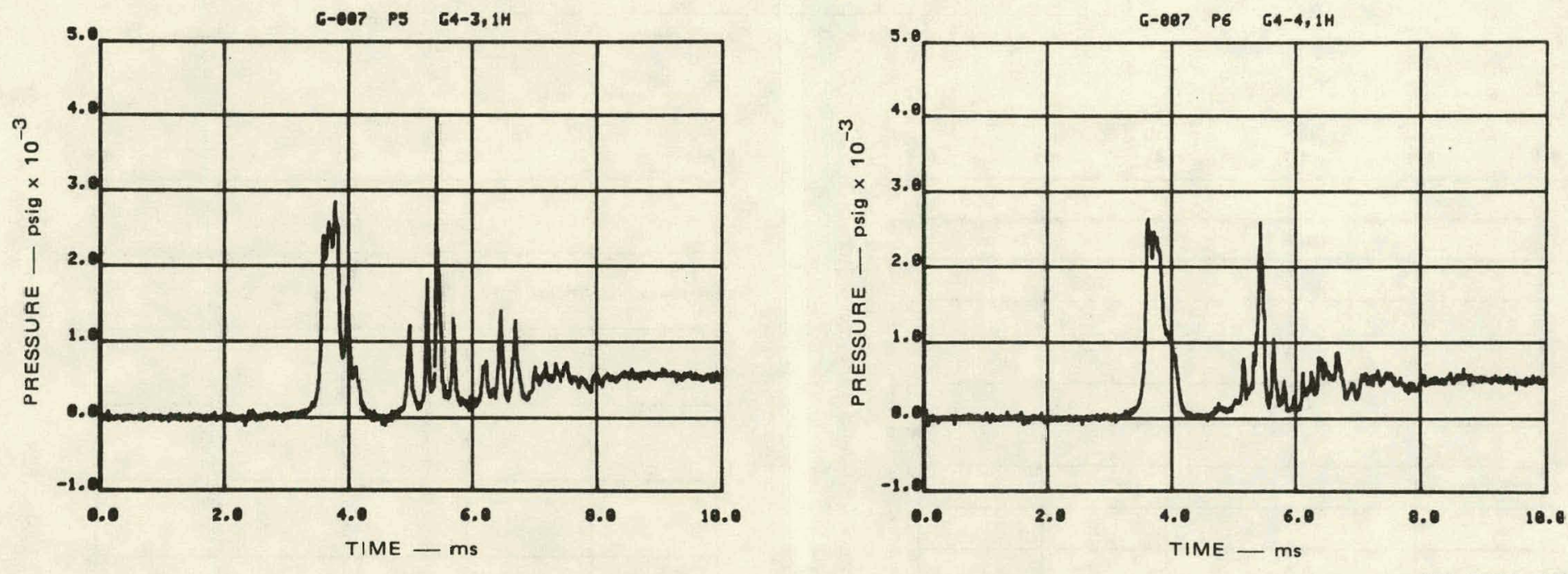

FIGURE D.6 EXPERIMENT G-007 (Continued) 

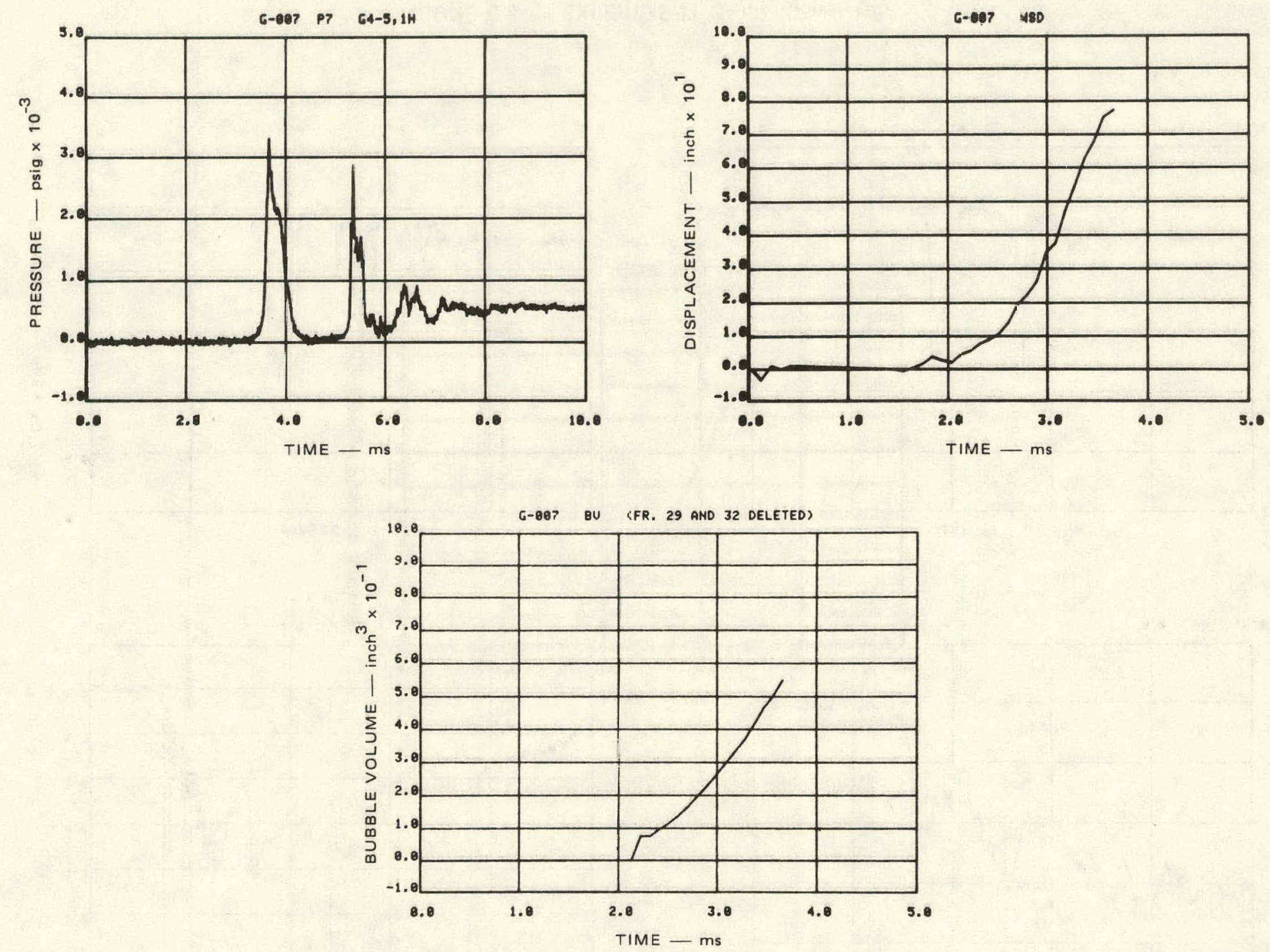

FIGURE D.6 EXPERIMENT G-007 (Continued) 


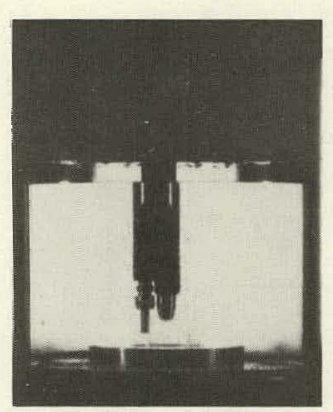

$\mathrm{t}=1.309 \mathrm{~ms}$ from cetonation $\Delta t=0.000 \mathrm{~ms}$
Doors begin to open

$\ominus$
N

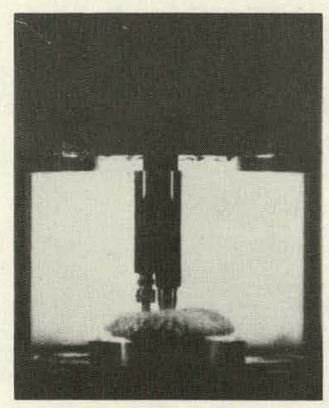

$t=2.704$

$\Delta \mathrm{t}=1.395 \mathrm{~ms}$

Bubble reaches

pressure transdicer

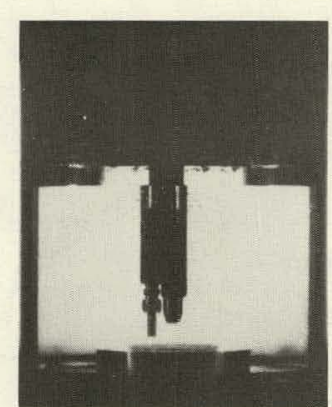

$\mathrm{t}=1.942 \mathrm{rs}$

$\Delta \mathrm{t}=0.633 \mathrm{~ms}$

at core barrel openir

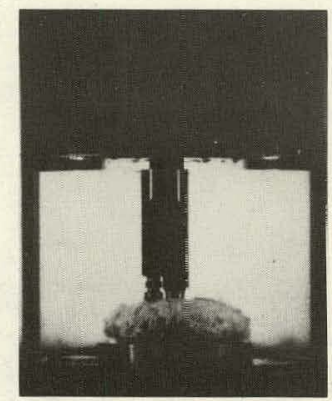

$\mathrm{t}=2.990 \mathrm{~ms}$

$\Delta \mathrm{t}=1.68 \mathrm{Ims}$

Bubble continues
to grow

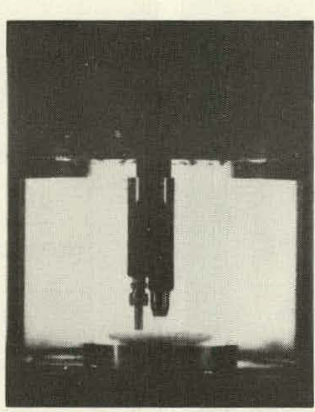

$\mathrm{t}=2.323 \mathrm{~ms}$

$\Delta \mathrm{t}=1.014 \mathrm{~ms}$

into pool

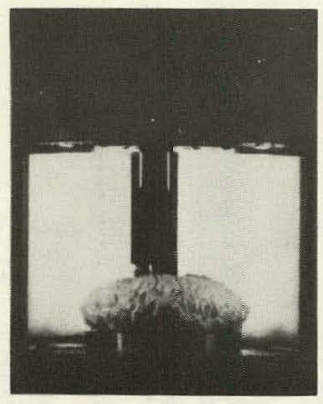

$\mathrm{t}=3.276 \mathrm{~ms}$
$\Delta \mathrm{t}=1.967 \mathrm{~ms}$

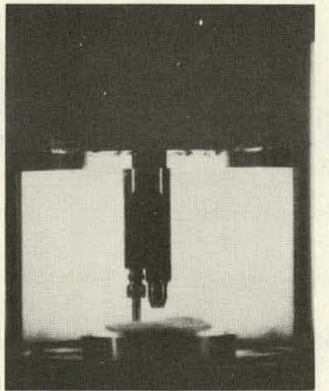

$\mathrm{t}=2.418 \mathrm{~ms}$ $\Delta \mathrm{t}=1.109 \mathrm{~ms}$

Bubble reach

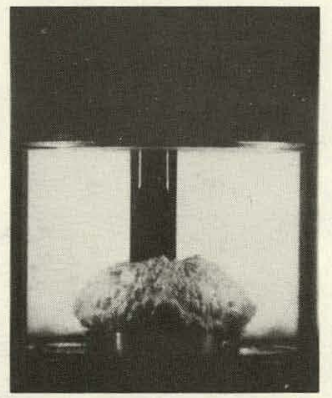

$\mathrm{t}=3.562 \mathrm{~ms}$

$\Delta \mathrm{t}=2.253 \mathrm{~ms}$

Slug impact

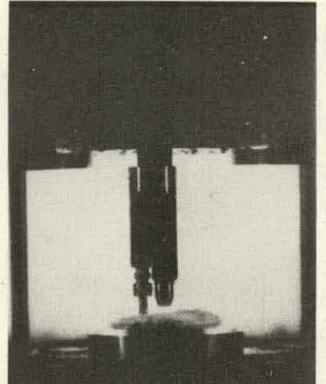

$\mathrm{t}=2.514 \mathrm{~ms}$

$\Delta t=1.205 \mathrm{~ms}$
Bubble engulfs vortex

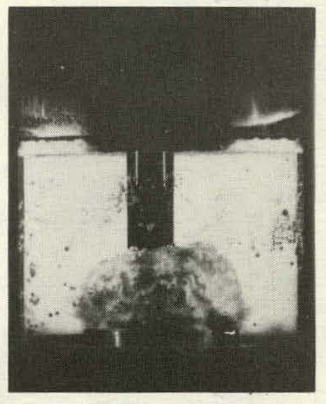

$\mathrm{t}=4.325 \mathrm{~ms}$

$\Delta \mathrm{t}=3.016 \mathrm{~ms}$

Post impact cavitation

MP-3923-551

FIGURE D.6 EXPERIMENT G-007, PHOTO SEQUENCE (Concluded) 


\section{EXPERIMENT G-008}

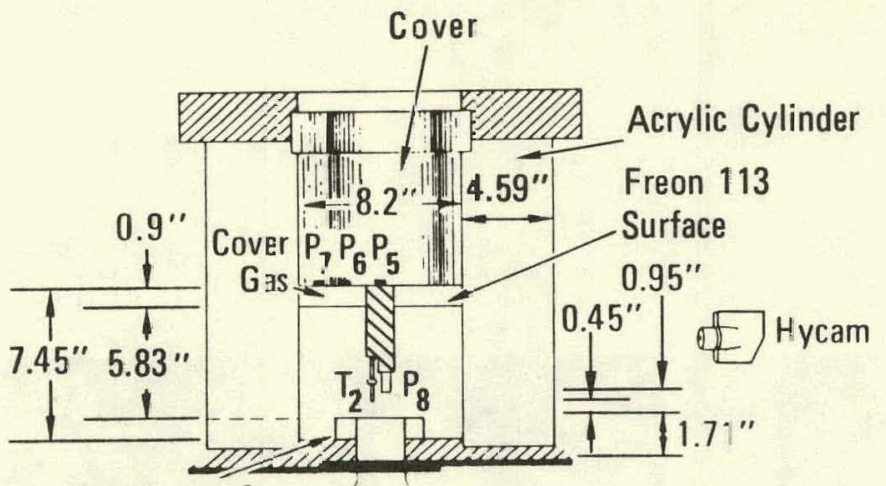

Transparent Upper Care

Heating Element $\mathrm{P}_{1} \quad$ P-Pressure Transducer Lower Czre $P_{2} \quad T$-Thermocouple
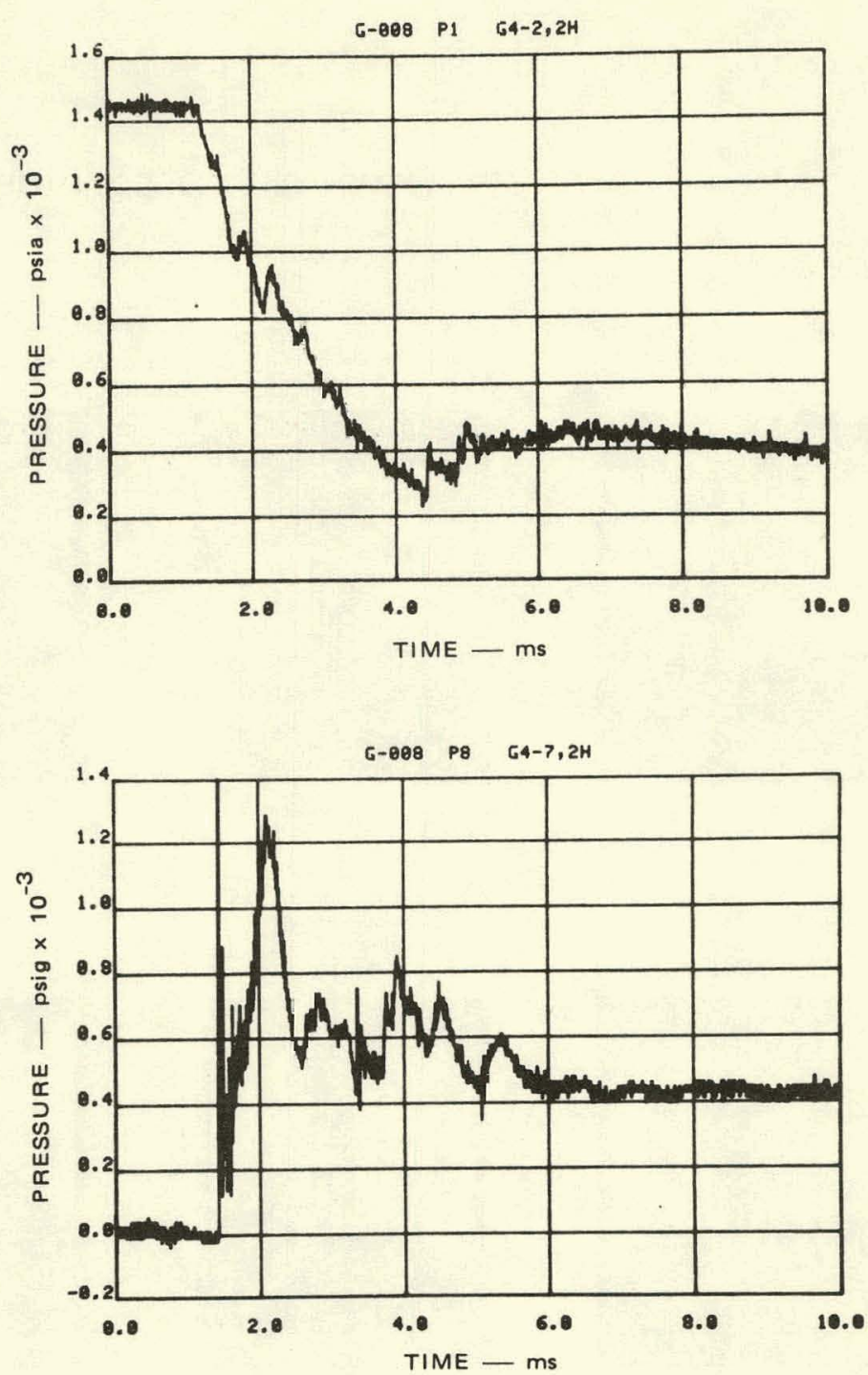

MA-3929-552

FIGURE D.7 EXPERIMENT G-008, NITROGEN BUBBLE SOURCE 

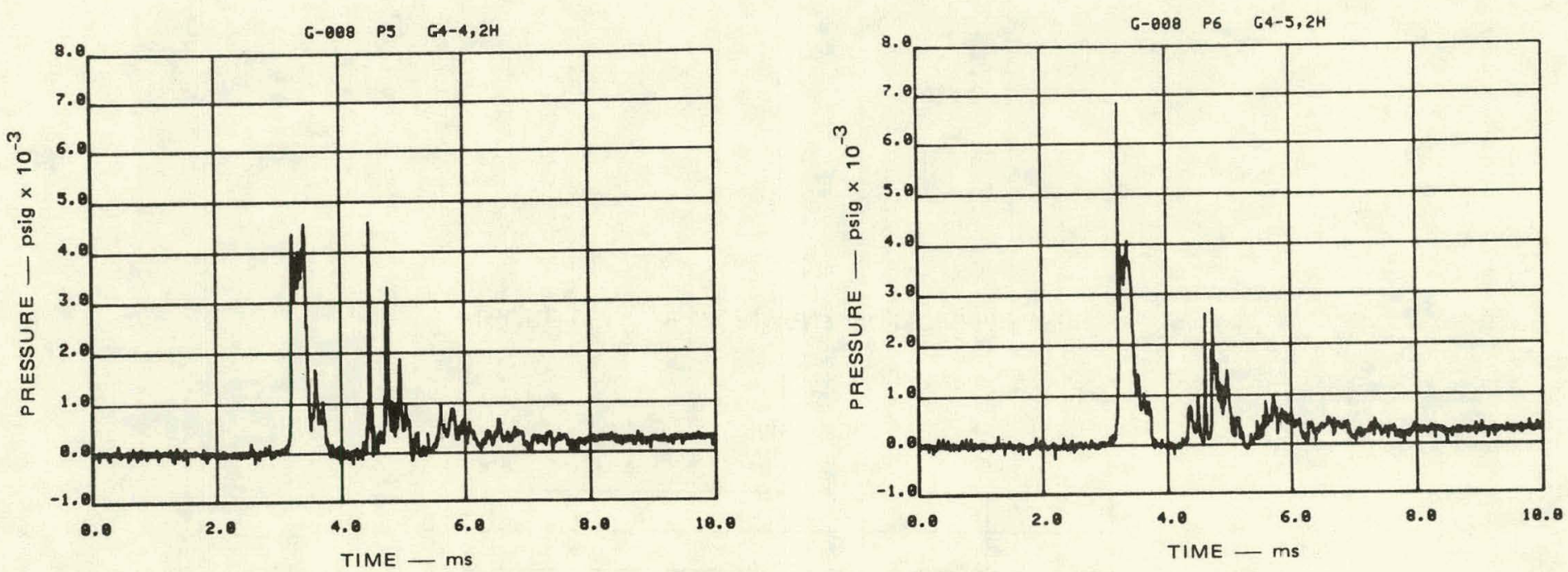

본
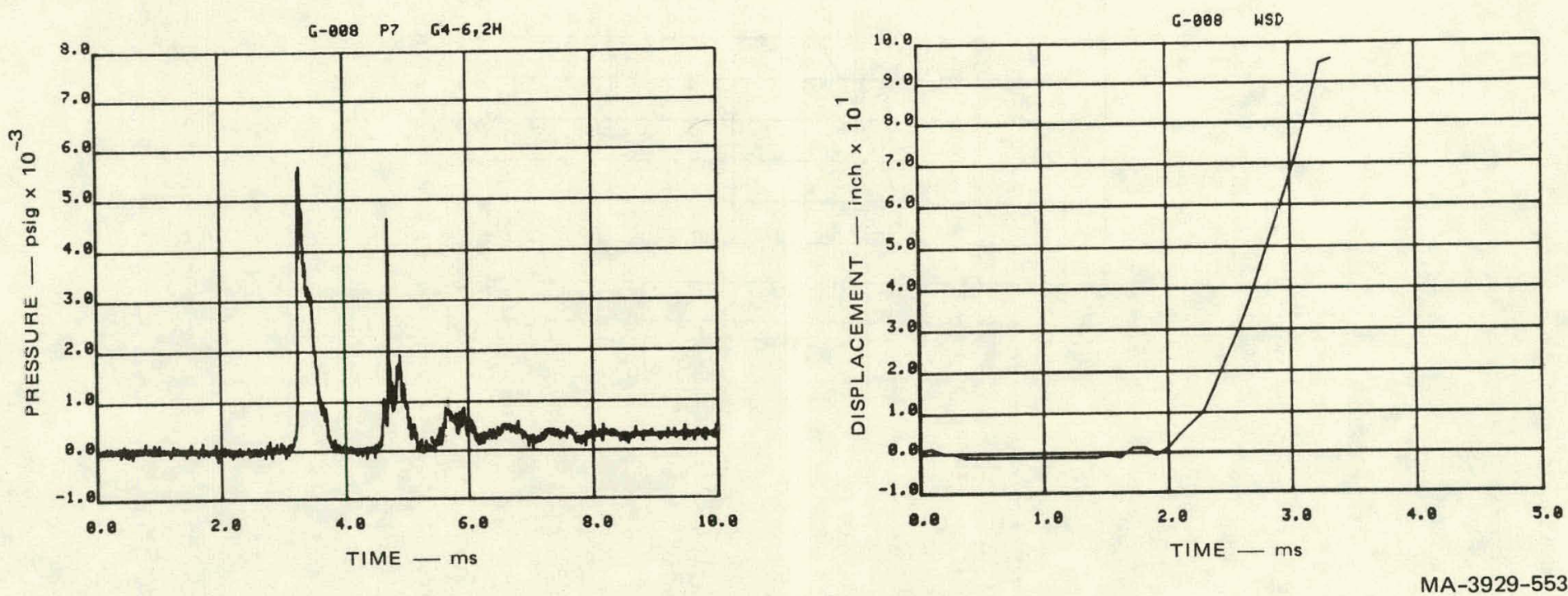

FIGURE D.7 EXPERIMENT G-008 (Continued) 


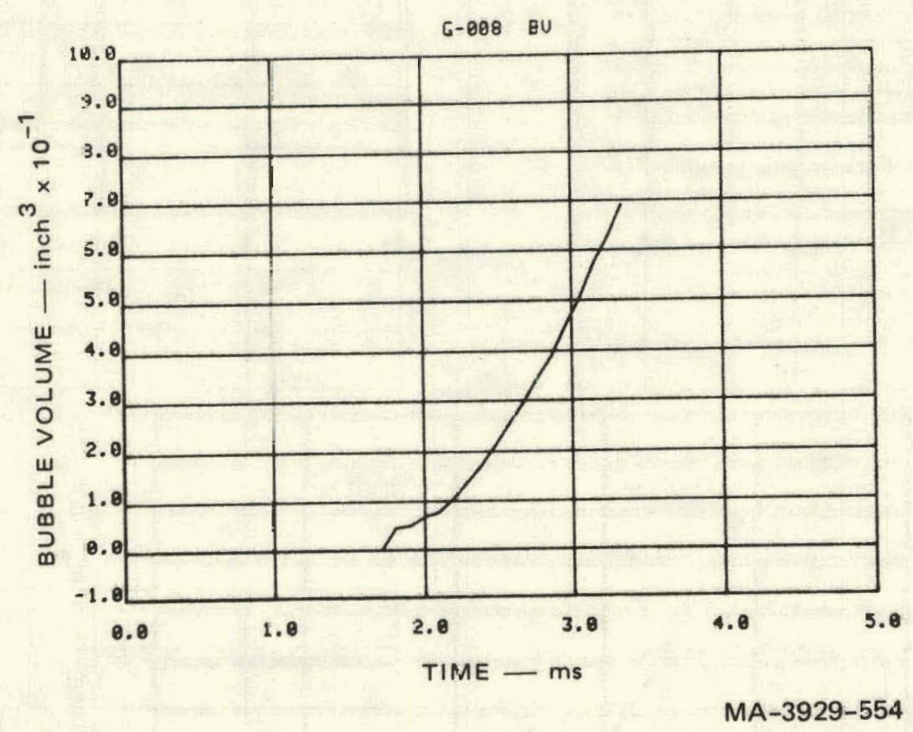

FIGURE D.7 EXPERIMENT G-008 (Continued) 


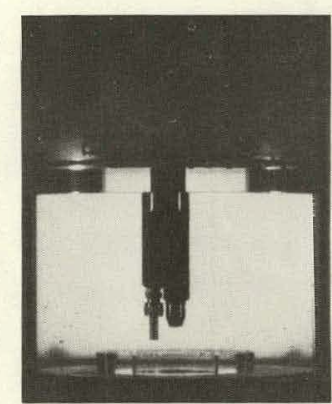

$\mathrm{t}=1.199 \mathrm{~ms}$ from detonation

$\Delta \mathrm{t}=0.000 \mathrm{~ms}$
Doors begin to open

$\forall$
1
0

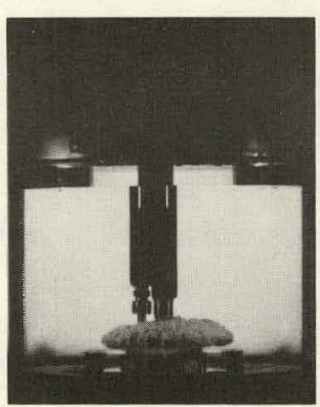

$\mathrm{t}=2.381 \mathrm{~ms}$

$\Delta \mathrm{t}=1.182 \mathrm{~ms}$

Bubble reaches

pressure transducer

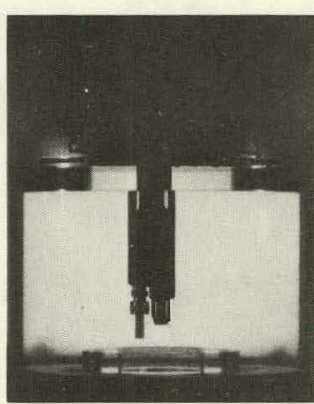

$\mathrm{t}=1.712 \mathrm{~ms}$

Vortex forms

at core barrel opening

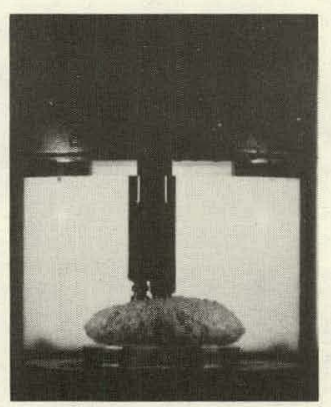

$\mathrm{t}=2.667 \mathrm{~ms}$ $\Delta \mathrm{t}=1.46 \varepsilon \mathrm{ms}$
Bubble continues to grow

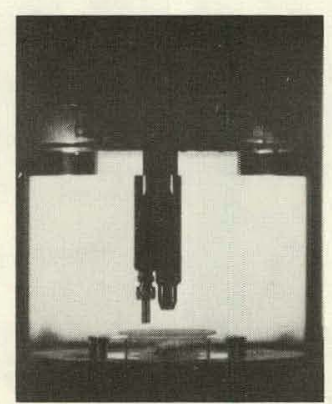

$\mathrm{t}=1.903 \mathrm{~ms}$

$\Delta \mathrm{t}=0.704 \mathrm{~ms}$

upper core

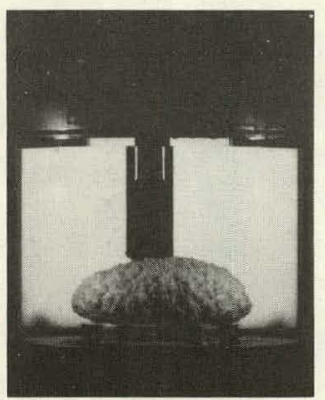

$\mathrm{t}=2.954 \mathrm{~ms}$

$\Delta \mathrm{t}=1.755 \mathrm{~ms}$

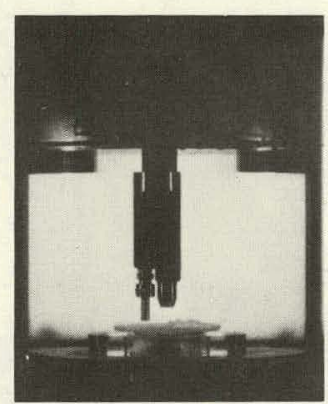

$\mathrm{t}=2.094 \mathrm{~ms}$

Bubble emerges

into pool

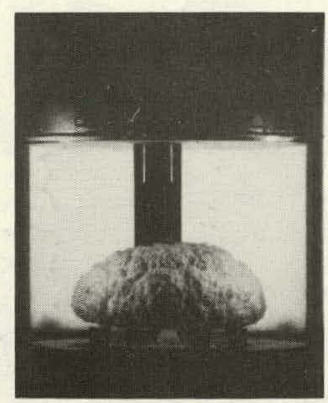

$\mathrm{t}=3.240 \mathrm{~ms}$

$\Delta \mathrm{t}=2.041 \mathrm{~ms}$

Slug impact

at $\Delta \mathrm{t}=2.03 \mathrm{~ms}$

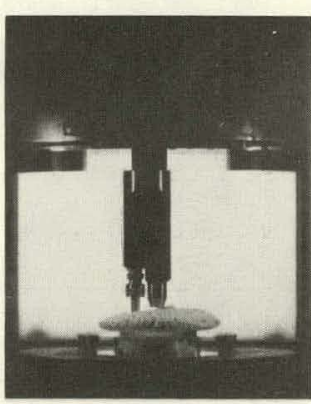

$\mathrm{t}=2.285 \mathrm{~ms}$

Bubble engulfs vortex

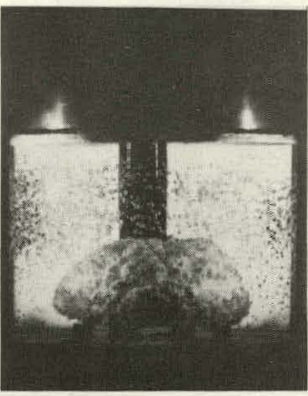

$\mathrm{t}=3.814 \mathrm{~ms}$

$\Delta \mathrm{t}=2.615 \mathrm{~ms}$.

Post impact cavitation

MP-3929-555

FIGURE D.7 EXPERIMENT G-008, PHOTO SEQUENCE (Concluded) 

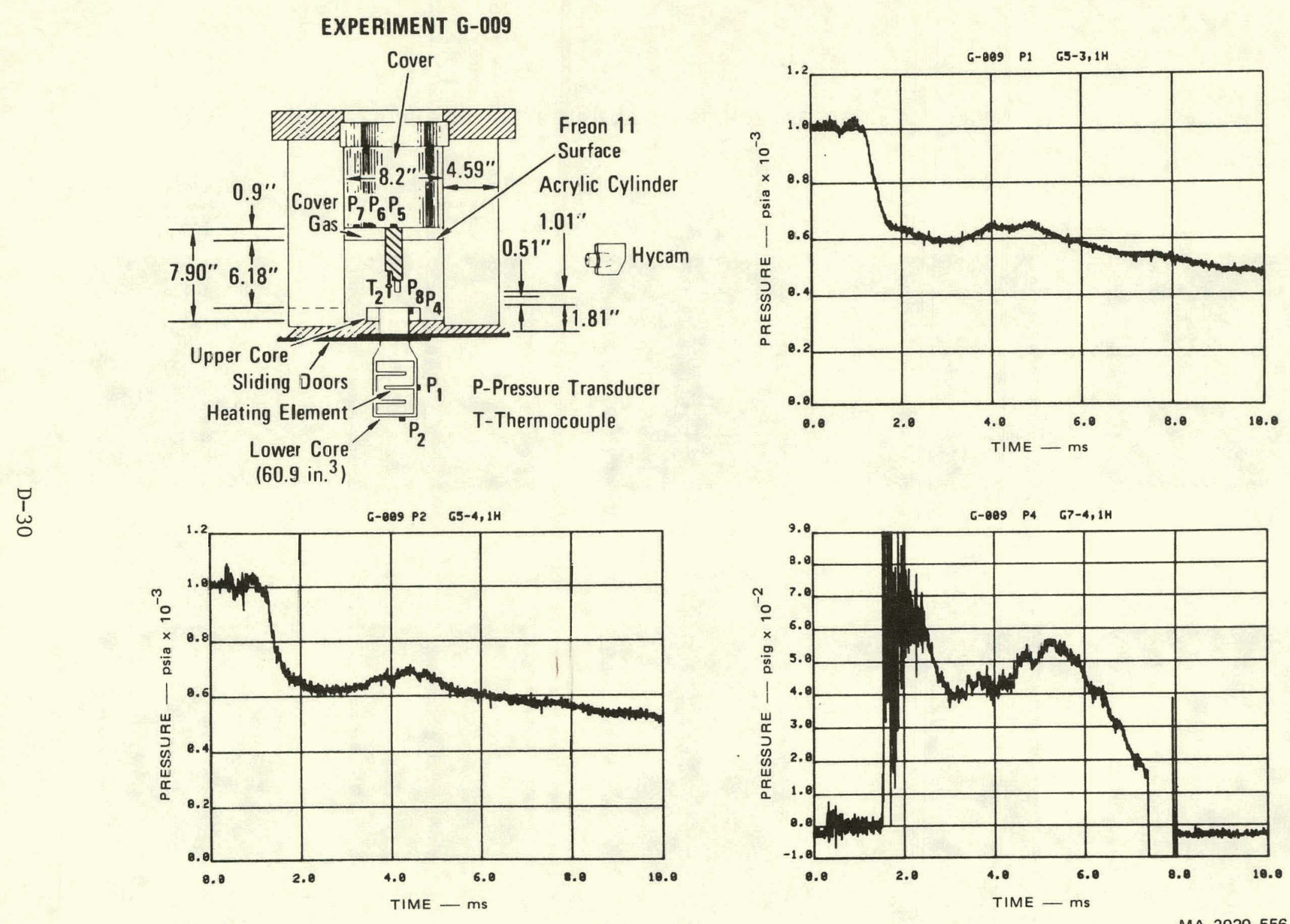

FIGURE D.8 EXPERIMENT G-009, FLASHING WATER BUBBLE SOUFCE 

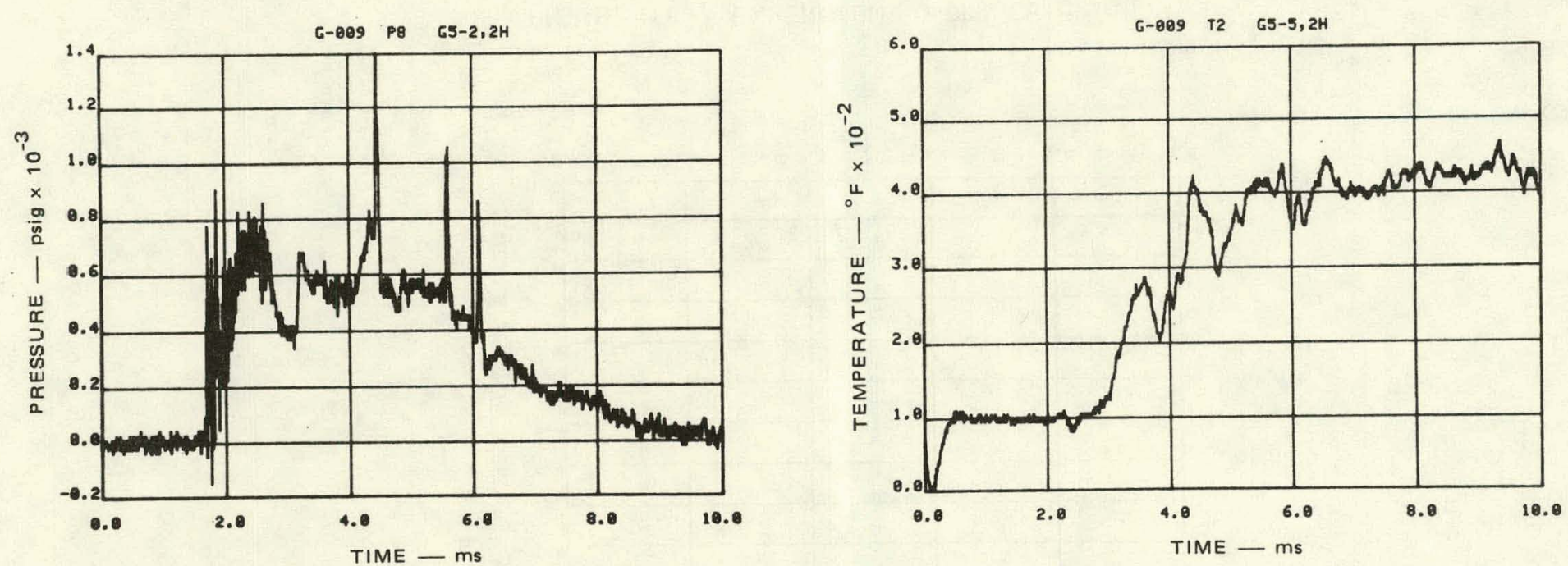

$\underset{\mapsto}{\oplus}$
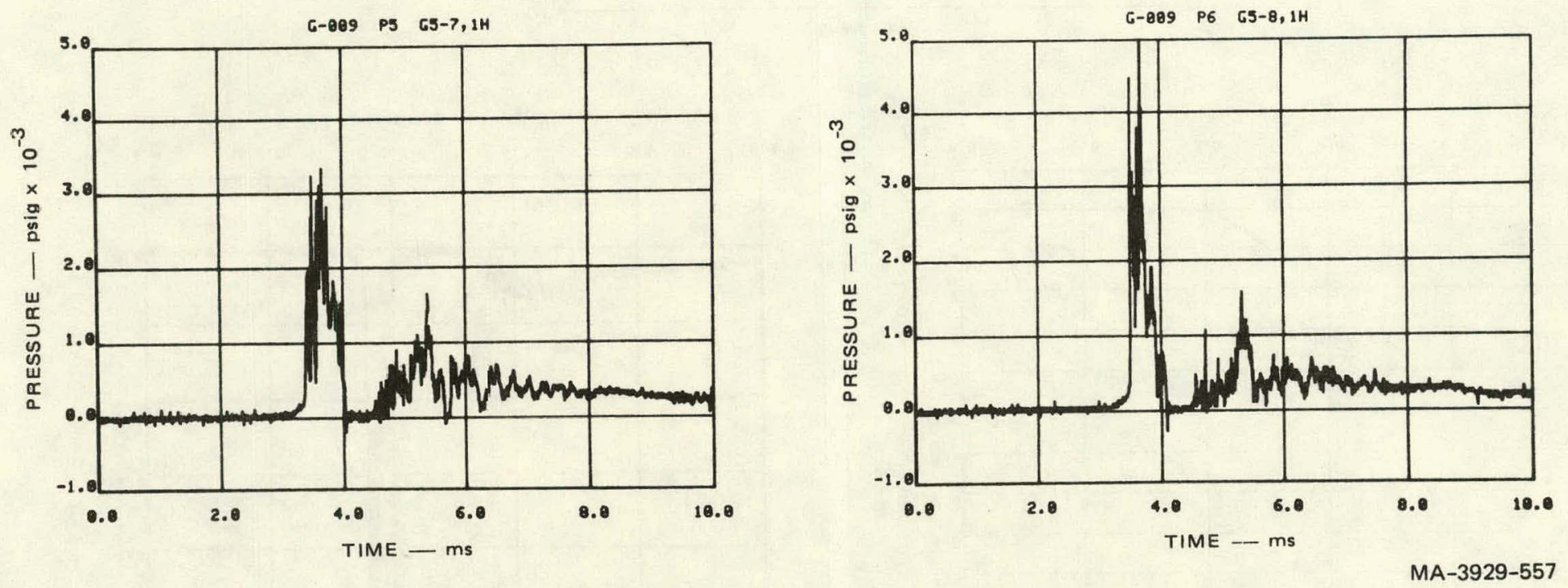

FIGURE D.8 EXPERIMENT G-009 (Continued) 

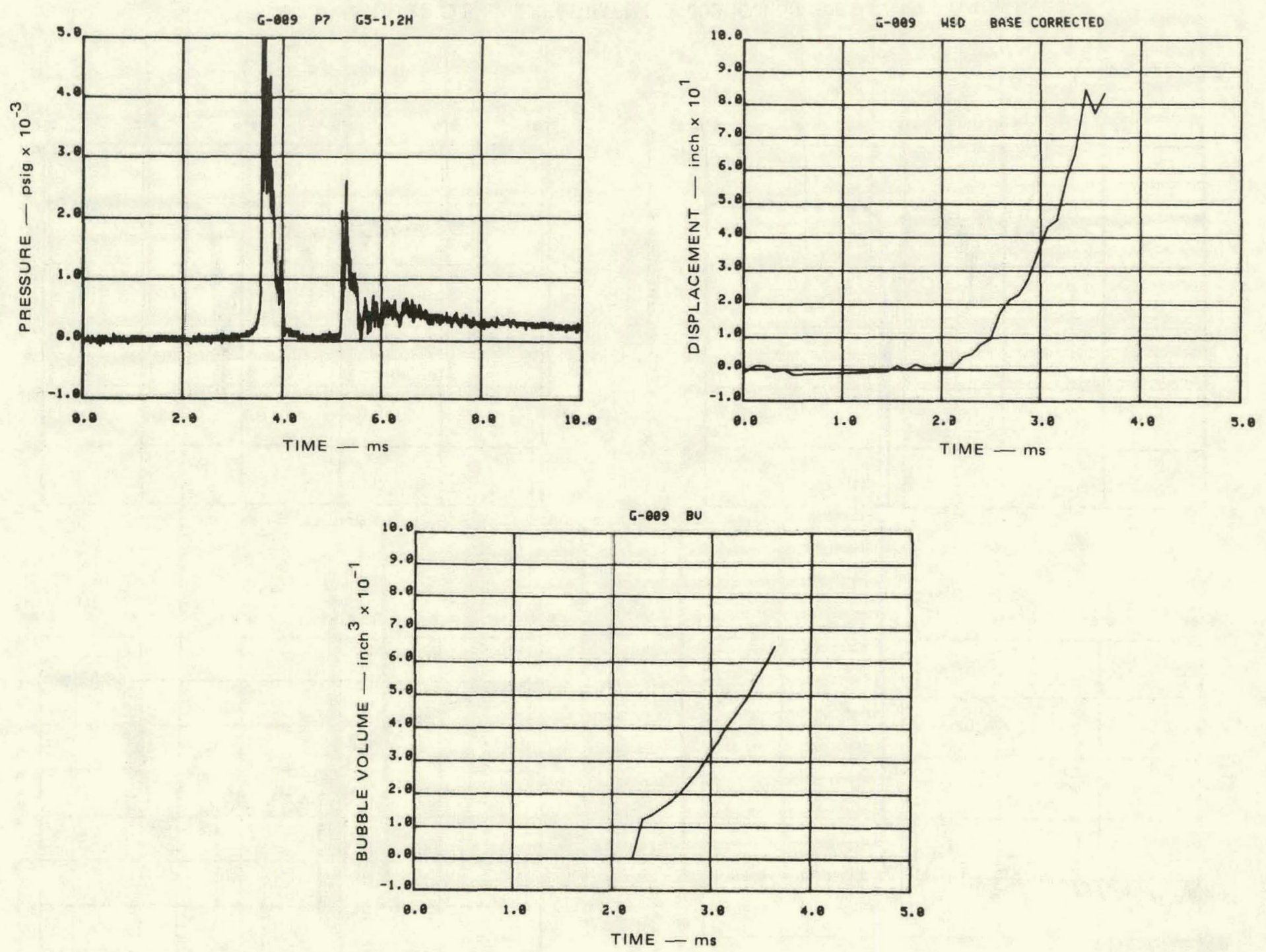

FIGURE D.8 EXPERIMENT G-009 (Continued) 


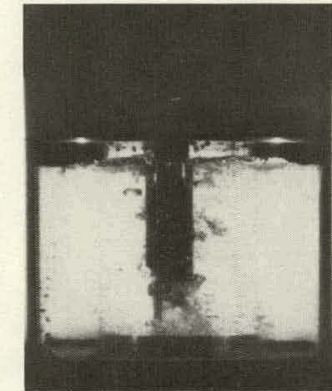

$=1.313 \mathrm{~ms}$ from detonation $\Delta t=0.000 \mathrm{~ms}$

Doors begin to open -

†
$\omega$
$\omega$

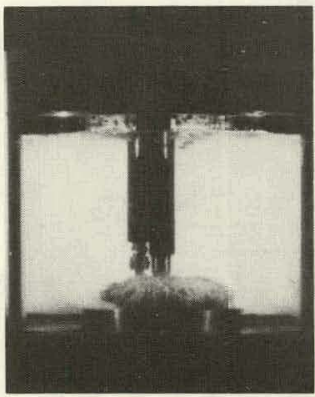

$\mathrm{t}=2.685 \mathrm{~ms}$ $\mathrm{t}=2.685 \mathrm{~ms}$ pressure transduce

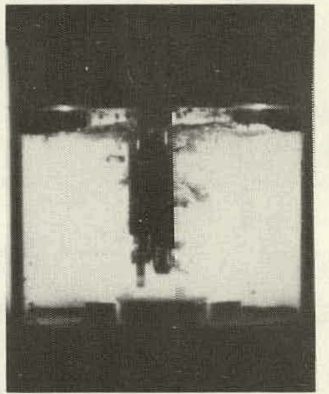

$\mathrm{t}=1.925 \mathrm{~ms}$

$\Delta t=0.61 \overline{\mathrm{ms}}$

Boiling surpressed

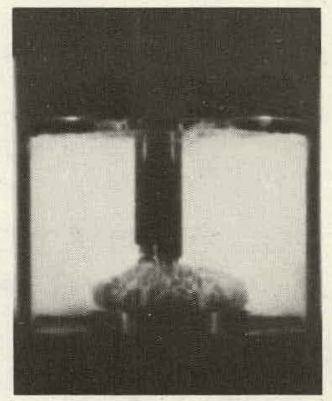

$\mathrm{t}=2.970 \mathrm{~ms}$

Bubble cortinues

to grow

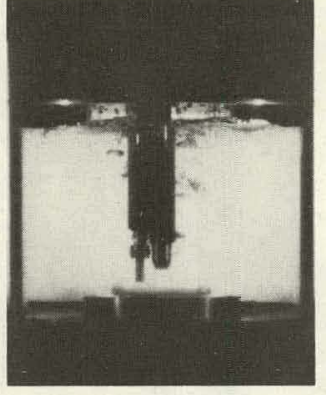

$\mathrm{t}=2.115 \mathrm{~ms}$

$\Delta \mathrm{t}=0.802 \mathrm{~ms}$

upper core

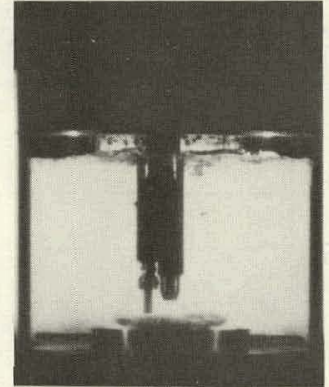

$\mathrm{t}=2.305 \mathrm{~ms}$

$\Delta \mathrm{t}=0.992 \mathrm{~ms}$

Bubble emerges

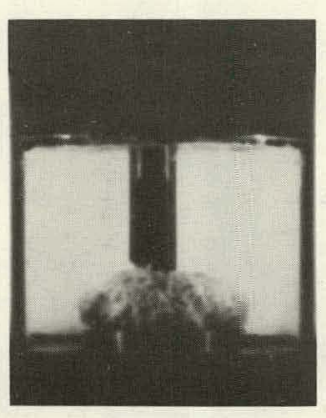

$\mathrm{t}=3.255 \mathrm{~ms}$

$\Delta \mathrm{t}=1.942 \mathrm{~ms}$

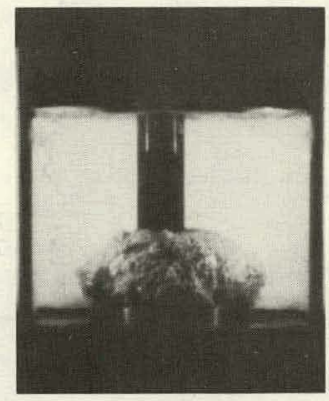

$\mathrm{t}=3.540 \mathrm{~ms}$

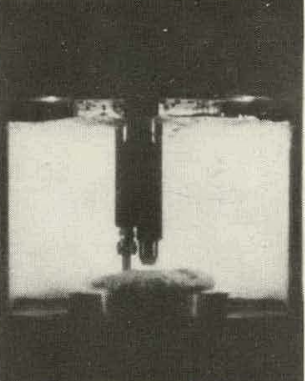

$\mathrm{t}=2.495 \mathrm{~ms}$ $\Delta \mathrm{t}=1.182 \mathrm{~ms}$ Bubble reaches $\Delta \mathrm{t}=2.227 \mathrm{~ms}$
Slug impact at $\Delta \mathrm{t}=2.21 \mathrm{~ms}$

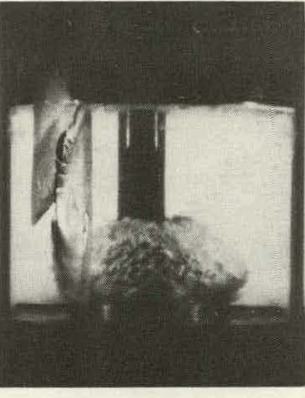

$\mathrm{t}=4.015 \mathrm{~ms}$ Post impact vessel failure

FIGURE D.8 EXPERIMENT G-009, PHOTO SEQUENCE (Concluded) 


\section{EXPERIMENT G-010}

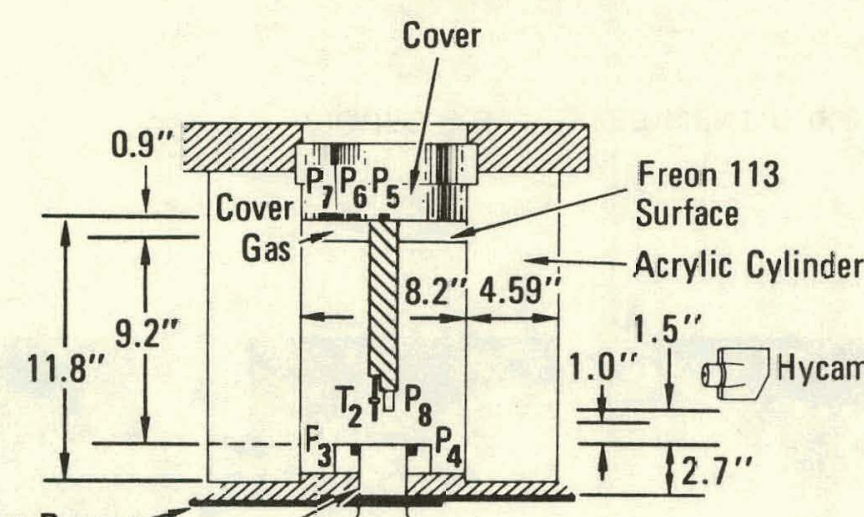

Sliding Doors

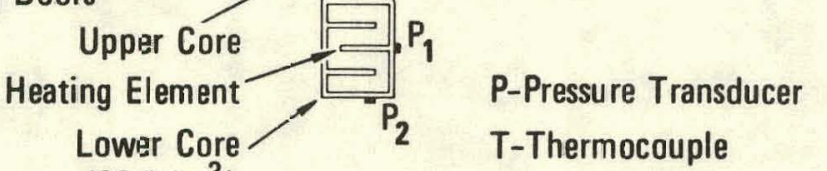

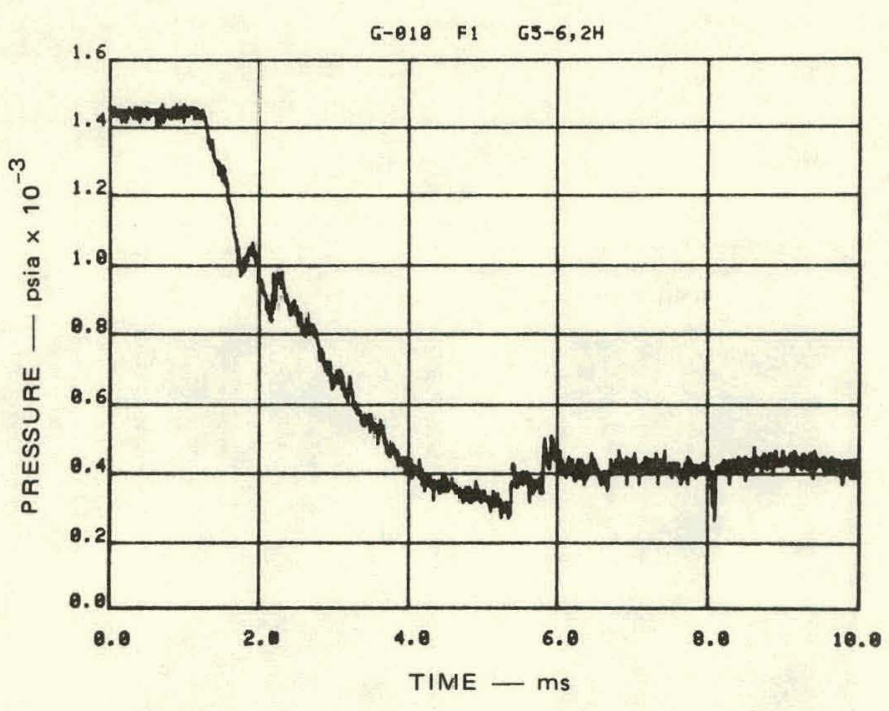

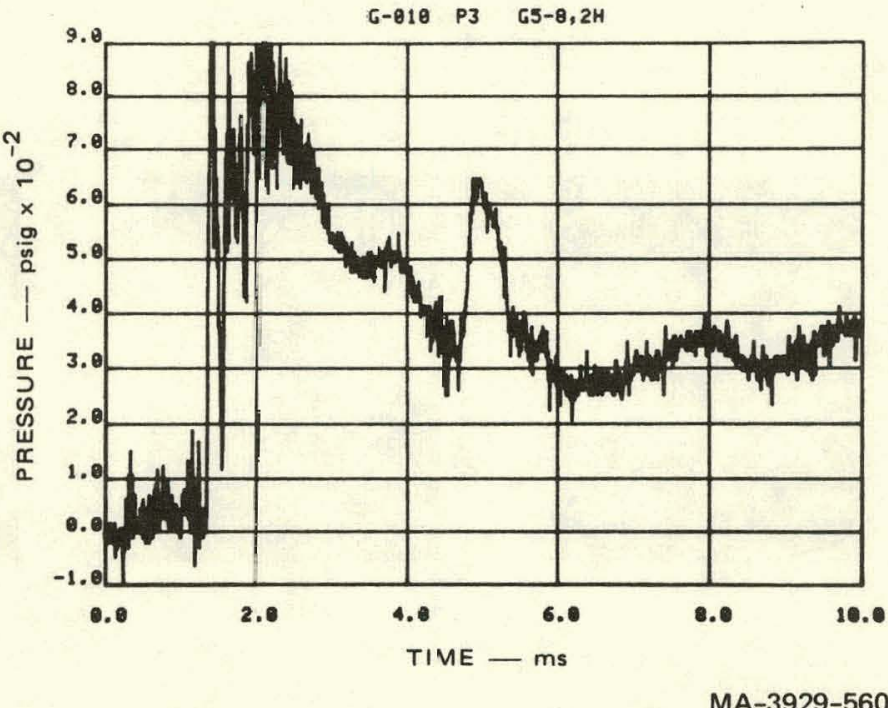

MA-3929-560

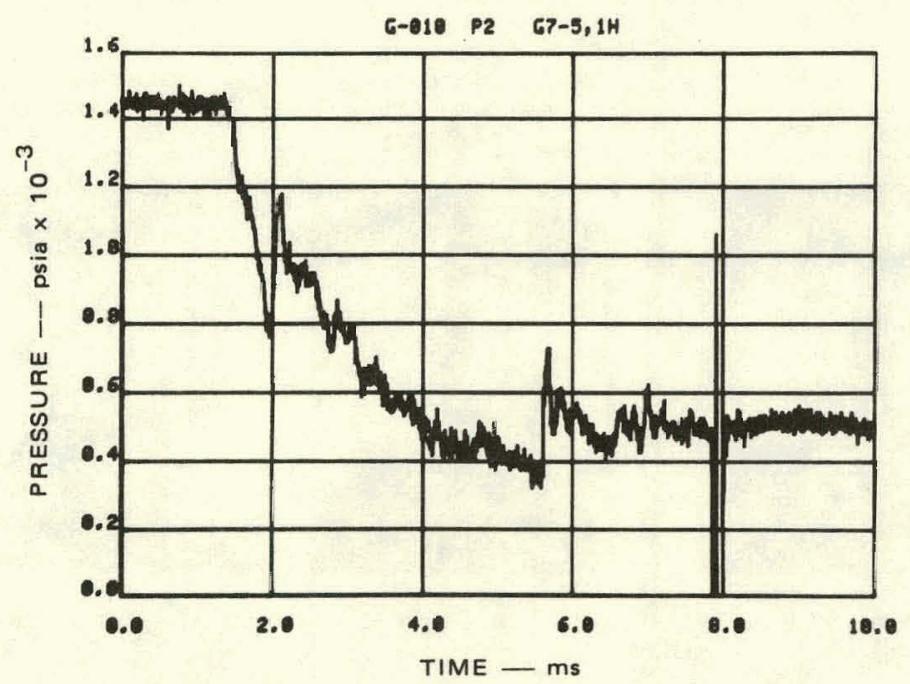

FIGURE D.9 EXPERIMENT G-010, NITROGEN BUBBLE SOURCE 

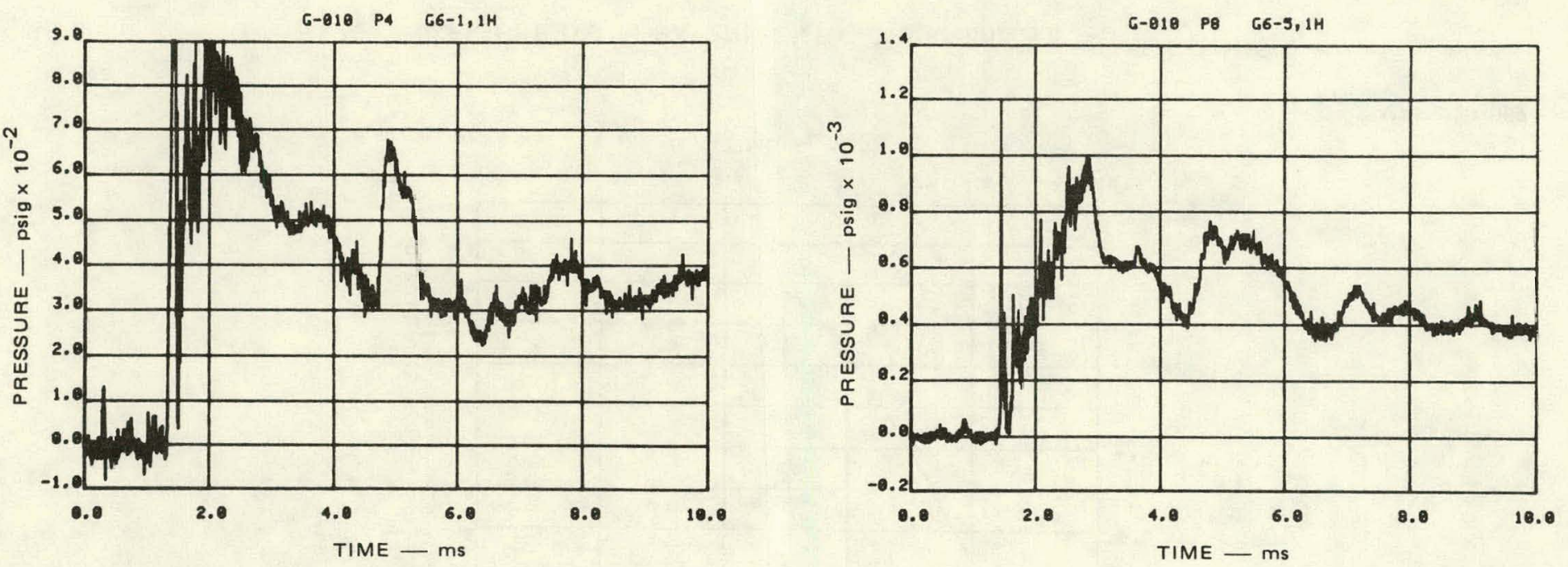

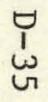
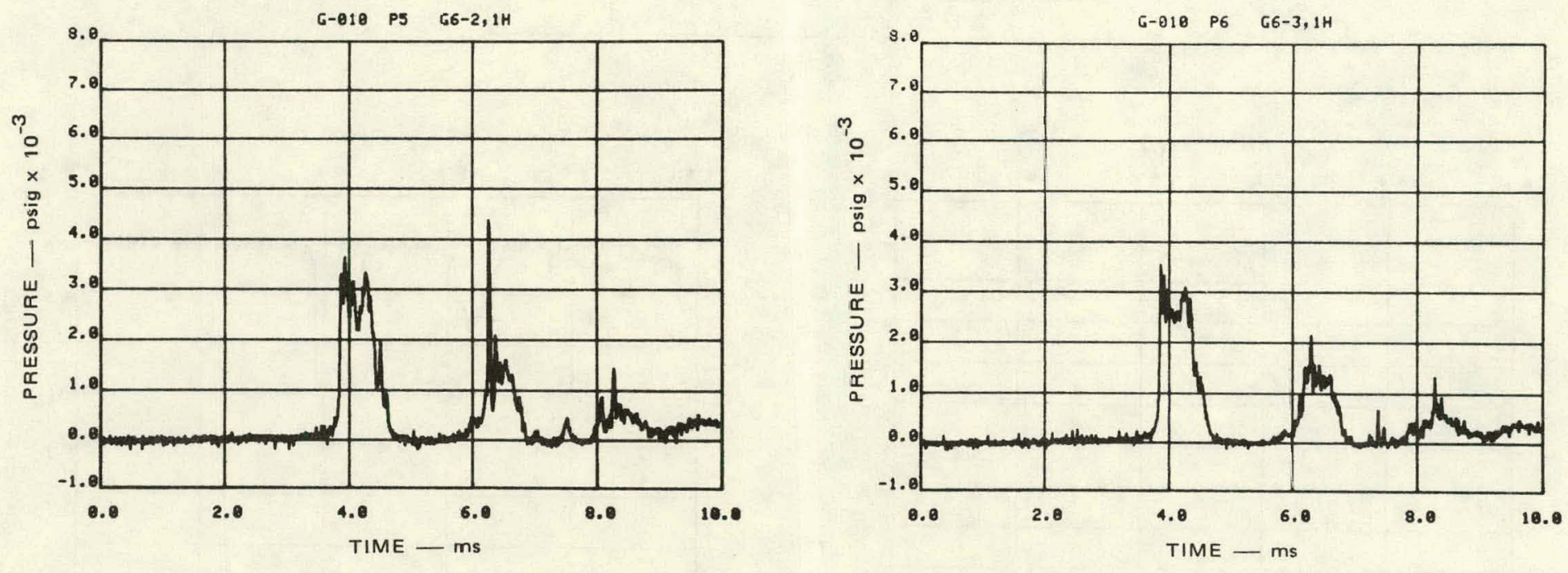

FIGURE D.9 EXPERIMENT G-010 (Continued) 

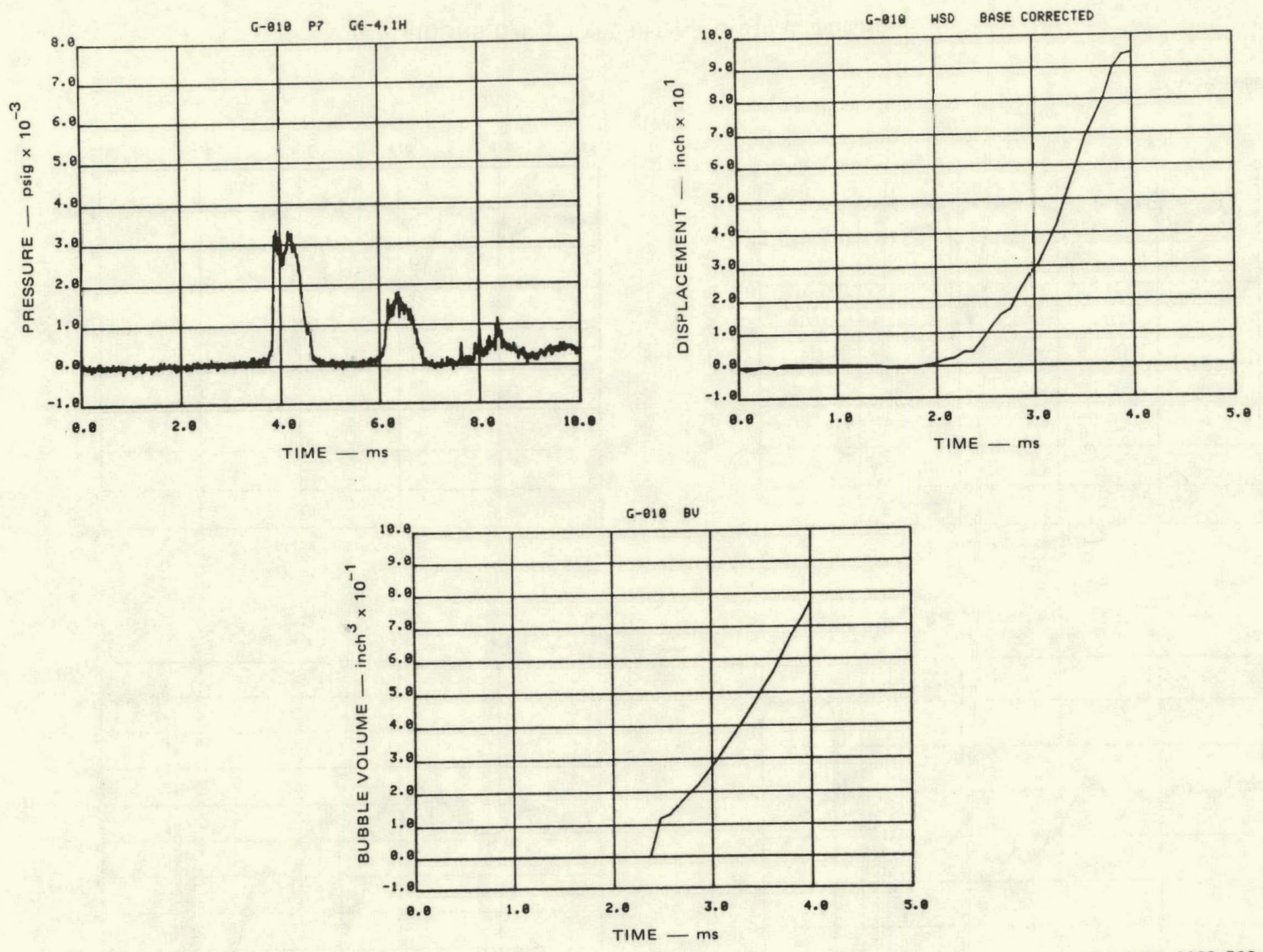


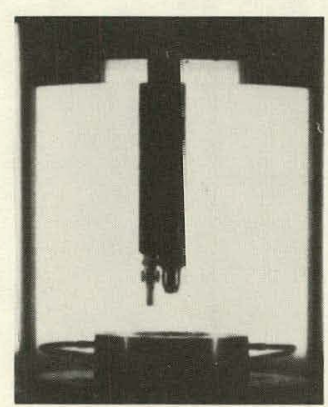

$\mathrm{t}=1.300 \mathrm{~ms}$ from detonation Doors begin to open

†
w

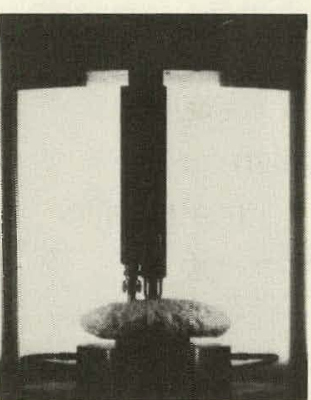

$\mathrm{t}=3.042 \mathrm{~ms}$

$\Delta \mathrm{t}=1.742 \mathrm{~ms}$

Bubble reaches

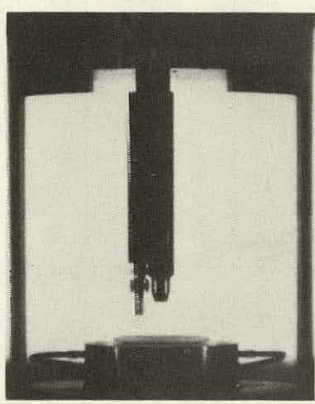

$\mathrm{t}=2.087 \mathrm{~ms}$

$\Delta \mathrm{t}=0.7 \varepsilon 7 \mathrm{~ms}$

upper cors

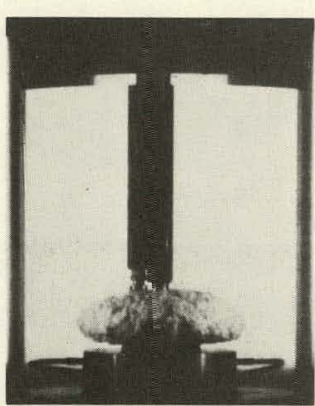

$\mathrm{t}=3.329 \mathrm{~ms}$ $\Delta \mathrm{t}=2.329 \mathrm{~ms}$ Bubble continues

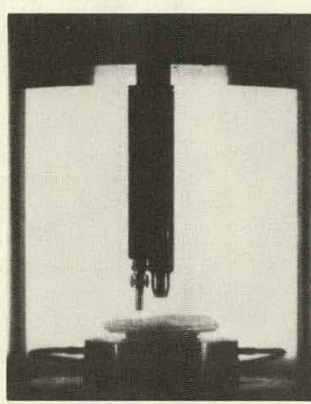

$\mathrm{t}=2.660 \mathrm{~ms}$

(1)

Bubble emerges

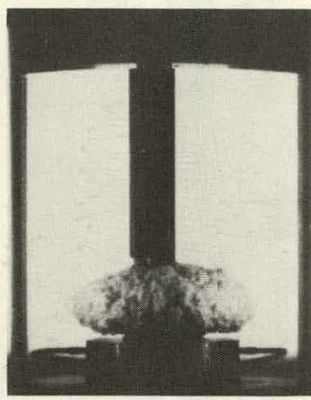

$\mathrm{t}=3.615 \mathrm{~ms}$

$\Delta t=2.315 \mathrm{~m}$

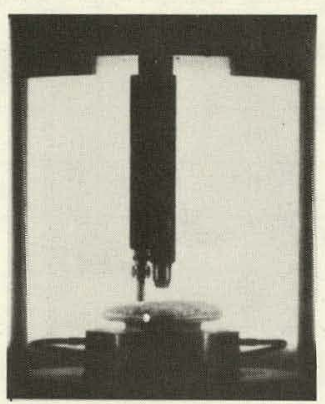

$\mathrm{t}=2.755 \mathrm{~ms}$

Bubble engulfs vortex

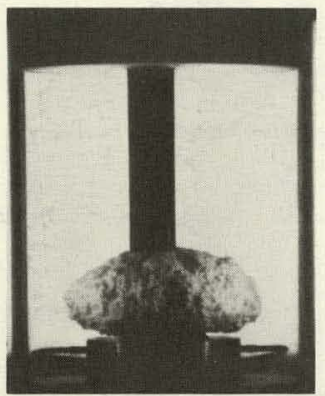

$\mathrm{t}=3.902 \mathrm{~ms}$

$\Delta \mathrm{t}=2.602 \mathrm{~ms}$

Slug impact

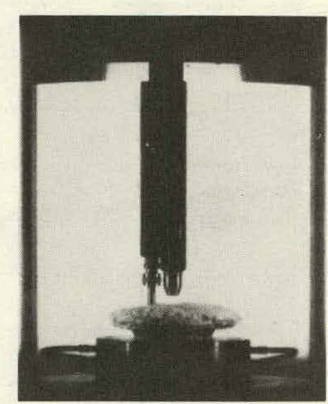

$\mathrm{t}=2.851 \mathrm{~ms}$

$\Delta t=1.551 \mathrm{~ms}$
Bubble reaches

thermocouple

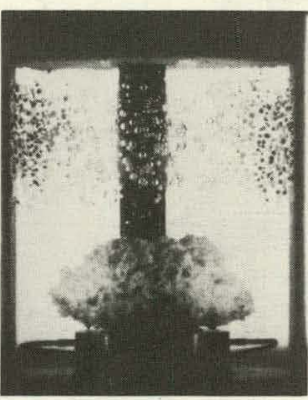

$\mathrm{t}=4.762 \mathrm{~ms}$ $\Delta t=3.462 \mathrm{~ms}$ Post impact

MP-3929-563

FIGUFE D.9 EXPERIMENT G-010, PHOTO SEQUENCE (Concluded) 

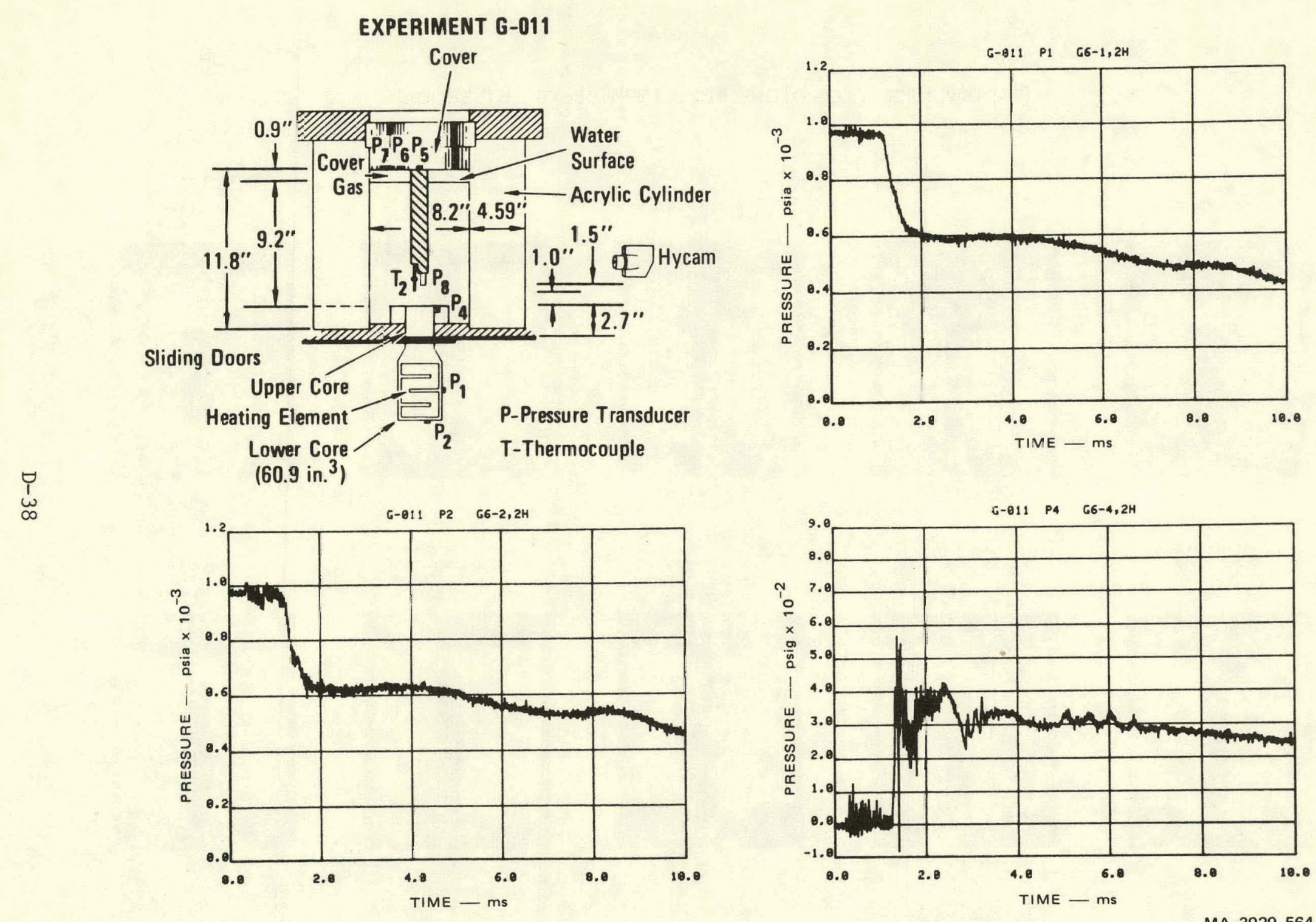

FIGURE D.10 EXPERIMENT G-011, FLASHING WATER BUBBLE SOURCE 

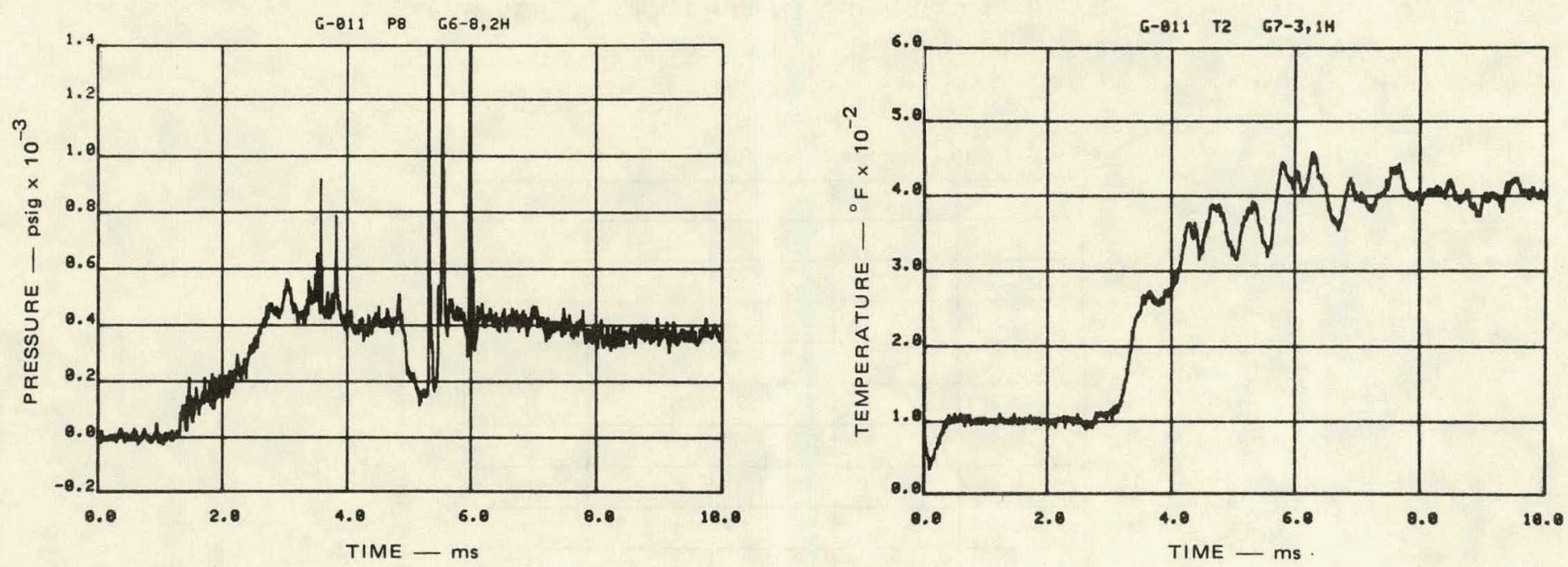

$\stackrel{\vartheta}{\omega}$
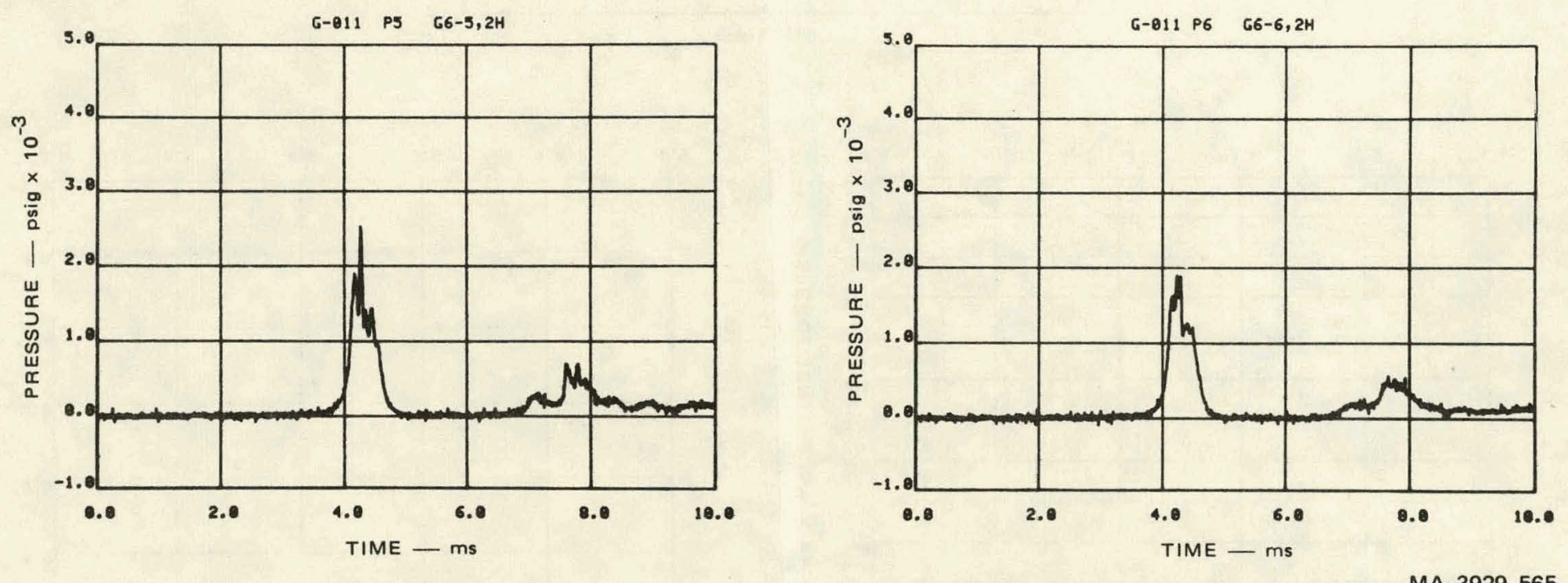

FIGURE D.10 EXPERIMENT G-011 (Continued) 

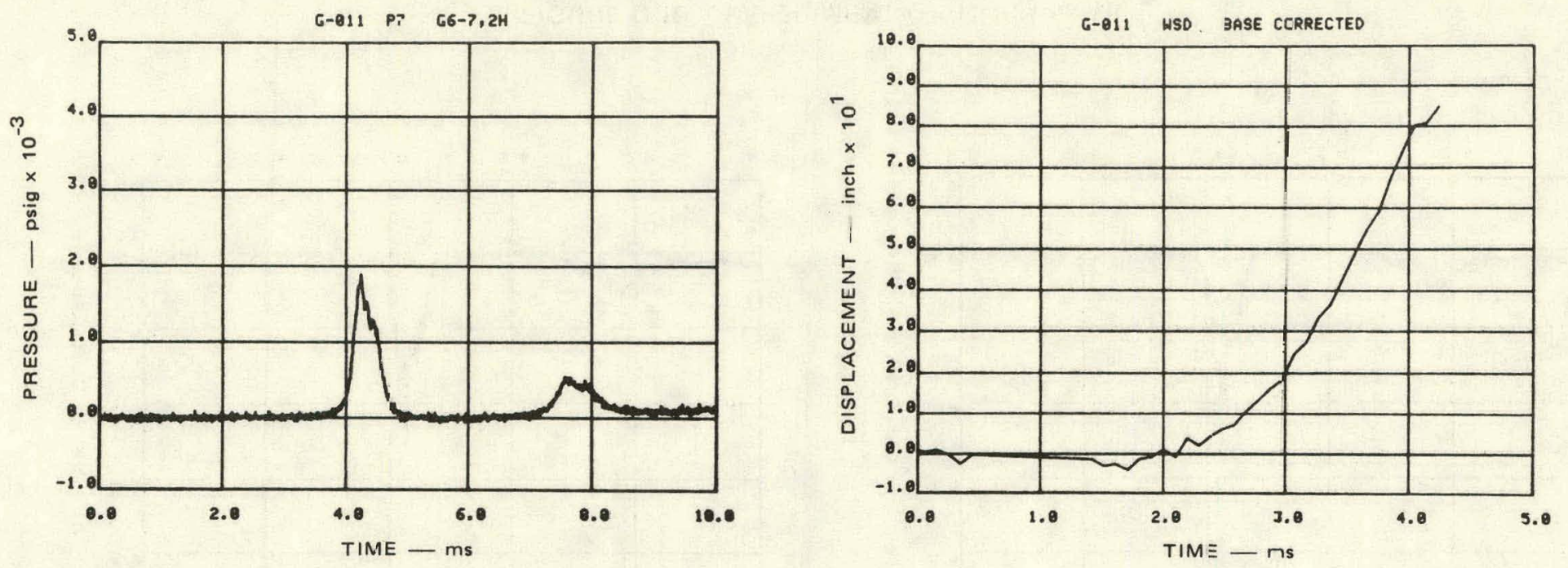

1
1
0

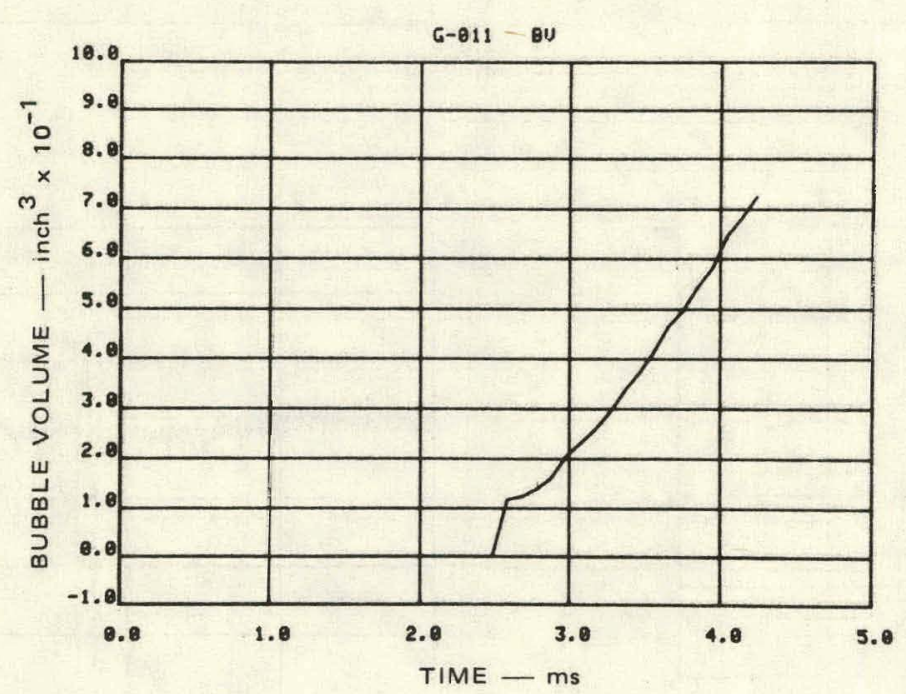

FIGURE D.10 EXPERIMENT G-011 (Continued) 


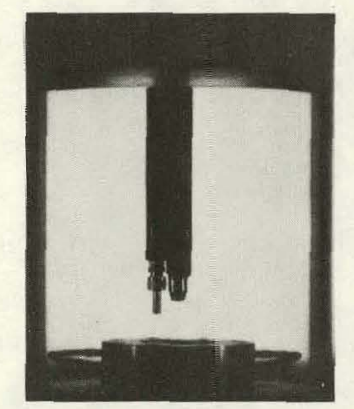

$\mathrm{t}=1.292 \mathrm{~ms}$ from detonation $\Delta \mathrm{t}=0.000 \mathrm{~ms}$
Doors begin to op

$\stackrel{\vartheta}{!}$

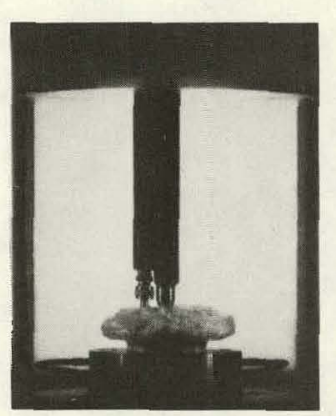

$\mathrm{t}=3.167 \mathrm{~ms}$

$\Delta t=1.875 \mathrm{~ms}$
Bubble reache:s

pressure transcluce

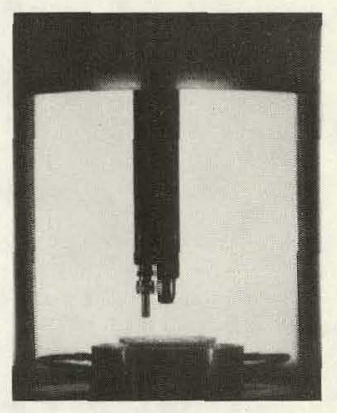

$\mathrm{t}=2.293 \mathrm{~ms}$

Vortex =orms

above upper core

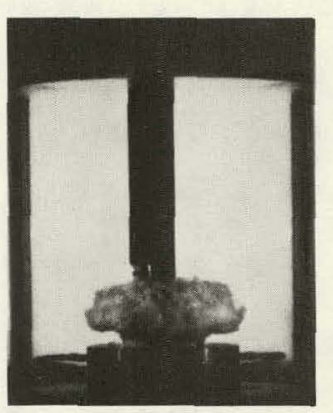

$\mathrm{t}=3.55 \mathrm{E} \mathrm{ms}$

Bubble continues

to grow

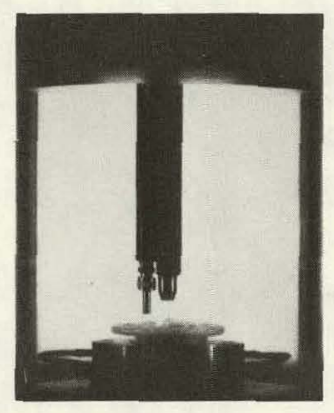

$\mathrm{t}=2.778 \mathrm{~ms}$

$\Delta t=1.486 \mathrm{~ms}$
Bubble emerges through vortex

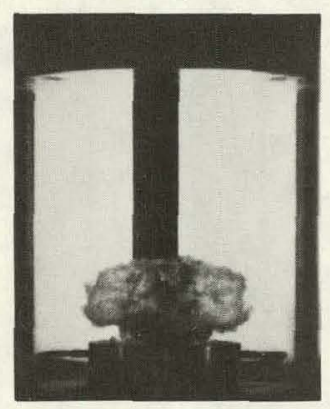

$\mathrm{t}=3.847 \mathrm{~ms}$

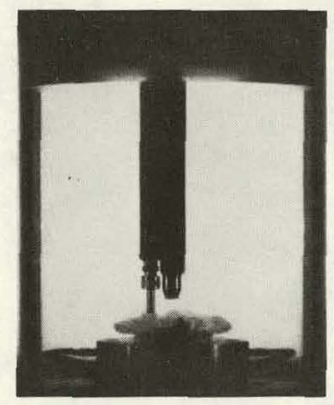

$\mathrm{t}=2.876 \mathrm{~ms}$

Bubble engulfs vortex

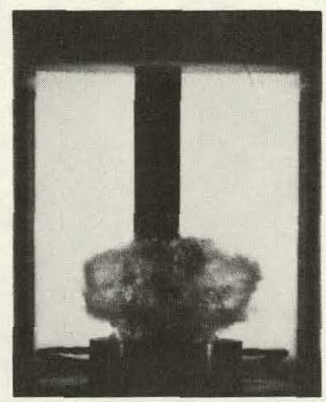

$\mathrm{t}=4.236 \mathrm{~ms}$

Slug impact

at $\Delta \mathrm{t}=2.92 \mathrm{~m}$

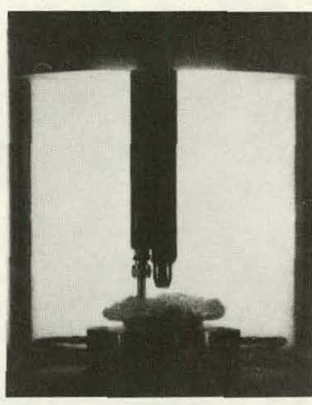

$\mathrm{t}=2.973 \mathrm{~ms}$

Bubble reaches thermocouple

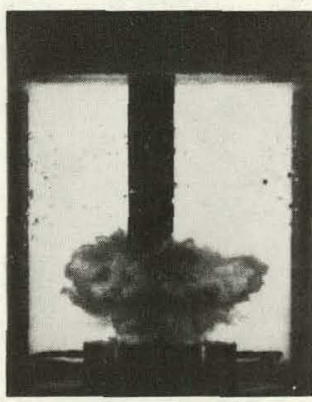

$\mathrm{t}=4.818 \mathrm{~ms}$ cavitation

FIGURE D.10 EXPERIMENT G-011, PHOTO SEQUENCE (Concluded) 
Appendix E

EXPERIMENT REPRODUCIBILITY

Of the ten experiments conducted in this series, four can be used to demonstrate the excellent reproducibility of these experiments. Experiments G-002 and G-011 with water as the coolant and experiments G-003 and G-004 with Freon 113 as the coolant were all conducted in the constant geometry configuration. In Figure E.1, the data from G-002 and G-011 are compared. The instrumentation common to both experiments is shown in Figure E.1(a). The data are compared in Figures E.1(b)-(g) and the bubble profilesat slug impact are compared in Figures E.1(h) and (i). The variation in lighting in those two photographs should be disregarded. As shown in Table D.2, the doors begin to open in G-011 at $1.29 \mathrm{~ms}$ and in G-002 at $1.19 \mathrm{~ms}$. Thus, the data in G-011 will appear shifted to the right of that in G-002 by $0.10 \mathrm{~ms}$. The excellent reproducibility of the data is seen in Figure E.I.

Freon coolant experiments G-003 and G-004 are compared in Figure E.2. As in Figure E.1, the data from the common instrumentation and the bubble profiles at slug impact are presented. The doors begin to open in G-003 at $1.20 \mathrm{~ms}$ and in G-004 at $1.32 \mathrm{~ms}$. Therefore, the data in G-004 wil1 appear shifted to the right of that in G-003 by $0.12 \mathrm{~ms}$. Although the cover gas gaps in G-002 and G-011 were very close, the gap in G-003 was $0.58 \mathrm{inch}$ and in G-004 il was $0.73 \mathrm{inch}$. 'lhus, slug impact is earlier in G-003 (3.75 ms) than in G-004 ( $4.20 \mathrm{~ms})$. We therefore expect a lower slug impact pressure in G-003 [Figure E.2(d)]. The remaining records in Figure E.2 demonstrate the excellent reproducibility of the Freon experiments. 


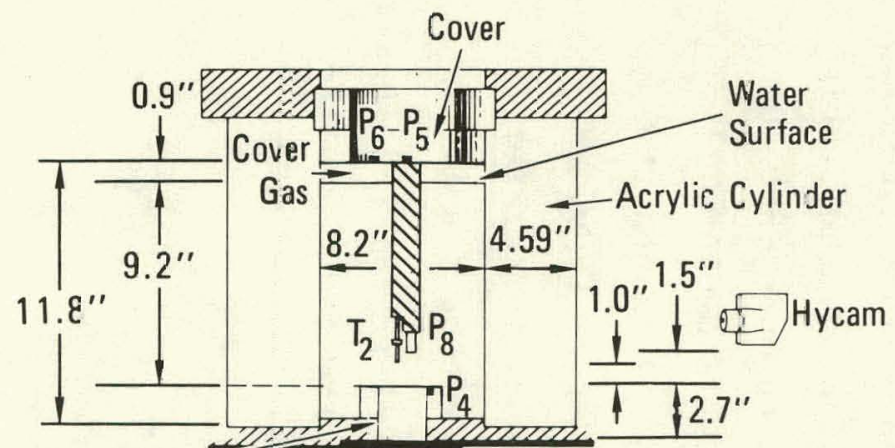

Upper Core

$$
\begin{aligned}
& \text { Sliding Joors } \\
& \text { Heating Elenent } \\
& \text { Lower Core } \\
& \left(60.9 \text { in. }^{3}\right)
\end{aligned}
$$

(a) COMMON INSTRUMENTATION EXPERIMENTS G-002 AND G-011

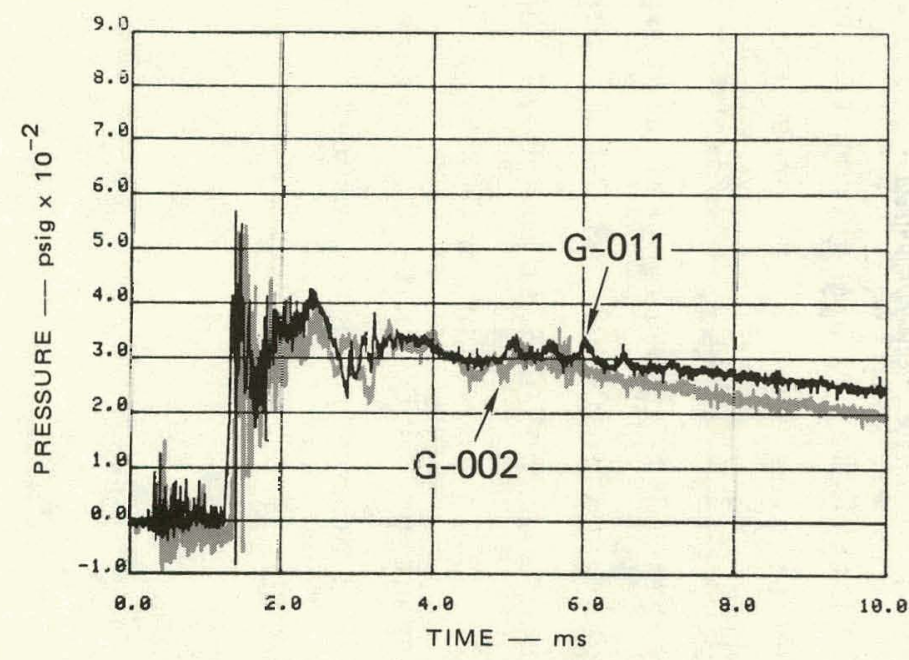

(c) UPPER CORE PRESSURE, $\mathrm{P}_{\mathbf{4}}$

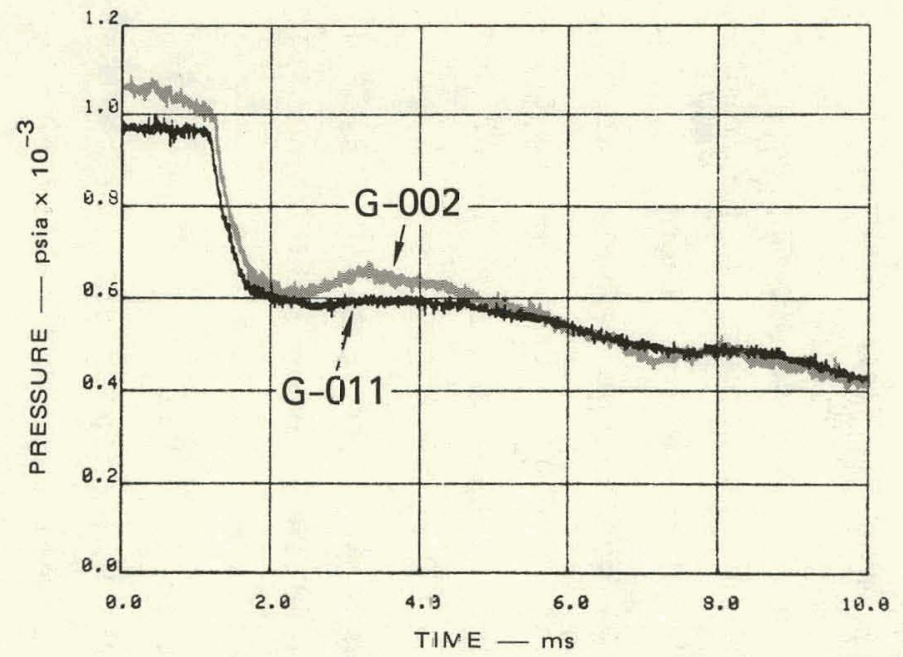

(b) LOWER CORE PRESSURE, $\mathrm{P}_{\mathbf{1}}$

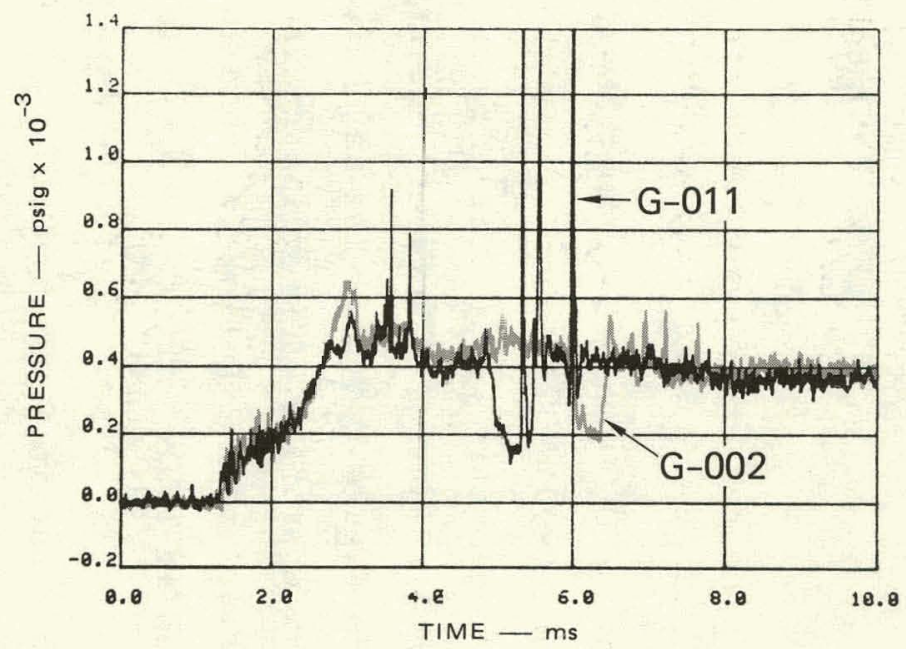

(d) POOL AND BUBBLE PRESSURE, $\mathrm{P}_{8}$

MP-3929-572

FIGURE E.1 EXPERIMENT REPRODUCIBILITY, WATEF COOLANT 


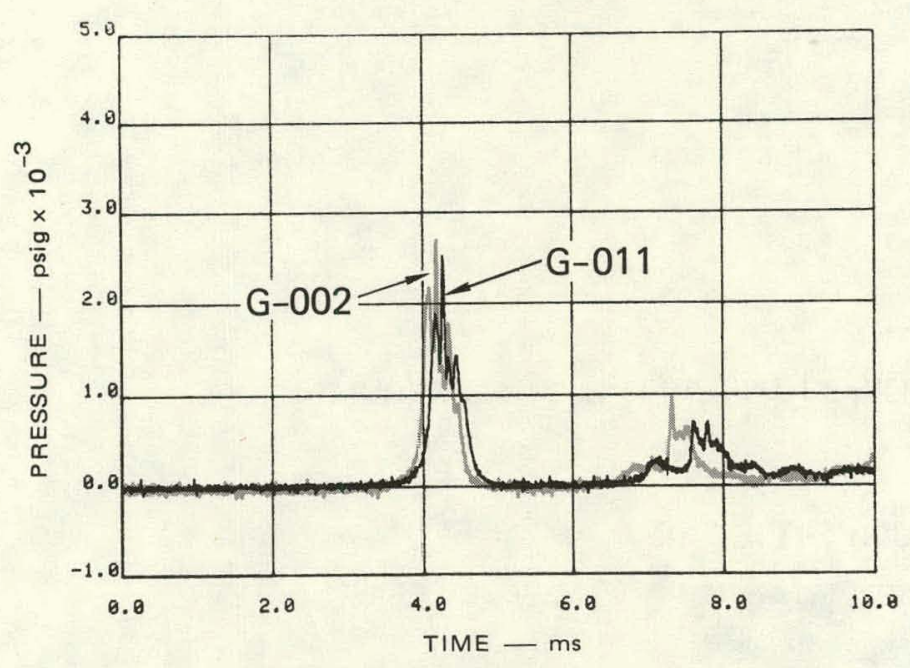

(e) COVER PRESSURE, $\mathrm{P}_{5}$

w

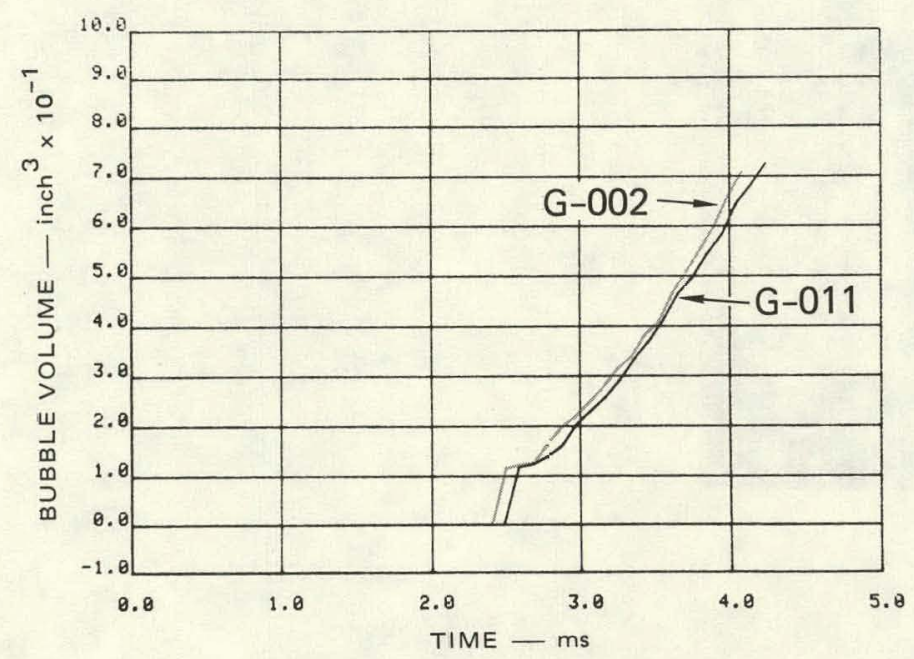

(g) BUBBLE VOLUME

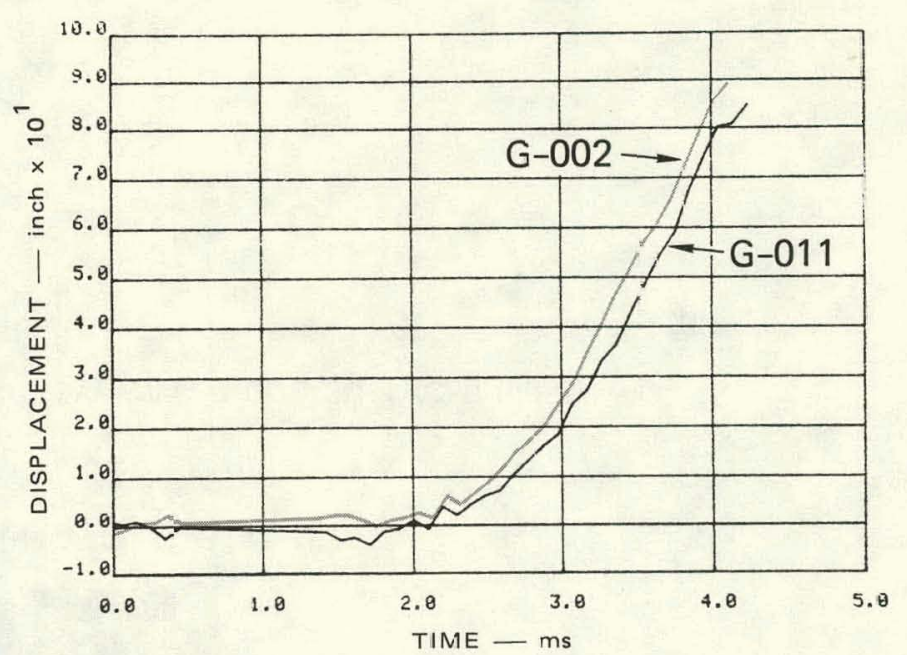

(f) CDOLANT SURFACE DISPLACEMENT

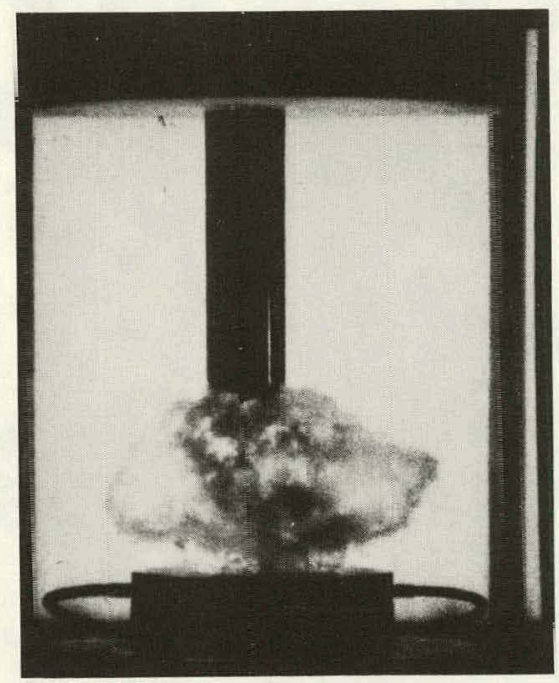

(h) SLUG IMPACT PHOTO, G-002

MP-3929-573 


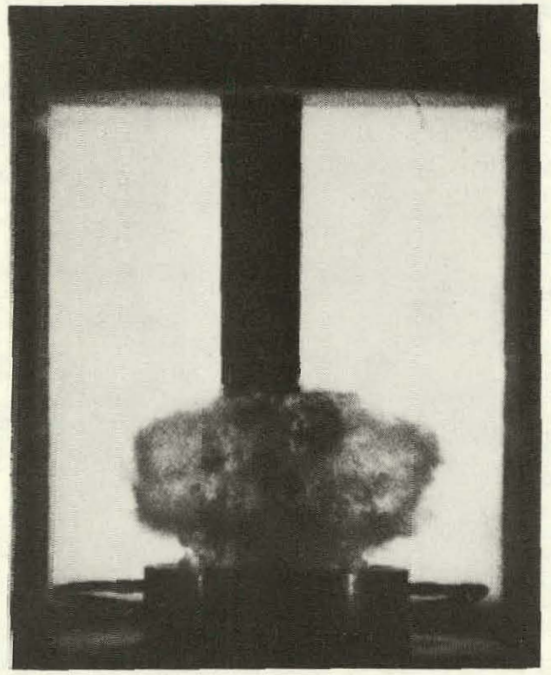

(i) SLUG IMPACT PHOTO, G-011

MA-3929-574

FIGURE E.1 EXQPER MINT REPRODUCIBILITY, WATER COOLANT (Concluded) 


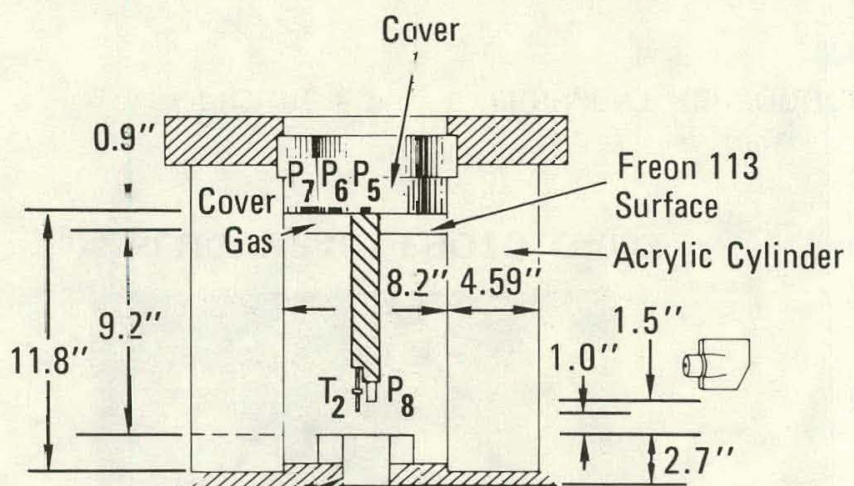

Sliding Doors

Upper Core

Heating Element

Lovser Core $\left(60.9\right.$ in. $\left.^{3}\right)$

(a) COMMON INSTRUMENTATION EXPERIMENTS G-003 AND G-004

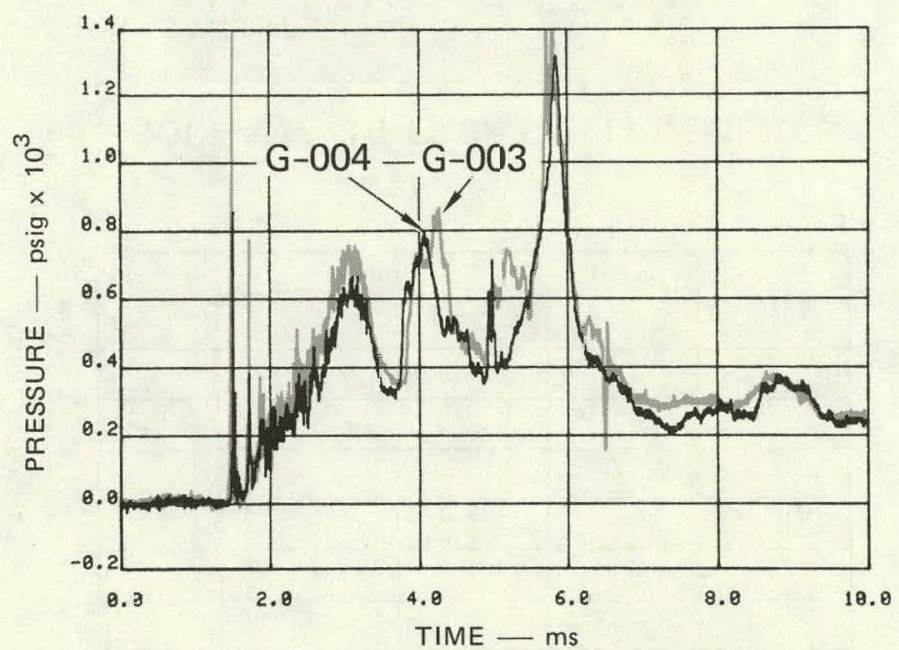

(c) PGOL AND BUBBLE PRESSURE, $\mathrm{P}_{8}$

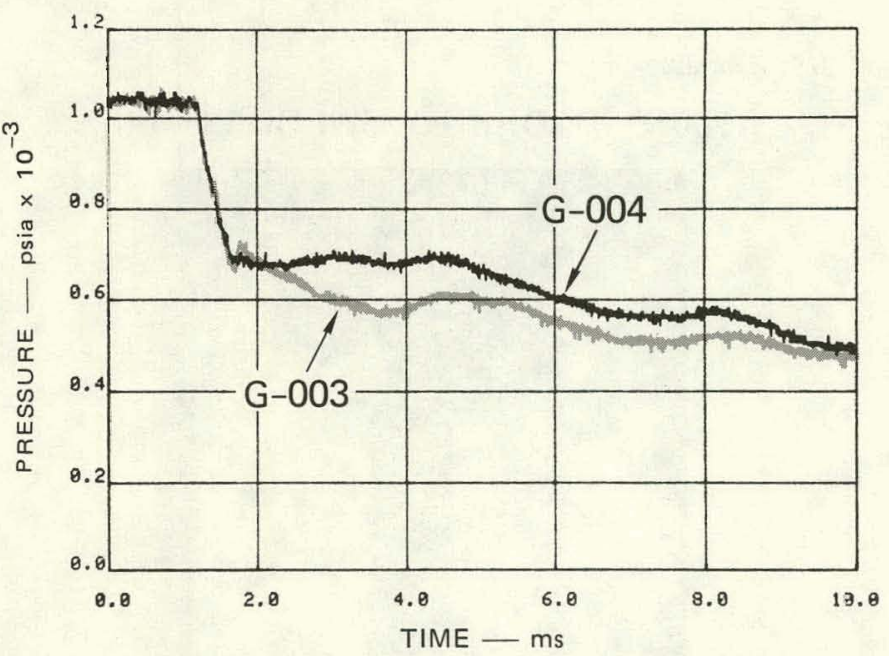

(b) LOWER CORE PRESSURE, $\mathrm{P}_{1}$

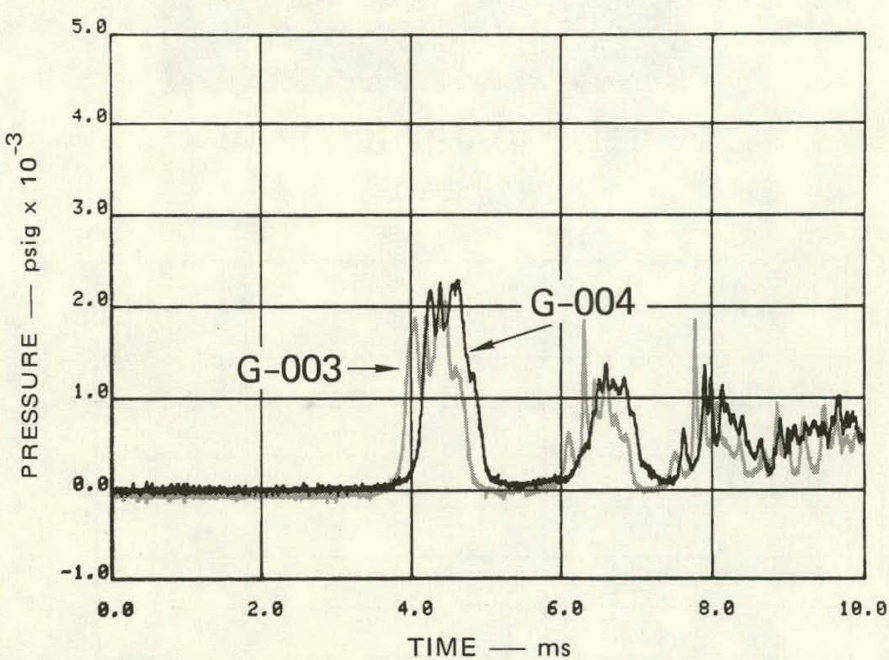

(d) COVER PRESSURE, $P_{5}$ 


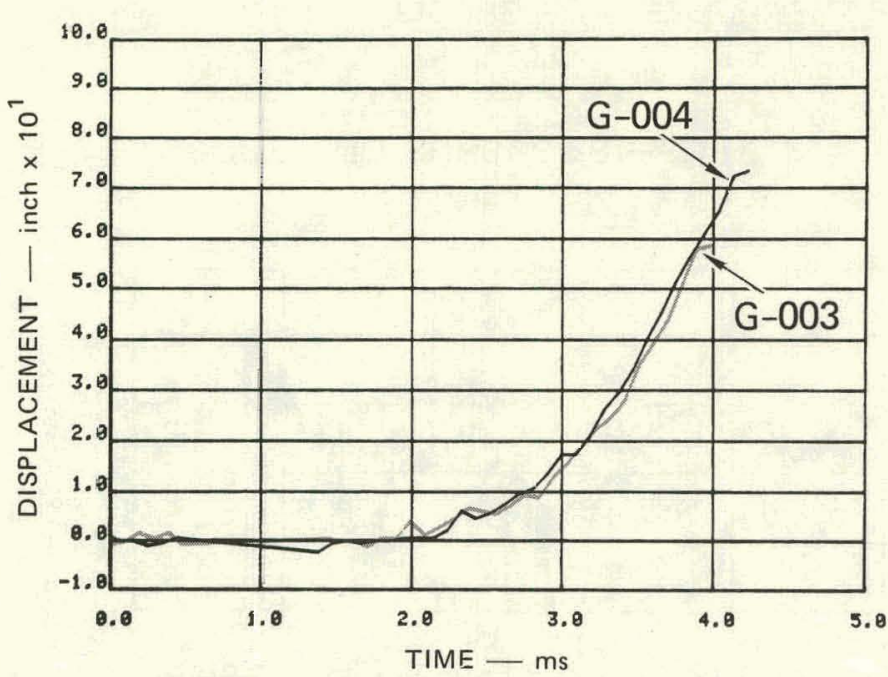

(e) COOLANT SURFACE DISPLACEMENT

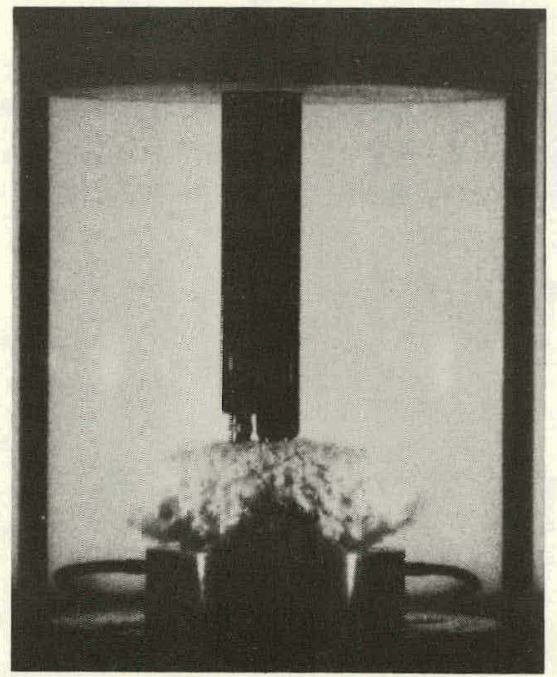

(g) SLUG IMPACT PHOTO, G-003

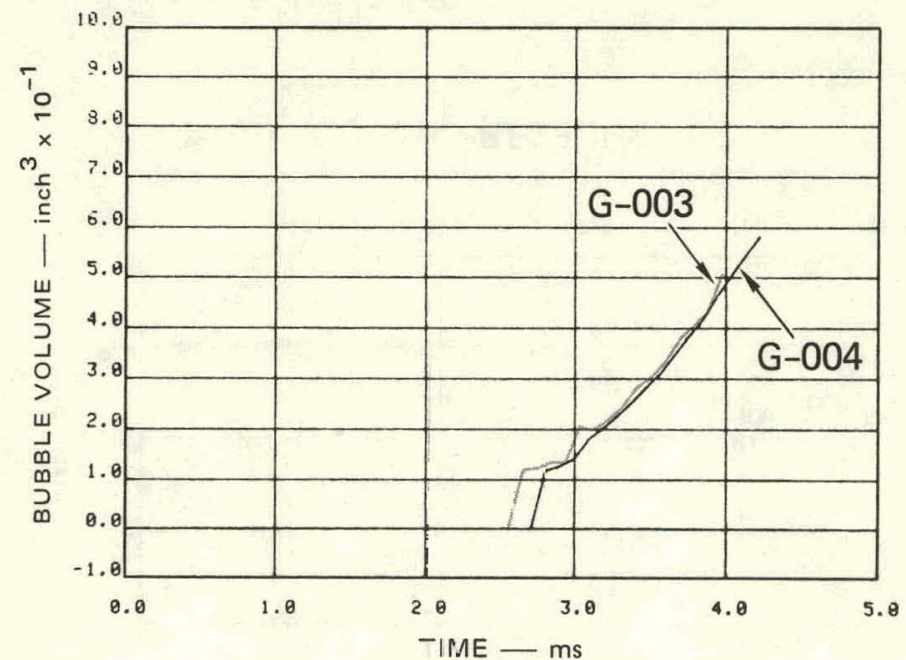

(f) BUBELE VOLUME

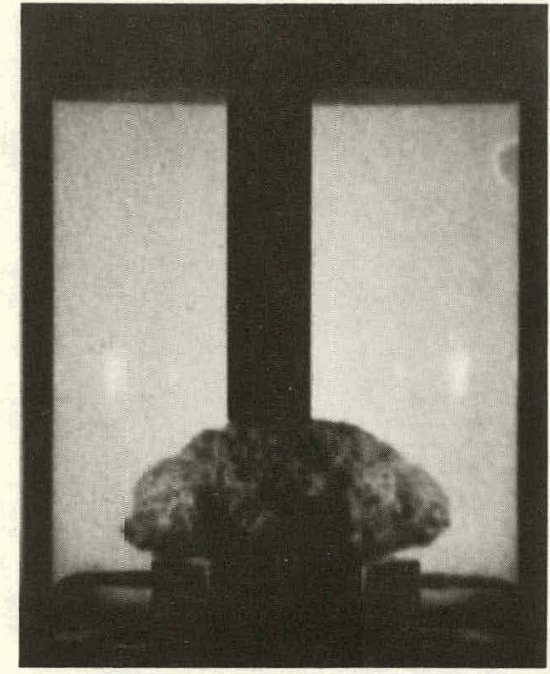

(h) SLUG IMPACT PHOTO, G-004

FIGURE E.2 EXPERIMENT REPRODUCIBILITY, FREON 113 COOLANT (Concluded) 
Appendix F

SIMPLE MODEL OF POOL MOTION

The simple expansion model described in this appendix and discussed in Section VII was initially developed to assess how similar the coolant surface displacement would be in a constant mass Freon 113 experiment relative to a reference test with water as the coulant. The model proved useful in making several other comparisons, which are discussed below following a description of the model.

Figure F.1 shows the fluid regions used to model the $1 / 30$-scale apparatus without internal vessel structures. A pressure source accelerates the coolant in regions 1 and 2, the upper core and pool. In phase A of the expansion, region 1 decreases in volume and region 2 increases in volume as the coolant in region 1 is displaced into region 2 . Once the upper core is empty, phase $B$ of the expansion, the mass in region 2 is constant. During phases $A$ and $B$, region 3, the cover gas, decreases in size as the coolant pool moves upward. Slug impact occurs when the volume of region 3 decreases to zero.

The pressure driving the expansion in phases $A$ and $B$ is an input to the calculation. No flow path pressure drop is calculated for the driving source. To allow for the fact that some pressure drop can occur in a real expanding source, the pressure driving the expansion in phases $A$ and $B$ is allowed to be different. Since the pressure in our flashing water source experiments is almost constant once the sliding doors open, the driving pressure in phase $\mathrm{A}, \mathrm{P}_{1}$, is a constant in these calculations. Pressure $P_{2}$ is the pressure at the boundary between the lower core and the pool. In phase $A$, this pressure increases from ambient to $P_{1}$ as the lower core empties. In phase $\mathrm{B}, \mathrm{P}_{2}$ is the pressure driving the slug motion. The cover gas pressure, $\mathrm{P}_{3}$, is a constant in these calculatluns. The effect of cover gas compression in these calculations is not considered. Since the motion considered is one-dimensional, the lower boundary of the 


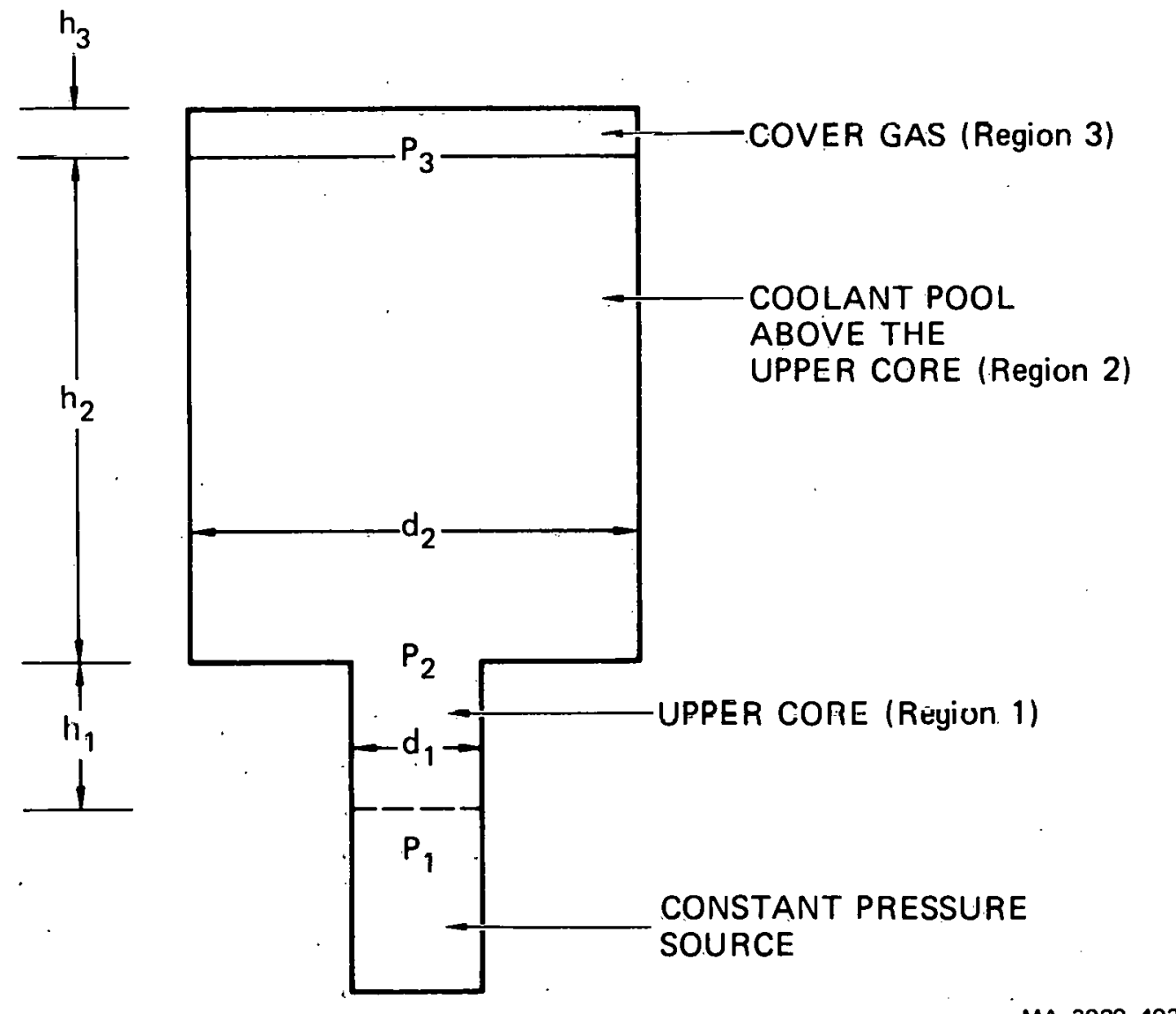

FIGURE F:1 SIMPLE EXPANSION MODEL 
coolant is a flat surface in both regions 1 and 2 . A hemispherical bubble is not considered. In addition, no entrainment is allowed at the moving source/coolant interface.

The motion of the coolant is governed by Newtonian mechanics. The equations of motion for the coolant in regions 1 and 2 are:

$$
\begin{aligned}
& P_{1}-P_{2}=\rho h_{1} a_{1} \\
& P_{2}-P_{3}=\rho h_{2} a_{2}
\end{aligned}
$$

where $\rho$ is the coolant density and $a_{1}$ and $a_{2}$ are the accelerations in regions 1 and 2 . Continuity requires:

$$
a_{1} d_{1}^{2}=a_{2} d_{2}^{2}
$$

Solving these three equations for $a_{1}$, we find:

$$
a_{1}=\frac{P_{1}-P_{3}}{\rho\left(h_{1}+h_{2}\left(\frac{d_{1}}{d_{2}}\right)^{2}\right)}
$$

During phase $A$, this relation and continuity governs the motion in region 1. Heights $h_{1}$ and $h_{2}$ change with time as the coolant moves. The motion in region 2 is calculated from the motion in region 1 and mass continuity.

In phase $B$, the coolant elug mntion is governed by

$$
a_{2}=\frac{P_{2}-P_{3}}{\rho h_{2}}
$$

where $h_{2}$ is the pool height in region 2 after the upper core has emptied.

This simple model can be used to scope the effects of changes in experiment parameters if realistic values are used for the independent variables in the calculations. Table F.l gives the values used for the cases that demonstrate the effects of experiment geometry and coolant

$$
\mathrm{F}-3
$$


Table F.1

\section{EXPANSION MODEL CALCULATIONS}

\begin{tabular}{|c|c|c|c|c|c|c|}
\hline Case & $\begin{array}{c}P_{1} \\
\text { Phase } A \\
\text { (psia: }\end{array}$ & $\begin{array}{c}\mathrm{P}_{2} \\
\text { Phase E } \\
\text { (psia) }\end{array}$ & $\begin{array}{l}\mathrm{h}_{\mathrm{T}_{\text {initial }}} \\
\text { (inches) }\end{array}$ & $\begin{array}{l}\mathrm{h}_{\mathbf{2}_{\text {initial }}} \\
\text { (inches) }\end{array}$ & $\begin{array}{c}\rho \\
\left(\mathrm{lbm} / \mathrm{ft}^{3}\right)\end{array}$ & $\begin{array}{c}\text { REMARKS } \\
\text { Configuration - Coolant }\} \text { Volatility }\end{array}$ \\
\hline A & 650 & 450 & 2.7 & 9.2 & 62.4 & Refererce - water \\
\hline B & 650 & 450 & 1.712 & 5.834 & 98.3 & Constart Mass - Freon 113 \\
\hline C & 650 & 450 & 2.7 & 9.2 & 98.3 & Constant Geometry - Freon 113 \\
\hline D. & 650 & 650 & 1.712 & 5.834 & 98.3 & Constant Mass - Freon 113 \\
\hline$E$ & 650 & 650 & 2.7 & 9.2 & 98.3 & Constant Geometry - Freon 113 \\
\hline
\end{tabular}


volatility. The calculations for these cases were performed on a computer. The geometry effects without volatility are studied in cases A, B, and C by using the same driving pressures in each case. The values shown are representative of those that occur in actual experiments of the reference type (water coolant). The effect of volatility is then demonstrated by the use of a higher pressure driving phase B, simulating the higher pressure that might occur in an HCDA bubble as a result of evaporation of some Freon 113 coolant. The coolant surface displacements calculated for these five cases were presented and discussed in section VII. 